\title{
A】l100 ๆ92914
}

NATL INST OF STANDARDS \& TECH R.I.C

|||||||||||||||||||||||||||||||||||||||||||||||||||||||

A1 1100992914

\section{INBS bullding sclence serles}

TA435.U58 V71;1975 C.1 NBS-PUB-C 1974

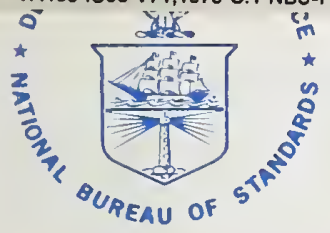

NBS BUILDING SCIENCE SERIES 71

\section{U.S. DEPARTMENT OF COMMERCE / National Bureau of Standards}

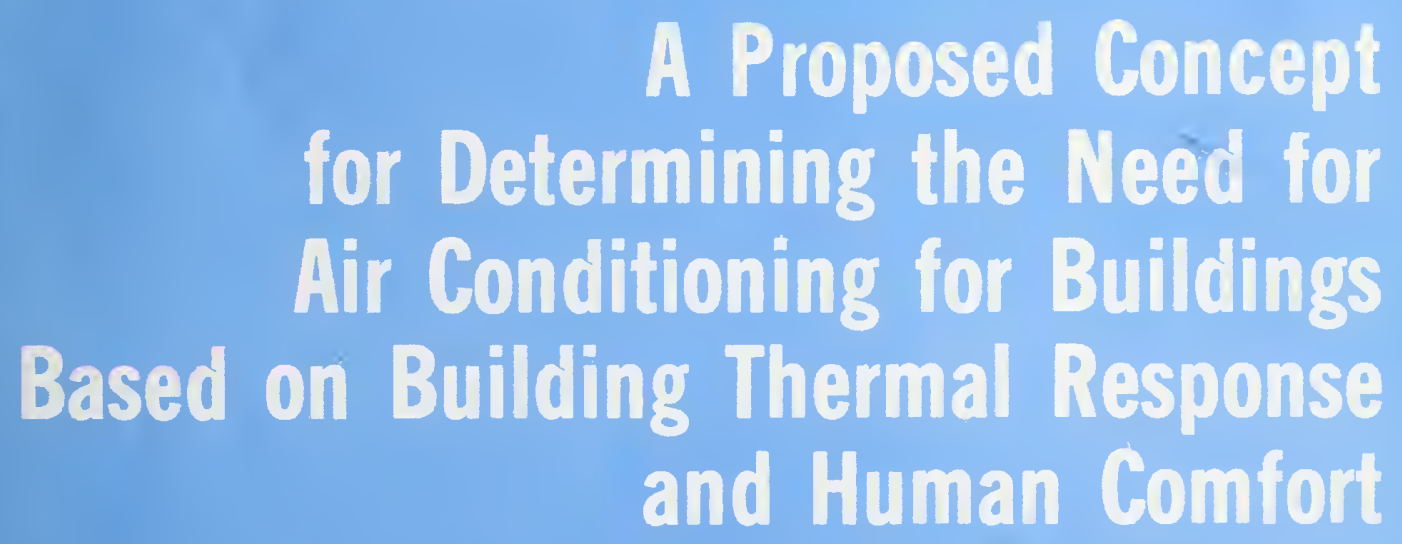

TA

435

.458

no. 71

1975

c. 2 


\section{The Building Science Series}

The Building Sciem:e Series disscminates technical information developed at the National Bureau of Standards on building materials, components, systems, and whole structures. The Series presents research results, test methods, and performance criteria related to the structural and environmental functions and the durability and safety characteristics of building elements and systems.

These puhlications, similar in style and content to the NBS Building Materials and Structures Reports (1938-59), are directed toward the manufacturing, design, construction, and research segments of the building industry, standards organizations, and officials responsihle for building codes.

The material for this Series originates principally in the Center for Building Technology of the NBS Institute for Applied Technology. The publications are divided into three general groups: Building Systems and Processes; Health, Safety and Comfort; and Structures and Materials. For further information regarding these publications please contact the Scientific and Professional Liaison Section, Center for Building Technology, Institute for Applied Technology, National Bureau of Standards, Washington, D.C. 20234. 


\section{A Proposed Concept for Determining the Need for Air Conditioning for Buildings Based on Building Thermal Response and Human Comfort}

J. E. Hill, T. Kusuda,

S. T. Liu and F. J. Powell

Institute for Applied Technology

National Bureau of Standards

Washington, D.C. 20234

Sponsored by

The Department of Housing and Urban Development 451 Seventh Street, S.W.

Washington, D.C. 20410

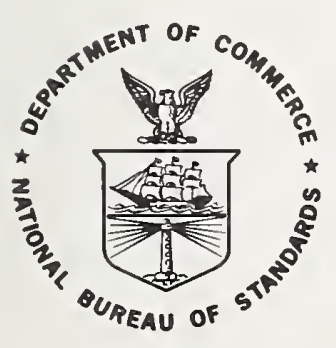

U.S. DEPARTMENT OF COMMERCE, Rogers C. B. Morton, Secrefary NATIONAL BUREAU OF STANDARDS, Ernest Ambler, Acting Director Issued August 1975 


\section{Library of Congress Cataloging in Publication Data}

United States. National Bureau of Standards.

A Proposed Concept for Determining the Need for Air Condilioning for Buildings Based on Building Thermal Response and Human Comfort.

(National Bureau of Standards Building Science Series: 71)

Supt. of Does. No.: C 13.29/2:7]

1. Air Conditioning. 2. Buildings-Thermal Properties. I. Hill, Jane's Edward, 1942- II. Tittle: A Proposed Concept for Determining the Need for Air Conditioning for Buildings ... III. Series: United Stales. National Bureau of Standards. Building Science Series; 71.

TÁ435.U58 No. 71 [TH7687] 690’08s $\left[697.9^{\prime} 312\right] \quad 75-619194$

\section{National Bureau of Standards Building Science Series 71}

Nat. Bur. Stand. (U.S.), Bldg. Sci. Ser. 71,155 pages (Aug. 1975)

CODEN: BSSNBV

For sale by the Superintendent of Documents. U.S. Government Printing Office, Washington, D.C. 20402 (Order by SD Catalog No. C13.29/2:71). Price $\$ 2.25$. (Add 25 percent additional for other than U.S. mailing). 
1. Introduction . . . . . . . . . . . . . . . . . . 1

2. Proposed Concept for Air Conditioning Criteria . . . . . . . . . . . 4

3. Calculation of Indoor Space Conditions by Building Thermal Simulation. . . 5

4. Classification of Buildings According to Their Thermal Response Characteristics. . . . . . . . . . . . . . . . . 6

5. The Predicted Indoor Habitability Index. . . . . . . . . . . . . 11

6. Preliminary Calculations and Analysis for Air Conditioning Criteria . . . . 13

7. Conclusions and Recommendations. . . . . . . . . . . . . . 19

8. References . . . . . . . . . . . . . . . . . . 21

9. Appendix A - Derivation of the Equations to Calculate the Mean Radiant Temperature Within NBSLD . . . . . . . . . . . . . 1a

10. Appendix B - A Review of Comfort and Physiological Indices . . . . . . 1b

11. Appendix C - Discussion of Regulatory Sweating Model . . . . . . . . . 1c 
A Proposed Concept for Determining the Need for Air

Conditioning for Buildings Based on Building Thermal Response and Human Comfort

James E. Hill, Tamami Kusuda, Stanley.T. Liu, Frank J. Powell

Center for Building Technology

Institute for Applied Technology

National Bureau of Standards

Washington, D.C. 20234

\section{Abstract}

Determining the need for air conditioning can be based on a wide variety of factors. To date, the only criteria that have been written and can be referenced are those of several federal organizations and many are not really criteria in the true sense of the word. They are guidelines to be used in the determination of fund allocation; in other words, provisions are made to air condition federal facilities in specific geographical locations if pertinent weather characteristics of that locality meet certain requirements. This paper presents the concept that a true criteria can be established based both on weather characteristics of the locality as well as characteristics of the building or structure under consideration.

The paper gives the details of a study showing the feasibility of such a scheme. A simulation was made of two proposed residences in several geographical localities. For the simulation, actual hour-by-hour weather data was used in conjunction with a sophisticated computer program. The results revealed for the non air-conditioned spaces, the extent and duration of undesirable indoor conditions based upon generally accepted comfort indices. The concept of a new "comfort" or "discomfort" index called Predicted Indoor Habitability Index (PIHI) is introduced. The authors indicate the way in which a criterion could be established that would be in the form of tables, indicating for a given specified building and geographical locality, whether mechanical cooling should or should not be installed.

Key Words: Air conditioning criteria; building thermal response; comfort indices; human comfort; predicted indoor habitability index

\section{Introduction}

At the present time, several United States government agencies make the decision to air condition single family or multifamily dwellings based on cost and general location of the housing unit (i.e., northern or southern part of the country). The United States Air Force, for example, specifies in their Manual 88-8 that if family housing is to be located in a region where the wet-bulb temperature is above $67^{\circ} \mathrm{F}$ for 1000 hours or more or the dry-bulb temperature is above $80^{\circ} \mathrm{F}$ for 400 hours or more during the hottest six consecutive months of the year, consideration should be given to installing mechanical cooling [1].* Criteria similar to this were adopted by the Department of Housing and Urban Development for their Operation BREAKTHROUGH Program [2]. Using this as the basis for the decision to provide air conditioning is clear cut and definitive; however, it is felt that other factors besides weather should be considered. These include the thermal performance of the enclosing structure and the range of indoor thermal conditions under which people can remain reasonably comfortable. Other factors that are considered "secondary" and have not been recommended for inclusion here involve such things as the surrounding acoustical environment and human preferences for visual communication with the surroundings.

One of the most important items that govern the indoor environment is the "thermal performance" of the enclosing structure. J. F. van Straaten of the Building Research Institute of South Africa discusses in his recent book Thermal Performance of Buildings [3] the way different structures respond when subjected to periodically varying solar conditions

* The number in the brackets refers to references at end of report. 
and environmental temperatures. The overall heat transfer coefficient for wall, floor or ceiling which gives a direct measure of the resistance to heat flow under steady-state conditions, is not the sole indicator of the heat flow to the inside environment when unsteady-flow conditions exist. The mass of the wall, floor and ceiling, which governs the energy storage capacity, is also a pertinent parameter to be considered.

Several studies are summarized in the van Straaten book that help to illustrate the complex interaction between the building and the environment. Several four-room singlestory structures of approximately $500 \mathrm{ft}^{2}\left(46 \mathrm{~m}^{2}\right)$ of floor area were built in both Pretoria and Durban, South Africa. These unoccupied, non-air conditioned buildings were instrumented to observe the indoor environmental parameters as a function of time. The climate in Pretoria can best be described as warm and dry with large daily variations in solar radiation and outdoor air temperature (a daily range exceeding $20^{\circ} \mathrm{F}\left(11^{\circ} \mathrm{C}\right)$ ). Under these conditions, massive brick buildings proved to be superior to lighter-weight buildings in minimizing the daily variation of the indoor temperature. The reason is that the "time lag" associated with the massive structure was such that the indoor environment remained cool during the hot part of the day (for example, a $79^{\circ} \mathrm{F}\left(26.1^{\circ} \mathrm{C}\right.$ ) indoor temperature compared with an $84^{\circ} \mathrm{F}$ $\left(28.9^{\circ} \mathrm{C}\right)$ outdoor temperature at noon) and also remained warm during the night $\left(74^{\circ} \mathrm{F}\left(23.3^{\circ} \mathrm{C}\right)\right.$ compared with $61^{\circ} \mathrm{F}\left(16.1^{\circ} \mathrm{C}\right)$ outside at 5:00 a.m.). The lighter wood structures with essentially no "time lag" allowed the indoor temperature to increase to undesirable limits during the day (for example, $93^{\circ} \mathrm{F}\left(33.9^{\circ} \mathrm{C}\right.$ ) inside compared with $87^{\circ} \mathrm{F}\left(30.5^{\circ} \mathrm{C}\right.$ ) outside at $2: 00 \mathrm{p} \cdot \mathrm{m}$. ) and to decrease to correspondingly low levels during the night (a $62^{\circ} \mathrm{F}\left(16.7^{\circ} \mathrm{C}\right.$ ) indoor temperature compared with a $61^{\circ} \mathrm{F}\left(16.1^{\circ} \mathrm{C}\right)$ outdoor temperature at 5:00 a.m.).

The conclusions that van Straaten made from the experiments in Durban were just the opposite of those in Pretoria. The climate is generally warm but humid which is also accompanied by large solar radiation intensities and outdoor temperature variations smaller than those in Pretoria (for example, a daily outdoor temperature range of less than $10^{\circ} \mathrm{F}\left(5.5^{\circ} \mathrm{C}\right.$ )). The massive buildings proved to be a distinct disadvantage. The walls could not cool down during the night enough to provide comfortable temperatures in the enclosures during the day.

Other interesting results of van Straaten's research include the improvement in performance of the lightweight structures in warm and dry climates by the addition of concrete floors and by painting the exterior of the structure white.

During 1971 and 1972, an experiment was conducted at the National Bureau of Standards where measurements of the dynamic heat transfer in an experimental masonry building were made in a large environmental chamber [4]. The structure was a one-room house $20 \mathrm{ft}(6.1 \mathrm{~m})$ wide, and $10 \mathrm{ft}(3 \mathrm{~m})$ high with walls of solid concrete block ( 8 in. $(0.2 \mathrm{~m})$ thick) and a flat roof made of reinforced precast concrete slabs ( 4 in. $(0.1 \mathrm{~m})$ thick). The building was exposed to a diurnal temperature cycle having a range of $60^{\circ} \mathrm{F}\left(33.4^{\circ} \mathrm{C}\right)$ extending from $40^{\circ} \mathrm{F}$ $\left(4.4^{\circ} \mathrm{C}\right)$ to $100^{\circ} \mathrm{F}\left(37.8^{\circ} \mathrm{C}\right)$ for a series of tests where changes were made in the amount and location of insulation, and the amount of indoor mass. Tests were conducted where internal heating was used to maintain the indoor air temperature between specific limits as well as tests where no internal heating was supplied and the indoor air temperature was allowed to float.

For the floating tests, it was found that the combination of mass in the walls and roof facing the interior with the insulation placed on the outer surfaces of the building was very effective in reducing and controlling the variation of the indoor air temperature. Placing 2 in. $(0.051 \mathrm{~m})$ of commercial expanded polystyrene insulation on the inside building surface reduced the variation of the inside air temperature from $10.5^{\circ} \mathrm{F}\left(3.1^{\circ} \mathrm{C}\right.$ ) (for the uninsulated case) to $5.1^{\circ} \mathrm{F}\left(3.1^{\circ} \mathrm{C}\right)$. Furthermore, when this insulation was placed on the outside surface of the building, the variation in the inside air temperature was reduced to $2^{\circ} \mathrm{F}\left(1.1^{\circ} \mathrm{C}\right)$.

It should be apparent from the types of investigations cited above that climate as well as building construction plays a significant role in determining a need for air conditioning.

Obviously, another factor to be considered in establishing air conditioning criteria is the range of indoor thermal conditions under which people remain comfortable or not overly uncomfortable. The American Society of Heating, Refrigerating and Air-Conditioning Engineers' Standard 55-74 [5] is very specific in its stipulation of thermal comfort conditions. It states in part that at the center of and $2.0 \mathrm{ft}(0.61 \mathrm{~m})$ from each exposed wall and at the center of the room, the following should be met at all times: 
1. When a dry-bulb temperature (DBT) equais the mean radiant temperature (MRT), the dry-bulb temperature equals the adjusted dry-bulb temperature

$\left(\mathrm{ADBT}=\frac{\mathrm{DBT}+\mathrm{MRT})}{2}\right.$ and the values measured within the occupied zone sha11

be on the boundary or within the "comfort envelope." The "comfort envelope"

is defined as a quadrangle with the following corner coordinates:

$\mathrm{ADBT}=71.5$ and $77.6^{\circ} \mathrm{F} \quad\left(21.9\right.$ and $\left.25.3^{\circ} \mathrm{C}\right)$ at $14 \mathrm{~mm} \mathrm{Hg}$

$\left(1.87 \times 10^{3} \mathrm{~N} / \mathrm{m}^{2}\right)$ vapor pressure and $\mathrm{ADBT}=72.6$ and

$79.7^{\circ} \mathrm{F}\left(22.6\right.$ and $\left.26.5^{\circ} \mathrm{C}\right)$ at $5 \mathrm{~mm} \mathrm{Hg}\left(0.667 \times 10^{3} \mathrm{~N} / \mathrm{m}^{2}\right)$.

2. The water vapor pressure in the occupled zone shall be at or between 5.0 and $14.0 \mathrm{~mm} \mathrm{Hg}\left(1.87 \times 10^{3}\right.$ and $\left.0.667 \times 10^{3} \mathrm{~N} / \mathrm{m}^{2}\right)$. These conditions correspond approximately to 20 and 65 percent relative humidity.

3. When the mean radiant temperature in the occupied zone differs from the dry-bulb temperature, the dry-bulb temperature shall be reduced by one degree for each degree mean radiant temperature elevation above air temperature and vice versa.

4. The air velocity in the occupied zone sha1l be $70 \mathrm{fpm}(0.35 \mathrm{~m} / \mathrm{s})$ or less at any time.

In addition, it also states the allowable limits of oscillation in the temperature and relative humidity.

One might conclude based on this Standard then that if the indoor thermal environment of non-air conditioned buildings falls into this condition "most of the time", the building need not have mechanical cooling even if it is located in an area where climatic criteria might indicate a need for it. Obviously, the biggest unknown factor needed to be established in a study such as this, is how to quantify the phrase "most of the time" in the preceding sentence. In addition, as will be pointed out later in this paper, a better evaluation of the tolerance of people to varying indoor conditions above and below the recommended steady state domfort conditions is needed.

It should also be noted that the concept of determining a need for air conditioning based on building thermal performance is not new. Givoni in his latest book [6] introduces a "Building Bioclimatic Chart". His concept is based on the "Bioclimatic Chart", introduced earlier by 0lgay [7]. Givoni's chart is essentially a psychrometric chart on which he has drawn an enclosed region indicating thermal comfort conditions. From experience and study, three additional regions have been drawn: one to indicate the range of outdoor conditions where choice of building materials and design, features (large thermal resistance, large thermal mass, etc.) make comfort conditions inside attainable without air conditioning; a second region to indicate the outdoor conditions where efficient ventilation through the structure could result in comfort conditions; and a last region showing the range of outdoor conditions where mechanical cooling would be required.

Loudon [8] describes a method of calculating summertime indoor temperatures based on climatic and building factors which was developed at the Building Research Station in England. In addition, experimental data is presented showing that there was a strong correlation between the predicted peak temperatures in occupied schools and office buildings and users' comments on overheating in the summer, obtained from social surveys. He concludes, "... if temperatures are calculated on assumptions which have been set out, criteria can be set which enable one to decide in advance whether a given design of office or school is likely to be thermally comfortable". This is precisely the basis on which the study described in this paper was undertaken.

The present paper shows how a sophisticated building simulation computer program can be used in conjunction with actual weather data to predict the time-varying indoor thermal conditions. In addition, it is conceptually shown how such results could be used for establishing air conditioning criteria. 


\section{Proposed Concept of Air Conditioning Criteria}

One of the ways to determine if a building should have mechanical cooling is to construct it without cooling equipment, determine if the indoor environment is acceptable, and if not, install the equipment. This is, of course, not feasible in most cases. However, the particular concept presented here is similar in many respects. By combining the pertinent weather parameters with those of the building under consideration, a simulation model predicts what would occur without mechanical cooling. The conditions are then compared with accepted indoor comfort data to determine whether the space should or should not be conditioned.

Anquez, et. a1. of the Centre Scientifique et Technique du Batiment (CSTB) in France, published in 1965 the results of a study entitled "The Protection of Glazed Windows from Solar Radiation" [9]. Their objective was to develop standards for devices that are used to protect windows from solar radiation in non-air conditioned buildings of average and low thermal inertia. Their procedure was to divide France into four climatic regions and then through the use of mathematical simulations on "typical" buildings of specified dimensions, exposure of glazed areas, thermal inertia, and degree of ventilation, determine to what extent shading devices could be used to insure the maintenance of a comfortable indoor temperature during an average summer. The results were published in the form of tables, one of which is shown in Table 1 . Someone considering a specific design who could locate his building at the proper place in this table, could tell at a glance what type of window shading, if any, could be used to insure comfortable conditions in the summer ${ }^{a}$.

The determination of air conditioning criteria by the present authors has not been carried to the point of publishing tables such as the one cited from the French study. However, it is felt that the ultimate goal of this project, which has been funded by the Department of Housing and Urban Development (HUD), would be to publish a document containing information analogous to the table. For a given climatic region of the United States and given building (characteristized by the pertinent parameters), one could tell during the design phase whether mechanical cooling should or should not be installed.

The manner in which a computer program could be used for determining a need for air conditioning is depicted in Figure 1. Weather data from a specific climatic zone and adequate specifications of a building would be combined in the simulation model, the output of which would be the space conditions. The frequency and duration of the various indoor parameters would then be compared with a suitable indoor comfort index (identified in this paper as the Predicted Indoor Habitability Index (PIHI)) to determine whether the space should or should not be conditioned.

Before the project can successfully be completed, the following is required:

1. A computer program which has been proven accurate for predicting indoor temperatures,

2. A division of the United States into climatic zones and a knowledge of representative weather parameters from each zone,

3. A classification of buildings according to their thermal response, and

4. A clear definition of the Predicted Indoor Habitability Index (PIHI) as introduced in this paper.

Section 3. presents a description of the computer program used in this study and which adequately satisfies requirement 1 . above.

Technical Committee 4.2 of the American Society of Heating, Refrigerating and AirConditioning Engineers is in the process of developing "typical weather data" for the purpose of computing building energy requirements. For the first phase of the study reported in this paper, hour-by-hour weather conditions obtained from the National Climatic Center in Asheville, North Carolina were used for the specific localities studied.

\footnotetext{
"The meaning of the "solar factor" referred to in Table 1 has not been explained in the present paper. It is felt not necessary for the purpose of the illustration.
} 
Section 4. of this paper describes the analysis that has been done to date on the classification of buildings.

Section 5. describes the authors' concept of a Predicted Indoor Habitability Index and Appendix $B$ contains a review of various comfort and heat stress indices that could be considered now as a basis for PIHI.

Section 6. describes what is called a feasibility analysis that has been done to give an indication of how successful the project might ultimately be.

\section{Calculation of Indoor Space Conditions by Building Thermal Simulation}

Numerous papers have been published and calculation manuals prepared in the area of heating/cooling load determination. Very few of these, however, have dealt with the indoor temperature estimates for the condition where air conditioning is non-existent or inadequate. Room temperature prediction is, on the other hand, very actively studied in Europe, Japan, Israel, and India where mechanical cooling is still very expensive for the majority of dwellings and consequently a determination of the basic need for air conditioning is very important.

The heat transfer calculations for room temperature prediction are similar to the heating/ cooling load calculations; however, the former are somewhat more complex than the latter because they require exact heat balance calculations for the room air, surrounding walls and infiltrating outdoor air. Since the major importance is the hour by hour room temperature profile, it is necessary to account for the transient heat conduction and thermal storage in the building and internal mass.

In order to determine the temperature and humidity in non-air conditioned rooms responding to randomly fluctuating outdoor climatic conditions, a computer program to simulate hourly performance of building heat gain and heat storage has been developed at the National Bureau of Standards [10,11, 12]. The program is called "NBSLD" and consists of various subroutines for calculating heat gains, which are similar to those recommended by the ASHRAE Task Group on Energy Requirements [13]. One major extension of the program beyond the recommended ASHRAE TG subroutines is a routine called RMTMP, which solves for room air temperature through the use of a series of simultaneous heat balance equations. The details of this routine is given in reference [12].

Figure 2 depicts the overall calculation sequence of NBSLD. Shown in the dash lined boxes are input data to be supplied where as those in solid lined boxes indicated calculations to be performed. The cycle indicators show the iteration cycles for the number of buildings, the number of rooms in a given building and the number of days for which the calculations are performed. Table 2 lists all the pertinent building data required for the calculations. More specific identification of the exact way in which the input data is prepared is described in reference [12].

This particular computer simulation has been verified by experimental work on two separate research projects at NBS [4, 14]. The first study [4] involved a small masonry building and the experiment was described previously in this paper. Figure 3 is a typical test result taken from reference [4] and shows to what degree NBSLD was able to account for the transient conduction occurring in the thick masonry walls (to within $+1.0^{\circ} \mathrm{F}\left(0.55^{\circ} \mathrm{C}\right.$ ) for outdoor temperature variations from 45 to $100^{\circ} \mathrm{F}\left(7\right.$ to $\left.38^{\circ} \mathrm{C}\right)$ and to compute the indoor temperature fluctuation. In the latter study [14], a more realistic living unit was used, namely a four-bedroom, lightweight house that was completely furnished and had the activity of a six-member family simulated within. The house was also tested inside the environmental chamber where the outdoor conditions were simulated and precisely controlled. 
In order to evaluate indoor conditions for human comfort or physiological stress, it is desirable that the indoor air velocity be estimated. The indoor air velocity is, however, believed to vary depending upon the air leakage rate, ventilation rate, thermal gradient of the room, basic design of the room, and any local air moving device such as a portable fan. According to Givoni [6], the indoor air motion could vary between 5 to $60 \%$ of outdoor wind velocity depending upon the nature of the air passage resistance through the room.

Since the information available for predicting indoor air velocity as function of temperature distribution and wind velocity is very scanty, NBSLD has not been designed to calculate this parameter. It has been assumed in the present study that the indoor air velocity would be less than $20 \mathrm{ft}$ per minute $(0.1 \mathrm{~m} / \mathrm{sec})$. This assumption should yield. an upper-bound value of comfort index or physiological index for summer conditions and is therefore safer to use than to overestimate the cooling due to elevated air velocities.

The form of NBSLD available at the start of this study did not allow for the calculation of mean radiant temperature (MRT). Since the room temperature calculation routine (RMTMP) does calculate the temperature of all the interior surfaces, it was very simple matter to modify the program to calculate this quantity. Then MRT was used as part of the input data to the calculation of the appropriate physiological or comfort indices that were used in this study. Appendix A describes the equations that were inserted into the program to calculate MRT .

\section{Classification of Buildings According to Their Thermal Response Characteristics}

This part of the paper describes a method for classifying kinds of residential buildings in relation to their thermal behavior.

Construction data were taken from the proposals of 18 of the 22 participating Housing System Producers in the HUD Operation BREAKTHROUGH Program. Since the contractors involved in that program represented a cross section of the Housing System Producers in the building industry, it was felt that data contained in their proposals provided meaningful information about the practice, and the state of the art, in housing design. Consequently, it was felt that a realistic classification procedure could be established relative to the typical residential building based upon thermal parameters for composite structural components.

\subsection{Type of Building Data Compiled}

From the drawings and specifications submitted by the Housing System Producers in the Operation BREAKTHROUGH Program, two types of data were collected. The first concerned the method of construction and materials used for the exterior enclosures and interior partitions of a building, and the associated thermophysical property data of the materials. Pertinent thermal performance parameters associated with the structural components such as the U-value, weight per unit area, thermal mass, and the thermal time constant were then computed. Their computation, physical meaning and usefulness will be discussed later in this section. The second type of data was of a geometric nature and involved the following:

1. Total floor area of a dwelling unit.

2. Floor area for each of the rooms in a dwelling unit.

3. Type of walls and openings, windows, doors, and their areas for each of the rooms in a unit.

4. Total glass area of a dwelling unit.

5. Crack length of the windows and doors. These data are required in order to know air movement and infiltration characteristics.

6. Shading coefficient for the glazed area. 


\subsection{Method of Data Presentation}

Data collected from the drawings and specifications were processed by the NBS UNIVAC 1108 computer and printed out in the unified manner in tabular form. Two types of tables were developed, corresponding to the two types of data discussed in 4.1. Typical examples are given here as Tables 3 to 6 .

Table 3 gives the building construction and material data for one of the dwellings of one of the 18 Housing System Producers surveyed. This table contains a typical layer by layer description and the thermophysical properties of the materials used in the construction of the structural components (exterior walls, interior partition, party wall, floor/ceiling, roof/ceiling, ground floor, basement wall, basement floor, window). The order of the layers are from the outside of a room toward the inside for the side walls and from top to bottom for roofs and floor/ceilings. The thermal property values were taken from the contractor's drawings and specifications and from the 1972 ASHRAE Handbook of Fundamentals [15]. Occasionally data from the specific heat $\left(C_{p}\right)$ of certain materials were not available, and a value of $.20 \mathrm{Btu} /\left(1 \mathrm{~b} \cdot{ }^{\circ} \mathrm{F}\right)\left(.013 \mathrm{cal} /\left(\mathrm{g} \cdot{ }^{\circ} \mathrm{C}\right)\right)$ was assumed. Since the value of $\mathrm{C}_{\mathrm{p}}$ does not vary much for most of the building materials (on the order of .15 (.0098) to .40 (.026) with a major portion of the materials in the lower range of the spectrum), the walue of .20 (.013) was chosen. The surface air film resistance values were taken from the ASHRAE Handbook of Fundamentals also and based on the summer design conditions since the overall project was established for the purpose of determining summer air conditioning criteria.

Table 4 gives the four relevant parameters associated with and affecting the thermal performance of a building. They were computed from the data given in Table 3 . A brief description follows:

1. U-value: The U-value is the overall heat transfer coefficient including the surface air film resistance (at $7.5 \mathrm{mph}(3.4 \mathrm{~m} / \mathrm{s}$ ) wind outside and still air inside) under steady-state conditions. This is the major factor used by designers in estimating the cooling load of a building. As pointed out previously, under unsteady-state conditions the U-value is no longer the only controlling factor in heat flow through walls since it does not take into account the energy storage effect of the walls. However, it does give an indication of the amount of resistance the wall offers to heat flow and, therefore, acts as one of the parameters in determining the overall heat transfer through the walls.

2. Thermal Mass, $\rho C \mathrm{C}$ : The thermal mass is a counterpart of the U-value and gives an indication of the energy storage capacity of the walls. It is computed from the following equation:

$$
\rho C_{p} L=\sum_{i=1}^{N} \rho_{i} C_{p i} L_{i}
$$

where $\rho_{i}, C_{p i}, L_{i}$ are the density, specific heat, and thickness, respectively, of the ith layer in a multilayer wall. $\mathrm{N}$ is the total number in the wall.

3. Weight per unit surface area, $\rho L$ : Because of the small variations in the specific heat for most building materials, the energy storage capacity of a wall is almost directly proportional to the weight per unit surface area of the wall. This parameter is, therefore, closely related to the thermal mass in that a knowledge of the values of the specific heat, which are not available for certain materials, is not required. The weight per unit area of a wall is computed by

$$
\rho L=\sum_{i=1}^{N} \rho_{i} L_{i}
$$


4. Thermal Time Constant: The thermal time constant is a function of the thermal diffusivities of the layers in a multilayer wall and is defined. [6] as the heat stored per unit of heat transmitted. It is, therefore, a combination of the thermal mass and the thermal resistance of the wall. It is derived on the basis of the analogy between the heat flow represented by a thermal circuit and the time constant of a R-C electrical circuit, and is given by Givoni [6]':

$$
\text { Thermal Time Constant }=\sum_{i}\left(\tau_{i}\right)
$$

where

$$
\tau_{i}=\left(R_{o s}+L_{1} / k_{1}+\ldots+L_{i} / 2 k_{i}\right) \cdot\left(L_{i} \rho_{i} C_{p i}\right)
$$

where $R_{\text {os }}$ is the resistance of the surface air film and $k_{i}$ is the thermal conductivity of the material of the ith layer. In the case of an air space, the resistance of the air space is substituted for $L_{i} / k_{i}$.

Similar to the thermal diffusivity of a homogeneous single layer wall, the thermal time constant is a measure of the thermal damping capacity of a multilayer wall on the amplitude and time lag of the inner surface temperature, or indoor air temperature, with respect to a periodically varying outdoor temperature. It should be pointed out that the thermal time constant given by equation (3) also takes into account the order the layers of materials are arranged. A change in the order of the arrangement will change the rate of heat flow through the wall under transient conditions. This is because the outside surface temperatures of: the walls with different orders of arrangement in their layers will be different during the transient states. For example, during the day, the outside surface temperature of a wall with an insulation layer next to the external surface layer will be higher than a wall constructed of the same layers of materials but with the insulation layer placed further away from the external surface layer. The former construction will. result in more heat being transferred back to the external environment by convection and radiation, and consequently less heat being transferred into the interior space. It is noted that this phenomenon is not accounted for by either the U-value or the thermal mass where the order of arrangement of the layers is immaterial.

Table 5 gives the geometrical data for one of 28 dwelling units ranging from 1-bedroom to 4-bedrooms. The 28 units were chosen randomly from six of the 22 Housing System Producers. The survey of the 6 Housing System Producers was done for the purpose of obtaining some average values of unit size, floor area, and window area for a normal dwelling unit. The orientation of the unit is not specified since this is one of the factors that is influenced by site location, terrain, units group plan, etc. as much as by thermal performance consideration. For a group of attached units (single family attached, multi-family low rise or high rise), the unit at the ends, or corner, of the group was chosen since it has the largest amount of wall area exposed to the outside environment and consequently results in the most severe indoor temperature variation, or the largest cooling load, among the group, and represents the worst case as far as air conditioning is concerned. Table 5 also gives the crack lengths of the windows and doors which are required in an air infiltration study. Data for lighting (as an internal heat source) and furniture (as an internal heat sink) were not available. The data for the shading coefficient on windows were assumed values for regular sheet glass with light indoor venetian blinds shading. These data would, of course, be different values for other types of glass and shading.

Table 6 gives a summary of the different type areas associated with the dwelling, plus three parameters that can be used for the classification of dwelling units on a geometrical basis. These three parameters are: 
1. Floor Area: The floor area represents the total amount of living space in a dwelling unit and gives an indication of the size of the unit among the same type of dwellings.

2. Ratio of Exterior Wal1. Area to Floor Area: The ratio gives an indication of the complexity of the shape of the unit. For example, a simple rectangular unit will have a lower ratio than a complex geometrically shaped unit.

3. Ratio of Window Area to Floor Area: This ratio indicates the relative amount of glass area in a unit which has a direct bearing on the amount of solar radiation transmitted directly into the interior space.

In general, data contained in Tables 3 to 6 are required by the computer program NBSLD for indoor temperature or load prediction purposes.

\subsection{Analysis of Data and Discussion}

A study of all the data compiled in this part of the project indicates the following:

1. Unit Size: The range and average size of the dwelling units in terms of total $\mathrm{ft}^{2}\left(\mathrm{~m}^{2}\right)$ of floor area are tabulated below:

\begin{tabular}{ccccc} 
& $\begin{array}{l}\text { Min. } \\
\text { Area }\end{array}$ & $\begin{array}{l}\text { Max. } \\
\text { Area }\end{array}$ & Average & $\begin{array}{c}\text { Total } \\
\text { Units } \\
\text { Used }\end{array}$ \\
\hline $\begin{array}{c}\text { 4-Bedroom } \\
\text { Unit }\end{array}$ & $1065(98.9)$ & $1740(161.6)$ & $1340(124.5)$ & 11 \\
$\begin{array}{c}\text { 3-Bedroom } \\
\text { Unit }\end{array}$ & $910(84.6)$ & $1480(137.5)$ & $1100(102.2)$ & 16 \\
$\begin{array}{c}\text { 2-Bedroom } \\
\text { Unit }\end{array}$ & $700(65.0)$ & $1200(111.5)$ & $905(84.1)$ & 15 \\
$\begin{array}{c}1-\text { Bedroom } \\
\text { Unit }\end{array}$ & $580(53.9)$ & $960(89.2)$ & $735(68.3)$ & 8 \\
\hline
\end{tabular}

It is noted that the total number of units upon which the average values were based is not statistically significant. However, for the study of air conditioning criteria where a typical size unit is to be used, slight variation from the above listed average values would not have any significant influence on the results.

2. Glass Area: The total glass area in the dwelling units ranged from $10 \%$ to $26 \%$ of the total floor area, with an average value of $17 \%$ for 50 units studied. The variation of $10 \sim 26 \%$ occurs in both the large size and the small size units (FHA Minimum Property Standards require $10 \%$ minimum for light). It can, therefore, be said that the size of a dwelling unit has no effect on the relative amount (with respect to floor area) of the glass in the design of a typical housing unit.

3. Individual Room Size: The variations in the sizes of the major rooms in a dwelling unit are quite large, and are listed below for reference: 


\begin{tabular}{lrcr} 
& \multicolumn{1}{c}{$\begin{array}{c}\text { Range } \\
\mathrm{ft} \\
\left(\mathrm{m}^{2}\right)\end{array}$} & $\begin{array}{c}\text { Average } \\
\mathrm{ft} \mathrm{2}^{2} \\
\left(\mathrm{~m}^{2}\right)\end{array}$ \\
\hline Living Room & $140 \sim 270(13.0 \sim 25.1)$ & $200(18.6)$ \\
$\begin{array}{l}\text { Dining Room } \\
\text { Kitchen }\end{array}$ & $95 \sim 125(8.8 \sim 11.6)$ & $110(10.2)$ \\
1st Bedroom & $50 \sim 150(4.6 \sim 13.9)$ & $95(8.8)$ \\
2nd Bedroom & $125 \sim 220(11.6 \sim 20.4)$ & $165(15.3)$ \\
Other Bedrooms & $100 \sim 220(9.3 \sim 20.4)$ & $115(10.7)$ \\
Bathroom & $80 \sim 180(7.4 \sim 16.7)$ & $40(3.7)$ \\
\hline
\end{tabular}

Normally, the larger living rooms were associated with a 3 or 4-bedroom unit. The lower limits in the above list are controlled by the FHA Minimum Property Standards.

4. U-value! The U-values for the different designs of the walls and roof/ ceiling constructions by the 18 housing system producers were fairly uniform within each weight class of construction. The ranges and average values for the exterior wall and the roof/ceiling elements were,

$$
\begin{aligned}
\text { Exterior wall }= & .062 \sim .178 \mathrm{Btu} /\left(\mathrm{h} \cdot \mathrm{ft}^{2} \cdot{ }^{\circ} \mathrm{F}\right)\left(.352 \sim 1.01 \mathrm{~W} /\left(\mathrm{m}^{2} \cdot{ }^{\circ} \mathrm{C}\right)\right. \\
& \text { average value }=.104(.59) \\
\text { Roof/ceiling }= & .041 \sim .114 \mathrm{Btu} /\left(\mathrm{h} \cdot \mathrm{ft}^{2} \cdot{ }^{\circ} \mathrm{F}\right)\left(.233 \sim .647 \mathrm{~W} /\left(\mathrm{m}^{2} \cdot{ }^{\circ} \mathrm{C}\right)\right. \\
& \text { average value }=.062(.35)
\end{aligned}
$$

In general, for the exterior wall system, the higher than average U-values were associated with the heavy type construction such as concrete wall. For lightweight construction such as wood frame wall and sandwich panel wall with various cores and facings, the U-values were all comparable.

5. Weight per Unit Area: As stated previously, the weight per unit area and the thermal mass are closely related, having an almost linear relationship because of the slight variation in the values of the specific heat for different building materials. This linear relationship is shown in Figure 4. The weight can, therefore, be used to indicate the thermal storage capacity of a wall or roof/ceiling system. For the 18 Housing System Producers studied, the ranges of the weight of different building enclosures were,

$$
\begin{array}{ll}
\text { Exterior wall: } & 2.5 \sim 98 \mathrm{lb} / \mathrm{ft}^{2}\left(12 \sim 478 \mathrm{~kg} / \mathrm{m}^{2}\right) \\
\text { Roof/ceiling: } & 2.5 \sim 69 \mathrm{lb} / \mathrm{ft}^{2}\left(12 \sim 337 \mathrm{~kg} / \mathrm{m}^{2}\right) \\
\text { Floor/ceiling: } & 4 \sim 86 \mathrm{lb} / \mathrm{ft}^{2}\left(20 \sim 420 \mathrm{~kg} / \mathrm{m}^{2}\right) \\
\text { Ground floor: } & 2 \sim 901 \mathrm{~b} / \mathrm{ft}^{2}\left(10 \sim 439 \mathrm{~kg} / \mathrm{m}^{2}\right) \\
\text { Party wall: } & 5 \sim 72 \mathrm{lb} / \mathrm{ft}^{2}\left(24 \sim 351 \mathrm{~kg} / \mathrm{m}^{2}\right)
\end{array}
$$

(including load bearing interior wall) 
The types of the construction of the building included: wood frame, sandwich panel with various cores and facings, metal frame, brick wall, and concrete wall systems. A classification based on the weight of the exterior wall system is recommended as follows:

Lightweight (wood frame, sandwich panel): Less than $20 \mathrm{lb} / \mathrm{ft}^{2}\left(98 \mathrm{~kg} / \mathrm{m}^{2}\right)$

Medium weight (wood frame with frace brick, brick, lightweight concrete): $20 \sim 50 \mathrm{lb} / \mathrm{ft}^{2}(98$. $244 \mathrm{~kg} / \mathrm{m}^{2}$ )

Heavyweight (brick, concrete): higher than $50 \mathrm{lb} / \mathrm{ft}^{2}$ $\left(244 \mathrm{~kg} / \mathrm{m}^{2}\right)$

6. Thermal Time Constant: The ranges of values for the different building enclosures are,

$$
\begin{array}{ll}
\text { Exterior wall: } & 3.2 \sim 115 \mathrm{~h} \\
\text { Roof/ceiling: } & 4.1 \sim 165 \mathrm{~h} \\
\text { Floor/ceiling: } & 3.4 \sim 86 \mathrm{~h} \\
\text { Ground floor: } \quad 2.2 \sim 96 \mathrm{~h} \\
\text { Party wall: } \quad 6.2 \sim 44 \mathrm{~h} \\
\text { Interior Partitions: } 1.7 \sim 10 \mathrm{~h}
\end{array}
$$

It can be seen that the ranges of values for the thermal time constant are quite large and are comparable with the ranges for the weight of the structures. Figures 5 and 6 show the relation between the thermal time constant and the weight of exterior wall and roof/ ceiling systems, respectively. The large scattering of the data points shows the effect of the arrangement of the layers of different materials and the placement of insulations and/or air spaces in a wall system. However, Figures 5 and 6 also show that even though the local scattering of data points is large, the overall trends of increasing thermal time constant with increasing weight is preserved, and the classification of buildings by weight may be sufficient. For a more refined and accurate classification of buildings, with respect to indoor thermal environment, the thermal time constant might be a better index because of its close functional resemblance with the thermal diffusivity of a single layer wall. This should, however, be verified by further work, using data on a variety of selected typical residential units of different design as input to the computer program NBSLD and comparing the results under identical external environmental conditions at various locations throughout the country.

\section{Predicted Indoor Habitability Index}

There are approximately fifteen published indices or groups of experimental data that have been presented to indicate man's comfort or discomfort when subjected to a certain environment. The majority are experimental in nature (i.e., human subjects have been exposed to a specified and controlled environment and asked to describe their feeling or at least have physiological measurements taken on them during the exposure). However, during the last several years there has been a great deal of interest in describing mathematically the thermal interaction between man and his environment, thus enabling one to predict what occurs or how one might feel in given surroundings. Appendix B contains a comprehensive review of those indices felt to be the most pertinent to this study. 
The authors of this paper have introduced the concept of Predicted Indoor Habitability Index (PIHI) for several reasons. It is felt that the decision to air condition a building should be based on the fact that the value of certain chosen parameters describing the indoor environment would exceed a certain level for a specified amount of time during the "air conditioning" season unless mechanical cooling were installed. Therefore, it would be desirable to establish a new scale to satisfy this requirement. For example, a very simple arbitrarily chosen scale might be:
PIHI $=0$
if the months (corresponds to slightly warm - see Appendix B) the summer months
PIHI $=10$ if the KSU index exceeds a value of 5 for $10 \%$ of the hours during the summer months.
PIHI $=5$ if the KSU index exceeds a value of 5 for $5 \%$ of the hours during

However, there are other factors that should also be included in the analysis to establish PIHI. These include among other things, consideration of the "persistency factor". Certainly a situation where the indoor environment is "uncomfortable" for long periods of time wouldn't necessarily be equivalent to one where it was just as uncomfortable for more but shorter periods of time. In addition, shouldn't consideration be given to the relative level of "discomfort" that occurs during these periods? An indoor environment where the KSU index was 6 (warm) for a certain period of time wouldn't be equal to one where it was 7 (hot) for the same period even though they did exceed 5 for the same amount of time.

Other important factors should also be noted at this point. Most of the indices reviewed in Appendix B are valid for, or at least have been developed for, quasi-steady situations. The subjects have been exposed to (or the models simulate the subjects being exposed to) steady-state environments for periods of time up to four hours and their response given accordingly. Very seldom does this occur in the average residence and the technique of extending these indices to a more transient environment needs at least a "close look". ASHRAE, in their Comfort Standard [5], recommend limiting the rate of change of dry-bulb temperature in a space to $4^{\circ} \mathrm{F} / \mathrm{h}\left(2.2^{\circ} \mathrm{C} / \mathrm{h}\right)$ and the rate of change of water vapor pressure to $4.5 \mathrm{~mm} \mathrm{Hg} / \mathrm{h}\left(600 \mathrm{~N} / \mathrm{m}^{2}\right)^{\mathrm{a}}$. These limits have been verified somewhat by an experimental study at Kansas State University reported by Sprague and McNall [16]. College students wearing the "standard clothing" (see Appendix B) were subjected to an environment where the dry-bulb temperature and relative humidity was oscillated one at a time about the "comfort value" while the other parameter was maintained at the "comfort value". The conclusion of the study was that the Comfort Standard values are somewhat conservative but no change was recommended. In addition, Wyon et. a1. [17] studied the cyclic variations of temperature about some optimum. Subjects were free to reverse the direction of change of temperature swings and could thus control the amplitude and period of swings to which they were exposed. It was found that "their subjective tolerance of temperature swings was very much greater than is supposed by existing regulations".

Another factor to be considered is the effect of nonuniform environments. There is a capability built into many of the indices to handle a situation where the wall temperatures are different than the ambient air temperature. McNal1 et. al. [18, 19] have done studies at Kansas State University which have shown that for "reasonable degrees" of temperature separations between the enclosing surfaces and the air, the subjects experienced no significant discomfort which could be attributed to asymmetry and that the use of the mean radiant temperature in the computation of environmental condition was satisfactory. Other studies had been done earlier at Kansas State University [20, 21, 22] and at CSTB in France [23] on the same subject.

Finally, it was felt at the beginning of the study that the PIHI scale should ideally take into account the type of occupant in the residential dwelling under consideration or at least there should be a different scale for the different types of occupants. Recent studies, both within the U.S. and at the Technical University of Denmark, have shown that comfort conditions do not significantly depend upon age, adaptation, sex, or seasonal and

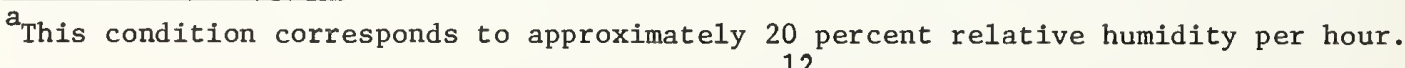


circadian rhythm [24, 25, 26, 27, 28]. However, it should be noted that even though the preferred comfort conditions have been the same, conditions of discomfort, which are perhaps the relevant ones to consider here, could very well be different for different age groups, sex, etc. [29]. This latter field is one that is just beginning to be researched.

In summary, the concept of the Predicted Indoor Habitability Index has been introduced as a scale or index that is required in order to successfully complete the job of establishing air conditioning criteria.

The authors have pointed out a number of factors that should be accounted for in establishing the scale and it is hoped that a separate research task can be initiated so that the index can be established. During the first phase of the project described in this paper, the state-of-the-art comfort indices were used in the analyses as will be seen in the next section.

\section{Preliminary Calculations and Analysis for Air Conditioning Criteria}

In order to determine whether the approach outlined in Section 2 is feasible for determining a meaningful air conditioning criterion, some preliminary analysis was carried out. Different apartments within complexes planned as part of HUD's Operation BREAKTHROUGH Program have been simulated in the National Bureau of Standards' computer program (NBSLD) described in Section 3. Hourly values of the important weather parameters, outdoor dry-bulb temperature, wet-bulb temperature, wind velocity, and cloud cover were taken from the United States Weather Bureau tapes (available from the National Climate Center in Asheville, North Carolina). The output of the simulation was hourly values of indoor dry-bulb and wet-bulb temperature. Algorithms for pertinent physiological and/or comfort indices were written so that daily profiles showing values of these indices could be obtained.

The analysis was begun by arbitrarily taking the weather data for the years 1949 through 1958 in Jersey City, New Jersey and simulating the behavior of one of the heavyweight apartments to be built on that site. The building data that were used are as follows:

1. The apartment building was assumed to face west and the individual apartment chosen was one at approximately mid-height of the 130 feet $(39.6 \mathrm{~m})$ high structure. No building shadow was used and the adjacent apartments and hállway were assumed to always be at the same temperature as the apartment.

2. The exposed wall is constructed of 7 inches $(17.8 \mathrm{~cm})$ of concrete, and 2 inches $(5.1 \mathrm{~cm})$ of insulation. It contains a $100 \mathrm{ft} 2\left(9.3 \mathrm{~m}^{2}\right)$ glass window (shading coefficient $=0.22$ corresponding to a double pane window with a white opaque roller shade). The total wall area is $212 \mathrm{ft}^{2}\left(19.7 \mathrm{~m}^{2}\right)$ leaving $112 \mathrm{ft}^{2}\left(10.4 \mathrm{~m}^{2}\right)$ of solid structure.

3. The floor/ceiling unit is composed of $51 / 2$ inches $(14 \mathrm{~cm})$ of concrete and $1 / 8$ inch $(0.32 \mathrm{~cm})$ cork tile with a total area of $550 \mathrm{ft}^{2}\left(51.1 \mathrm{~m}^{2}\right)$. The floor to ceiling height is $8.5 \mathrm{ft}(2.6 \mathrm{~m})$.

4. The partition walls contain 6 inches $(15.2 \mathrm{~cm})$ of concrete.

5. The maximum number of occupants is 2 , the maximum equipment load is $1 / 2 \mathrm{~W} / \mathrm{ft}^{2}\left(5.4 \mathrm{~W} / \mathrm{m}^{2}\right)$ of floor area, and the maximum lighting load is $3 \mathrm{~W} / \mathrm{ft}^{2}\left(32.3 \mathrm{~W} / \mathrm{m}^{2}\right)$ of floor area.

6. The infiltration or natural ventilation rate was simulated as 1 air change/h between $6 \mathrm{a} . \mathrm{m}$. and $7 \mathrm{p} . \mathrm{m}$. and 6 air changes $/ \mathrm{h}$ from $7 \mathrm{p} . \mathrm{m}$. to $6 \mathrm{a} \cdot \mathrm{m}$. 
Typical results for the months of July and September in Jersey City are shown in Figures 7 through 24. The data is for the summer of 1952 which was hotter than the mean for the 10 year period that was examined. The outside dry-bulb temperature was equal to or greater than $80^{\circ} \mathrm{F}\left(26.7^{\circ} \mathrm{C}\right)$ for 615 hours during the four months, June through September ( 3 rd highest in ten year period), and the outside wet-bulb temperature was equal to or greater than $67^{\circ} \mathrm{F}\left(19.4^{\circ} \mathrm{C}\right.$ ) for 1258 hours (3rd highest)a. Shown in Figure 7 is a plot of the solar energy falling on the west facade of the apartment (after modification by actual cloud cover) and a plot of outdoor dry- and wet-bulb temperature for the month of July. Figure 8 shows the output of the thermal simulation for this apartment; in other words, a monthly profile of indoor dry- and wet-bulb temperature. Since the ASHRAE Comfort Standard gives limits on the rate of change of indoor temperature and relative humidity, these values were computed and are shown in Figure 9. As can be seen, the suggested values of $4^{\circ} \mathrm{F} / \mathrm{h} \quad\left(2.2^{\circ} \mathrm{C} / \mathrm{h}\right)$ and $20 \% / \mathrm{h}$ were only exceeded once or twice during the month of the ten year period regardless of how hot the weather was.

Figures 10 through 15 show monthly profiles of several of the physiological indices discussed in Appendix B, calculated from the corresponding algorithms. Eight different indices are plotted in these figures for the month of July 1952. The particular indices selected were based on comfort votes of subjects exposed to selected environmental conditions for different periods of time, on calculated comfort responses using an analytica1 equation fitted to comfort data, and on several different expressions of heat stress related to the ratio of measured sweat rates to maximum possible sweat rates. Comments applicable to these profiles are as follows:

1. The new effective temperature (ET*) was equal to or higher than $81^{\circ} \mathrm{F}$ $\left(27.2^{\circ} \mathrm{C}\right) 60.8$ percent of the time and equal to or higher than $85^{\circ} \mathrm{F}$ $\left(29.4^{\circ} \mathrm{C}\right.$ ) only 27.0 percent of the time during the month (Figure 11).

2. The predicted mean vote for a person in standard clothing $(0.6 \mathrm{clo})$ was equal to or exceeded 1 (slightly warm) 40.3 percent of the time but was equal to or above 1 only 19.4 percent of the time then the clothing was reduced $(0.25 \mathrm{clo})$ (Figure 12$)$.

3. There was little or not heat stress regardless of the particular index used (old or new) (Figure 14).

4. The Kansas State Index was equal to or above 5 (slightly warm) only 21.1 . percent of the time (Figure 10).

5. More than 10 percent of the people were dissatisfied a significant portion of the time during the month regardless of whether light clothing or the "standard" clothing was worn (Figure 13).

Corresponding analysis could be made of the month of September from Figures 16 through 24. In addition, summary information for all ten years is given in Table 7 . The table shows for the 10 summers in Jersey City, the number of total hours in each summer that the outdoor dry-bulb temperature exceeded $80^{\circ} \mathrm{F}\left(26.7^{\circ} \mathrm{C}\right)$ and the outdoor wet-bulb temperature exceeded $67^{\circ} \mathrm{F}\left(19.4^{\circ} \mathrm{C}\right)$. In addition, the percent of the time in each month that selected indices exceeded prescribed levels was $c_{\nexists l} l$ culated and are shown.

The point has already been raised in Section 5 that an entirely new index will have to be established to serve the needs of this study. To demonstrate one reason why this is so, Figures 25 and 26 have been included for two warm months in 1953 and 1958, respectively. Figure 25 shows that the indoor $\mathrm{ET}^{*}$ exceeded $85^{\circ} \mathrm{F}\left(29.4^{\circ} \mathrm{C}\right) 14$ percent of the time during August of 1953. The specific way in which it occurred was for one two-hour period, twice it went above $85^{\circ} \mathrm{F}\left(29.4^{\circ} \mathrm{C}\right)$ for a duration of between 12 and 18 hours, and once for more than a 48 hour period. Figure 26 shows that in July of 1958 . ET* was above $85^{\circ} \mathrm{F}\left(29.4^{\circ} \mathrm{C}\right)$ for 13 percent of the time; however, the specific way in which it occurred was entirely different from that indicated in Figure 25. The question that arises is: would the fee1ing of discomfort be identical during these two months? If not, there appears to be justification for the establishment of a new scale (PIHI) that accounts for frequency and duration of uncomfortable conditions.

Wnder these conditions, air conditioning should be considered according to the previously referenced Air Force guidelines[1]. 
It is felt that given the kind of information just shown for a specific structure and location, the decision to air condition could certainly be made. However, it would be neither practical nor economical to undertake such an analysis for each individual case. It is still questionable whether it is feasible to carry out the analysis for many combinations of building groups and climatic zones across the United States. Therefore, a shortcut method was sought by examining the results of this thermal simulation very closely.

In Figures 27 through 32, it can be seen that correlations were attempted between time (in 4 months) each year for 10 years that a chosen index was above a prescribed value inside and time the outdoor dry-bulb or wet-bulb temperature exceeded $80^{\circ} \mathrm{F}\left(26.7^{\circ} \mathrm{C}\right.$ ) or $67^{\circ} \mathrm{F}$ $\left(19.4^{\circ} \mathrm{C}\right)$, respectively. Because of the structure of the present HuD criteria [2], 1t was felt that this would be one way to describe quantitatively the "thermal performance" of the unit. As the figures indicate, the correlations were not very significant.

Seeking a correlation covering a shorter period of time, Figures 33 and 34 show the daily maximum values of the KSU index inside as a function of maximum dry-bulb temperature and wet-bulb temperature outside for August of 1954 in Jersey City. The results are much better than the previous ones but still too scattered to be of much value. Additional similar correlations were tried where the independent variable was respectively, the outside dry-bulb temperature at 4 p.m., the outside dry-bulb temperature at 5 p.m., and the average of maximum dry-bulb temperatures the day before and on the day in question. However, when the same dependent variable was plotted as a function of average (over a 24 hour period) outdoor dry-bulb temperature the result was very much improved as shown in Figure 35 . The correlation coefficient ( $r$ ) for this particular set of data was 0.97 (maximum possible value $=1.0)^{a}$. The same degree of success was attained with other indices such as the new effective temperature shown in Figure 36 and for other months (see Table 8). This is in agreement with the findings of Loudon [8] in which he states: "...heavy buildings screened from solar radiation do not rise more than a few degrees above the mean outside temperature unless there are appreciable heat gains from lighting, occupants or other heat sources. It is primarily the daily-mean temperature that has to be considered, rather than the maximum; diurnal temperature variations can be smoothed by the thermal capacity of the building".

The daily average temperature used was not the average of the twenty-four hourly values but rather the average of the daily maximum and daily minimum. The particular average was chosen due to the fact that many United States Weather Bureau Stations report this parameter [31]. The discrepancy is usually quite small as the curves of Figure 37 indicate.

The straight lines of Figures 35 and 36 were determined by regression analysis (method of least squares) in order to fit the data as close as possible. In fact, similar regression lines were determined for June, July and August of all ten years. It was found that each of the 30 lines fell within the corridor of Figure 38 .

The importance of such correlation results lie in the fact that if proven valid for a class of buildings with similar thermal response characteristics, a particular line could be determined for a given housing unit-weather data group by a small number of calculations compared to a lengthy hour by hour computation. The results for an extended period of time could then be determined by scanning of weather tapes alone.

Table 9 was constructed by using a special routine to scan the weather tape. It shows for the year 1949 in Jersey City, the number of days during the year (in the right-hand column) in which the daily outdoor average dry-bulb temperature is equal to or greater than the temperature in the left-hand column. Consequently, if a linear relationship, such as Figure 35 or Figure 36, is established for a particular building, then the number of days

\footnotetext{
according to reference [30], for the population chosen, a significant correlation exists for $r>0.4$.
} 
in which the indoor environment could be expected to be at or above a certain specified comfort condition could be determined at a glance. For example, Figure 38 shows that for the particular building being analyzed, a KSU value of 5 corresponds to an outside temperature of approximately $81^{\circ} \mathrm{F}\left(27.2^{\circ} \mathrm{C}\right)^{\mathrm{a}}$. Table 9 indicates that the daily average temperature was equal to or exceeded this value 23 days during 1949 in Jersey City. This corpresponds to approximately 20 percent of the summer days (4. months). From the detailed printout of the hour-by-hour simulation computer run, it was determined that the KSU value equalled or exceeded 5 on 32 different occasions ${ }^{b}$.

For the remainder of the feasibility study conducted to date, emphasis was placed on determining the validity of the above "short-cut" approach. There were several questions that had to be answered. Was the correlation with outside average dry-bulb temperature valid for other types of buildings? Did the correlation change when the building was moved to another climatic region or could one "line" be assumed valid for all localities. What is.the minimum amount of hour by hour simulation needed to determine the relationship? What is the sensitivity of the correlation to changes in the configuration of a given building? The degree to which the above questions were satisfactorily answered is described in the remainder of this section.

The simulations and calculations done thus far did not include the calculation of mean radiant,temperature in the space. Consequently in the calculation of the indices, the MRT was always assumed equal to the dry-bulb temperature. Once the equations described in Appendix A for the calculation of mean radiant temperature were included in the simulation model, some plots were made to determine if the effect was significant. Figure 39 shows to what extent the mean radiant temperature differs from the indoor dry-bulb temperature on a relatively cool day that followed several warm ones. As can be seen from the plot, the difference can be as much as $4^{\circ} \mathrm{F}\left(2.2^{\circ} \mathrm{C}\right)$ if the MRT is calculated near a cold surface but only $1{ }^{\circ} \mathrm{F}\left(0.55^{\circ} \mathrm{C}\right)$ if calculated in the center of the space. In addition, the calculation showed that equation (8) of Appendix A was sufficiently accurate for the present application. Figure 40 shows the difference in the resulting correlation due to the inclusion of the MRT calculation. This was to increase the comfort vote by 0.5 at an average outdoor temperature of $75^{\circ} \mathrm{F}\left(23.9^{\circ} \mathrm{C}\right)$. Therefore, for the remainder of the study, the MRT calculation (in the center of the space) was included.

The air change rate assumed in the apartment simulation was most favorable for taking advantage of "natural cooling"' that is, a high rate of air flow rate at night (6 volume changes per hour) to precool the apartment and a low flow rate during the day when the outdoor temperature is likely to be high. Perhaps an assumption such as this shouldn't be used as a base for establishment of the criteria tables since this "optimum control" of outside air introduction will seldom be used in actual practice. Consequently some of the calculations were repeated to determine the effect of this variable.

Hour-by-hour calculations were repeated three times for the year 1949 for three additional rates of air change. First the air change rate was assumed constant at 1 volume change per hour ${ }^{\mathrm{c}}$. The calculations were repeated for the case where the flow rate was controlled according to the outdoor temperature. Finally, one other simulation was done where the air flow rate was controlled according to an empirical equation developed by Coblentz and Achenbach [32]. They measured actual infiltration rates in ten electricallyheated houses in Indiana. The homes were a variety of one- and two-storey brick and frame built over basements, crawl spaces, and concrete slabs. Based on the findings of earlier studies done at the University of Illinois [33], Coblentz and Achenbach expressed their results in terms of a polynominal expression where the infiltration rate was a linear function of the outdoor wind velocity $(W)$ and inside-outside temperature difference $(\Delta T)$.

$$
I=A+B W+C \Delta T
$$

a Corresponding to the center of the corridor.

${ }^{\mathrm{b}}$ Since 32 is larger than 23, the KSU index went above 5, dropped below, and rose above again on the same day.

$\mathrm{c}_{\text {This }}$ is the common assumption in most design calculations. 
Figure 41 shows the effect of the different assumptions on the indoor dry-bulb temperature during one particular day. Figure 42 is the corresponding plot for indoor wet-bulb temperature. Finally, Figure 43 shows the effect on the resulting correlation line. As can be seen, the Coblentz-Achenbach expression is perhaps the most "conservative" assumption to use, causing the comfort vote to be increased by 1.0 at an average outdoor temperature of $75^{\circ} \mathrm{F}\left(23.9^{\circ} \mathrm{C}\right)$ compared to the original assumption of 1 during the day and 6 at night. The assumption of 1 air change per hour resulted in an increase of 0.7 in the comfort vote at $75^{\circ} \mathrm{F}\left(23.9^{\circ} \mathrm{C}\right)$. Based on these results, it is felt that $1^{\circ}$ air change per hour should be used as the base assumption in establishing the criteria.

The "thermal performance" of the apartment was, of course, expected to change if the pertinent building characteristics were changed. Hour by hour calculations were made for the summer of 1949 when the large picture window facing west was changed from double pane with a white opaque roller shade (S.C. $=0.22$ ) to single pane with a medium colored venetian blind $(S . C .=0.64)$. Figure 44 shows the effect of this change on the resulting correlation "line" (an increase of 0.5 in the comfort vote at an average outdoor temperature of $75^{\circ} \mathrm{F}$ $\left(23.9^{\circ} \mathrm{C}\right)$ ) and Figure 45 shows the relationship between the new line and the previously determined corridor.

A simulation was done for the summer of 1949 when the originally defined building is simply reoriented so that the exposed wall and large picture window now face north. Figure 46 shows the relationship between the correlation "line" determined for this configuration and the previously determined corridor. Calculations were also done for the summer of 1949 when the above two changes (modified window and $90^{\circ}$ rotation) were combined. In addition, computer runs were made for the summer of 1954 where the same configuration char ges were made. Table 10 shows that with the configuration changes described, the correlation with the average outside dry-bulb temperature continued to be good.

The given building considered to this point had only 1 external surface (the west facing wal1). Figure 47 shows the effect of first making all the walls exposed to the outside environment and then finally the walls and the roof. Compared to the originally defined apartment, the comfort vote is increased by 0.5 at an average outdoor temperature of $75^{\circ} \mathrm{F}\left(23.9^{\circ} \mathrm{C}\right)$ when all surfaces are exposed to the outside.

It is felt that from observing results similar to those of Figures 43 through 46, that the window specifications, building orientation, and the number of exposed surfaces in the external structure are all parameters that must be considered independent variables in the matrix of the air conditioning criterion.

One of the most important factors to determine during the latter part of this feasibility study was to what extent the good correlation with outside average dry-bulb temperature would hold when the relative weight or massiveness of the structure was changed and/or the weather conditions or locality.

Another building was selected for simulation from the plans of the various Housing System Producers in the Operation BREAKTHROUGH Program. Since the first apartment simulated was a rather heavyweight one, it was decided to select one with very light weight construction elements. As shown in Table 11, the weight of the walls was only $41 \mathrm{~b} / \mathrm{ft}^{2}\left(20 \mathrm{~kg} / \mathrm{m}^{2}\right)$ compared to $81 \mathrm{lb} / \mathrm{ft}^{2}\left(395 \mathrm{~kg} / \mathrm{m}^{2}\right)$ for the first one.

A more detailed description of the building and individual apartment simulated is as follows:

1. The apartment building is a 5-story, two-level structure, with windows facing north and south. The first level consists of 3-story, 4-bedroom dwelling units, and the second level of a mix of 2-story, 2-bedroom and 1-story, 1bedroom units. The two levels are separated by 18-gage steel deck on a 1.33 inches $(3.38 \mathrm{~cm})$ thick concrete channel structure. The space chosen for simulation was one located at the third floor on level 1 and is part of a 3-story, 4-bedroom unit. No building shadow was used and the adjacent spaces were assumed to always be at the same temperature as the chosen space. 
2. The exposed wall (north and south) is constructed of 0.5 inches $(1.3 \mathrm{~cm}$ ) of gypsum sheathing and 0.5 inches $(1.3 \mathrm{~cm}$ ) of gypsum wall board, with 4 inches $(10.2 \mathrm{~cm})$ of air space in between. The overall exterior wall area facing south is $112 \mathrm{ft}^{2}\left(10.4 \mathrm{~m}^{2}\right)$, and contains $48 \mathrm{ft}^{2}\left(4.5 \mathrm{~m}^{2}\right)$ of opaque surface and $54 \mathrm{ft}^{2}\left(5.9 \mathrm{~m}^{2}\right)$ of single pane, $1 / 8$ inch $(0.32 \mathrm{~cm})$ window glass. The exterior wall facing north has the same composition.

3. The floor is composed of carpet on $5 / 8$ inch $(.16 \mathrm{~cm})$ plywood which is over an 8 inch $(20.3 \mathrm{~cm})$ air space, $5 / 8$ inch $(.16 \mathrm{~cm})$ plywood, 6 inches $(15.2 \mathrm{~cm})$ air space, and $1 / 2$ inch $(1.3 \mathrm{~cm})$ gypsum ceiling board. The ceiling is composed of $5 / 8$ inch $(.16 \mathrm{~cm}$ ) plywood on 18-gage steel deck on 1.33 inch $(3.38 \mathrm{~cm})$ concrete channel structure and $3 / 8$ inch $(0.95 \mathrm{~cm})$ plywood on $1 / 2$ inch gypsum ceiling board with 6 inches $(15.2 \mathrm{~cm})$ air space in between the plywood and ceiling board. The floor to ceiling height is $8 \mathrm{ft}(2.4 \mathrm{~m})$ and the total floor area, is $482 \mathrm{ft}^{2}\left(44.8 \mathrm{~m}^{2}\right)$.

4. The partitioned walls are composed of $1 / 2$ inch $(1.3 \mathrm{~cm})$ gypsum wall board and $3 / 8$ inch $(0.95 \mathrm{~cm})$ plywood with 4 inches $(10.2 \mathrm{~cm})$ of air space in between.

5. The maximum number of occupants is 3 , the maximum equipment load is $\frac{1}{2} / 2$ $\mathrm{W} / \mathrm{ft}^{2}\left(5.4 \mathrm{~W} / \mathrm{m}^{2}\right)$, and the maximum lighting load is $1 \mathrm{~W} / \mathrm{ft}^{2}\left(10.8 \mathrm{~W} / \mathrm{m}^{2}\right)$.

6. The infiltration or natural ventilation rate was simulated as 1 air change/ hour constant.

The hour by hour simulation was again repeated for this apartment in Jersey City, New Jersey. Figure 48 is a correlation plot of the maximum value of the KSU index inside and the average outside dry-bulb temperature, the same variables that correlated well for the first apartment simulated. As can be seen, the correlation again was quite good, which was encouraging due to the "shortcut" technique that could possibly be used in establishing the criterion. Figure 49 indicates that for the same month in the same locality, the maximum comfort vote in the same apartment would be approximately 0.5 higher for a given average outdoor dry-bulb temperature. The effect of making more of the apartment exposed to the outside was examined here as before. Figure 50 shows that the effect on this lightweight building was even more pronounced than with the heavyweight one. When all four walls plus the, roof were exposed and an additional window was added in the wall facing west (to make a more realistic unit) the comfort vote increased by 1.0 at an average outdoor dry-bulb temperature of $75^{\circ} \mathrm{F}\left(23.9^{\circ} \mathrm{C}\right)$.

Additional factors that were not exámined in any previous calculations, were the effect of amount of floor area and relative shape of the floor. This, of course, affects the surface to volume ratio of the space and could in turn be expected to affect the resulting indoor conditions. Figure 51 shows the results of simulating the lightweight apartment in New Jersey with the maximum amount of exposure and then changing the shape of the floor area to square $(22 \mathrm{ft}(6.7 \mathrm{~m})$ by $22 \mathrm{ft}(6.7 \mathrm{~m})$ instead of $14 \mathrm{ft}(4.3 \mathrm{~m})$ by $35 \mathrm{ft}(10.7 \mathrm{~m}))$ and then in turn reducing the floor area by a factor of three. As can be seen, the effect was minimal which should indicate that these variables not necessarily be included as independent parameters in the criterion matrix.

The only remaining factor to be examined in the feasibility study was the effect of moving to a different climate. Several additional hour by hour calculations or simulations were performed to investigate the effect of changing this parameter.

The heavyweight apartment was simulated on a hour by hour basis in Macon, Georgia for the year 1954. Table 12 indicates that for this apartment, a good correlation was still obtained with the average outside dry-bulb temperature. In fact, an entire corridor was established for Macon for the ten-year period 1949 to 1958 similar to that was done for New Jersey. The corridor is shown in Figure 52. 
A disturbing fact was observed at this point. If one overlays the corridor of Figure 52. on that of Figure 38 (see Figure 57), he discovers that for a given average outdoor drybulb temperature, the comfort vote in Macon would be approximately 0.25 higher. This indicates that other factors such as incident solar radiation and frequency and duration of hot conditions affect the resulting indoor environment. Also, it gave an indication to the fact that it might not be possible to establish the correlation "line" under one set of environmental conditions and assume that it is valid for all others.

To examine this latter fact closer, some specific results will be cited. Figure 53 shows the effect of simulating the heavyweight building in three different localities. As can be seen, the correlation "line" for this apartment is almost 1.0 comfort vote higher at an average outdoor dry-bulb temperature of $75^{\circ} \mathrm{F}\left(23.9^{\circ} \mathrm{C}\right)$ in Phoenix, Arizona than in Jersey City. Although the effect of climate appeared to be less pronounced for the lightweight apartment (Figure 54) it was observed to be just as pronounced once all the surfaces were assumed exposed (Figure 55).

At this point in the study, it became obvious that at least a small number of hour-byhour simulations would have to be done in each identified climatic zone. In additon, Table 13 indicates that the correlation with average outside dry-bulb temperature did not turn out to be the "best" of the limited number of variables that were examined as the building configuration and/or climatic zone was changed. Consequently, when this project was discontinued, it was felt that hour by hour simulations in conjunction 's'ith the histogram routines used to construct the data for Figures 25 and 26 would be the most desirable tools to use to complete the establishment of the criterion tables. Therefore, it was tentatively decided to abandon the concept of getting the final tabular values by a "shortcut", correlation "line" approach.

As noted previously, this will probably be an expensive (significant amounts of computer time are needed) and time consuming task to undertake because of the large number of variables to be accounted for. It appears that one "conservative" alternative is available. This alternative is as follows: Consider the apartment, building, or room in question exposed to the hot "design-day" conditions that air conditioning engineers use in sizing cooling equipment. The space would be exposed to this day's weather data for 4 to 7 consecutive days (until a steady periodic condition existed where the indoor environmental conditions were repeated from one day to the next). The peak value of one of the comfort indices would then be used to "grade" the environment either acceptable or not. The authors feel this approach should be studied only if the alternative would be to discontinue the work altogether.

To determine if this latter approach gives truly "conservative" results, additional calculations were carried out. The 1\% design values of outdoor dry-bulb and wet-bulb temperature presented in the ASHRAE Handbook of Fundamentals [15] for several selected cities (see Table 14) were used in conjunction with the dimensionless daily temperature cycle of Figure 56 (determined from surveying actual weather tapes) to produce a design day cycle for these cities. The heavyweight apartment was then subjected to this design day cycle (in the computer program) for seven straight days using the actual solar radiation in these localities and assuming zero cloud cover. Shown in Figure 57 are the results of the calculations where the maximum value of the KSU index in the apartment during the second and fifth day are plotted for each city. There was no noticeable change after the fifth day. As can be seen, the data points lie on the upper side of the previously determined corridor. Using this type of calculation approach, the decision to air conditioning the various cities would be made entirely on what ordinate value on this plot (or value of comfort index) was deemed acceptable.

\section{Conclusions and Recommendations}

Based upon the preliminary study described in this paper, the following conclusions have been drawn:

1. The computer program "NBSLD" and the modifications and routines that were made or added to it during this study, can be used to supply all information necessary to the establishment of an air conditioning criterion on a sound technical base. 
2. The degree to which a space or building would remain acceptable without the addition of mechanical cooling cannot be determined by the use of the "stateof-the-art", "steady-state" comfort indices alone. Other factors such as frequency and duration of hot conditions and consideration of the situations under which people are "uncomfortable" should be taken into account.

3. A criterion can be established in the form of tables that would specify whether or not mechanical cooling should be installed. The parameters that should be considered as independent variables in the tabular matrix are:
a. weight per unit area of the building enclosure,
b. number of exposed surfaces of the building enclosure,
c. degree of shading for the windows,
d. shape of roof if exposed (peaked or flat),
e. orientation of the building, and
f. geographical location

other possible independent parameters might be
a. air infiltration rate,
b. percent of the exposed surface area that is glass,
c. aspect ratio of the floor, and
d. floor area

4. On the basis of weight per unit area of a building enclosure, the following classification can be used:

Lightweight Structure: less than $20 \mathrm{lb} / \mathrm{ft}^{2}\left(98 \mathrm{~kg} / \mathrm{m}^{2}\right)$

Medium Weight Structure: $20(98)$ to $59 \mathrm{lb} / \mathrm{ft}^{2}\left(244 \mathrm{~kg} / \mathrm{m}^{2}\right)$

Heavyweight Structure: greater than $501 \mathrm{~b} / \mathrm{ft}^{2}\left(244 \mathrm{~kg} / \mathrm{m}^{2}\right)$

The following recommendations are made, based upon the study described:

1. A research contract should be given to some organization or individual doing physiology or related research work to establish both the definition and acceptable limits of the Predicted Indoor Habitability Index as introduced in this paper.

2. A separate research task should be undertaken to divide the United States into a sufficiently large number of climatic regions with typical hour-byhour summer weather data for June, July, and August established for each region.

3. Based upon the information within this paper and elsewhere, a sufficient number of "typical buildings" should be defined for simulation taking into account the pertinent independent variables in 3 . above.

4. In light of the "Energy Problem" in the United States today, this study should be continued to completion so that the results could be used for showing those situations where mechanical cooling are unnecessary. 


\section{References}

1. "Engineering Weàther Data", Chapter 6, Air Force Manual 88-8, June $15,1967$.

2. "Guide Criteria for the Evaluation of Operation BREAKTHROUGH Housing Systems", Volume 1 - Multifamily High Rise, PB 212055; Volume 2 - Multifamily Low Rise, PB 212056; Volume 3 - Single Family Attached, PB 212057; Volume 4 - Single Family Detached, PB 212058, 1970. (Available through NTIS, Springfield, Virginia 22151).

3. J. F. van Straaten, Thermal Performance of Buildings, Elsevier Publishing Company, 1967 .

4. B. A. Peavy, D. M. Burch and F. J. Powell, "Thermal Performance of an Experimental Masonry Building", NBS Building Science Series 45, 1973

5. ASHRAE Standard 55-74, "Thermal Environmental Conditions for Human Occupancy", ASHBAE, 345 East 47th Street, New York, New York 10017, 1966.

6. B. Givoni, Man, Climate, and Architecture, Elsevier Publishing Company, 1967.

7. V. Olgay, Design with Climate, Princeton University Press, New Jersey, p. $185,1963$.

8. A. G. Loudon, "Summertime Temperatures in Buildings", Paper 47/68, Building Research Station of England, 1968.

9. J. Anquez, J. C. Borel, and M. Croiset, "La Protection Solaire des Baies Vitrees", Cahiers du Centre Scientifique et Technique du Batiment No. 72, Paris, France, 1965.

10. T. Kusuda and F. J. Powe11, "Use of Modern Computer Programs to Evaluate Dynamic Heat Transfer and Energy Use Processes in Buildings", National Bureau of Standards Special Publication 361, Volume 1: Performance Concept in Buildings; Proceedings of the Joint RILEM-ASTM-CIB Symposium, Philadelphia, Pennsylvania (Issued March 1972).

11. T. Kusuda, "NBSLD, Heating and Cooling Load Calculation Program", APEC Journal, Volume III, No. 6, Winter $1973 / 74$.

12. T. Kusuda, "NBSLD, Computer Program for Heating and Cooling Loads in Buildings, NBS Report NBSIR 74-574, November 1974.

13. "Procedures for Determining Heating and Cooling Loads for Computerized Energy Calculations", The Task Group on Energy Requirements for Heating and Cooling, ASHRAE, 345 East 47 th Street, New York, 1971.

14. B. A. Peavy, D. M. Burch, and F. J. Powe1l, "Thermal Performance of a Four Bedroom Wood-Frame Townhouse", NBS Building Science Series 57, 1974.

15. ASHRAE Handbook of Fundamentals, ASHRAE, 345 East 47 th Street, New York, New York 10017, 1972 .

16. C. H. Sprague, and P. E. McNall, Jr., "The Effects of Fluctuating Temperature and Relative Humidity on the Thermal Sensation (Thermal Comfort) of Sedentary Subject", ASHRAE Transactions, Vol. 76, Part 1, 1970.

17. D. P. Wyon and I. Holmberg, "Systematic Observation of Classroom Behaviour During Moderate Heat Stress", Proceedings of the CIB (W 45) Symposium on Thermal Comfort and Moderate Heat Stress, London, 1972.

18. P. E. McNall and J. Schlegel, "The Effect of Asymmetric Radiation on the Thermal and Comfort Sensations of Sedentary Subjects", ASHRAE Transactions, Vo1. 74, p. 144, 1968.

19. P. E. McNall and R. E. Biddison, "Thermal and Comfort Sensations of Sedentary Persons Exposed to Asymmetric Radiant Fields", ASHRAE Transactions, Vol. 76, Part I, pp. 123136,1970 . 
20. R. G. Nevins, K. B. Michaels, and A. M. Feyerherm, "The Effect of Floor Surface Temperature on Comfort: Part I, College-Age Males; Part II, College-Age Females", ASHRAE Transactions, Vo1 70, pp. 29-43, 1964.

21. W. E. Springer, R. G. Nevins, A. M. Feyerherm, and K. B. Michaels, "The Effect of Floor Surface Temperature on Comfort: Part III, The Elderly", ASHRAE Transactions, Vo1. 72, Part I, pp. 292-300, 1966.

22. R. G. Nevins and A. M. Feyerherm, "Effect of Floor Surface Temperature on Comfort, Part IV: Cold Floors", ASHRAE Transactions, Vo1. 73, Part II, III.2.1-2.8, 1967.

23. J. Anquez, and M. Croiset, "Thermal Comfort Requirement Adjacent to Cold Wa1ls - Application to Glazed Opening", NBS Technical Note 710-4, 1972.

24. R. G. Nevins, F. H. Rohles, W. Springer, and A. M. Feyerherm, "A Temperature-Humidity Chart for Thermal Comfort of Seated Persons, ASHRAE Transactions, Vo1. 72, Part I, pp. 283-291, 1966.

25. F. H. Rohles and M. S. Johnson, "Therma1 Comfort in the Elderly", ASHRAE Transactions, Vo1. 78, Part I, 1972.

26. P. O. Fanger, "Thermal Environments Preferred by Man", Build International, Vo1. 6, No. 1, pp. 127-141, 1973.

27. S. Olesen and P. O. Fanger, "Can Man be Adapted to Prefer a Lower Ambient Temperature?", 5th International Congress for Heating, Ventilating and Air Conditioning, Part I, pp. 27-40, Copenhagen, 1971.

28. P. E. McNall, P. Ryan, and J. Joax, "Seasonal Variation in Comfort Conditions for College-Age Persons in the Middle West, ASHRAE Transactions, Vo1. 74, Part I, 1968.

29. R. G. Nevins, personal communications, 1974.

30. M. G. Natre1la, Experimental Statistics, NBS Handbook 91, 1963.

31. "Instructions for Climatological Observers Circular B", U.S. Weather Bureau Publication, January 1962 .

32. C. W. Coblentz and P. R. Achenbach, "Field Measurements of Air Infiltration in Ten Electrically-Heated Houses", ASHRAE Transactions, Vol. 69, 1963.

33. D. R. Bahnfleth et. a1., "Measurement of Infiltration into Residences", ASHRAE Transactions, Vo1. 63, pp. 439-452, 1957. 


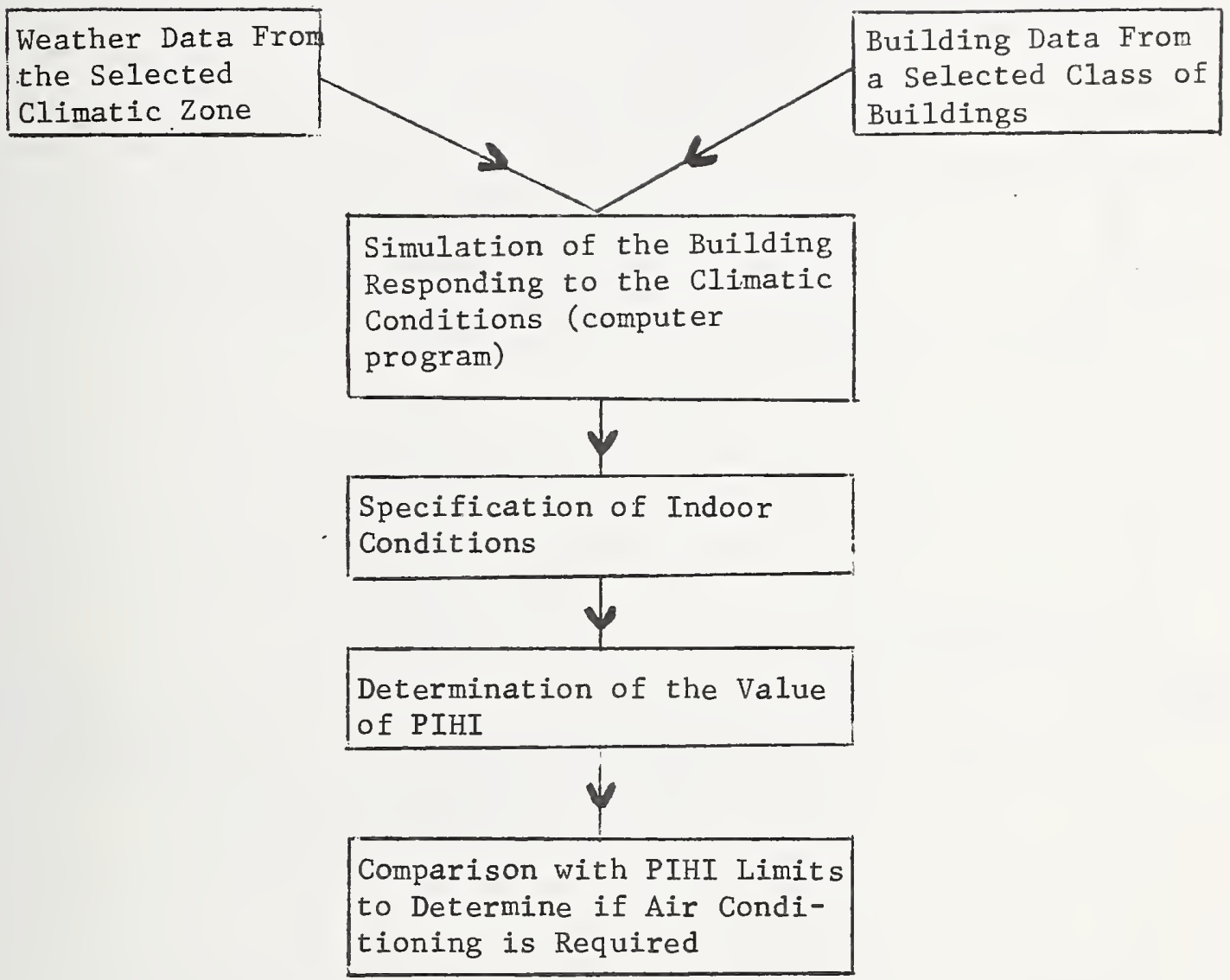

Figure 1 Concept of Determining the Need for Air Conditioning 


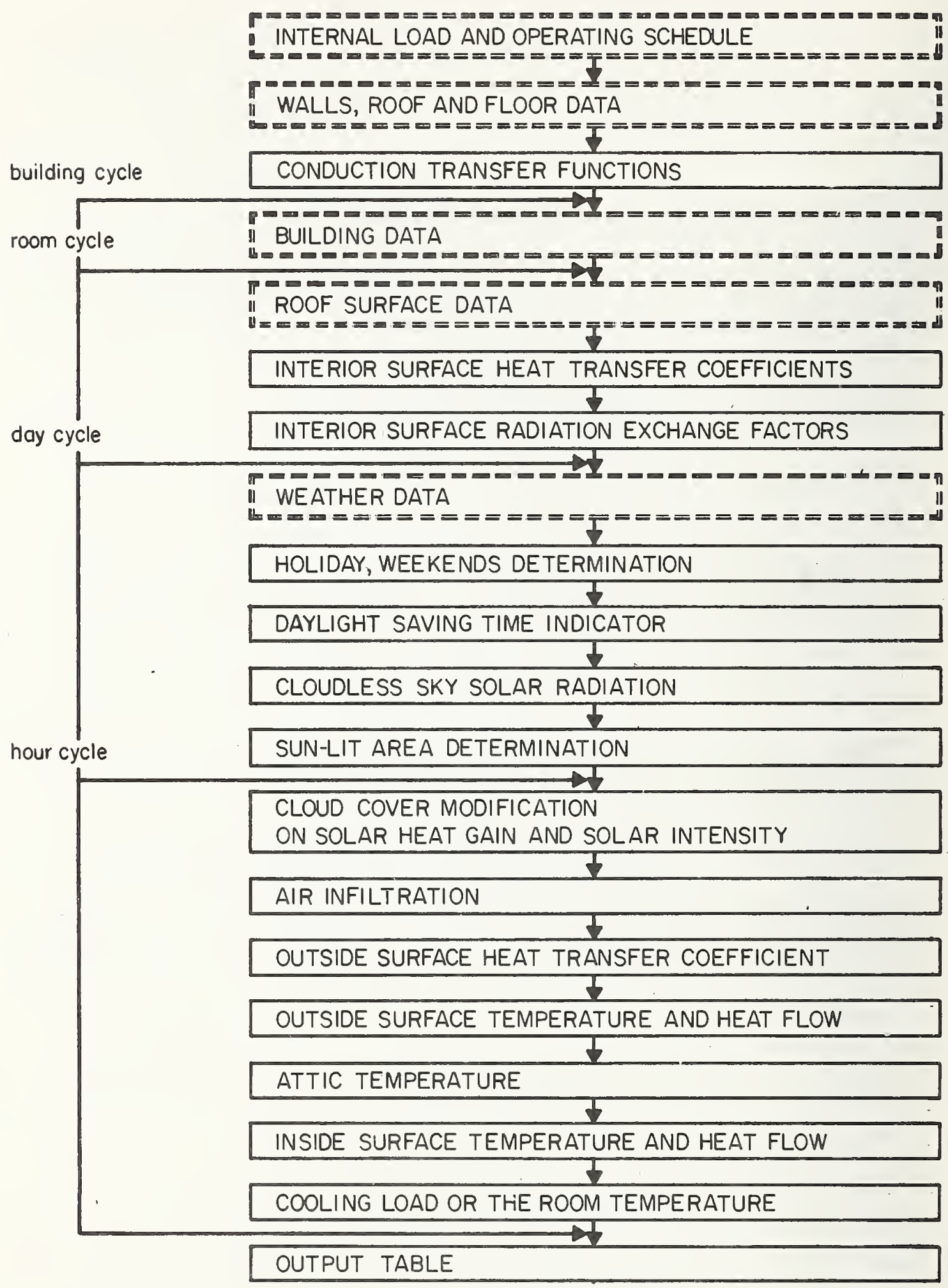

Figure 2 NBSLD Calculation Sequence 


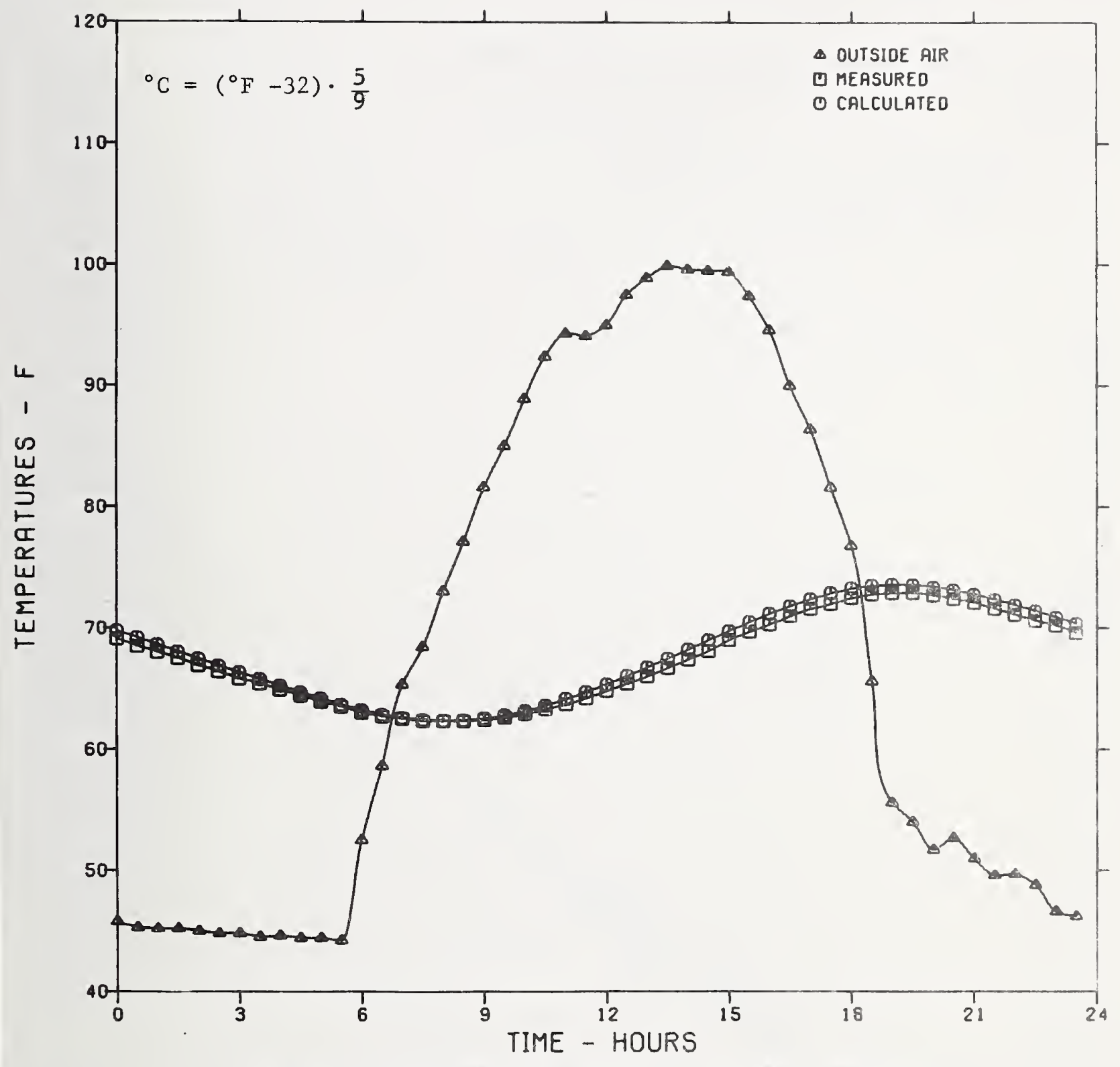

NO INSULATION, NO WINDOWS, INTERNAL MASS.

Figure 3 Comparison of Predicted and Measured Indoor Air Temperature for a $20 \mathrm{ft}(6.1 \mathrm{~m})$ by $20 \mathrm{ft}(6.1 \mathrm{~m})$ by $10 \mathrm{ft}(3.1 \mathrm{~m})$ Experimental Masonry Building 
EXTERIOR WALL

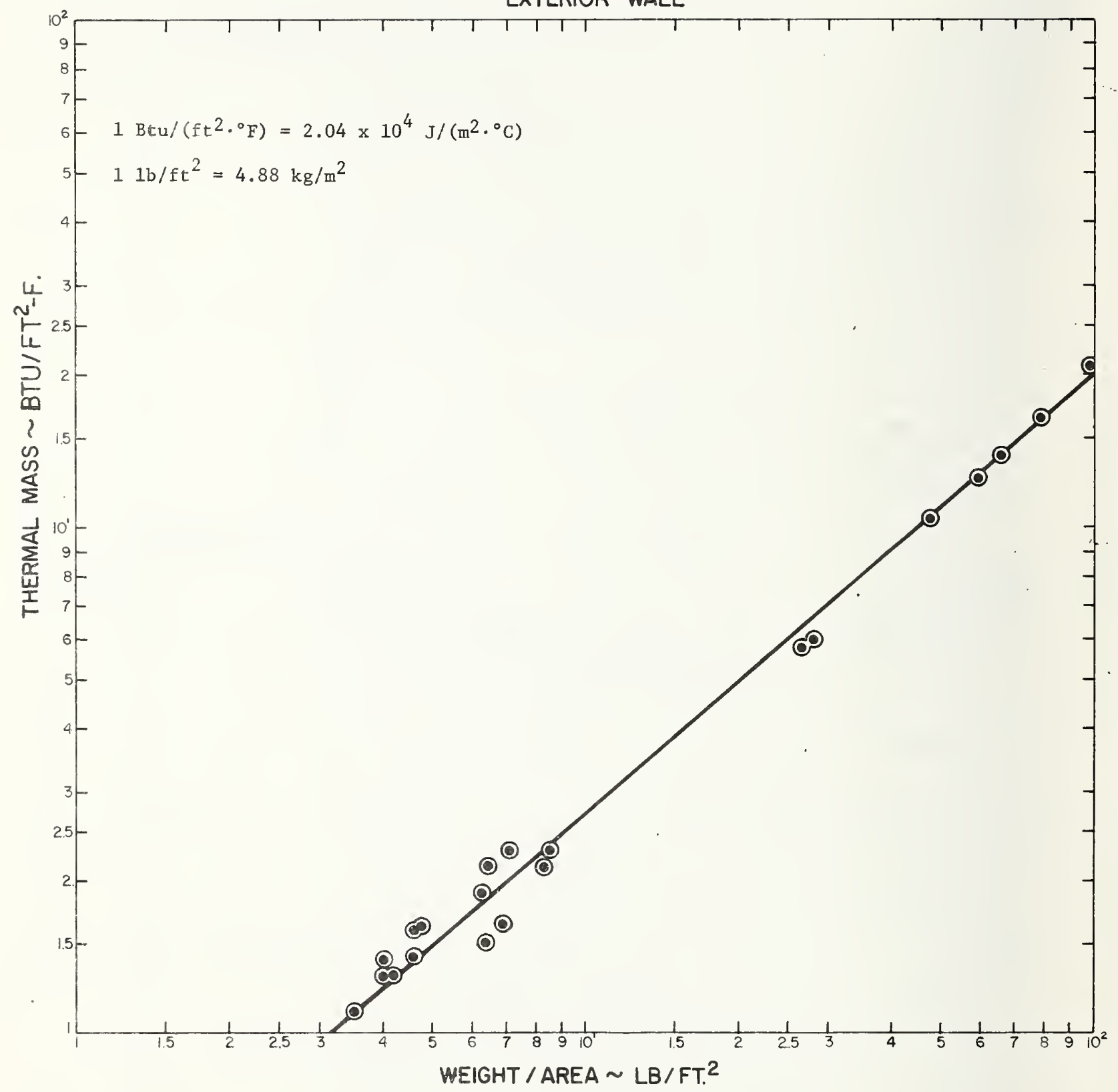

Figure 4 Relation of Thermal Mass to Weight for Selected Exterior Wall Constructions 


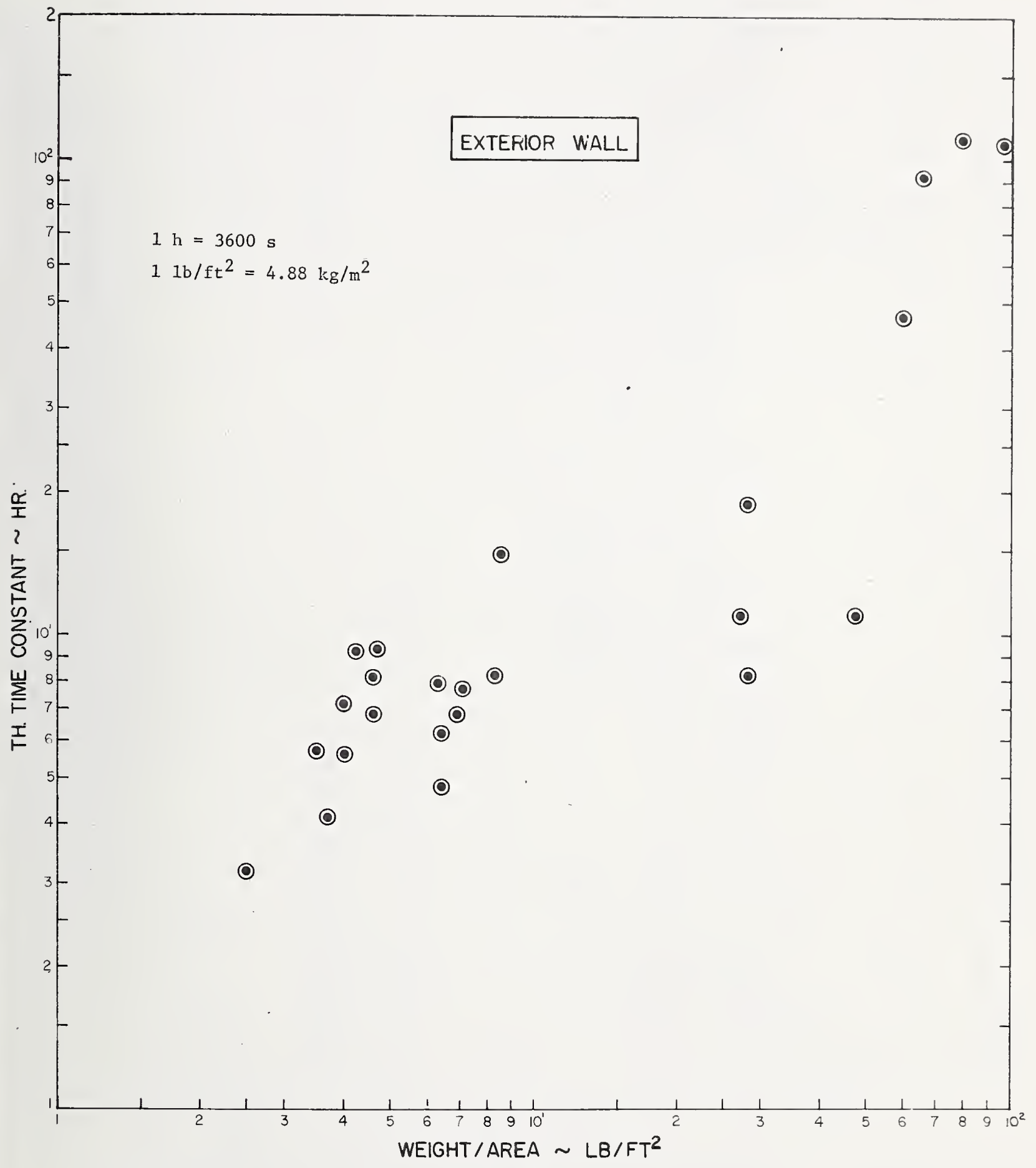

Figure 5 Relation of Thermal Time Constant to Weight for Selected Exterior Wa11 Constructions 


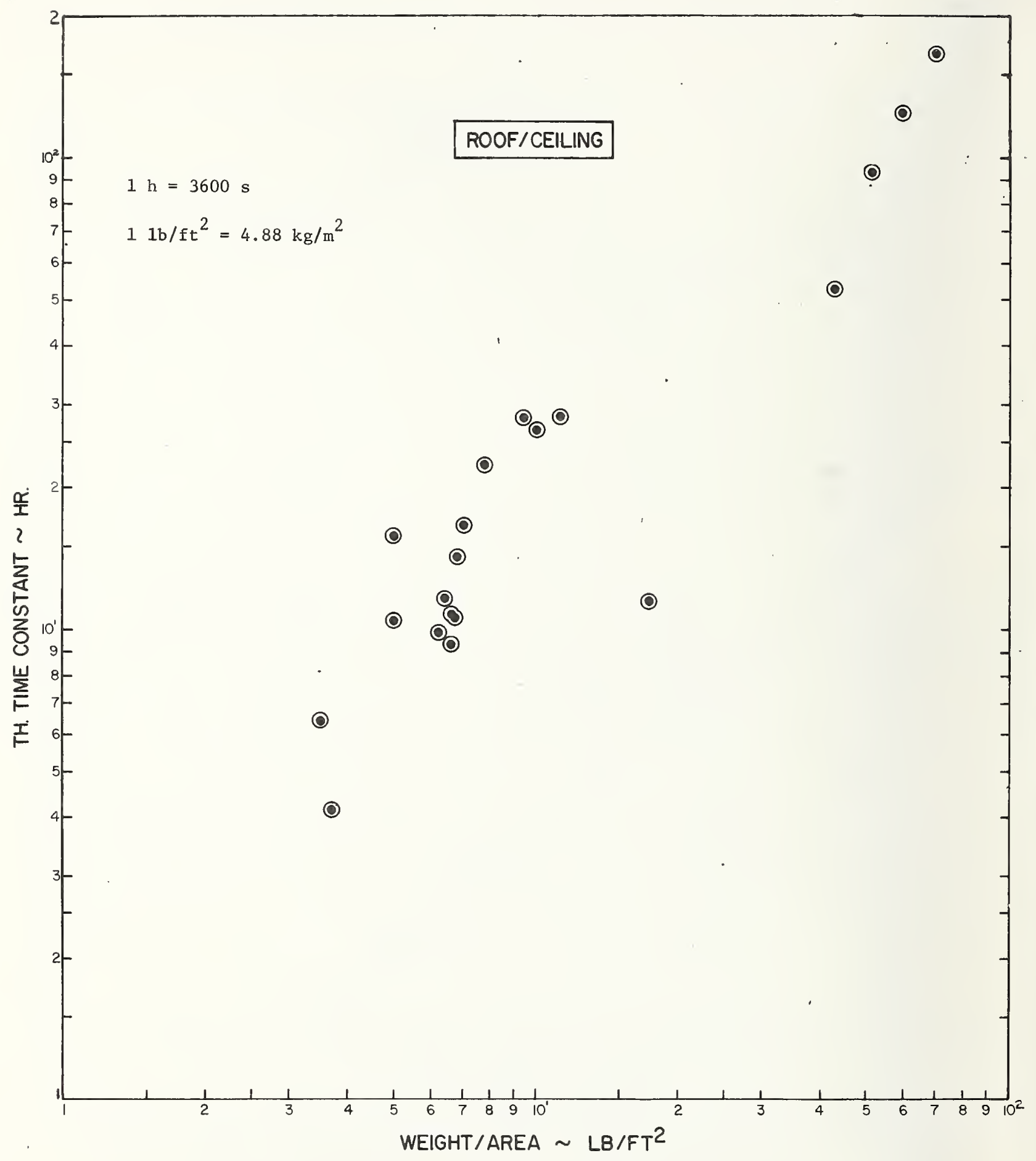

Figure 6 Relation of Thermal Time Constant to Weight for Selected Roof/Ceiling Constructions 


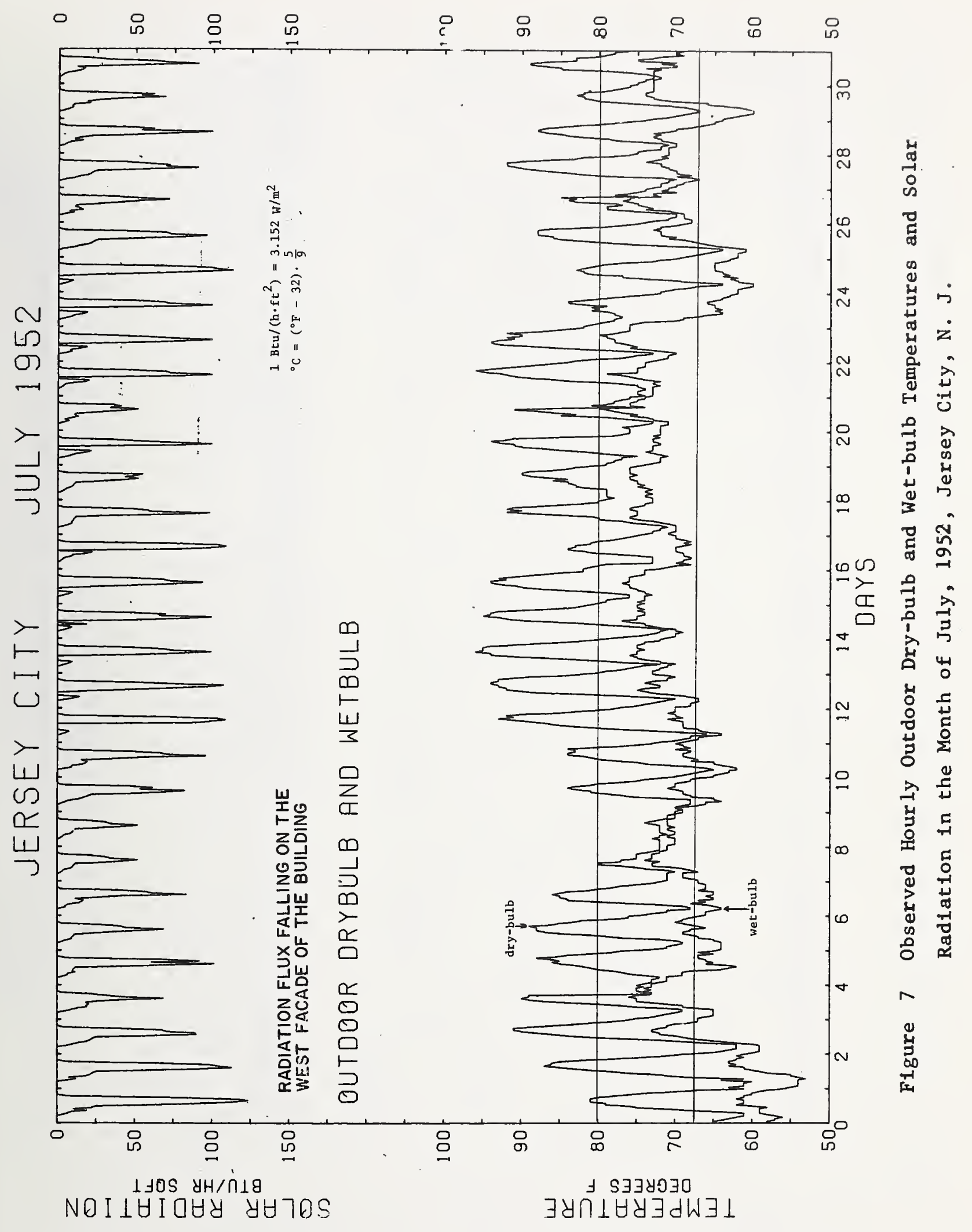




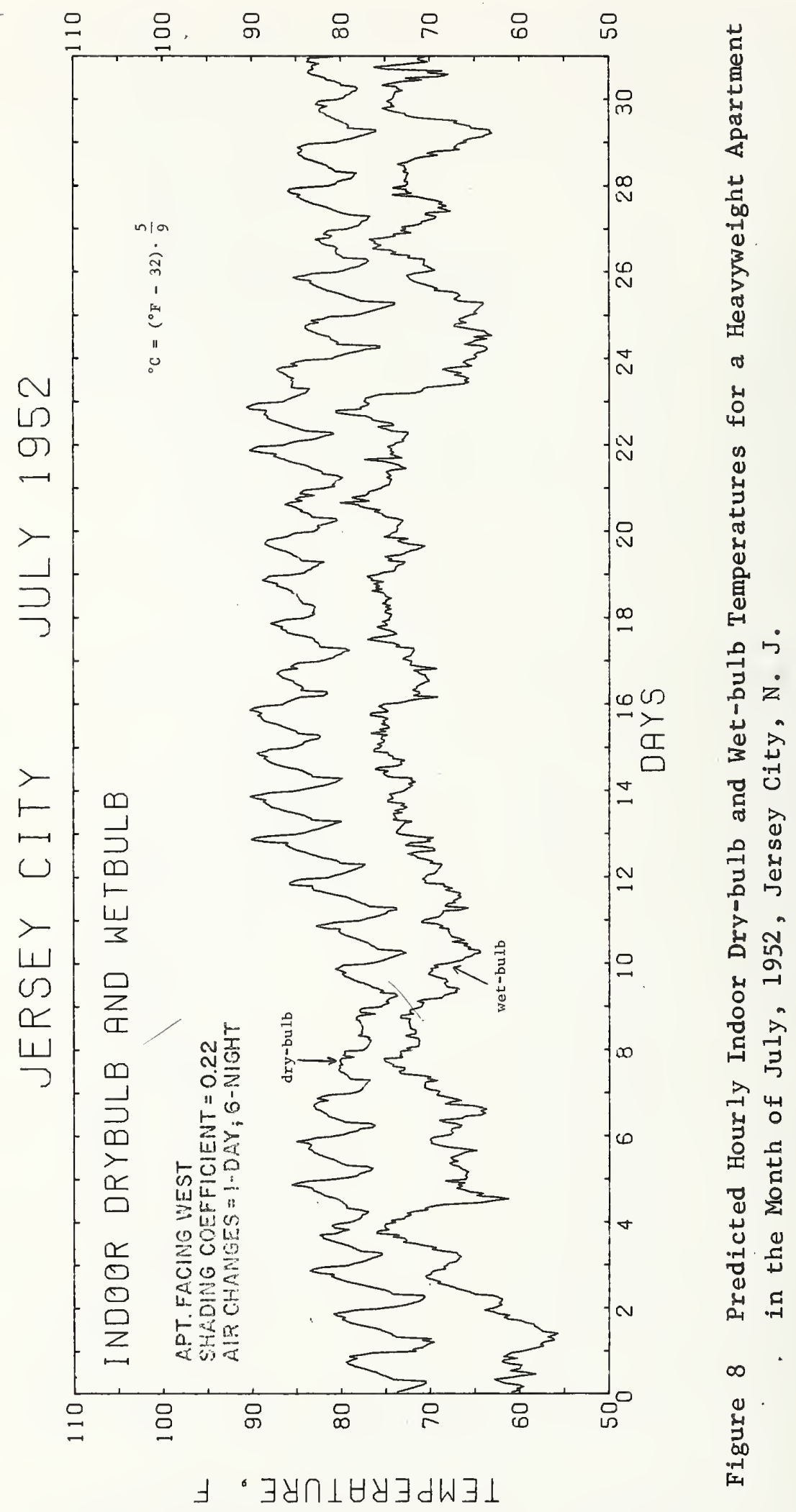



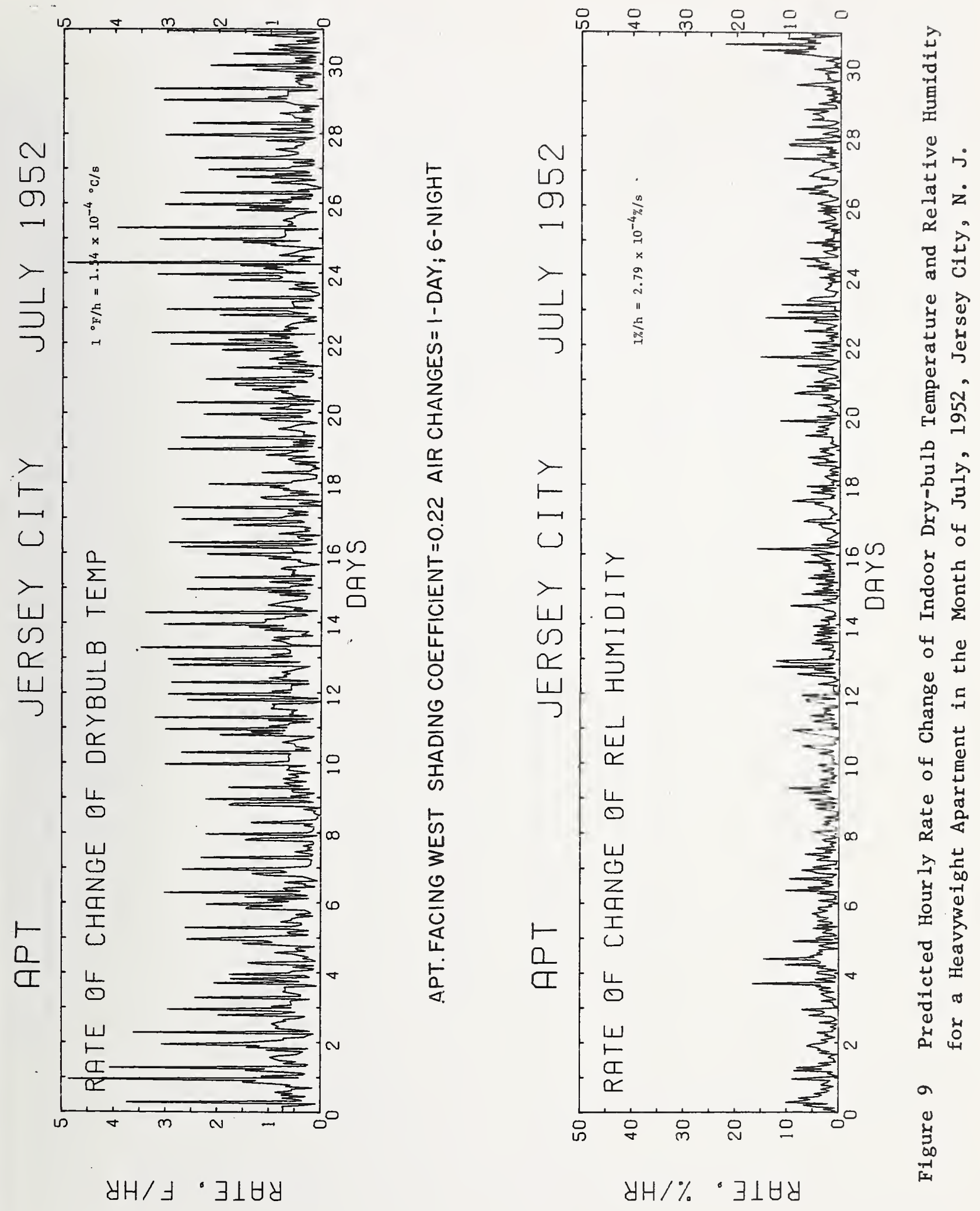

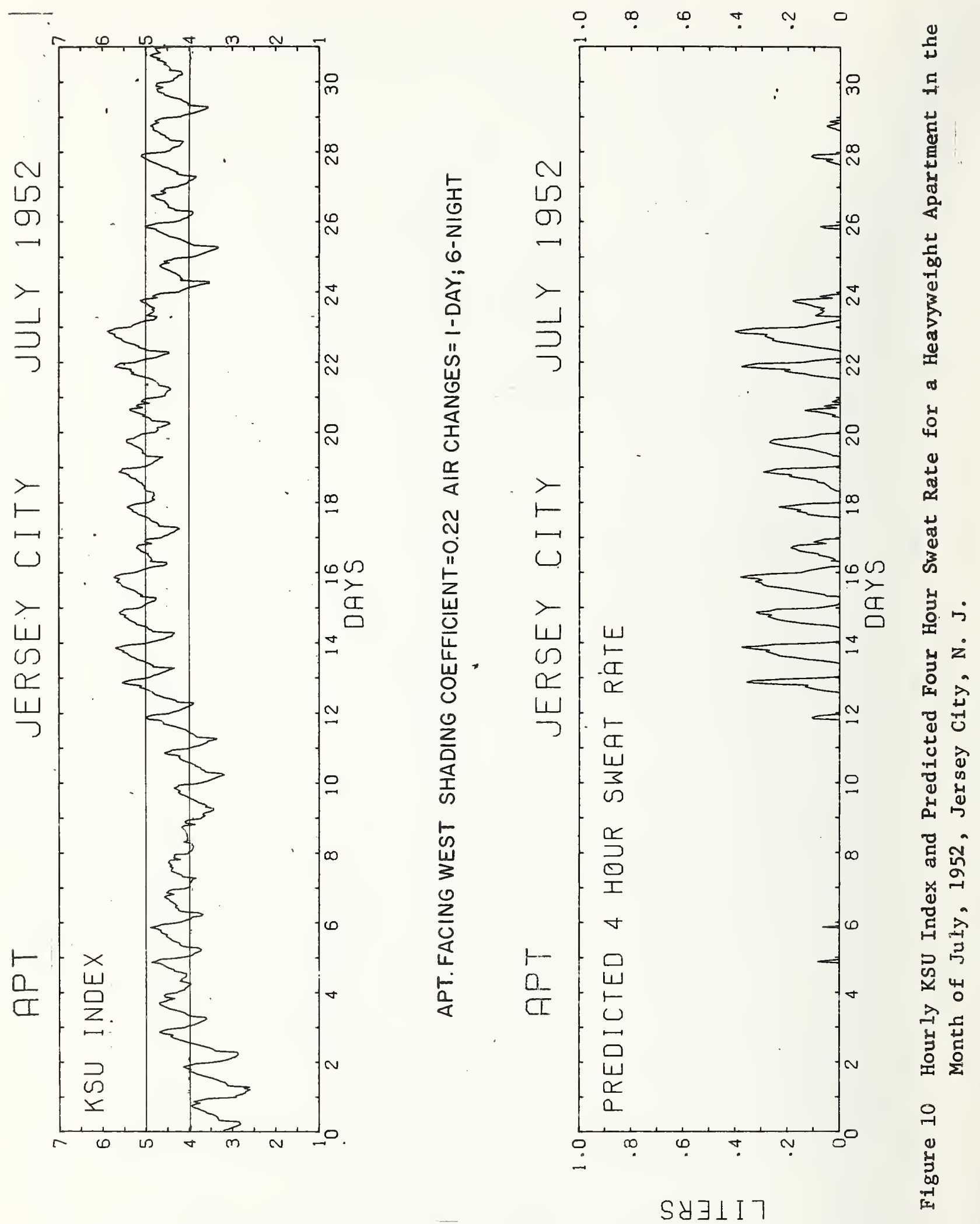

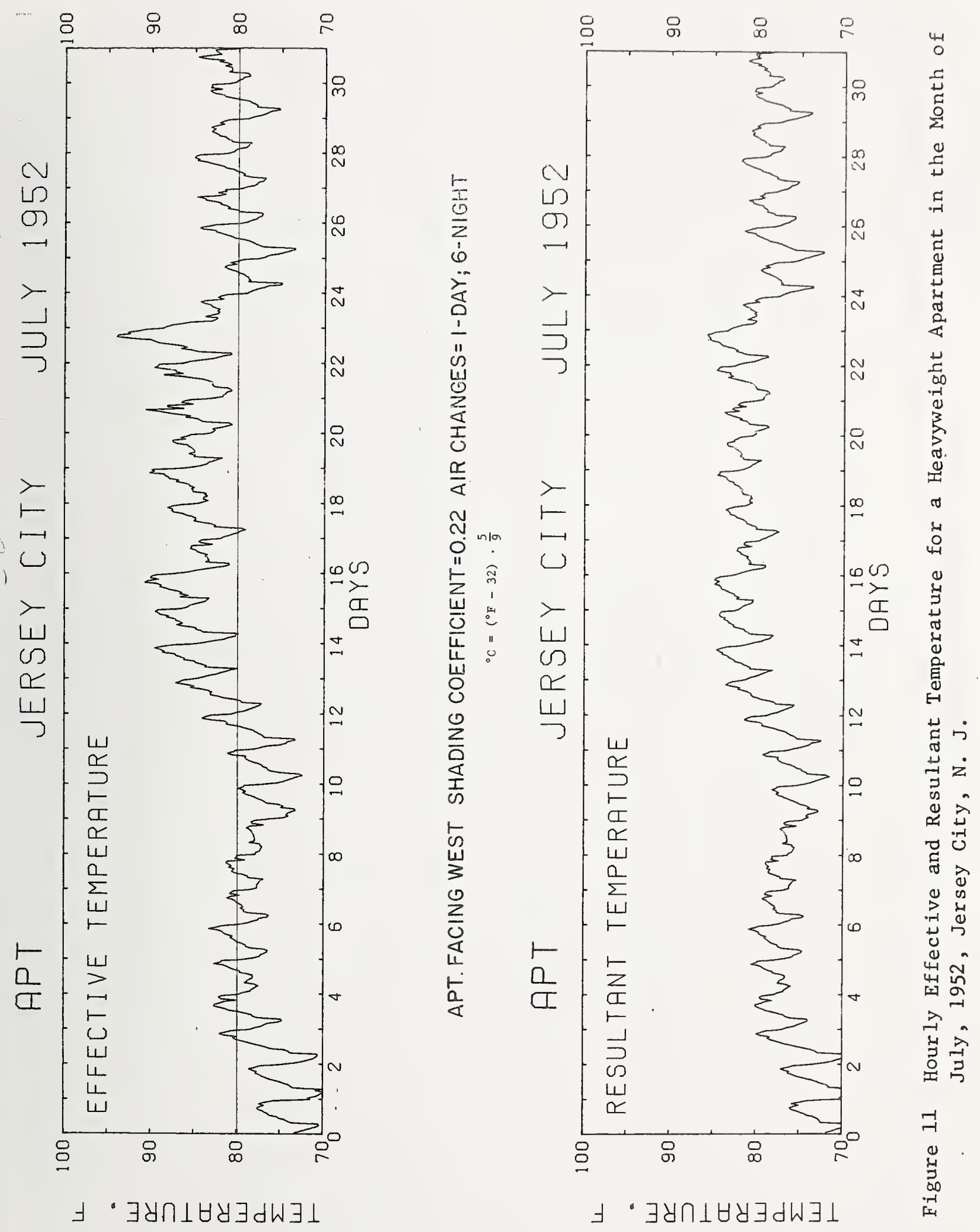

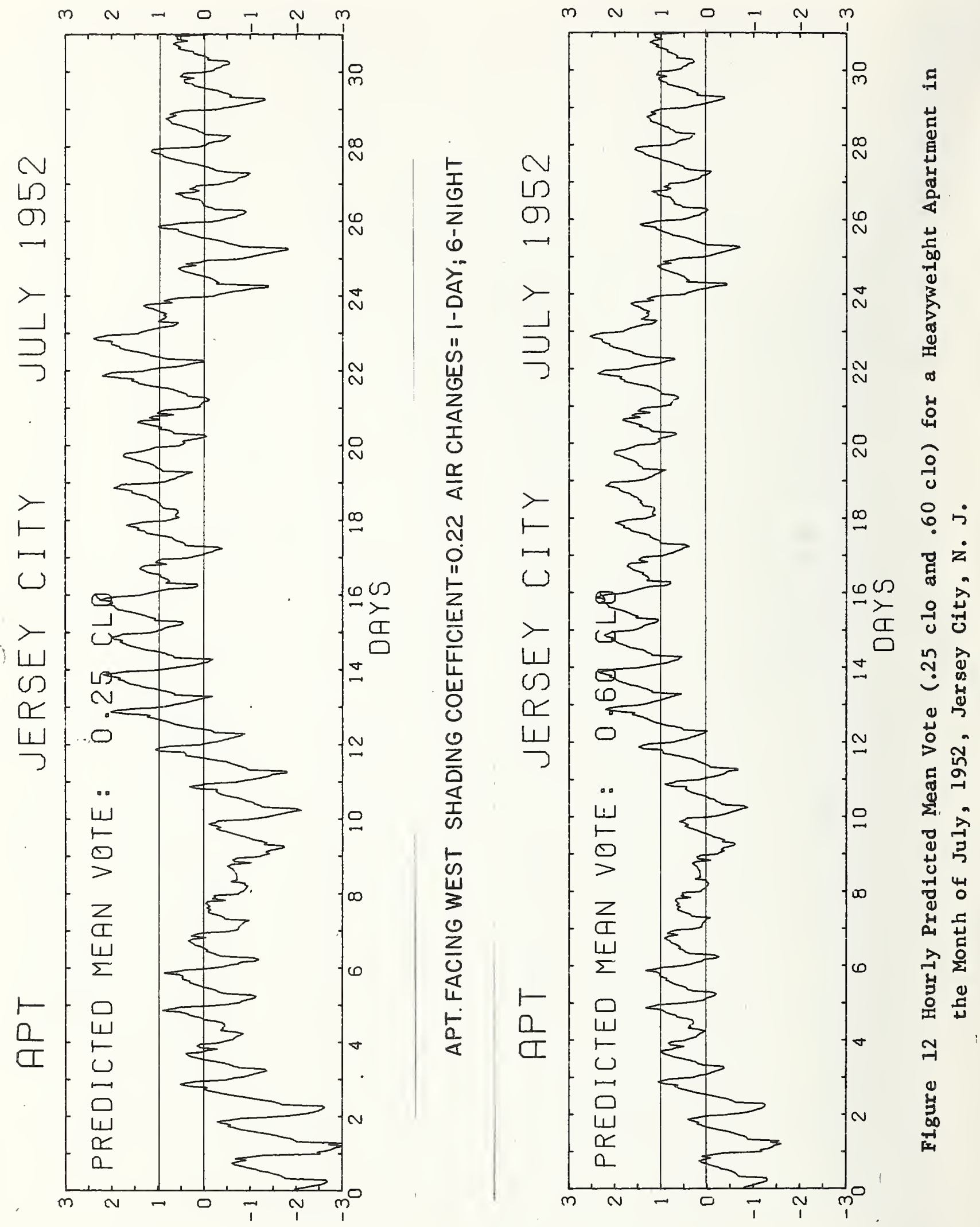

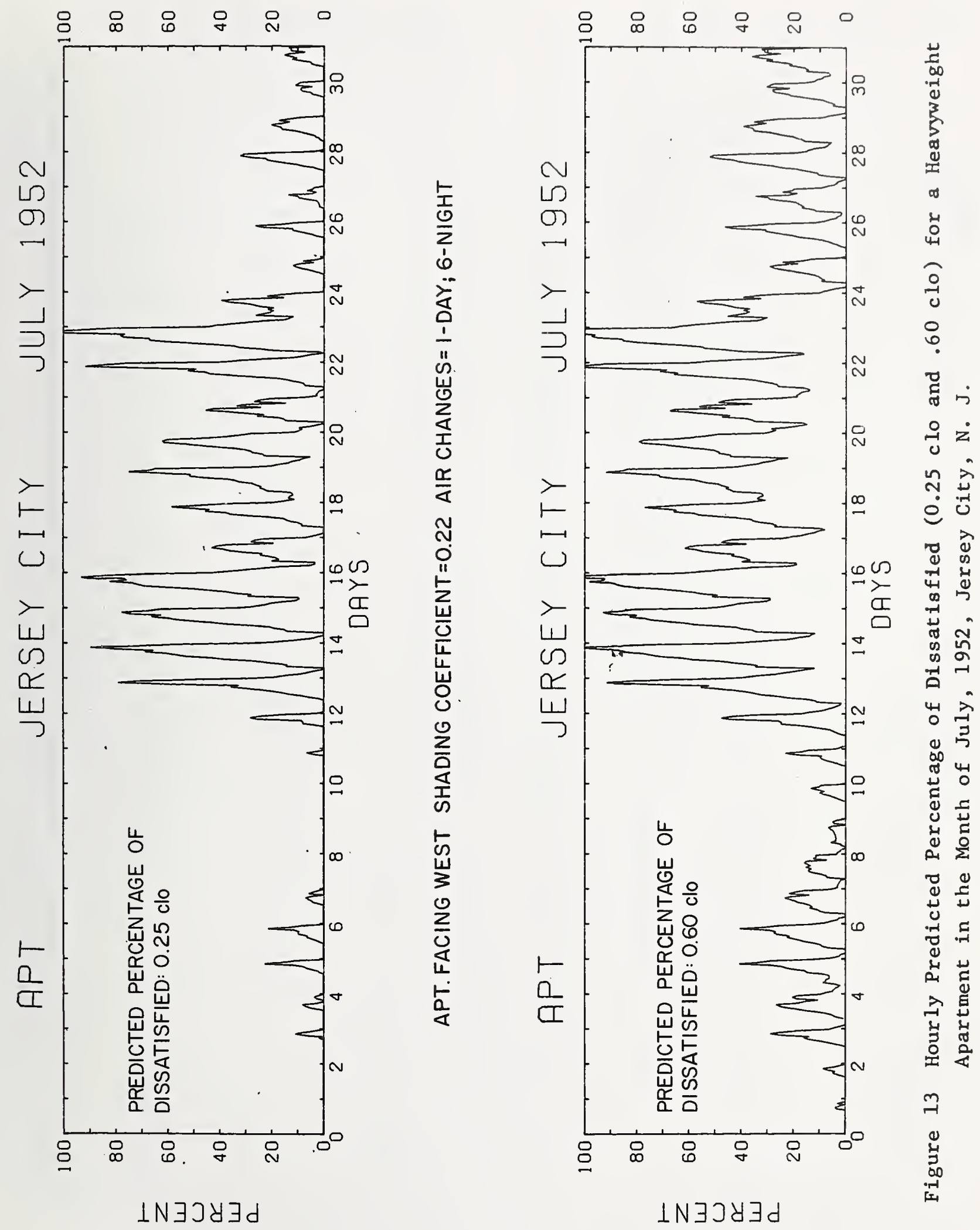

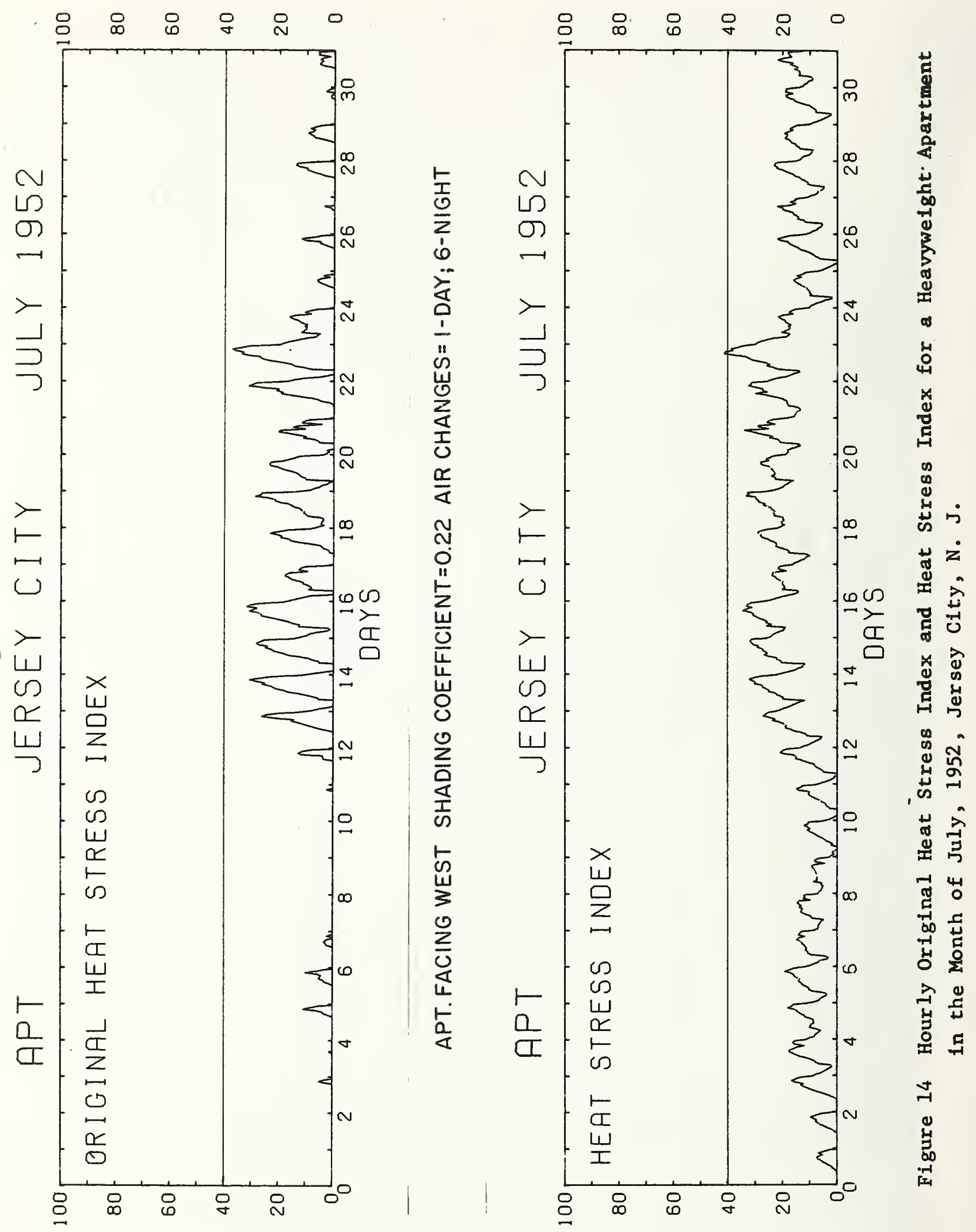


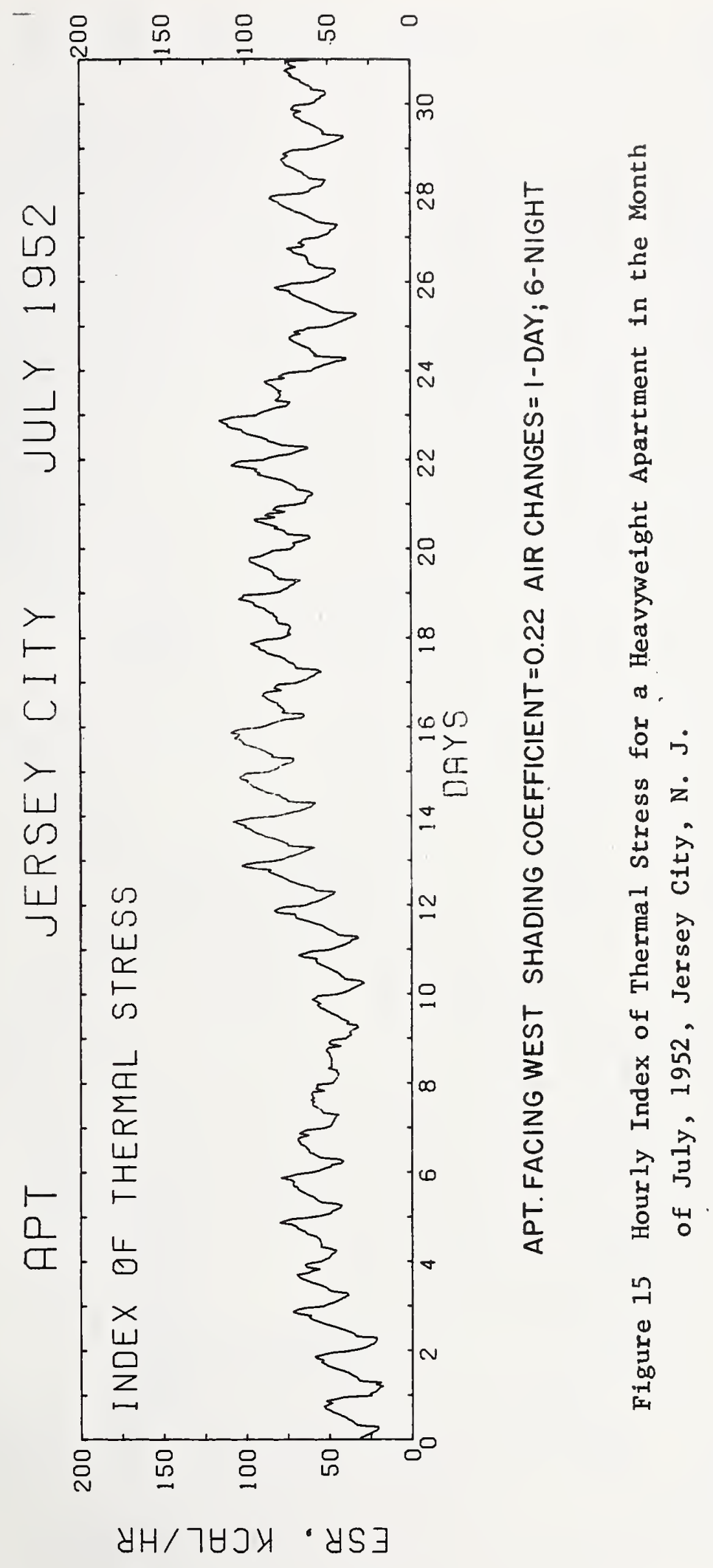




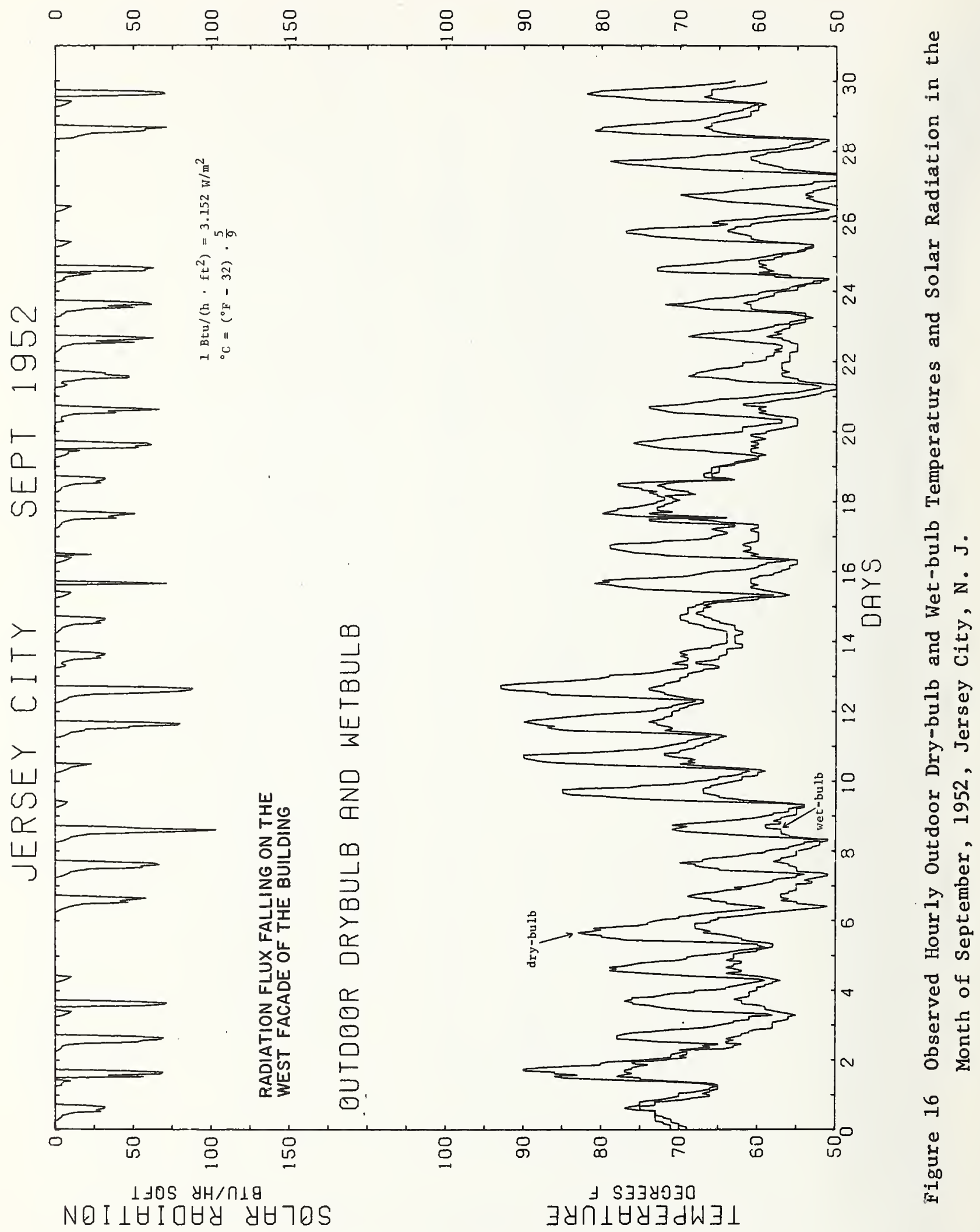




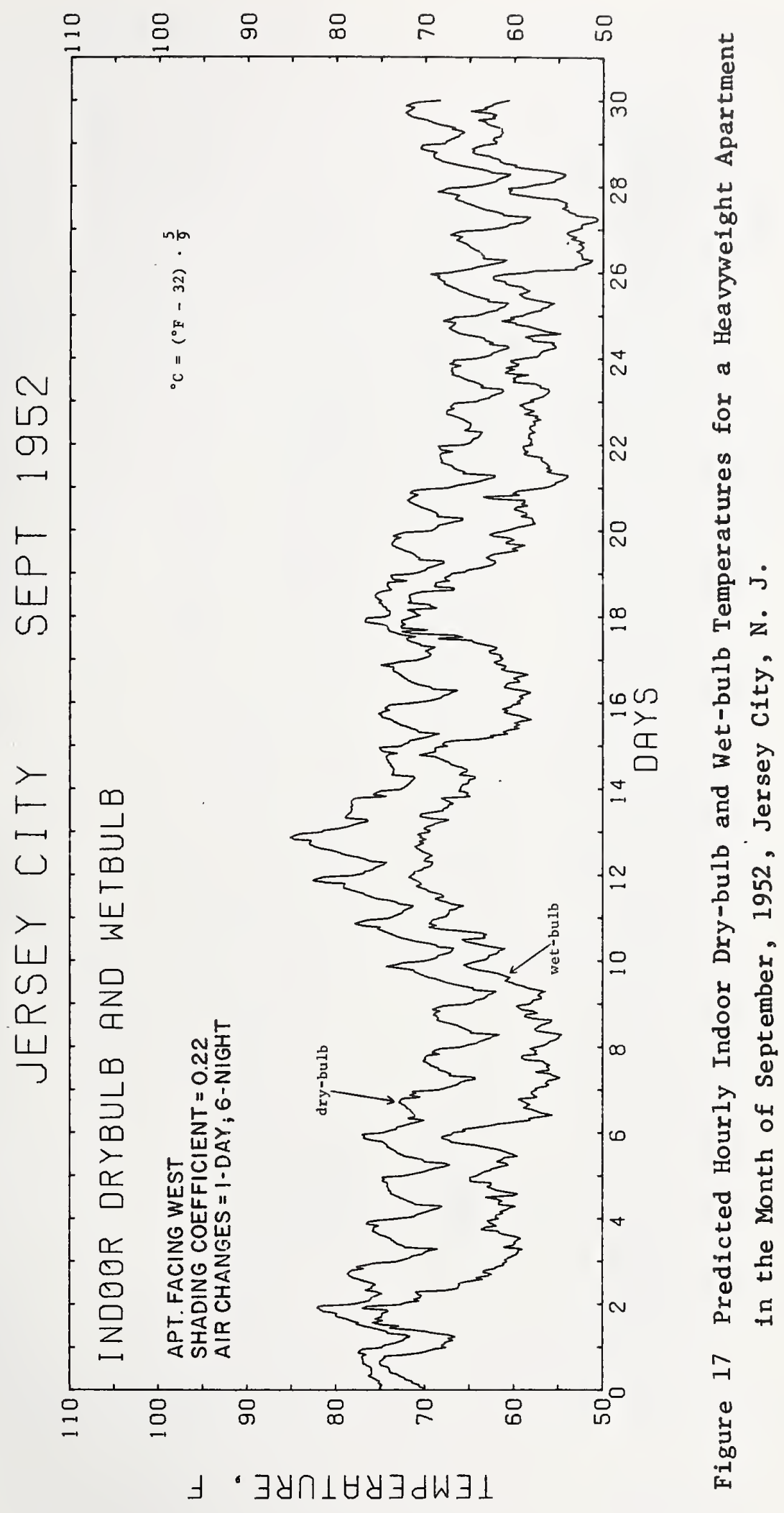



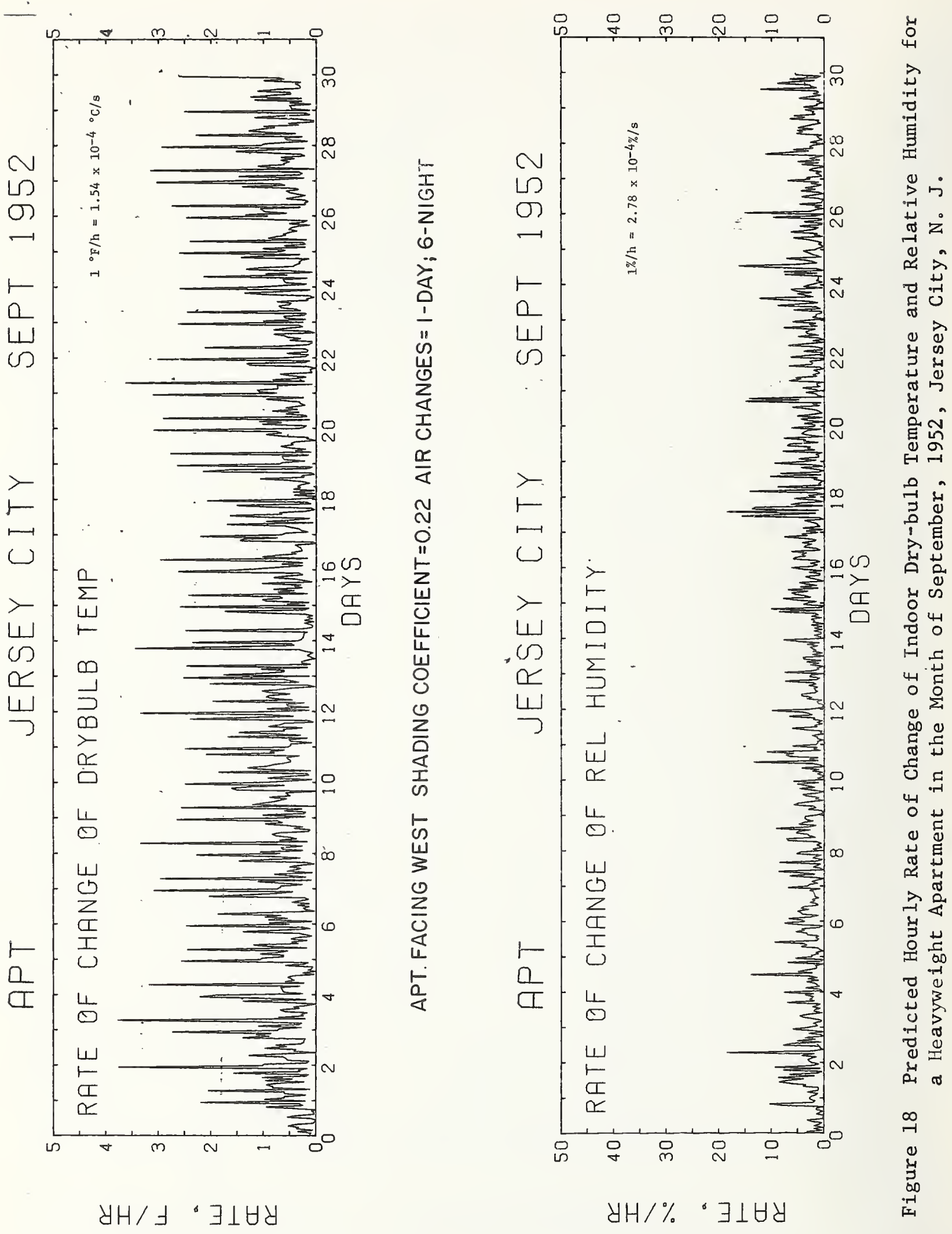

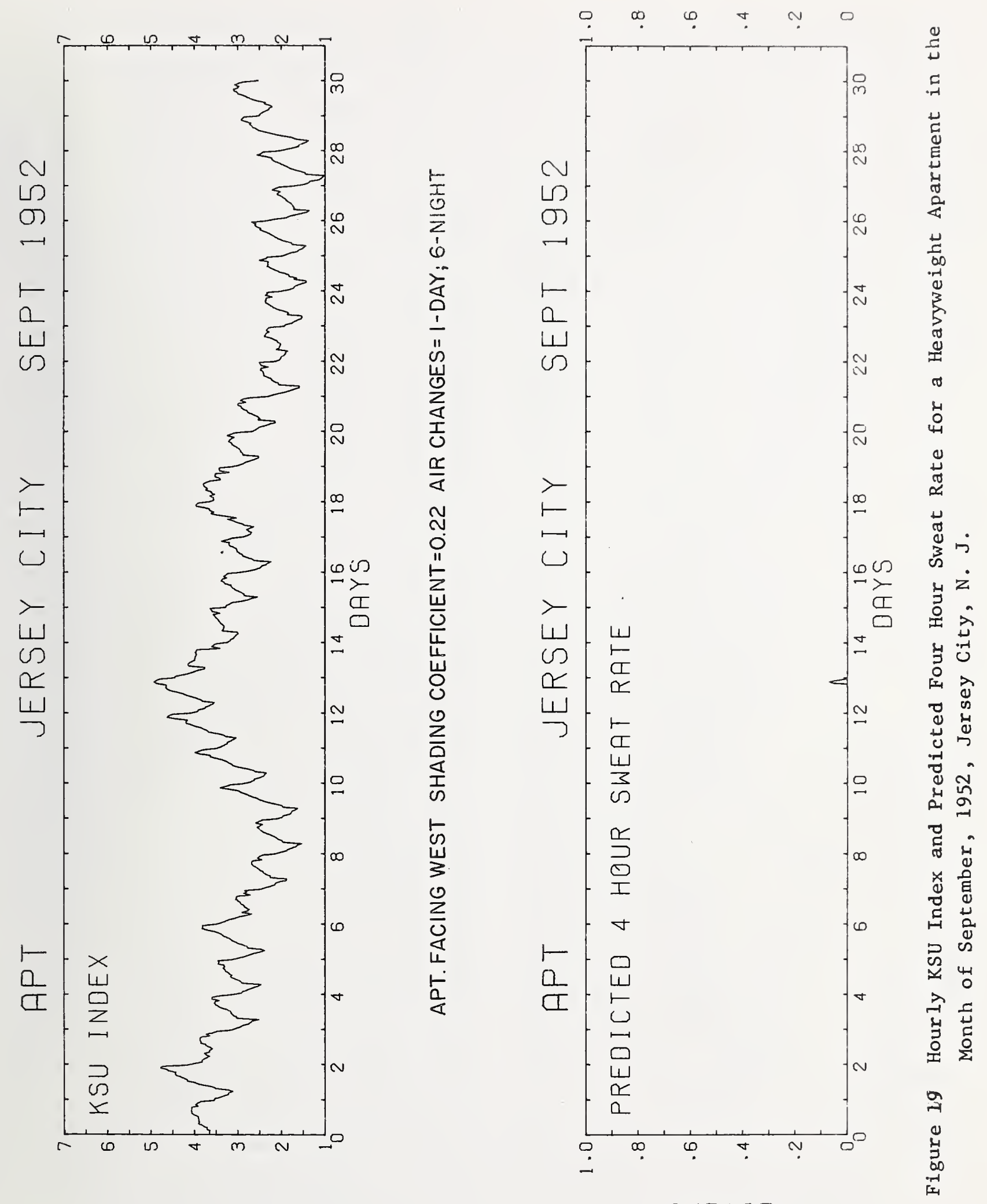

S키I 


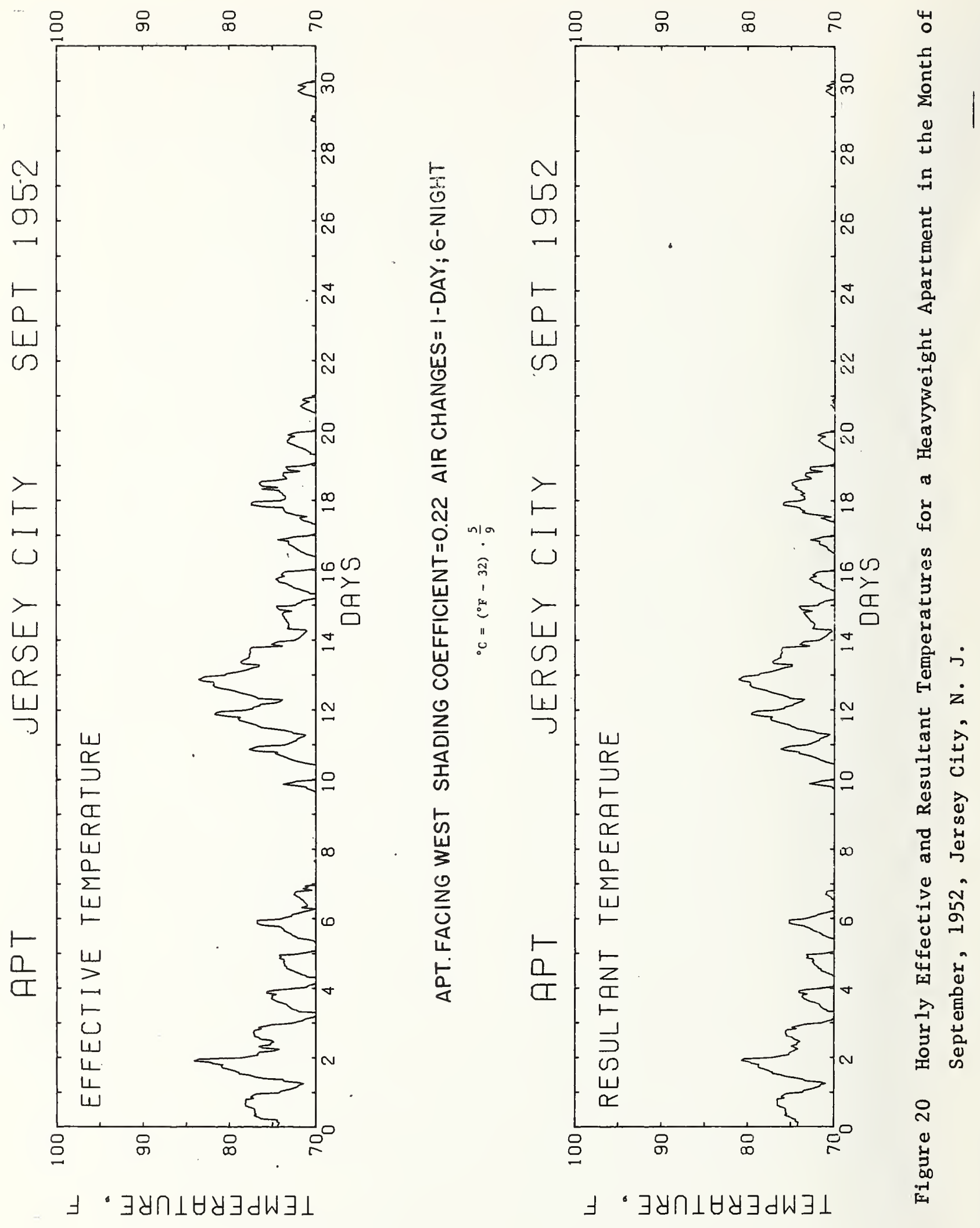




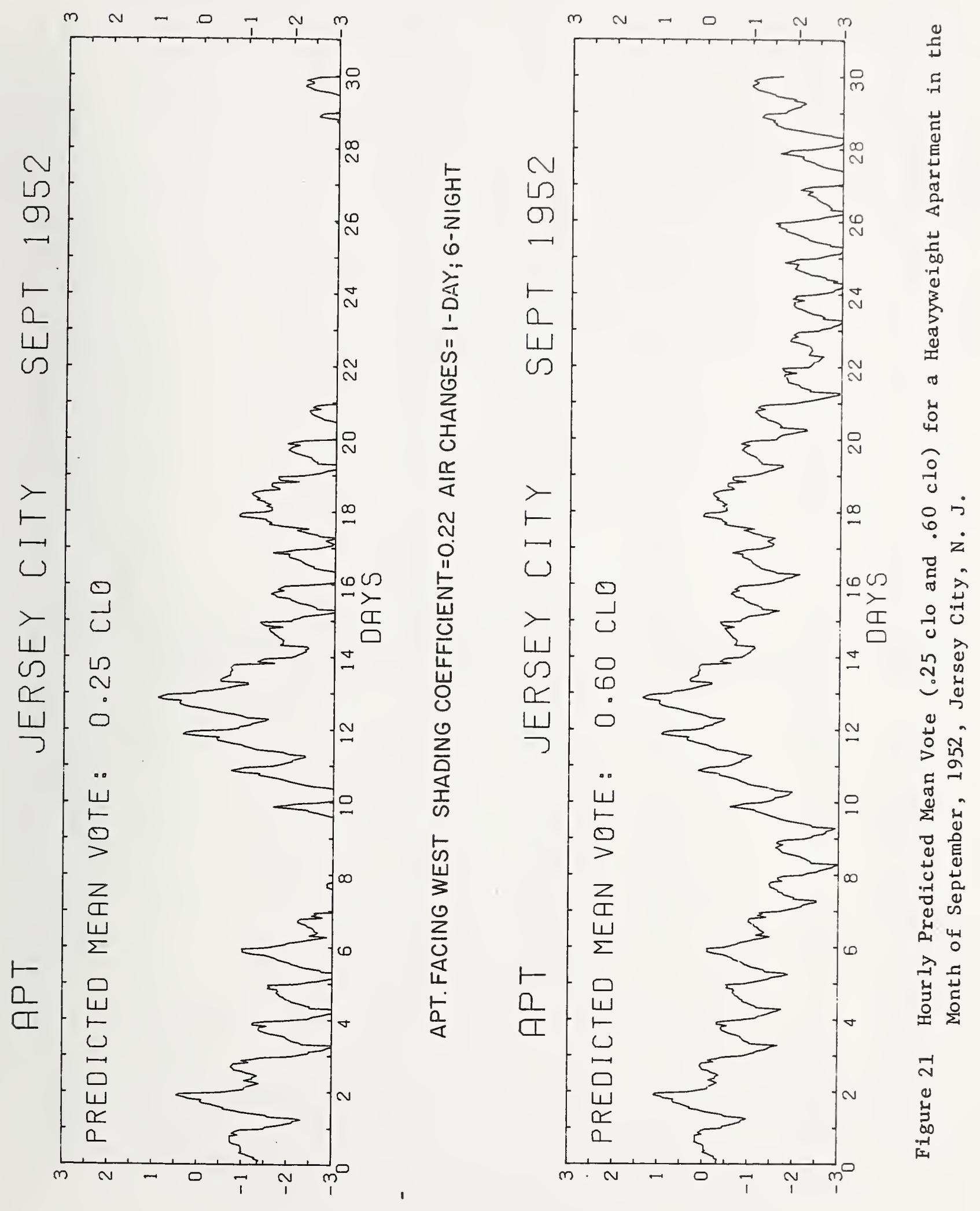



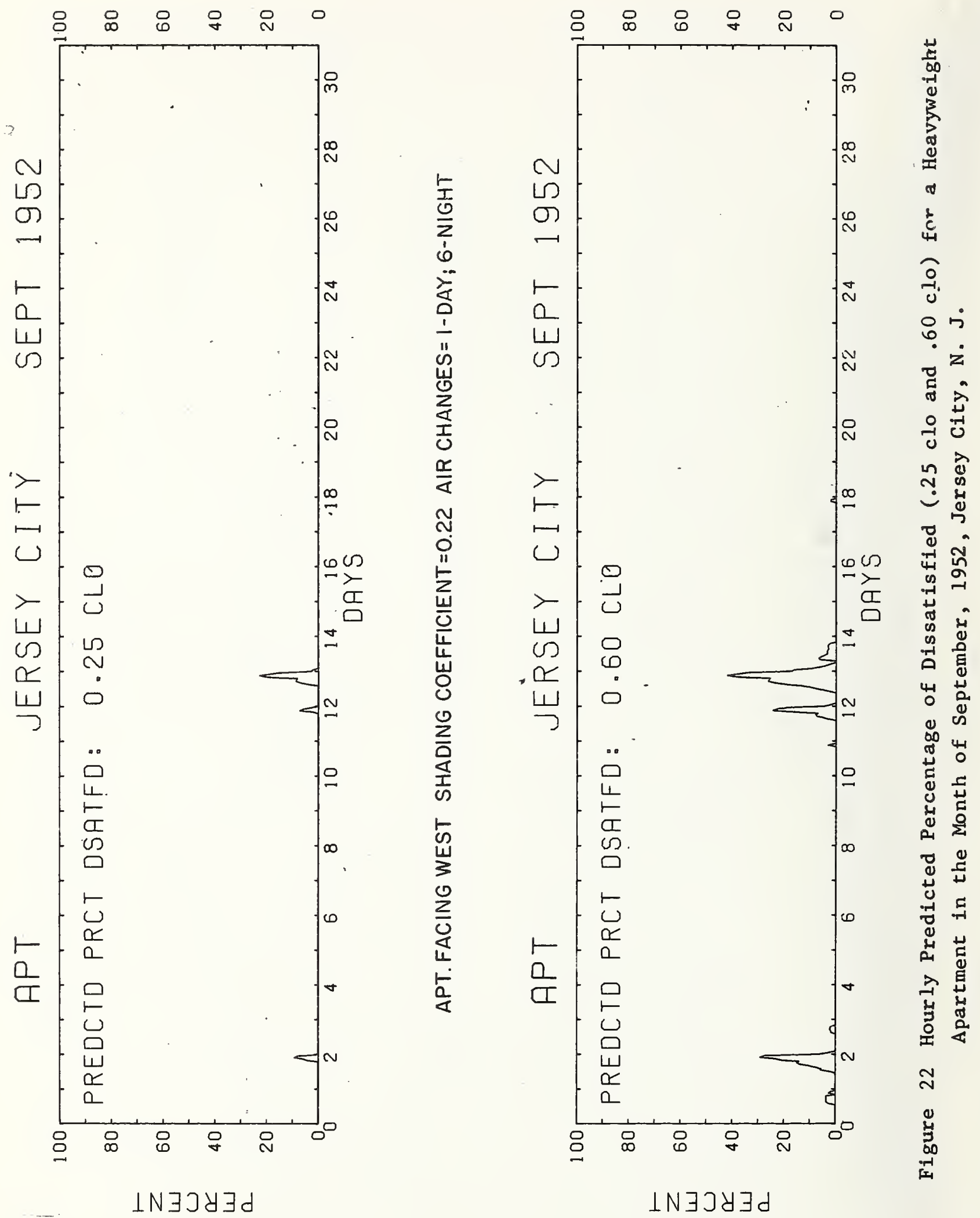

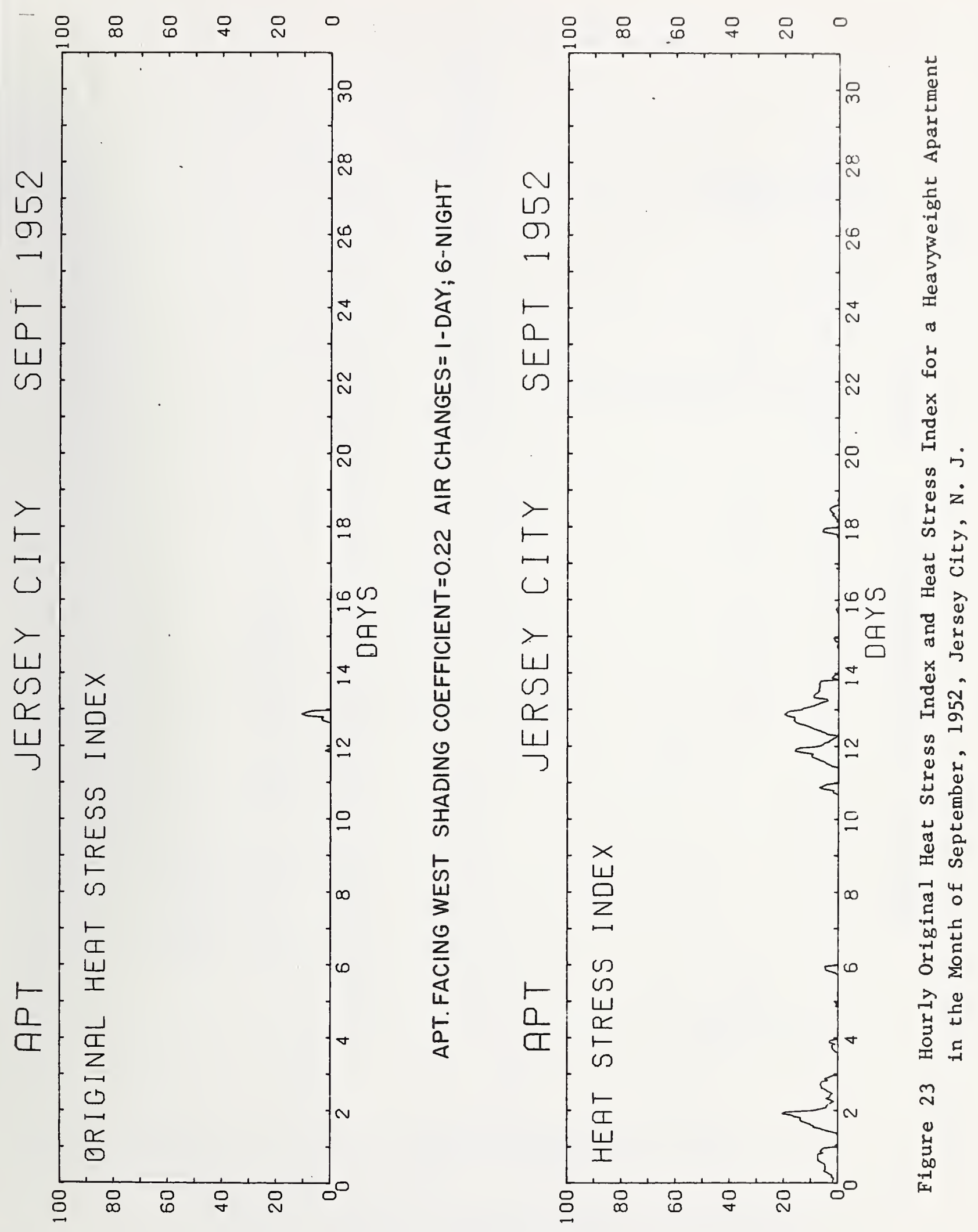


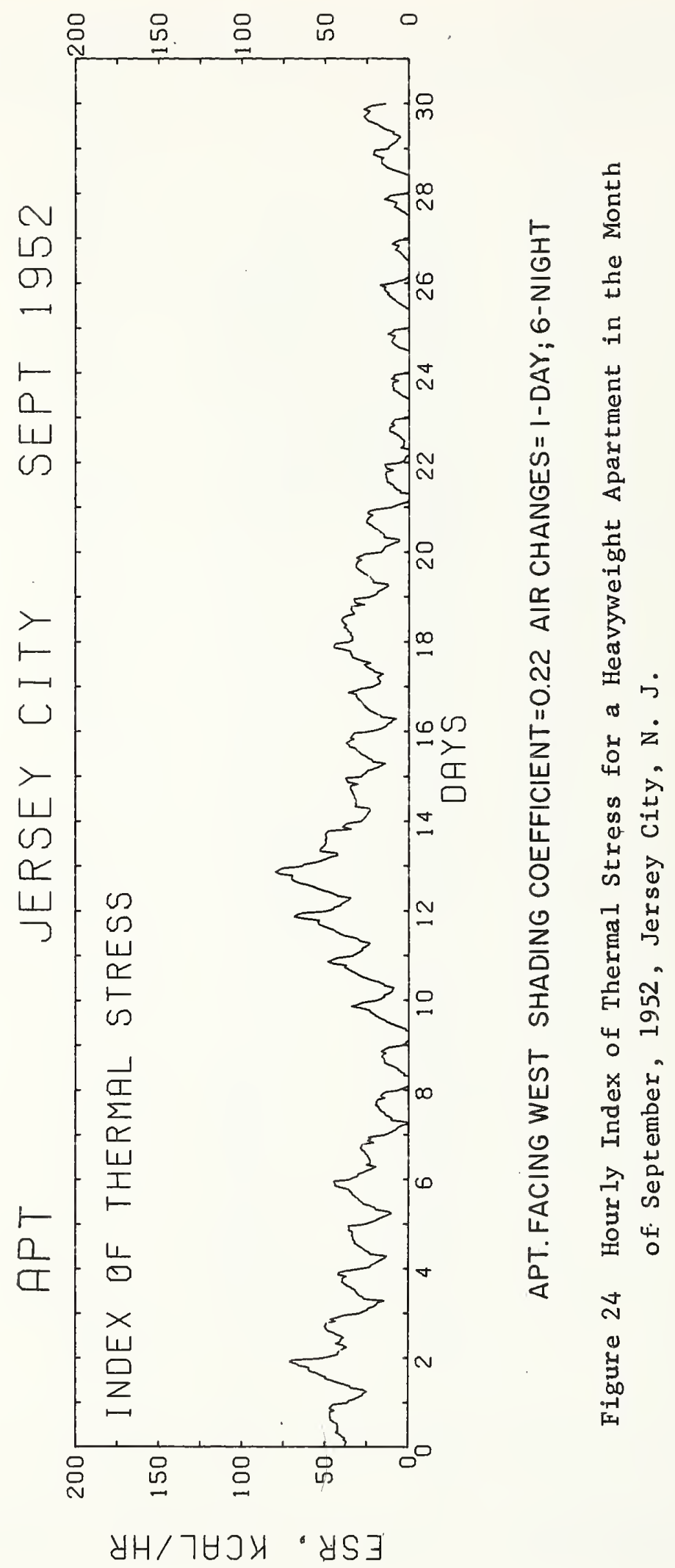




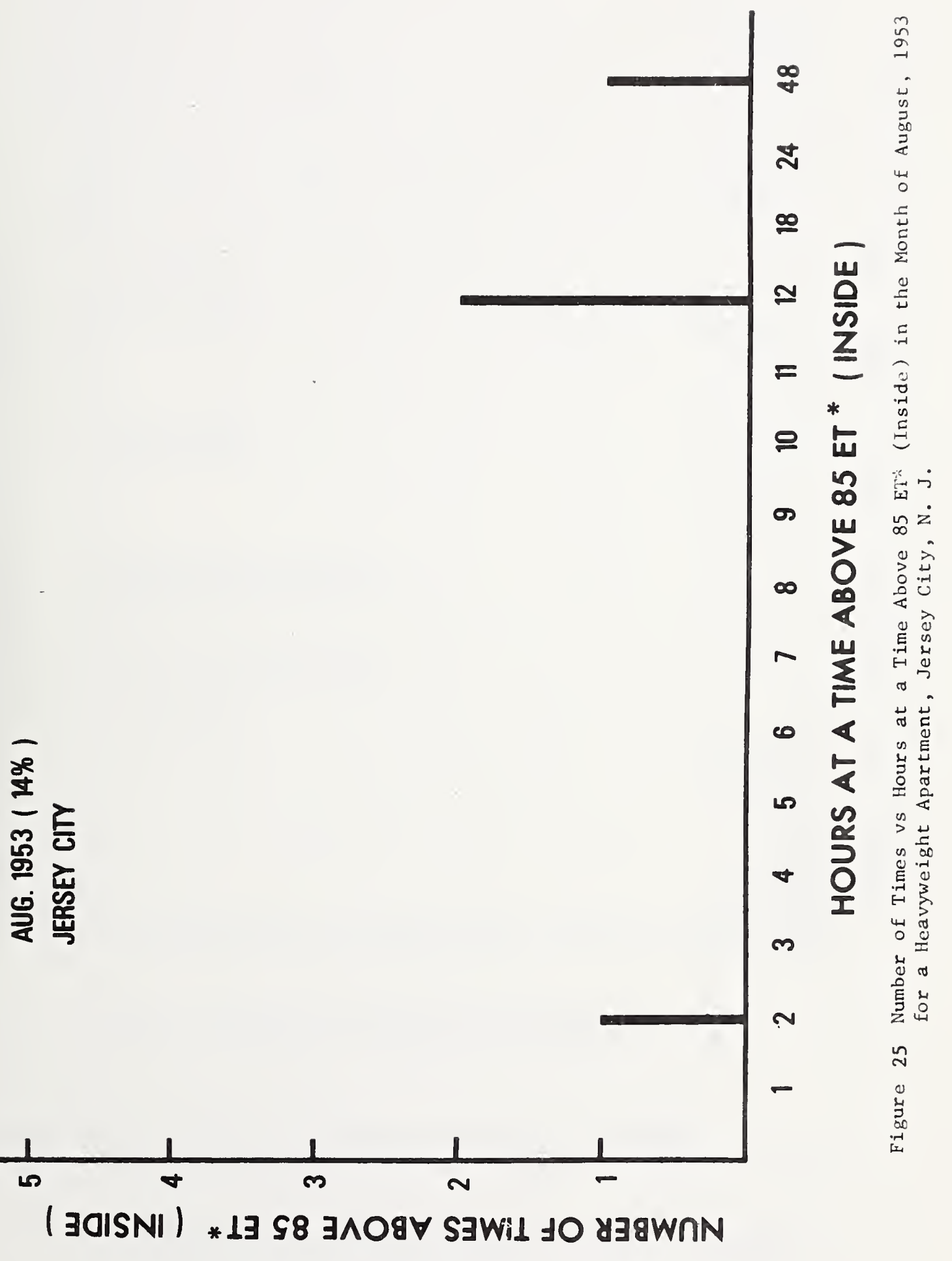




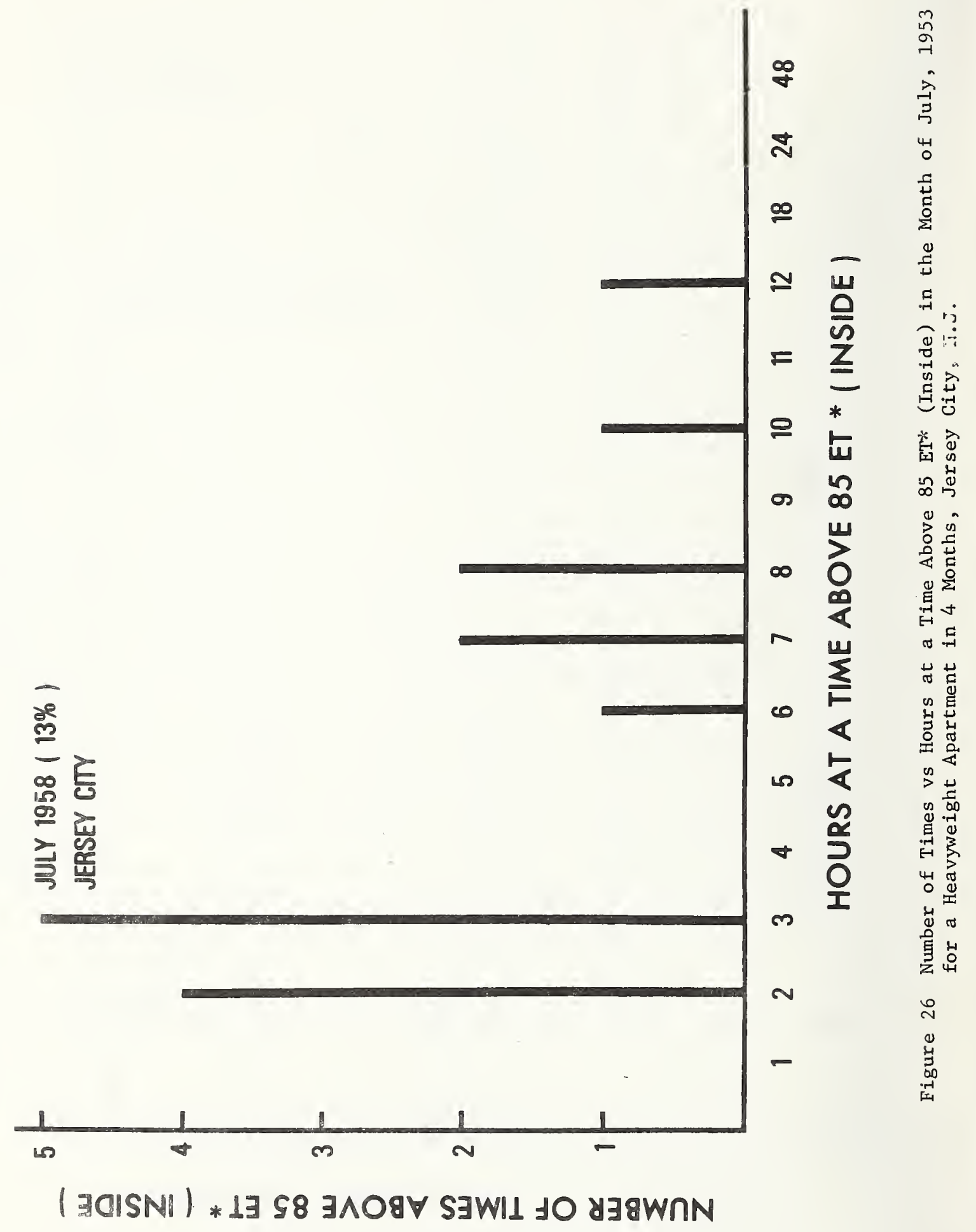




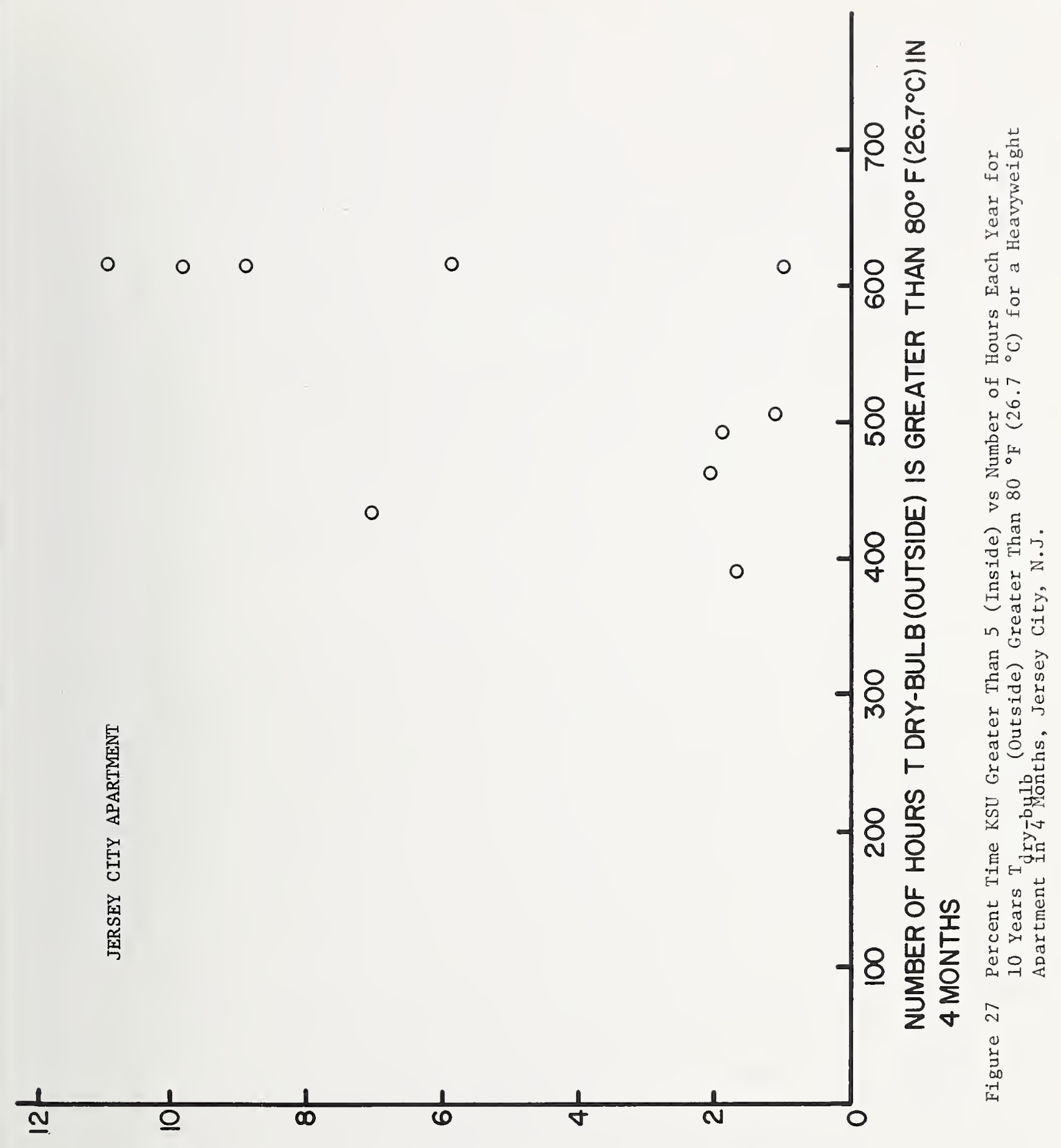

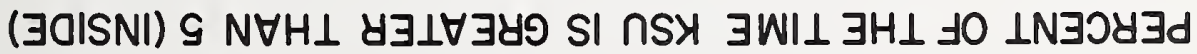




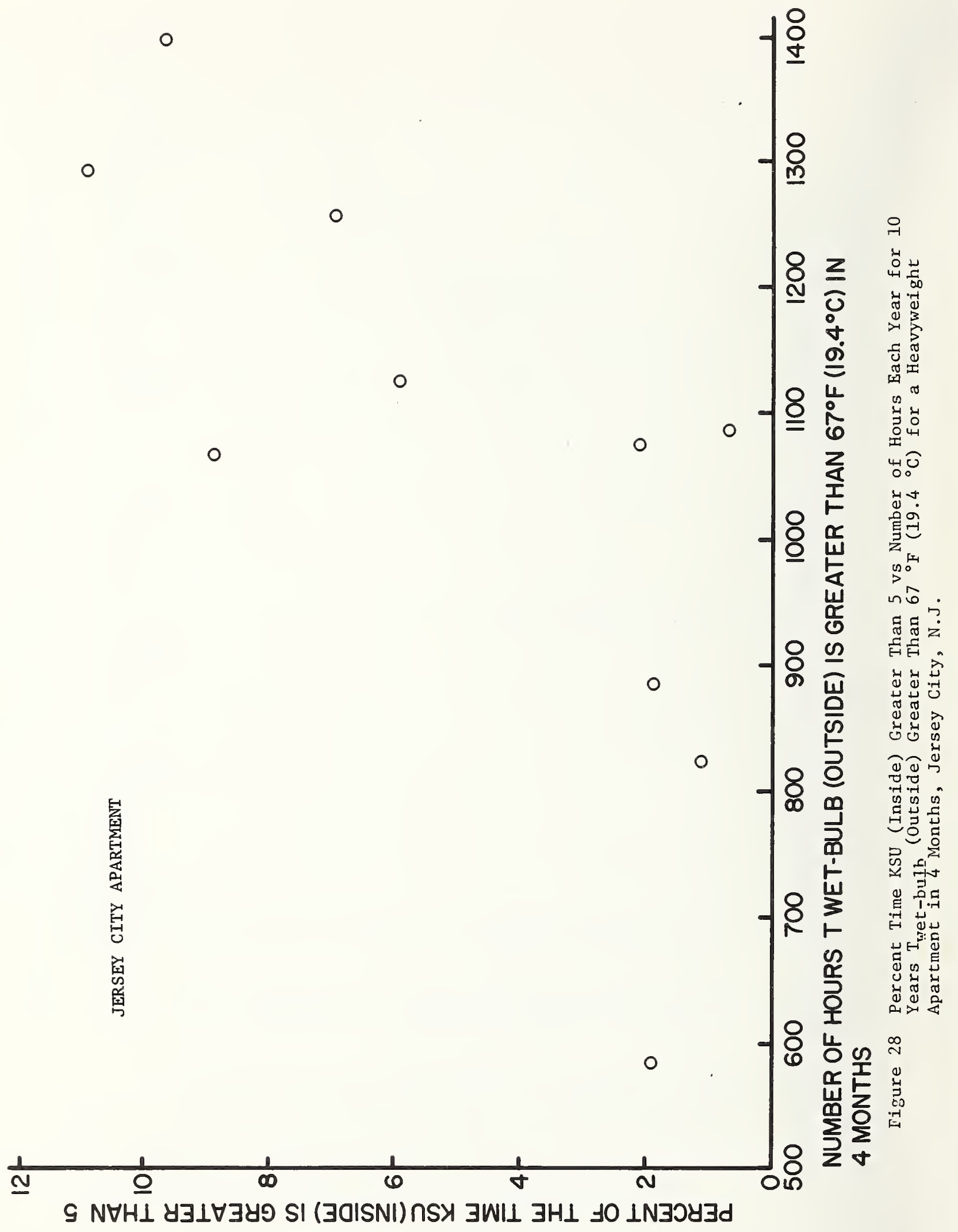




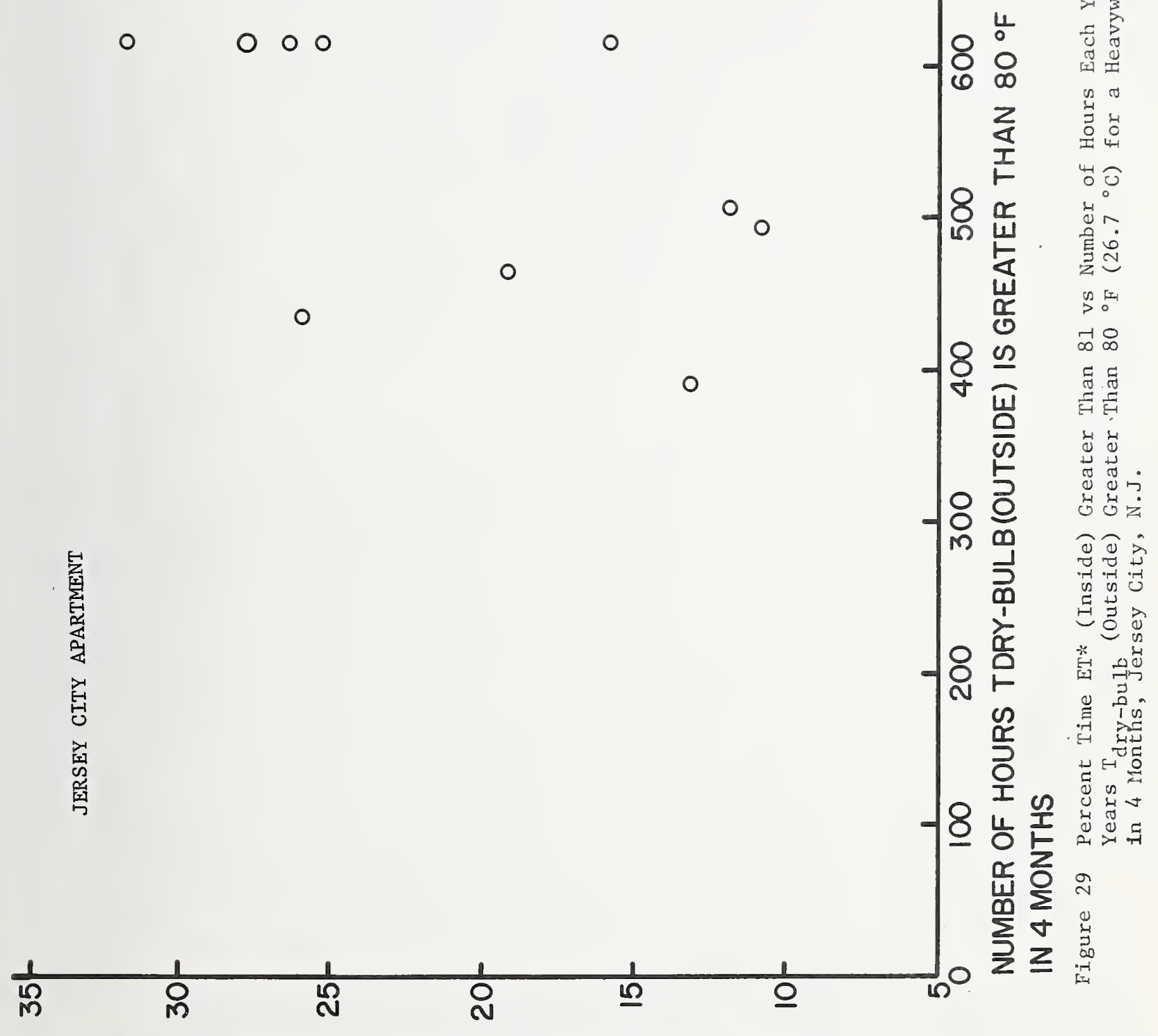

( $\exists O I S N I) ~ 18 ~ N \forall H \perp$ y $\exists \perp \forall \exists y$ S SI $\perp \exists \exists W I \perp \exists H \perp\rfloor O \perp N \exists J y \exists d$ 


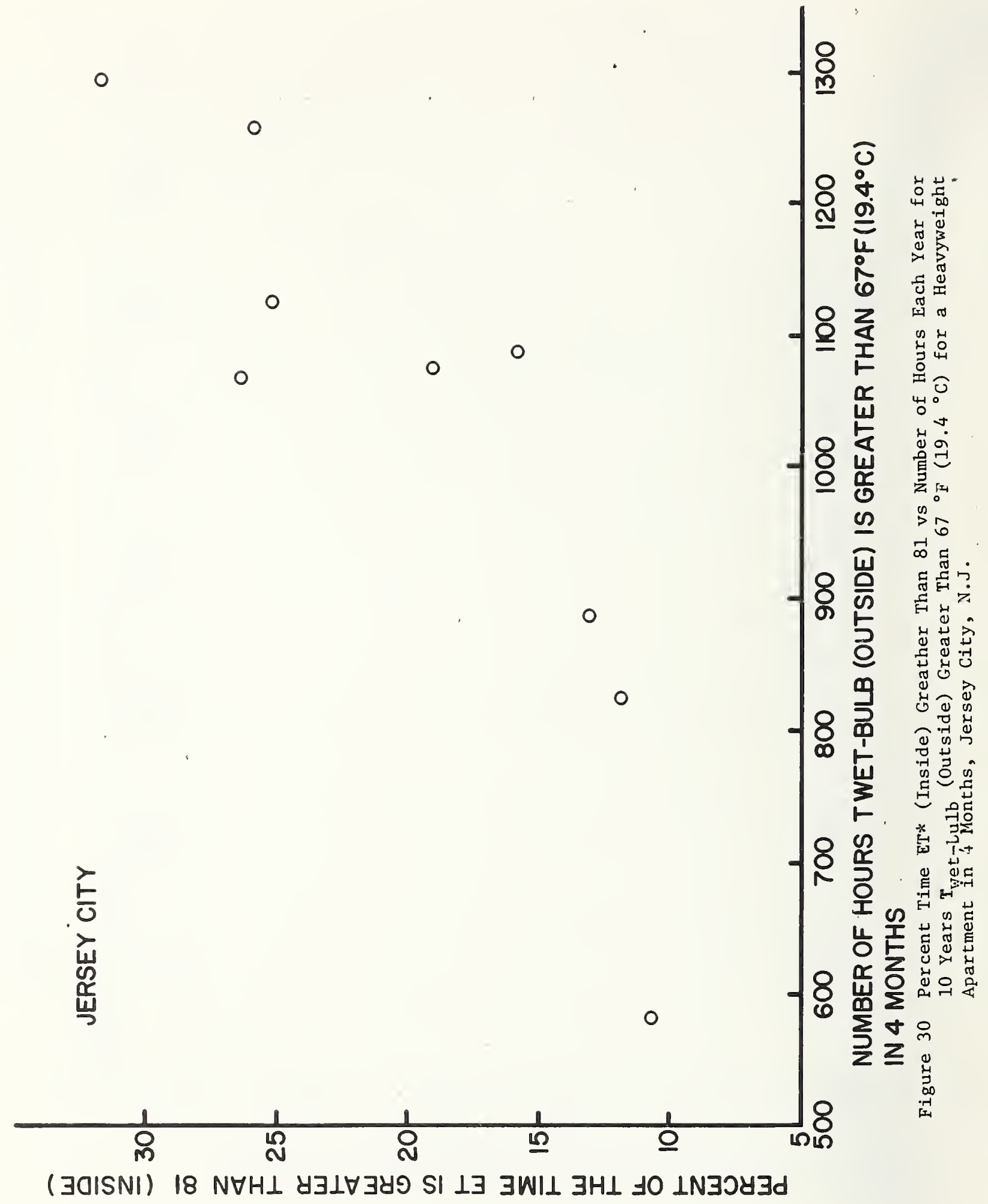


o

0

0

o

o

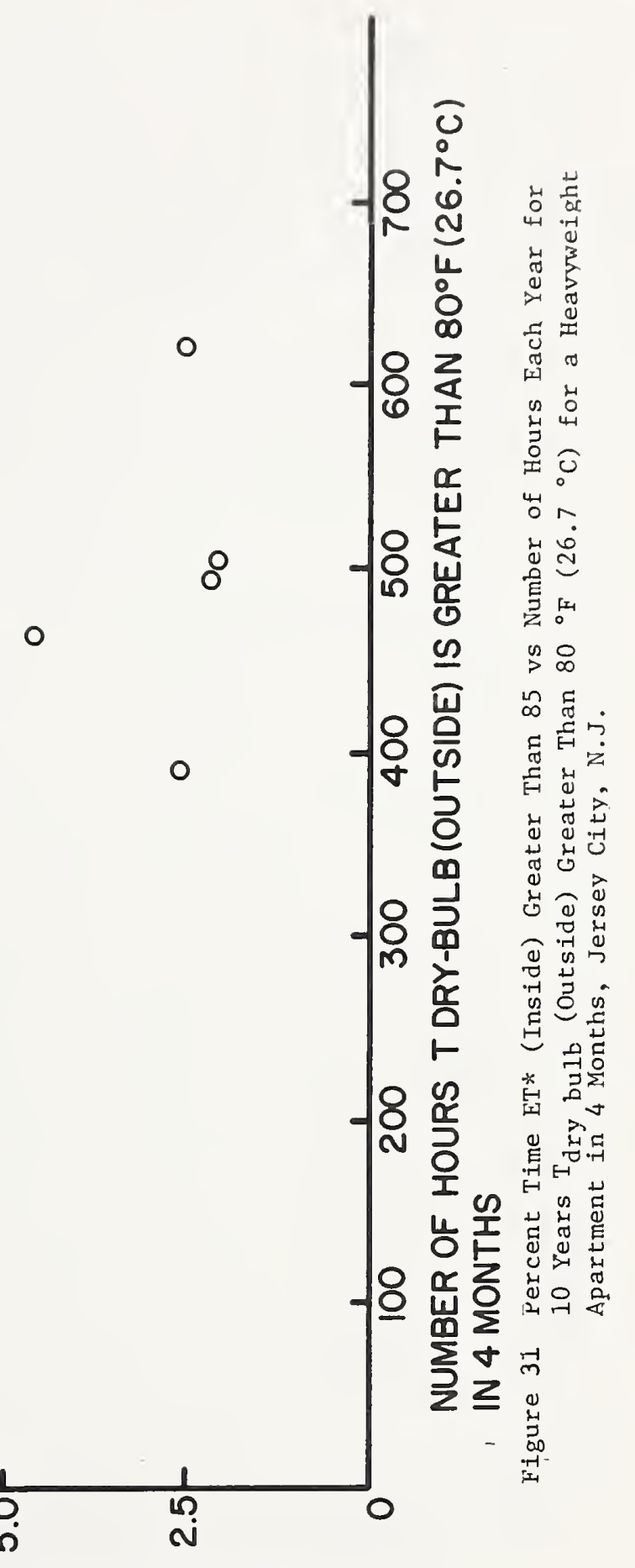

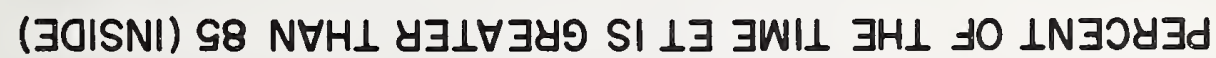




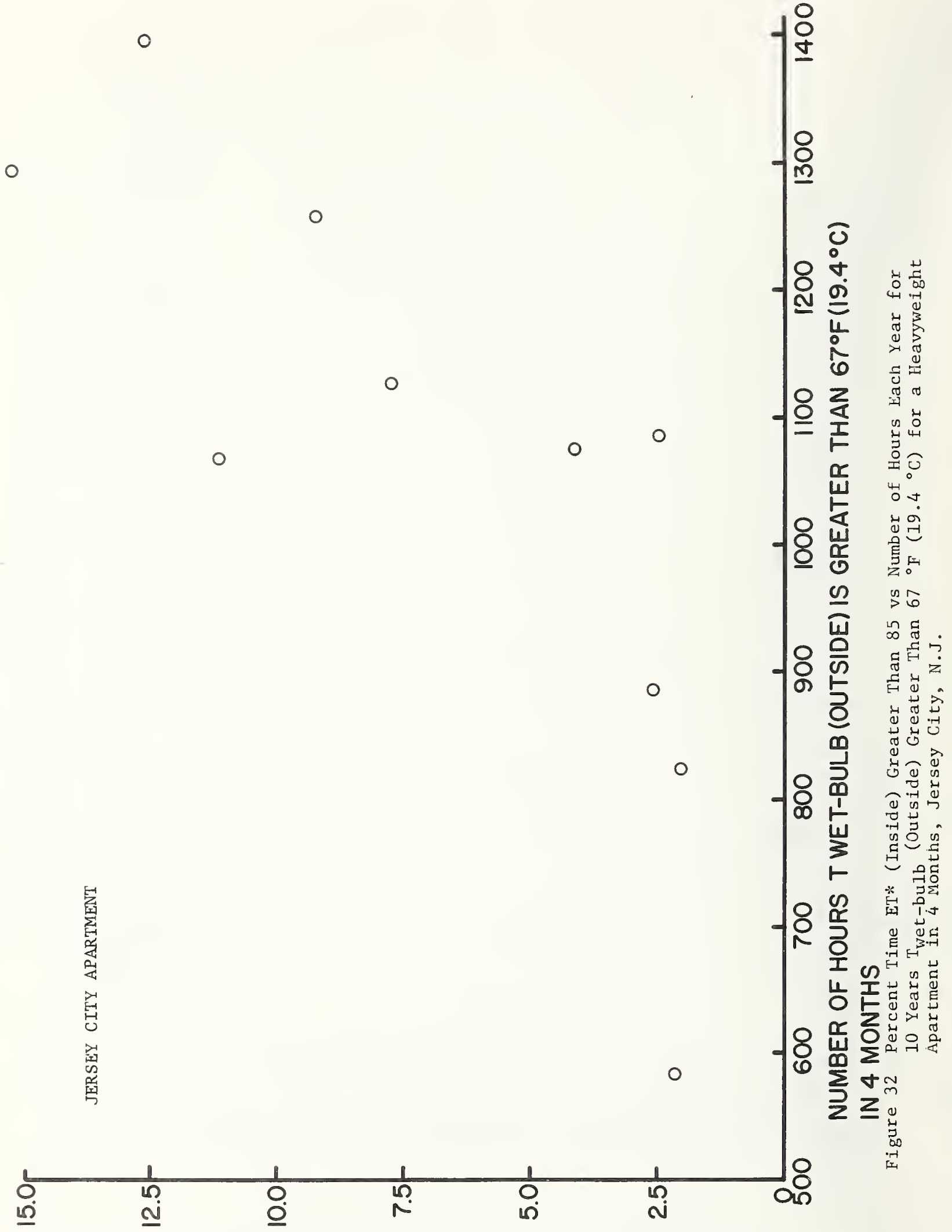

( $\exists O I S N I) ~ 98 ~ N \forall H \perp \quad \forall \exists \perp \forall \exists Y 9 S I \perp \exists \quad \exists W I \perp \exists H \perp \exists O \perp N \exists J Y \exists d$ 


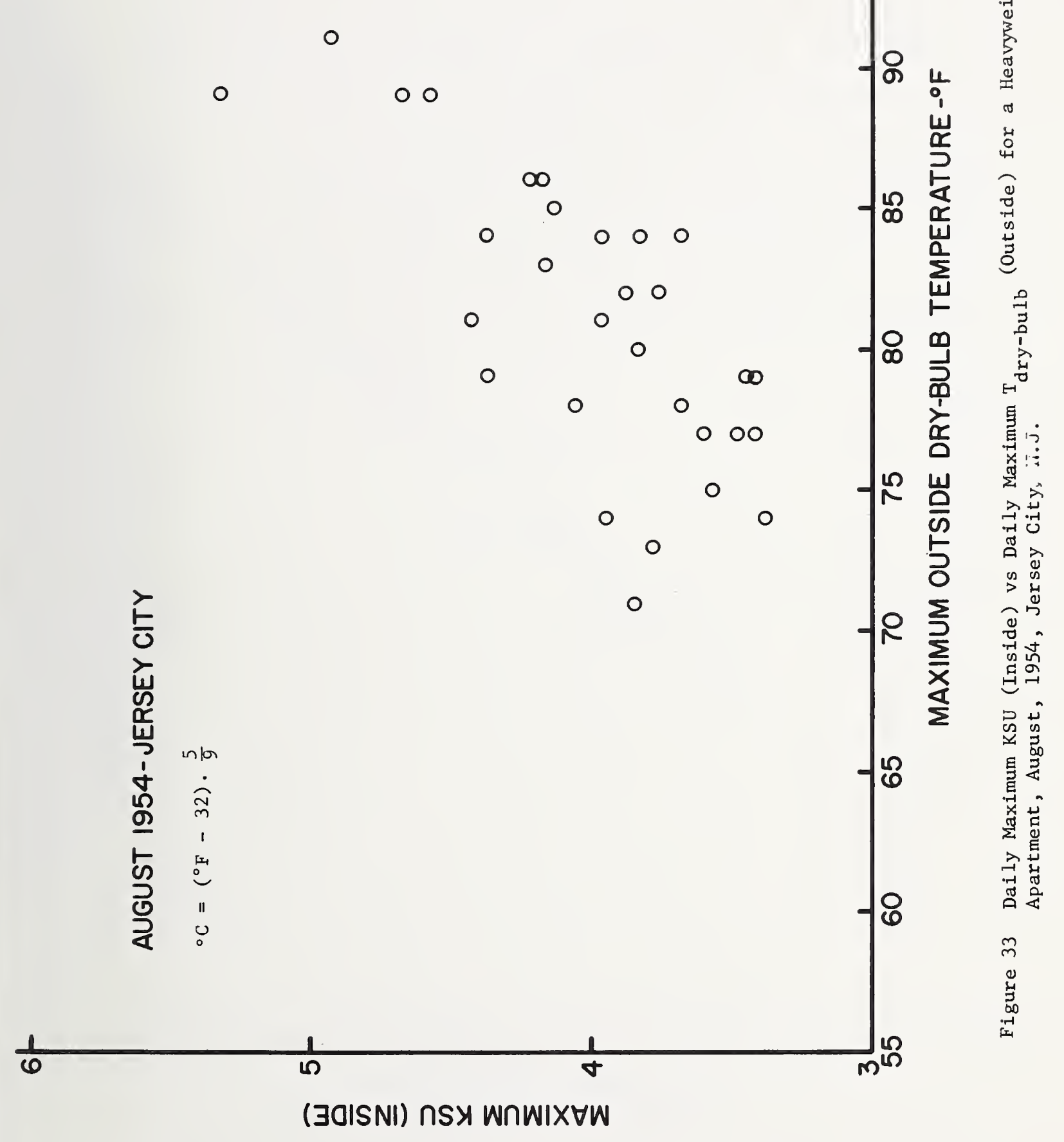




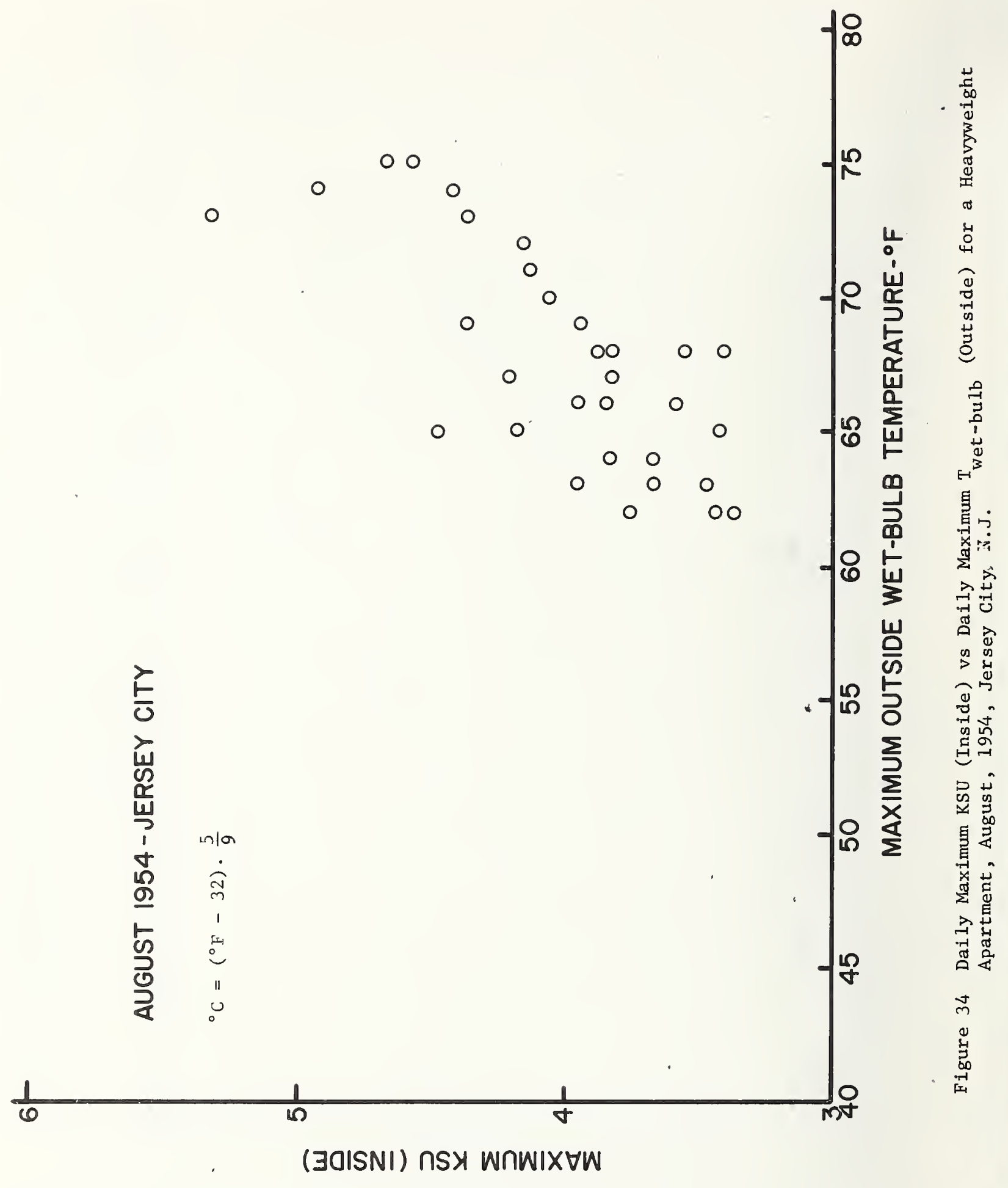



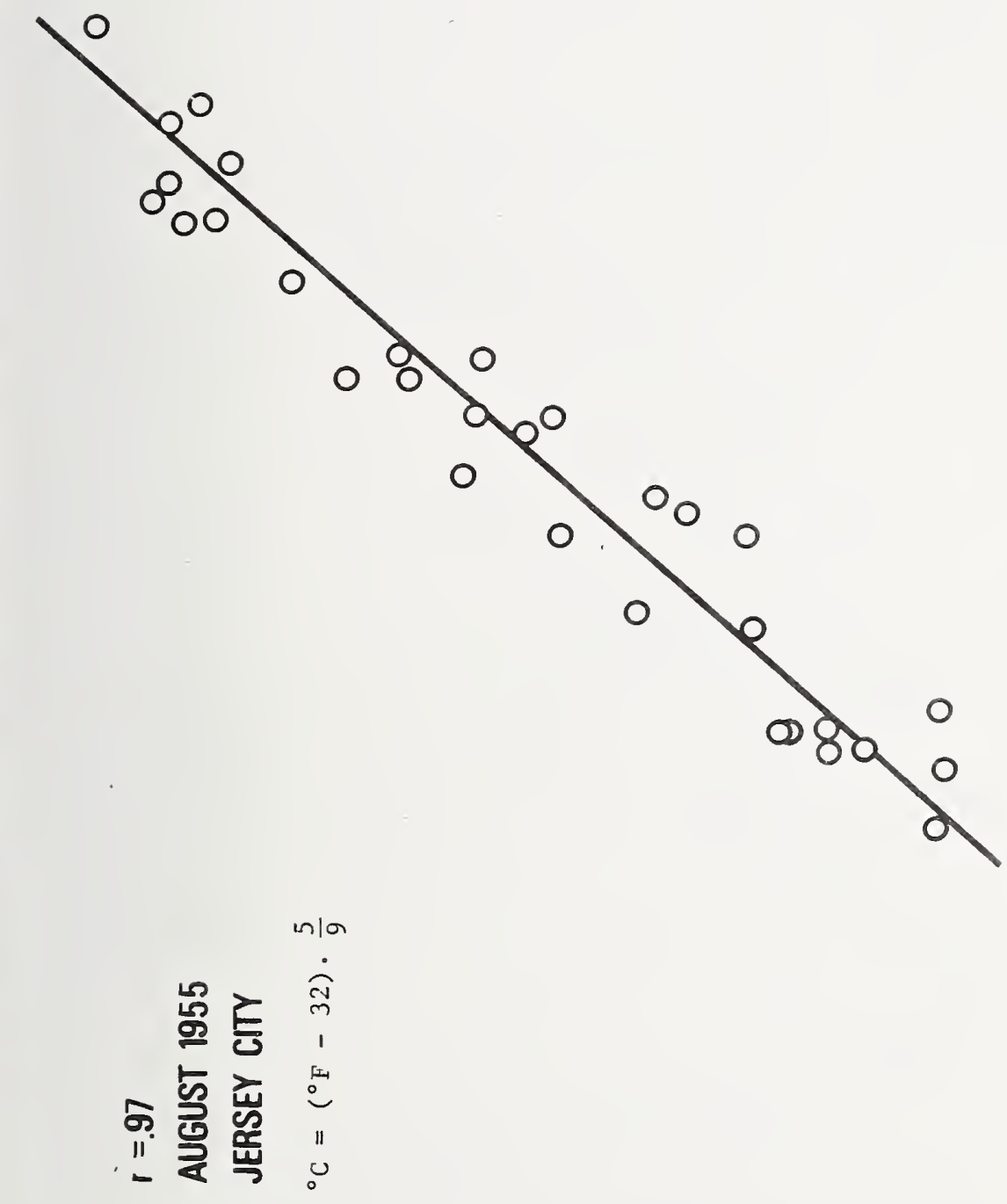


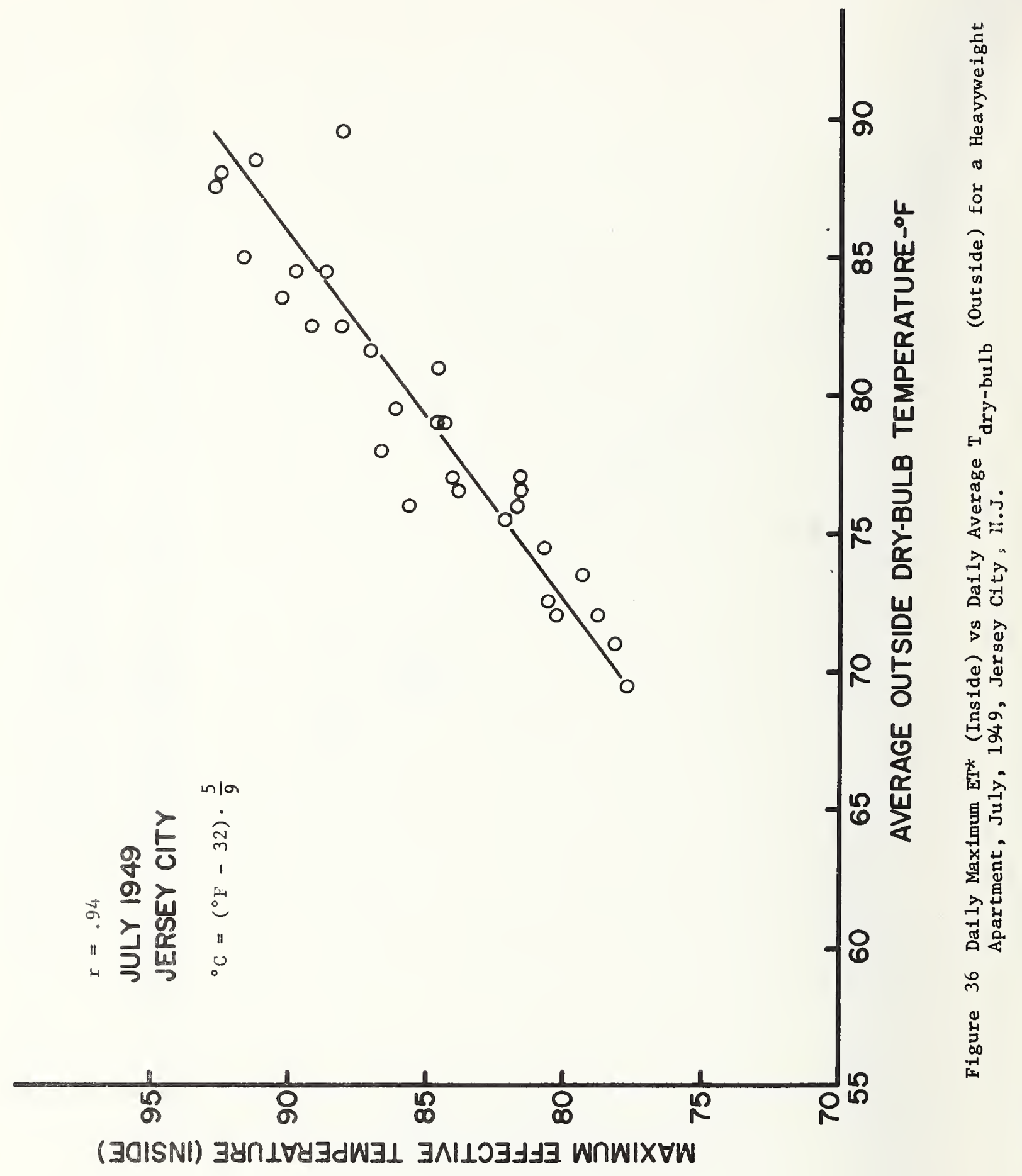




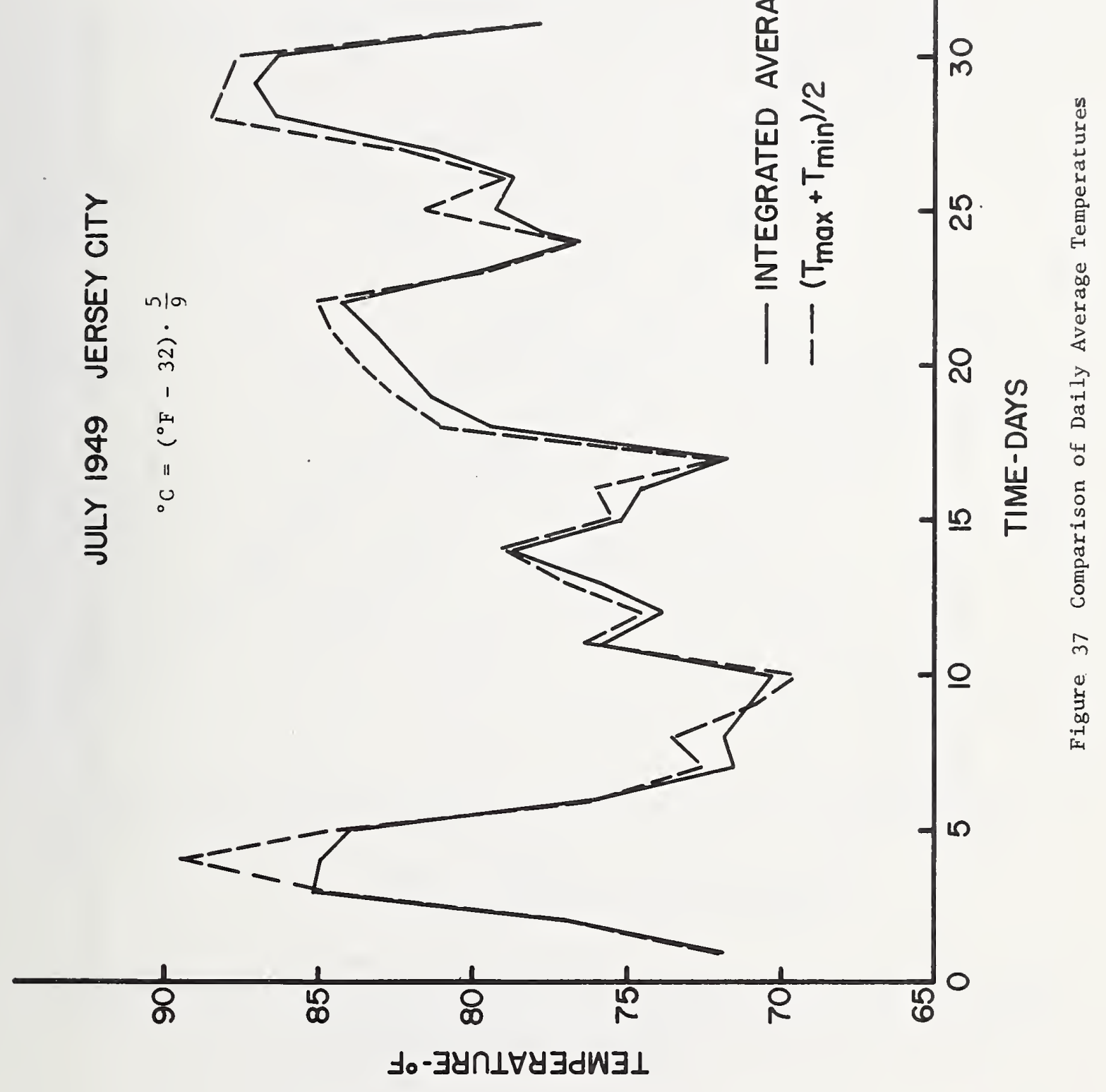




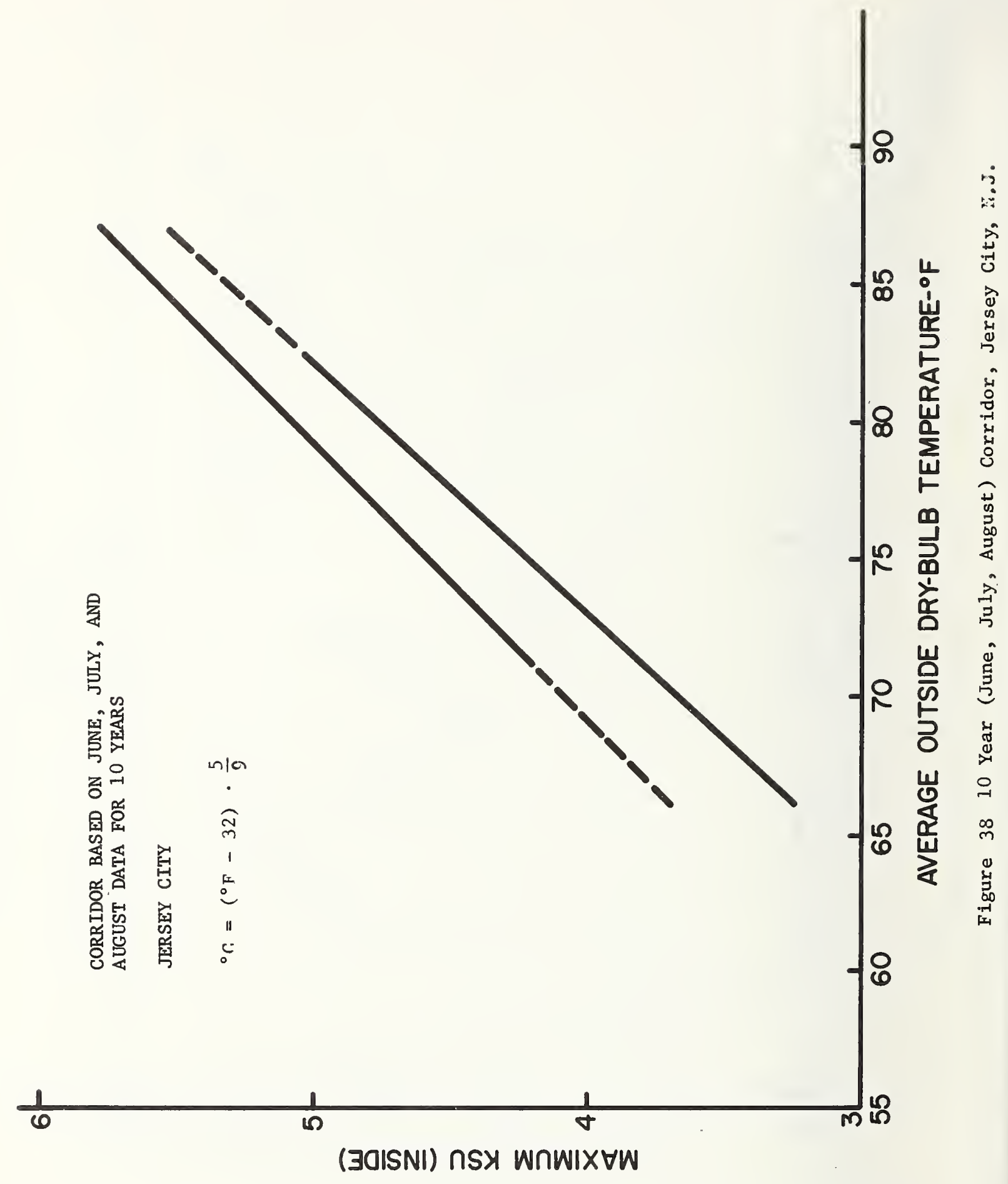


Heavyweight Apartment

Jersey City; June 28, 1949

1 Air Change Per Hour, Constant

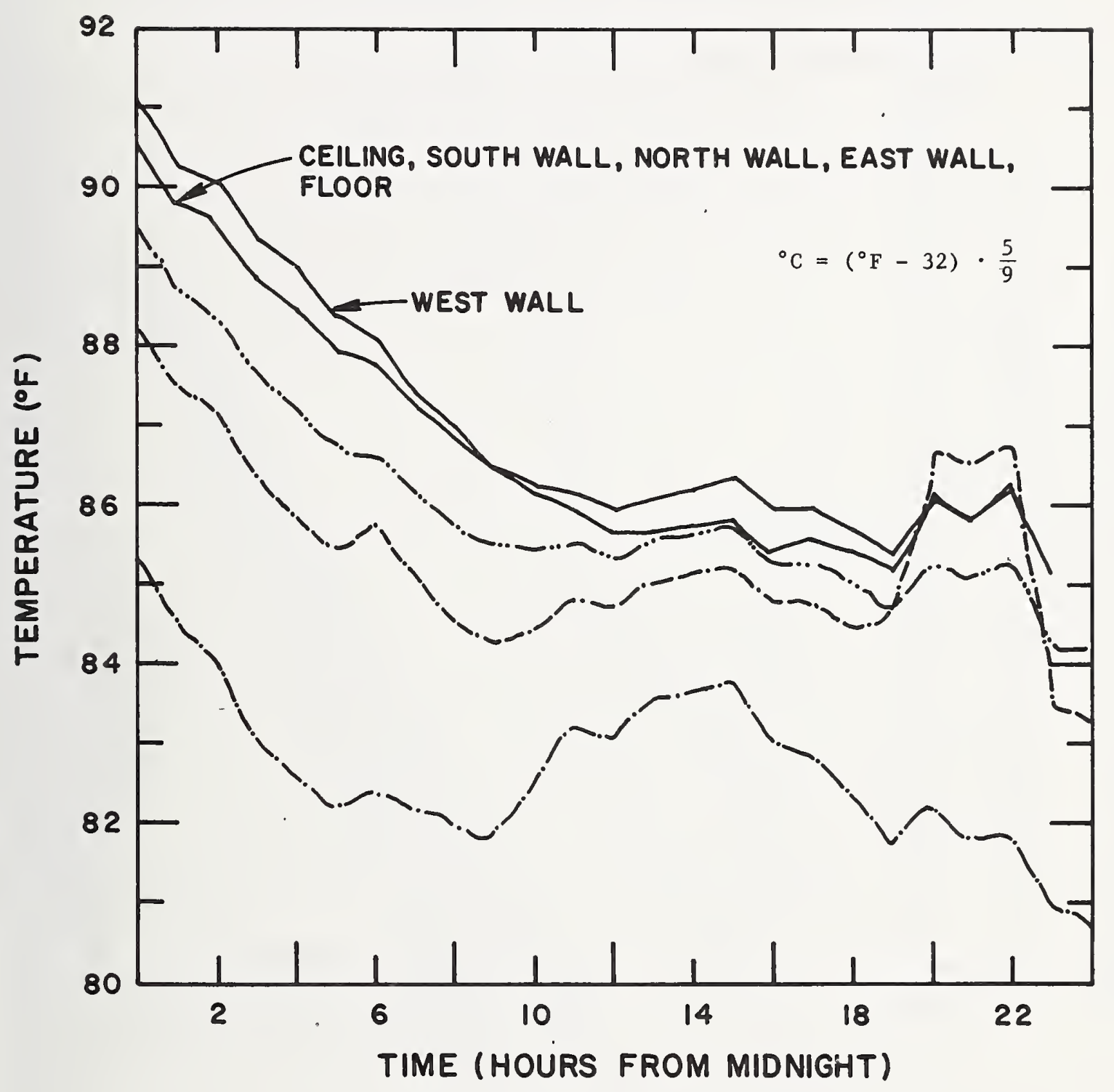

- - - Inside Air Temperature

-..... Mean Radiant Temperature (Center of Room)

- - Mean Radiant Temperature (2 ft $(0.6 \mathrm{~m})$ From the Window)

- Inside Wall Surface Temperatures

Figure 39A. Comparison of Mean Radiant Temperature Calculation Results for a Heavyweight Apartment, June 28, 1949, Jersey City, N.J. 
Heavyweight Apartment

Jersey City; June 28, 1949

1 Air Change Per Hour, Constant

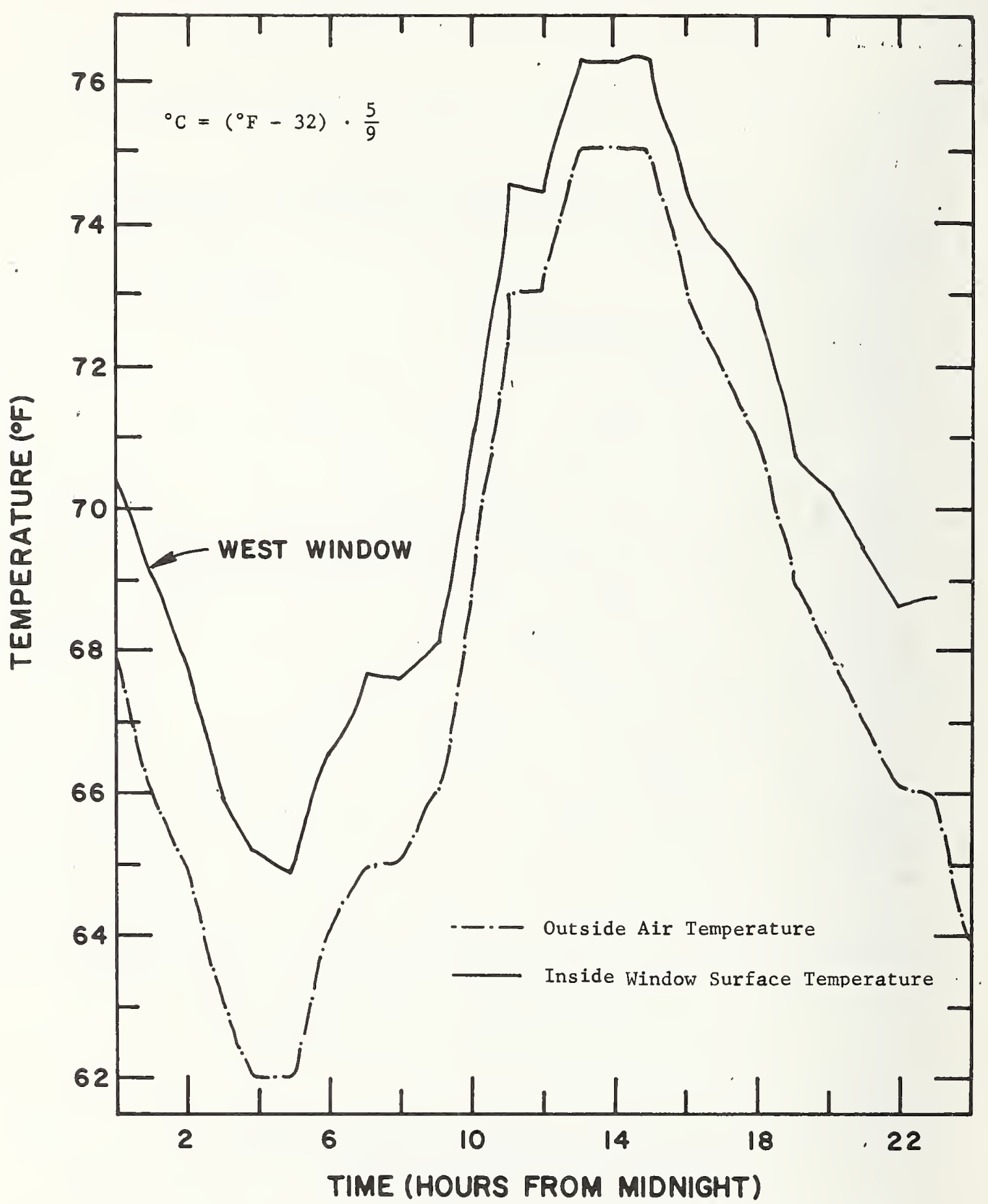

Figure 39B Comparison of Mean Radiant Temperature Calculation Results for a Heavyweight Apartment, June 28, 1949, Jersey City, N.J: 


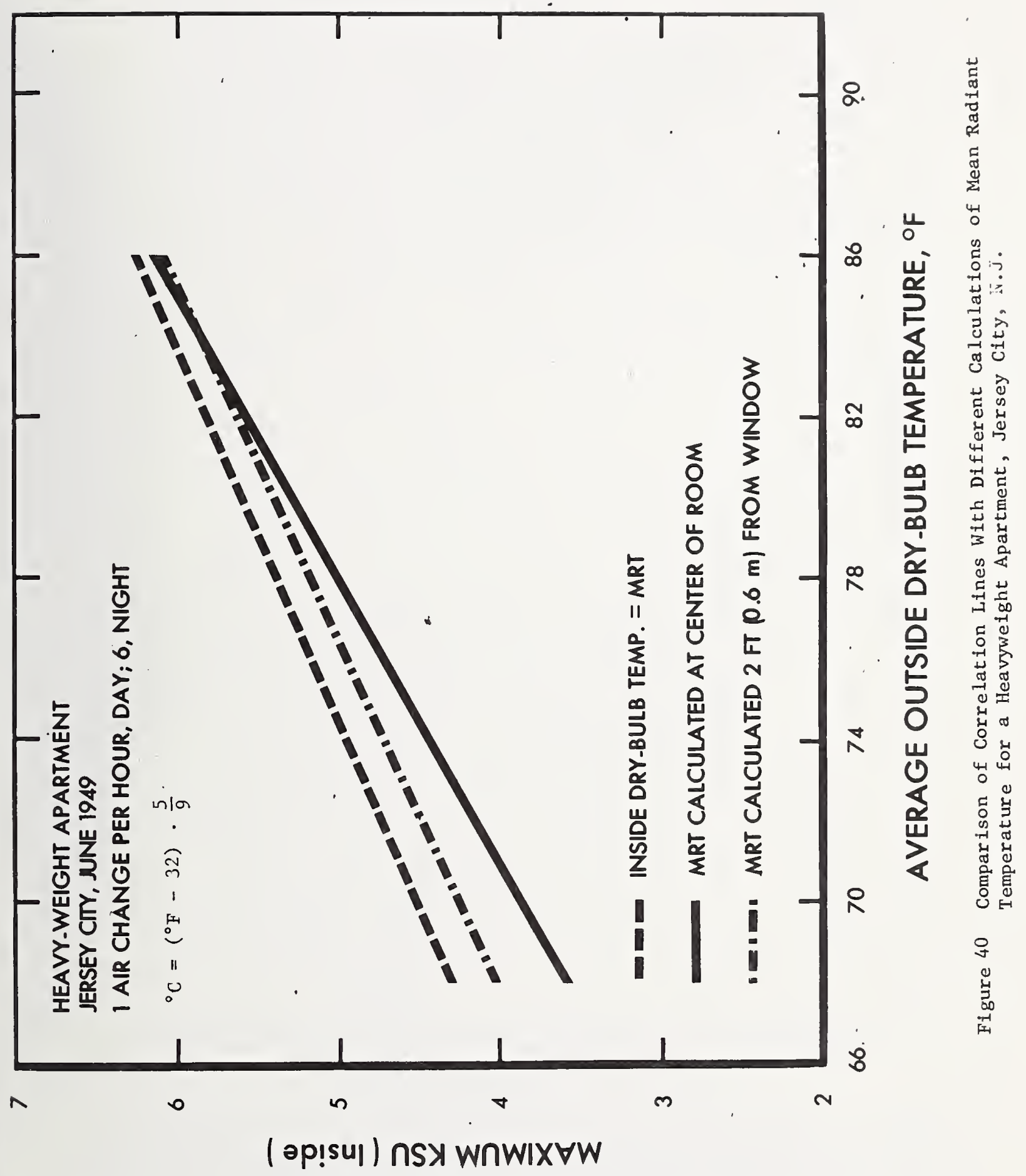




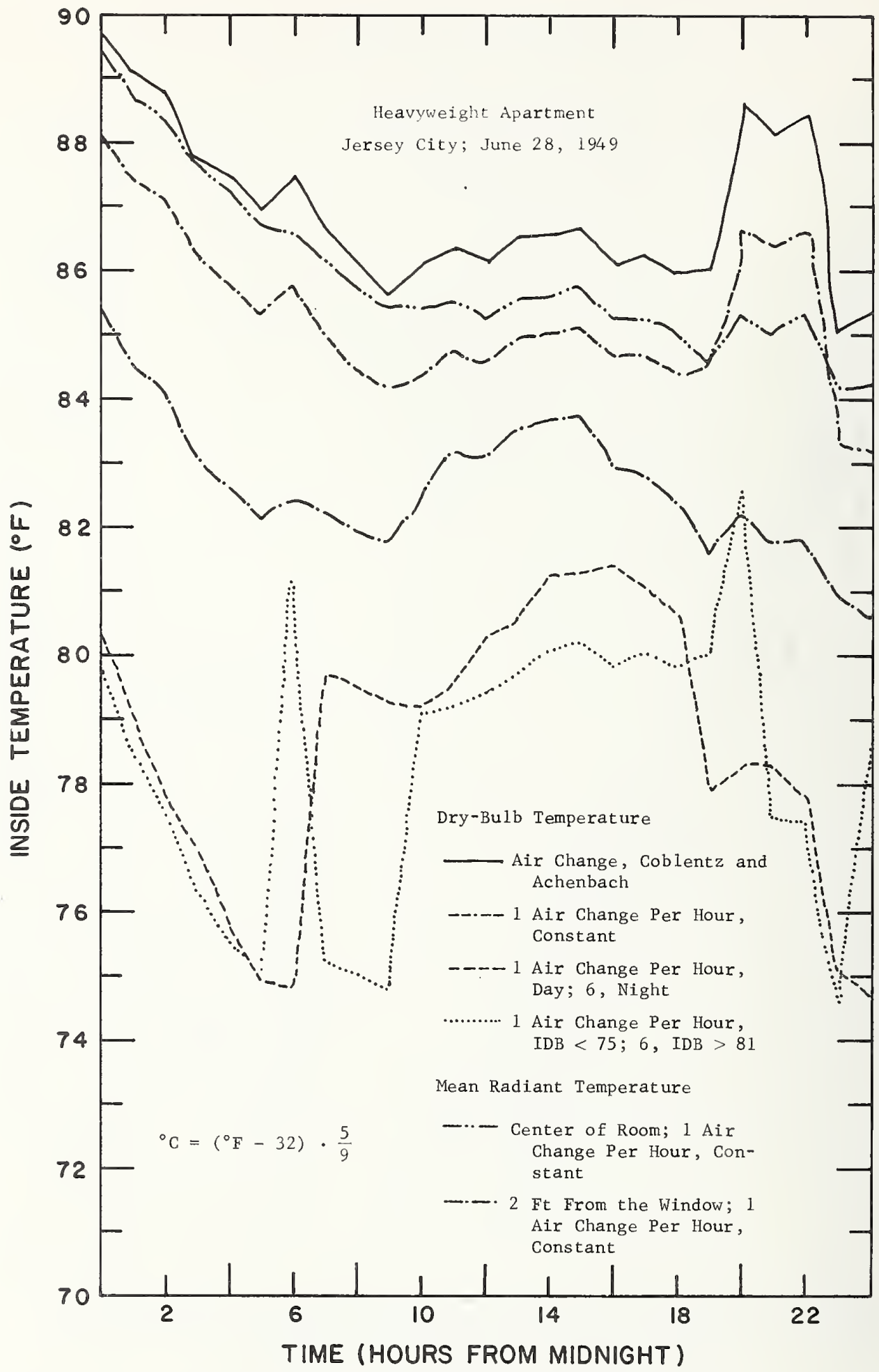

Figure 41 Comparison of Indoor Dry-bulb Temperature Profiles With Different Air Infiltration Assumptions for a Heavyweight Apartment, June 28, 1949, Jersey City, iT.J. 


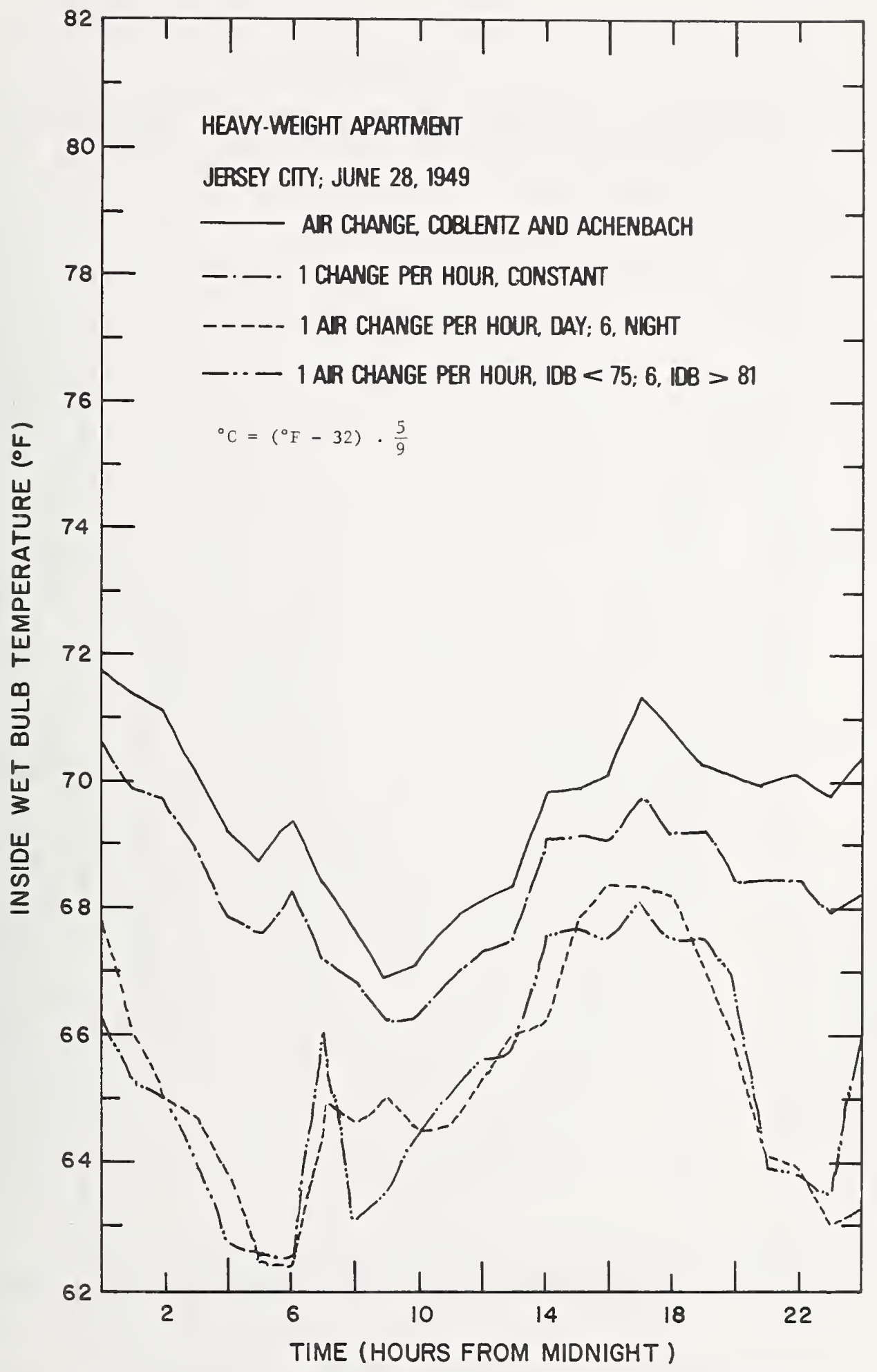

Figure 42 Comparison of Indoor Wet-Bulb Temperature Profiles With Different Air Infiltration Assumptions for a Heavyweight Apartment, June 28, 1949, Jersey City, N.J. 


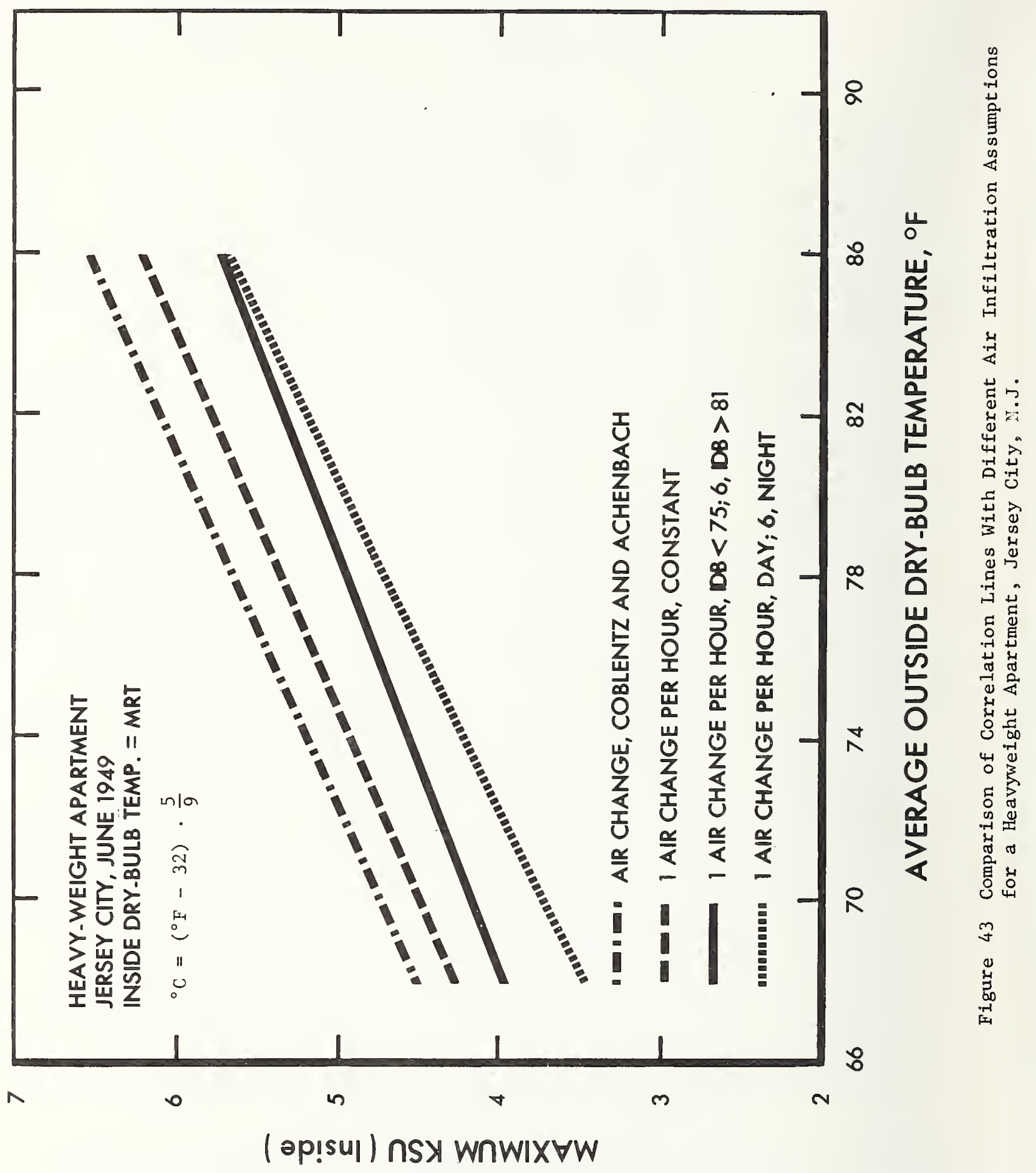




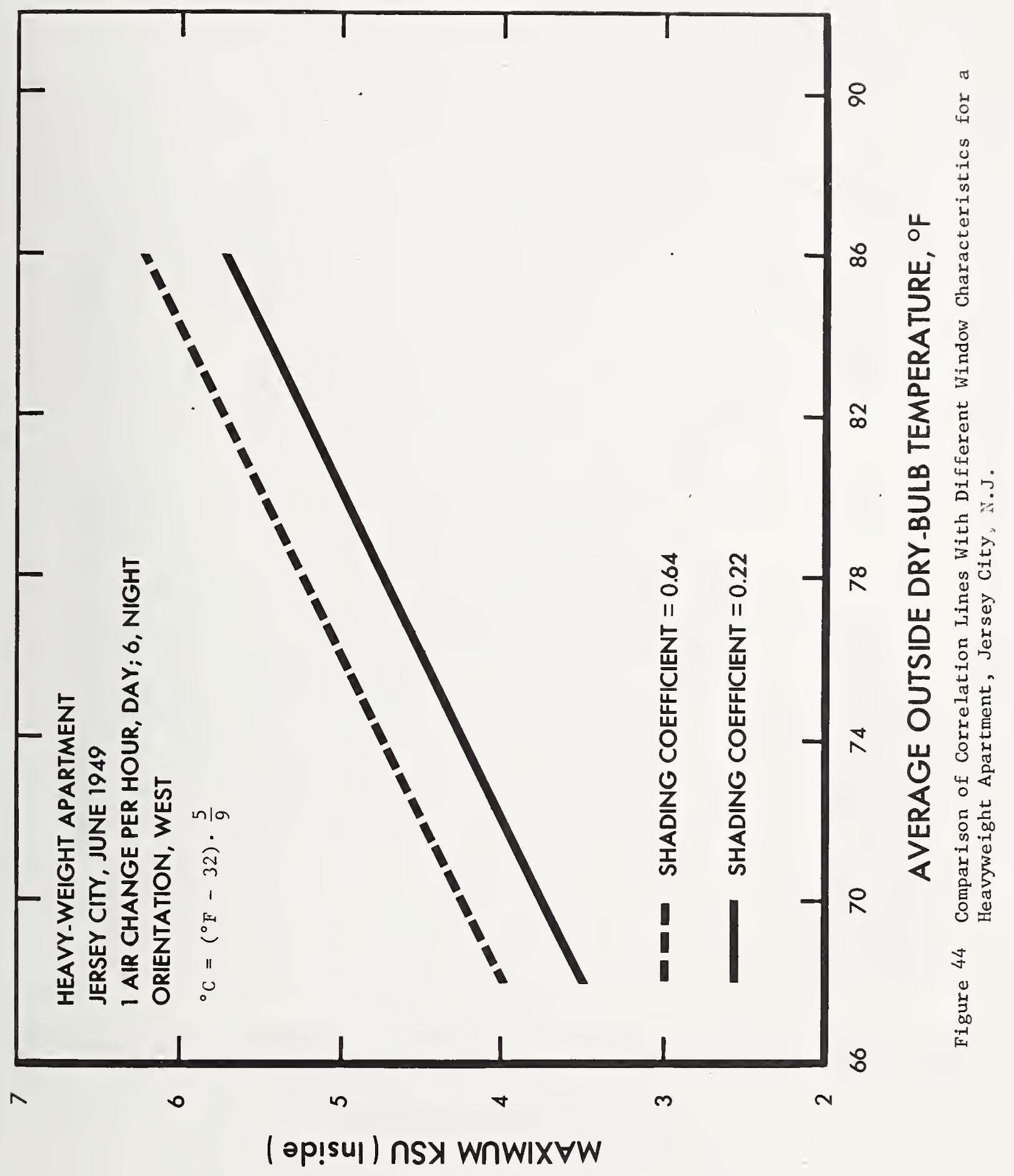




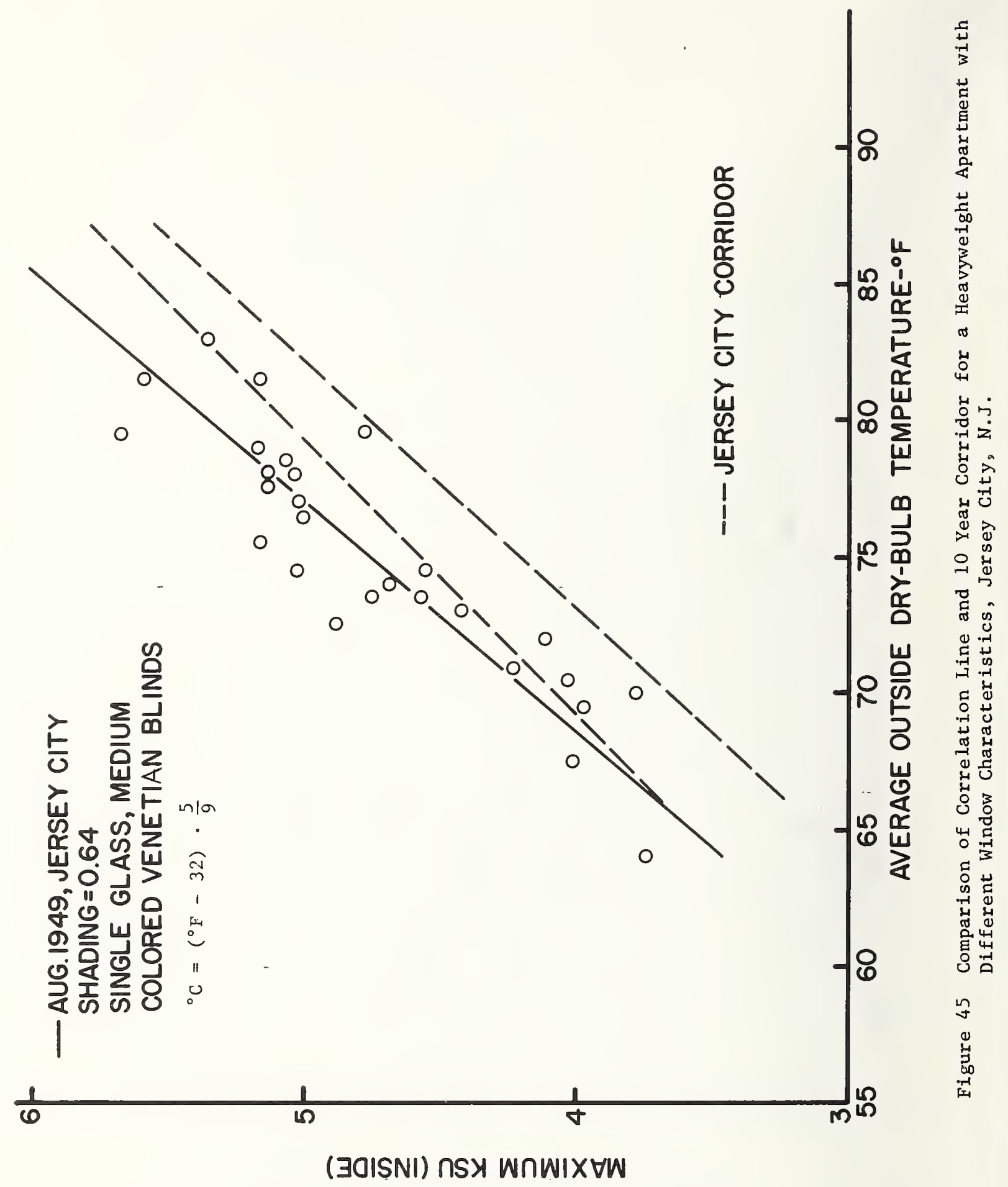




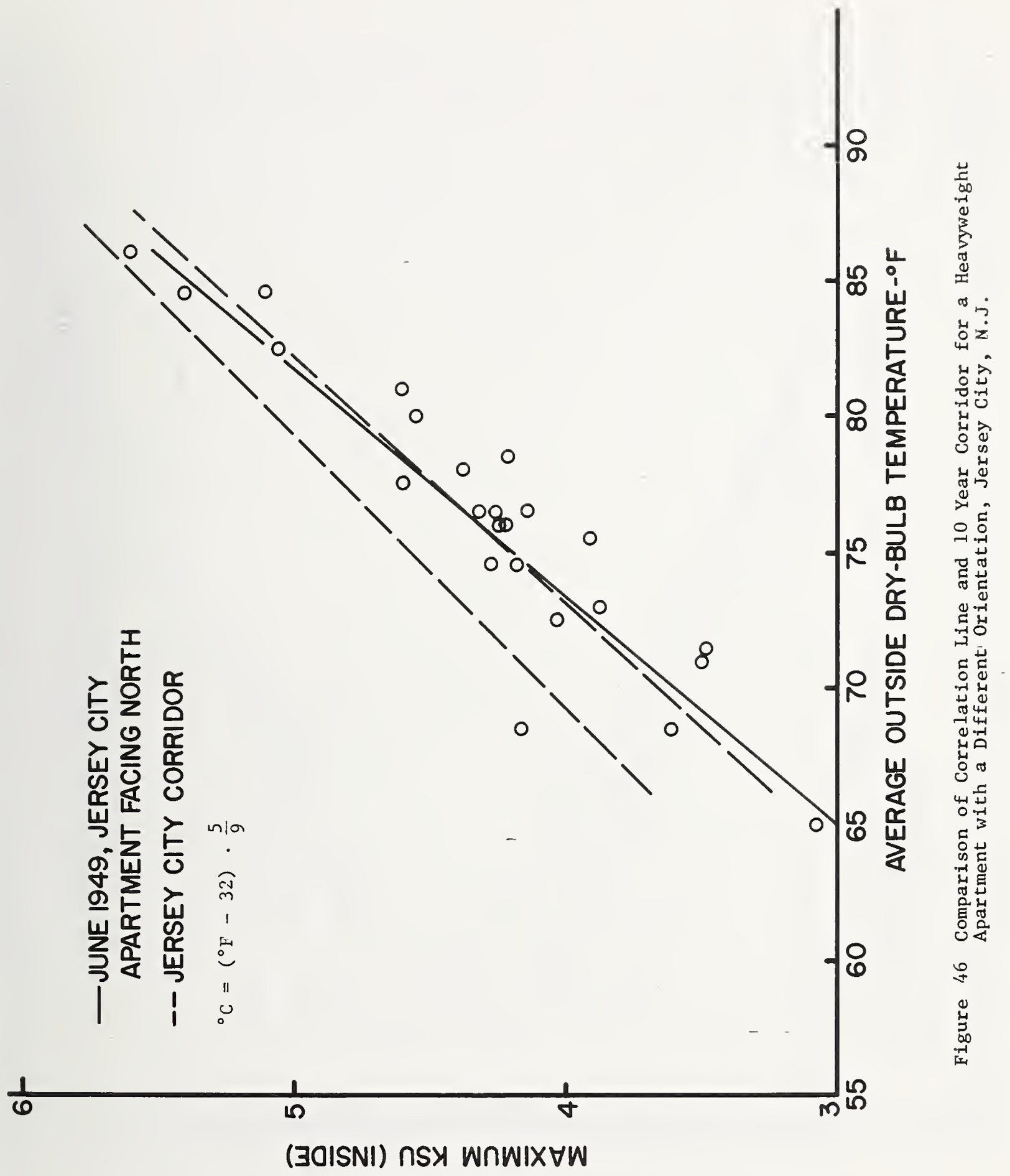




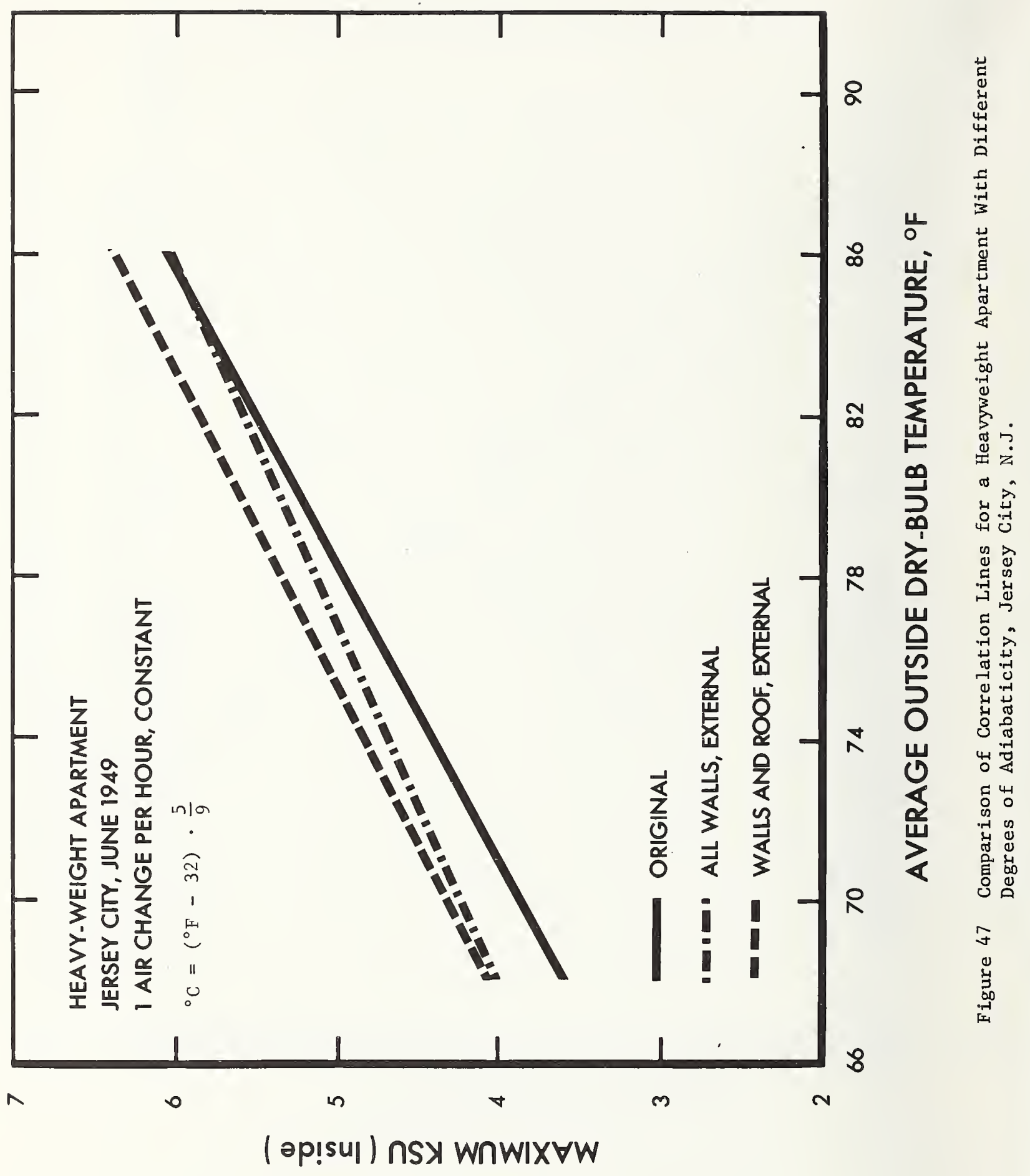




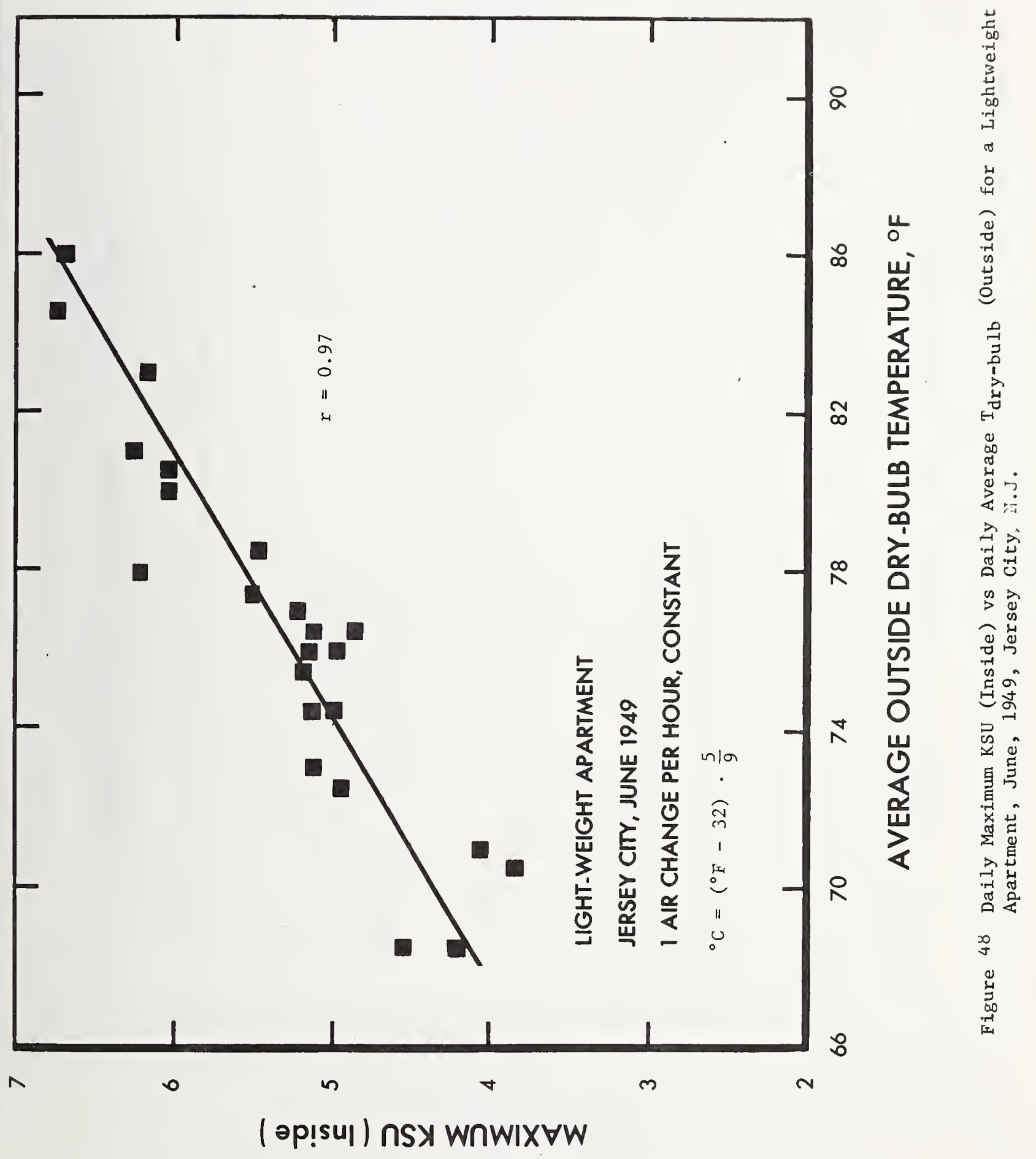




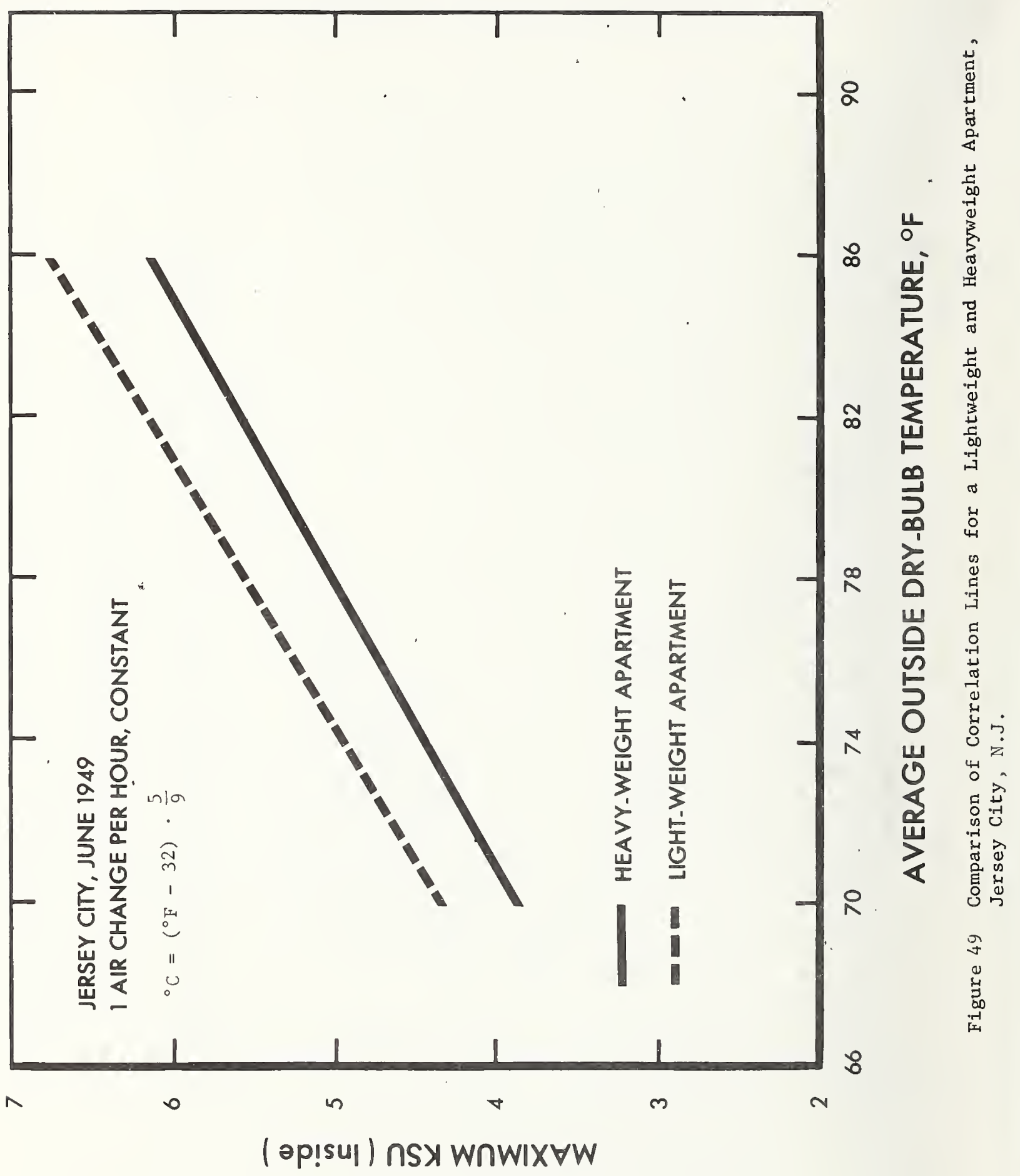




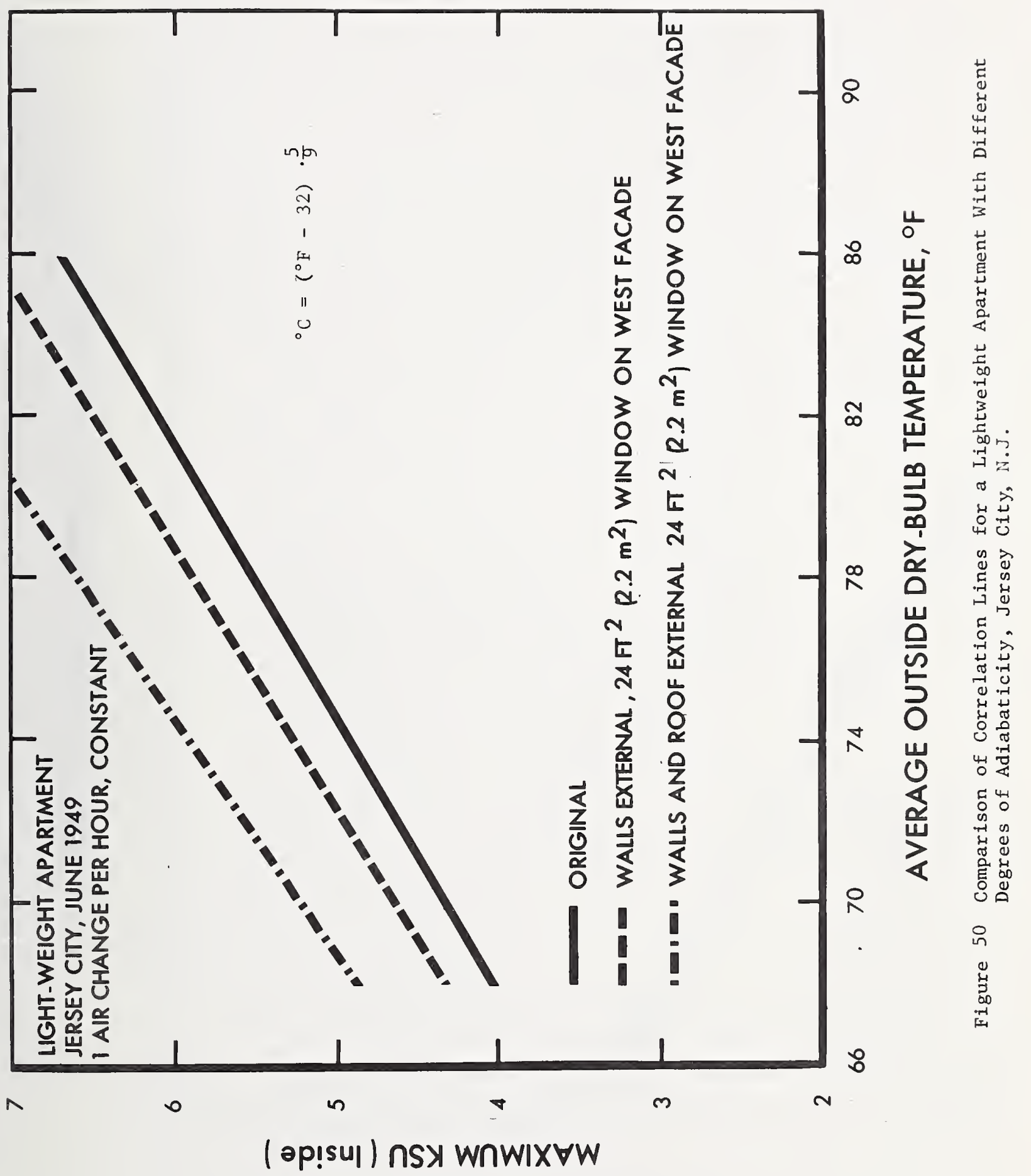




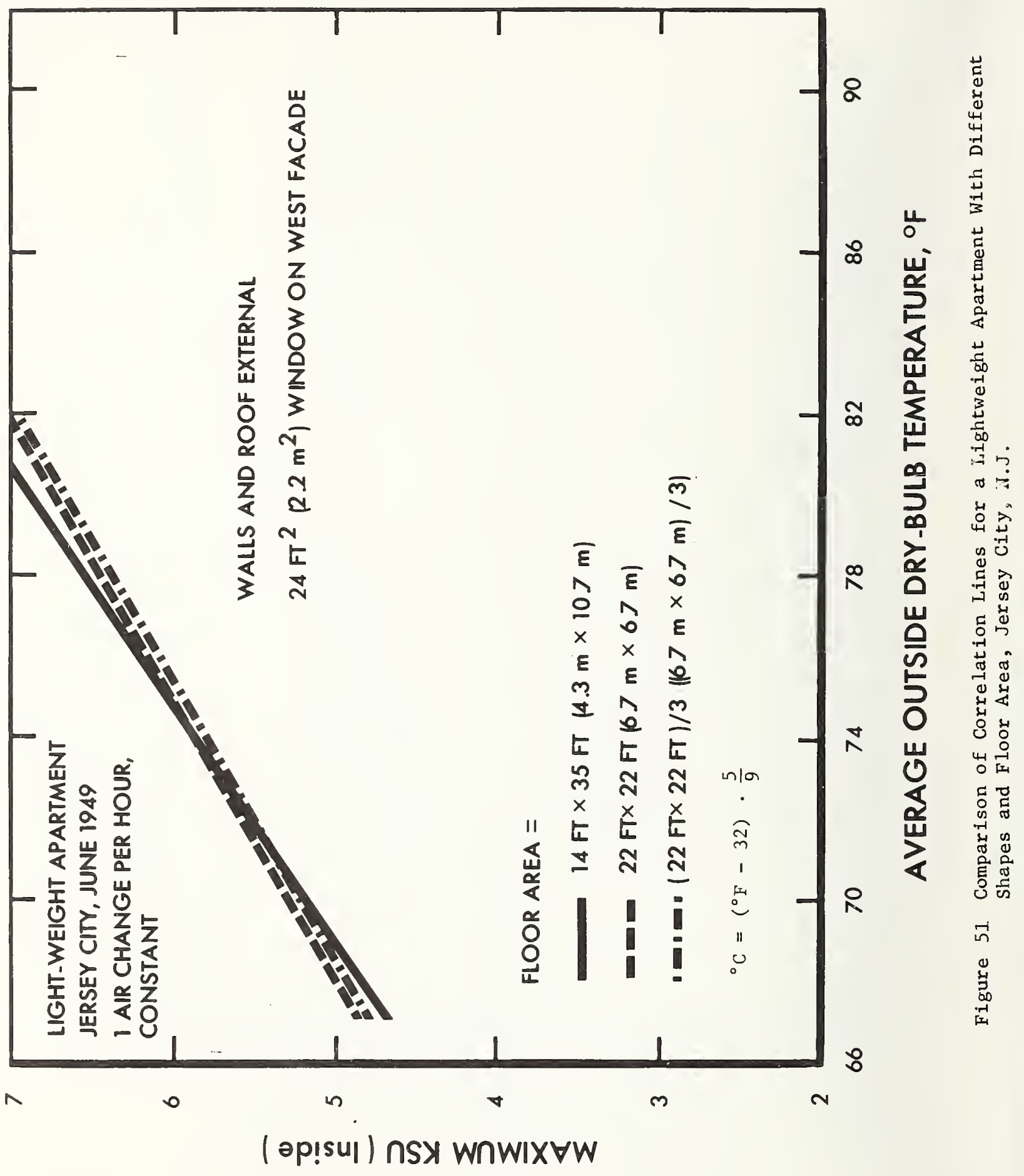




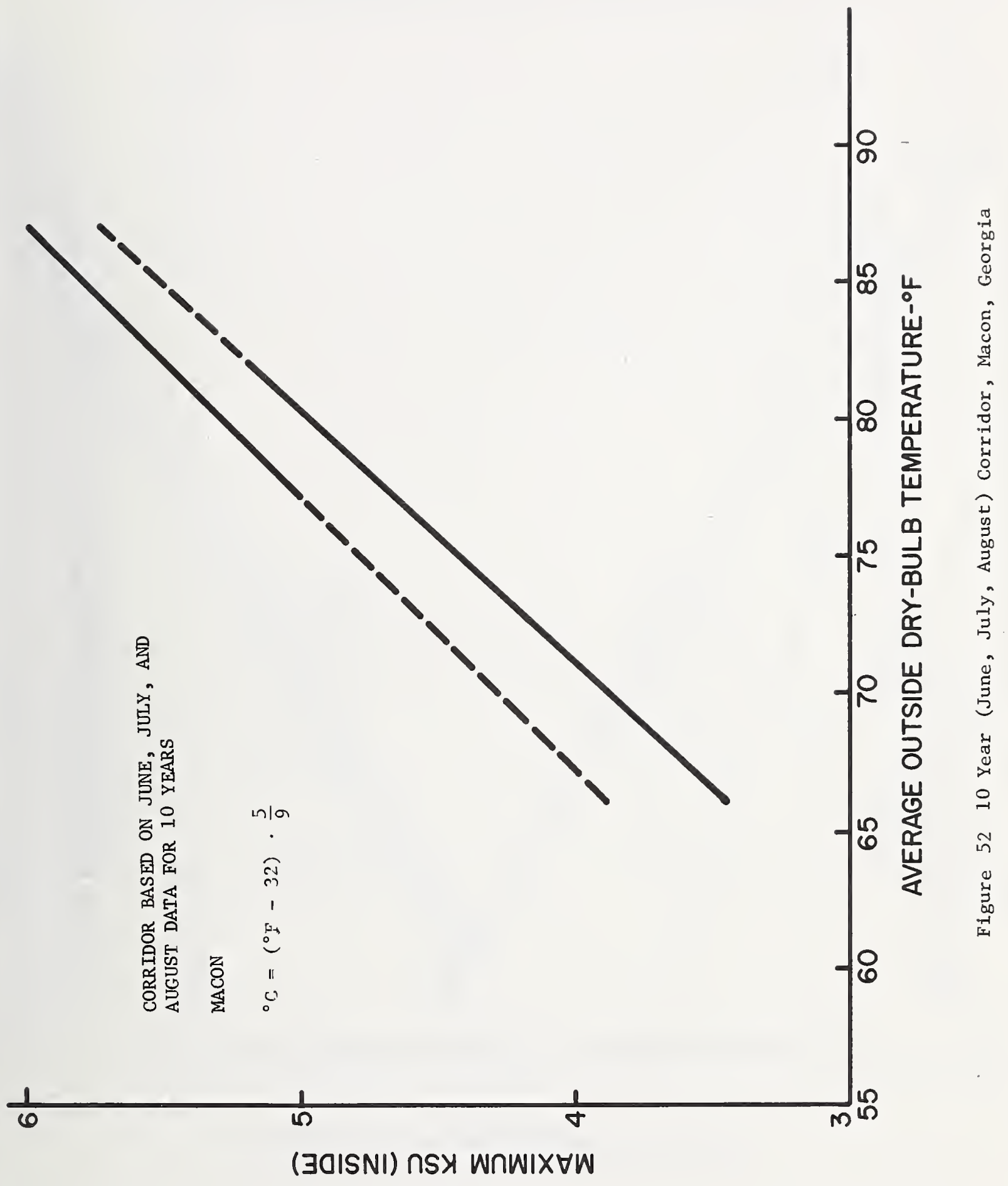




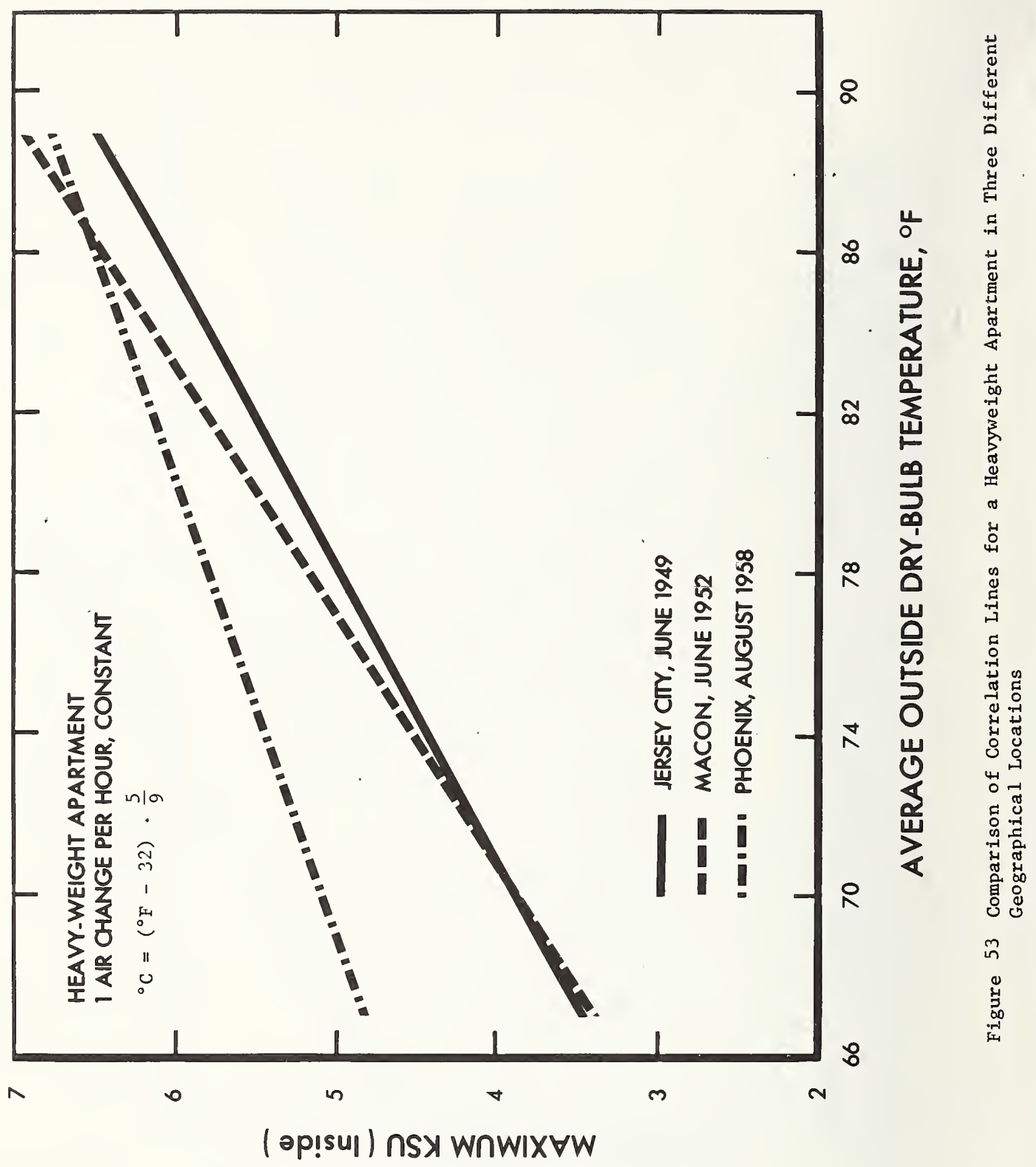




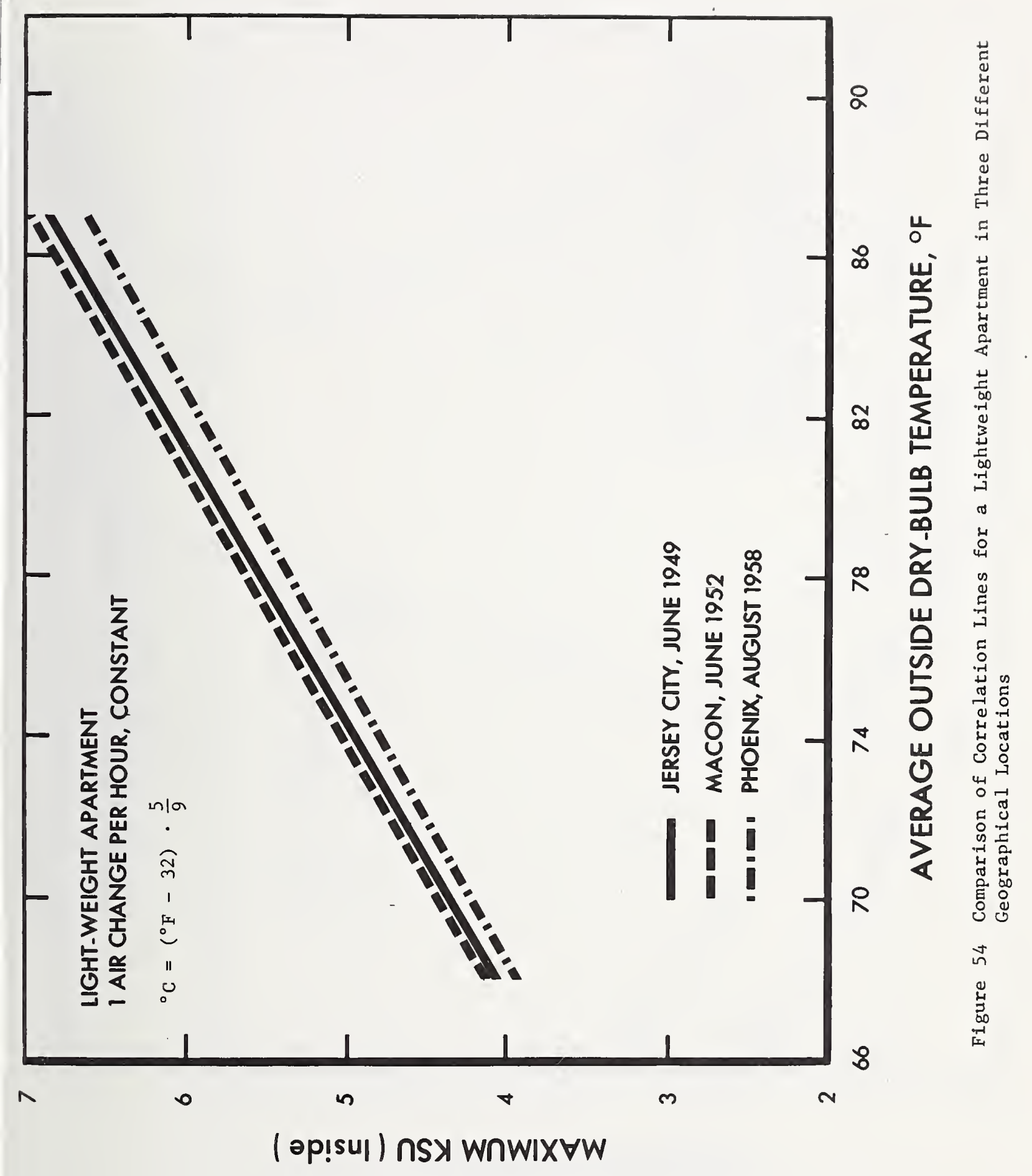




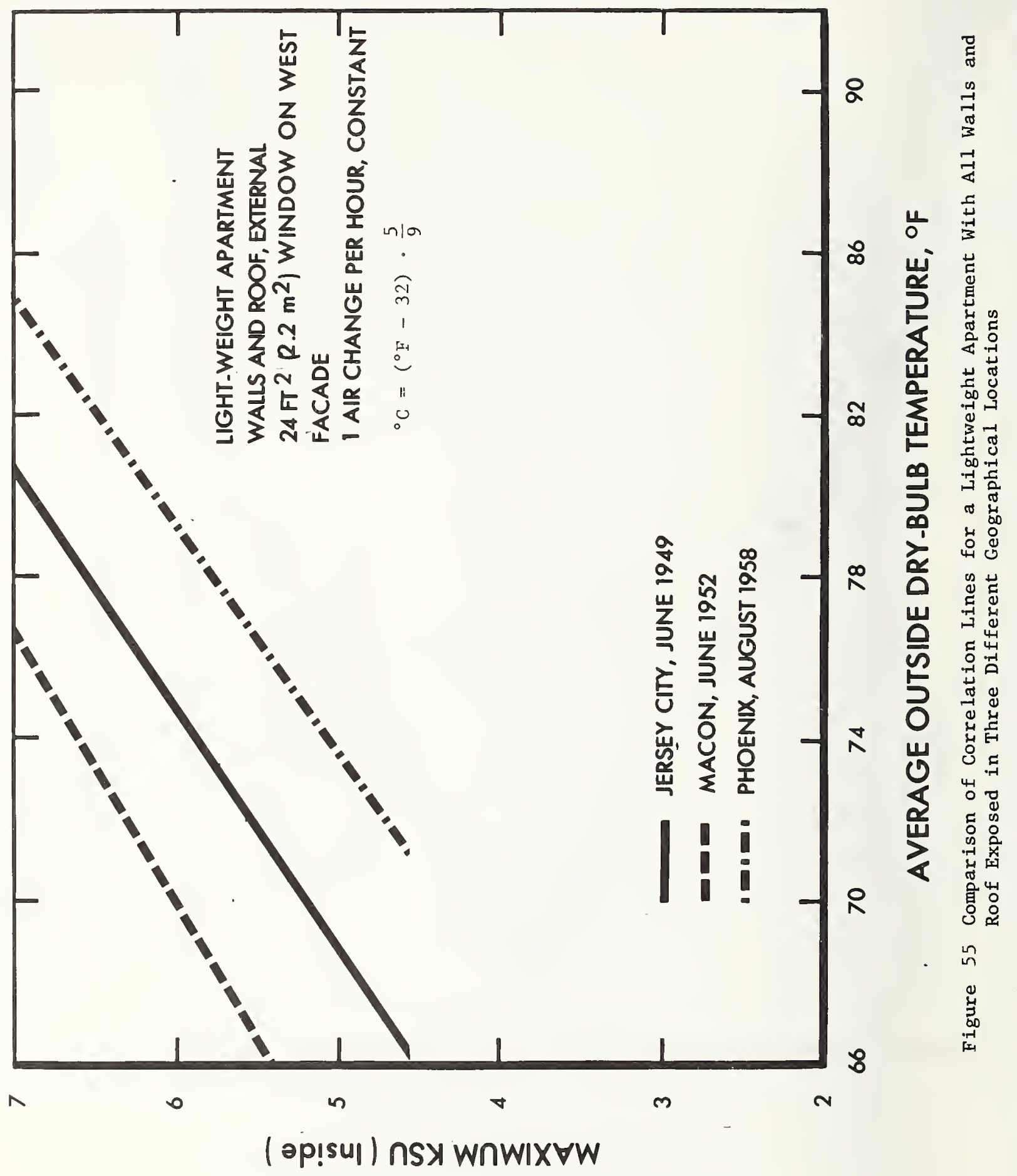




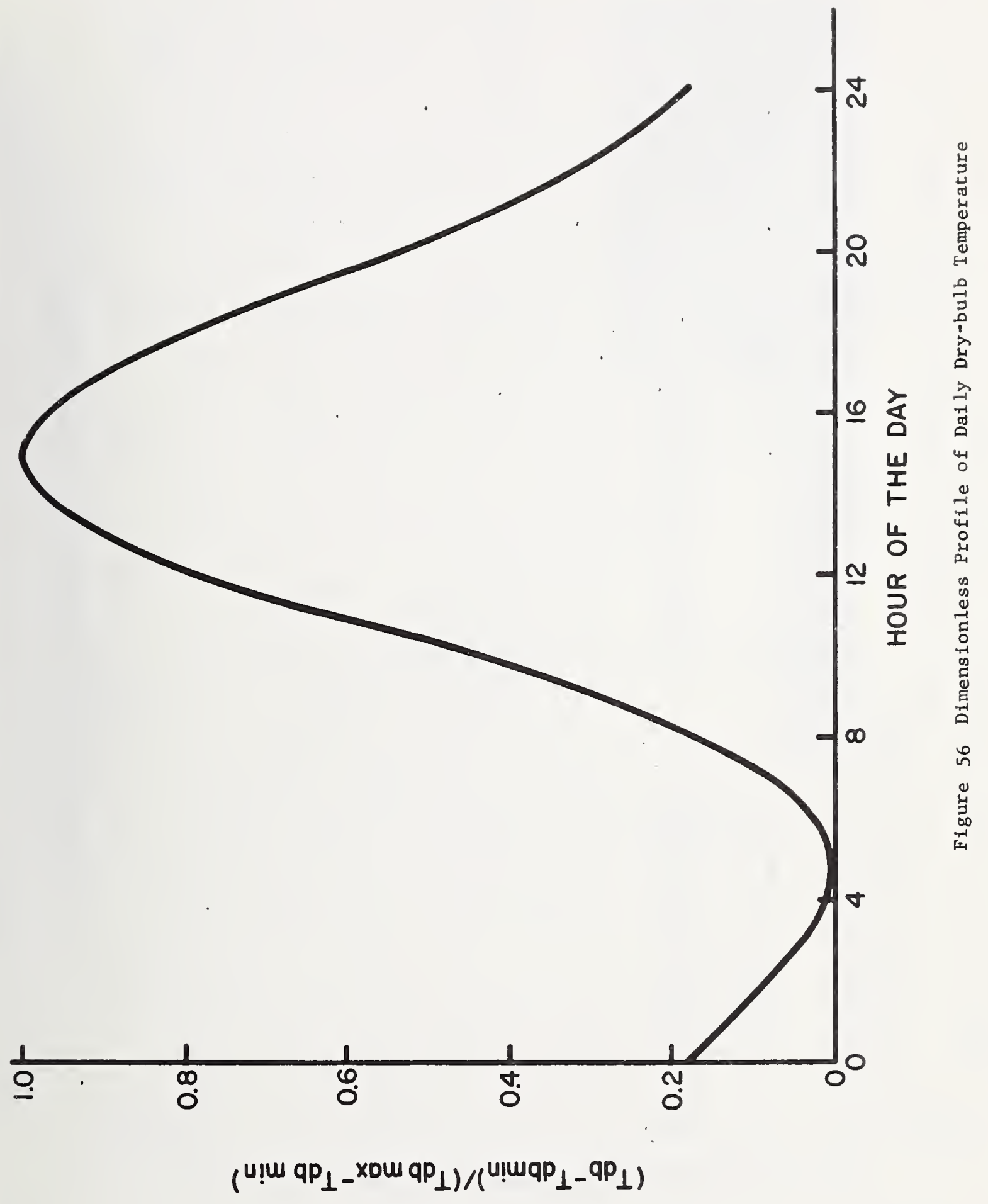




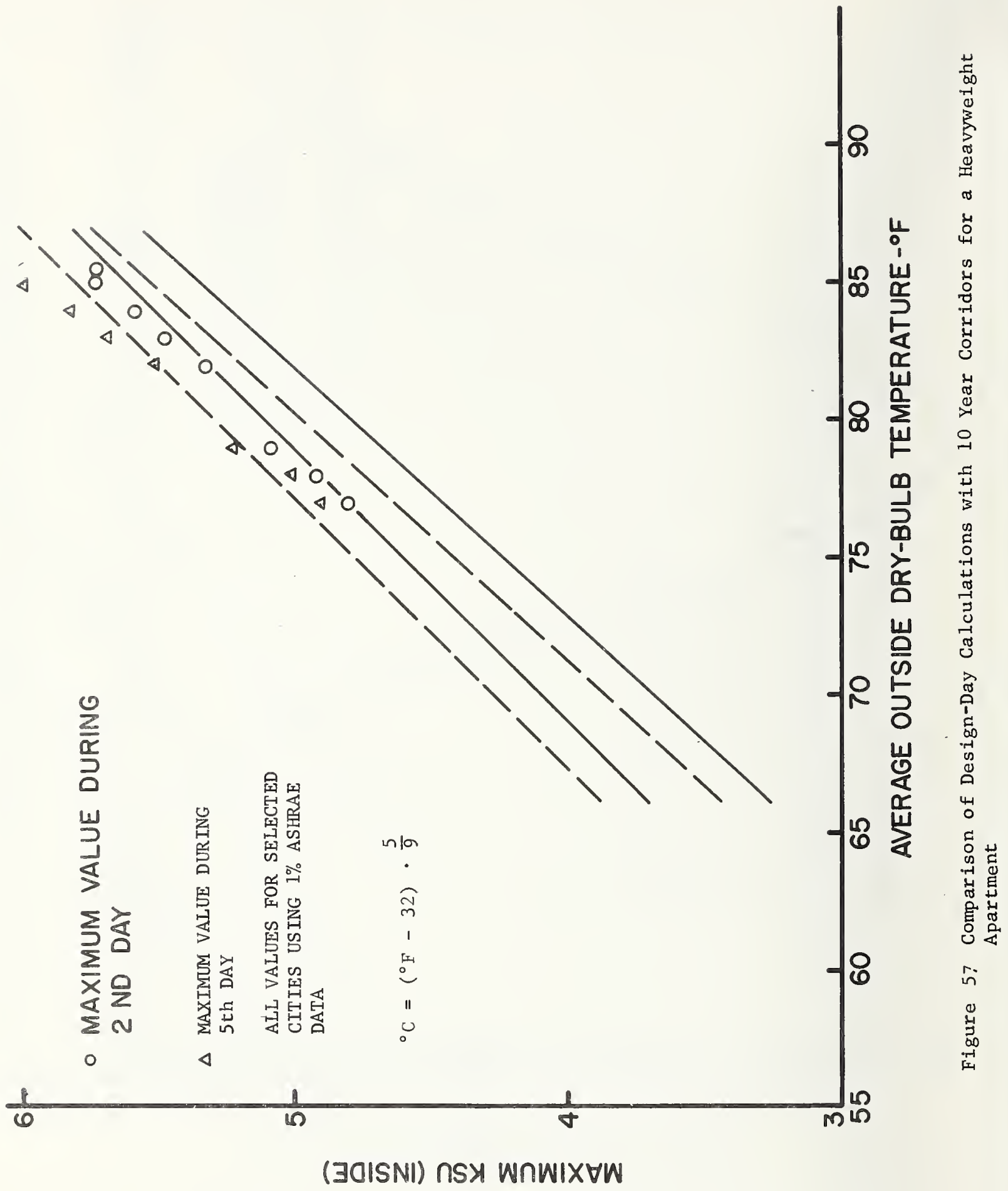




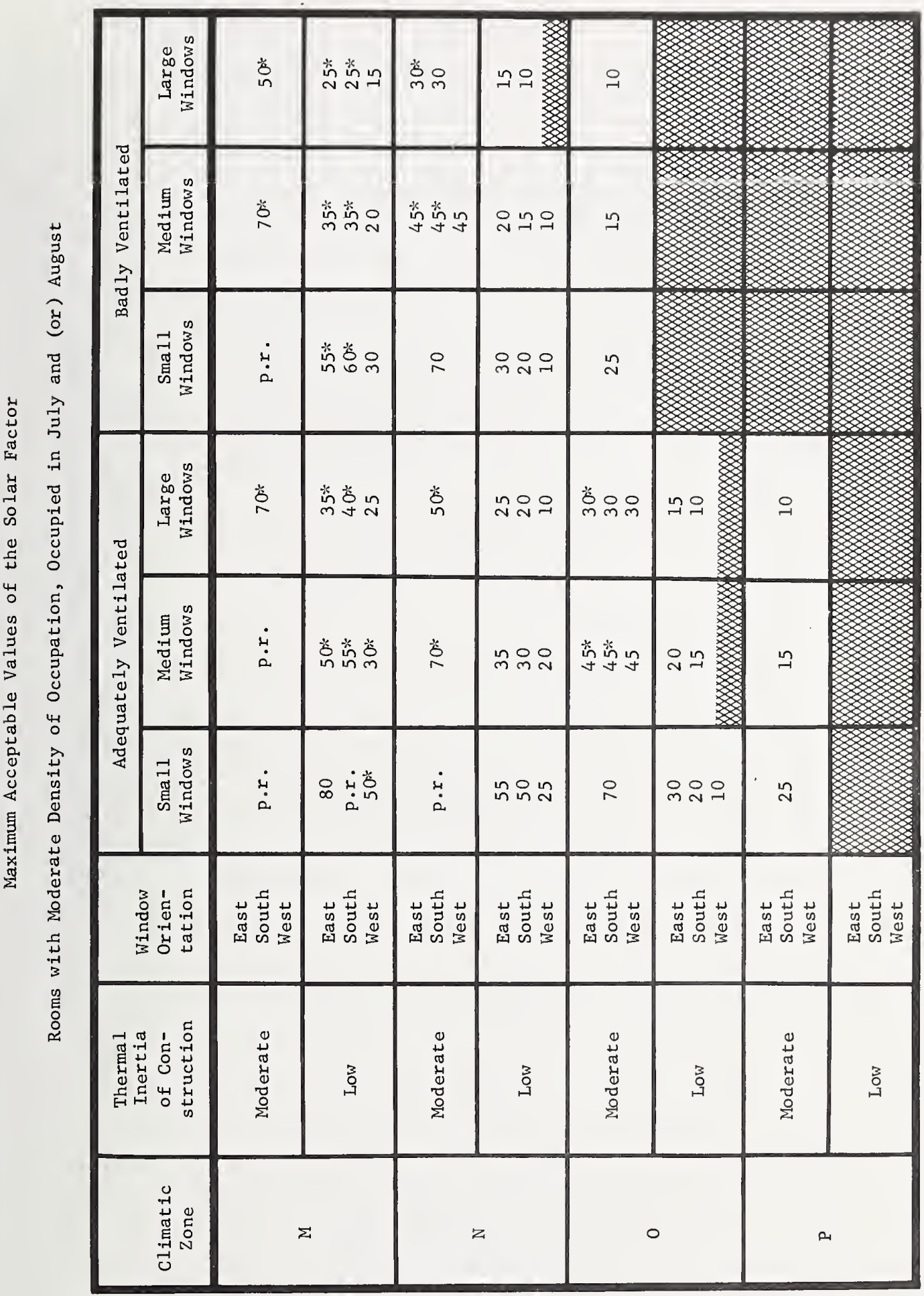


Table 2

Required Building Data for the "NBSLD" Calculations

- Individual room length, width, and height

- Occupant: number and hourly schedule

- Summer and winter design air infiltration rates

- For each exposure: (1) type (roof, wall, etc.)

(2) type or response factor to be used or specified U-value

(3) area

(4) orientation

(5) absorptivity to solar radiation (if opaque surface)

(6) shading coefficient (if transparent surface)

Properties of all building materials 
The abbreviations used in Tables $3-6$, besides those that are clearly defined, are:

E. Wall : Exterior wall

I. Wa1l : Interior wall or partition

P. Wall : Party wall

B. Floor: Basement floor

B. Wall : Basement wall

I. Door : Interior door

E. Door : Exterior door 


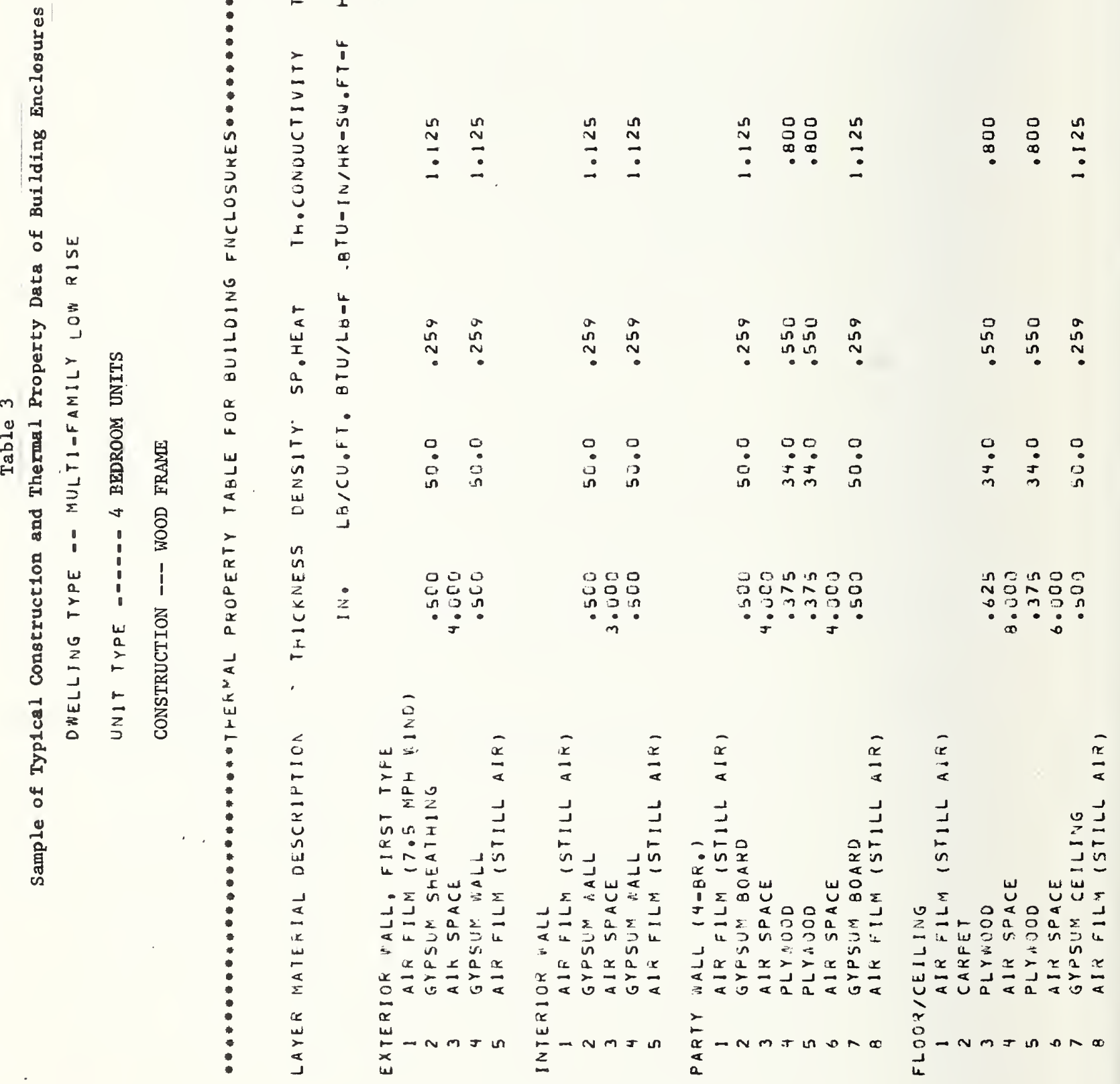




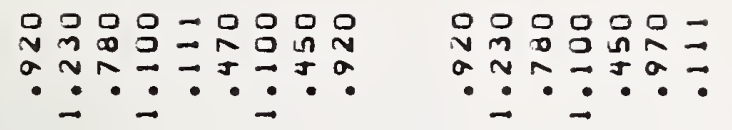

$\underset{3}{5}$

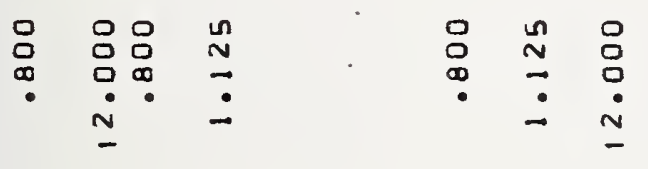

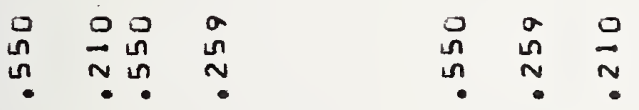

ช્త

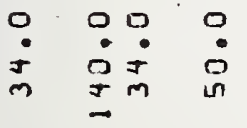

$\begin{array}{lll}0 & 0 & 0 \\ = & 0 & 0 \\ m & 1\end{array}$

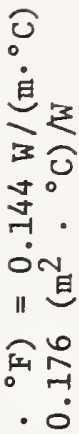

(⿻)

4 II

4
4

$\frac{\Sigma}{i n}$

نे

क

: F

is

$\stackrel{0}{0}$

L.

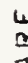

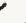

$\therefore 4$

मे

$\Sigma$

-

ว

里

$\frac{x}{4}$

-1 -1

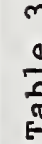
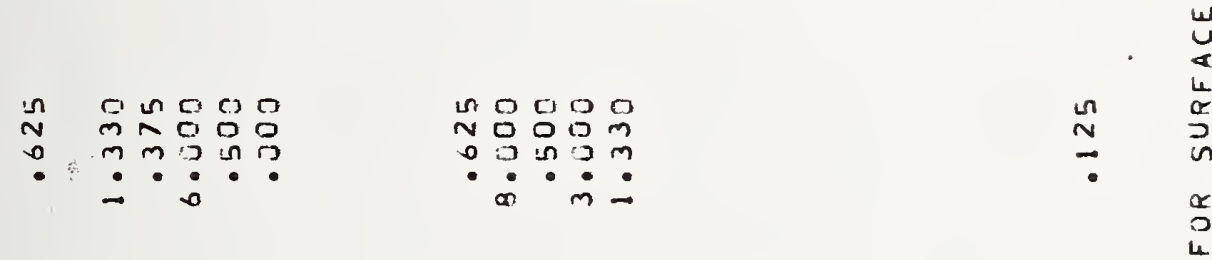

a.
0
2
2
0
0
0

$m$

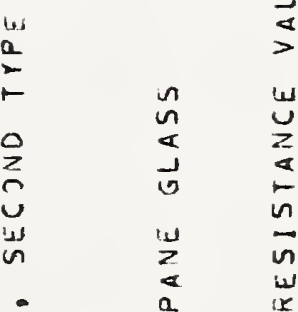

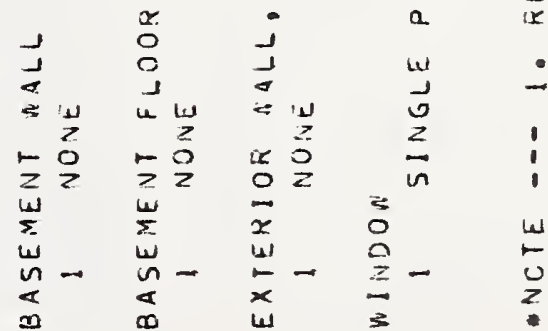

E

เี 11 玒

ข

○.

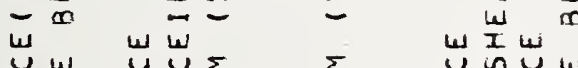

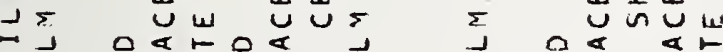
w口-0

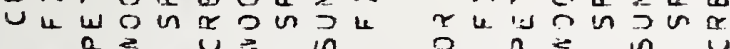
$x x x \geq x \geq>x a x$ a $x \geq x>x x \geq$

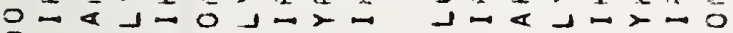

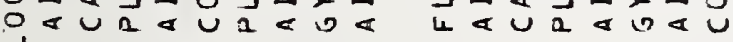
1.

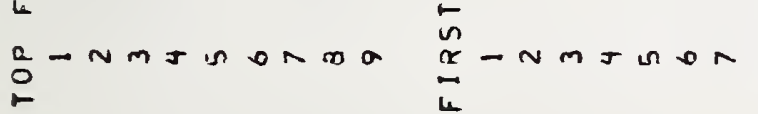




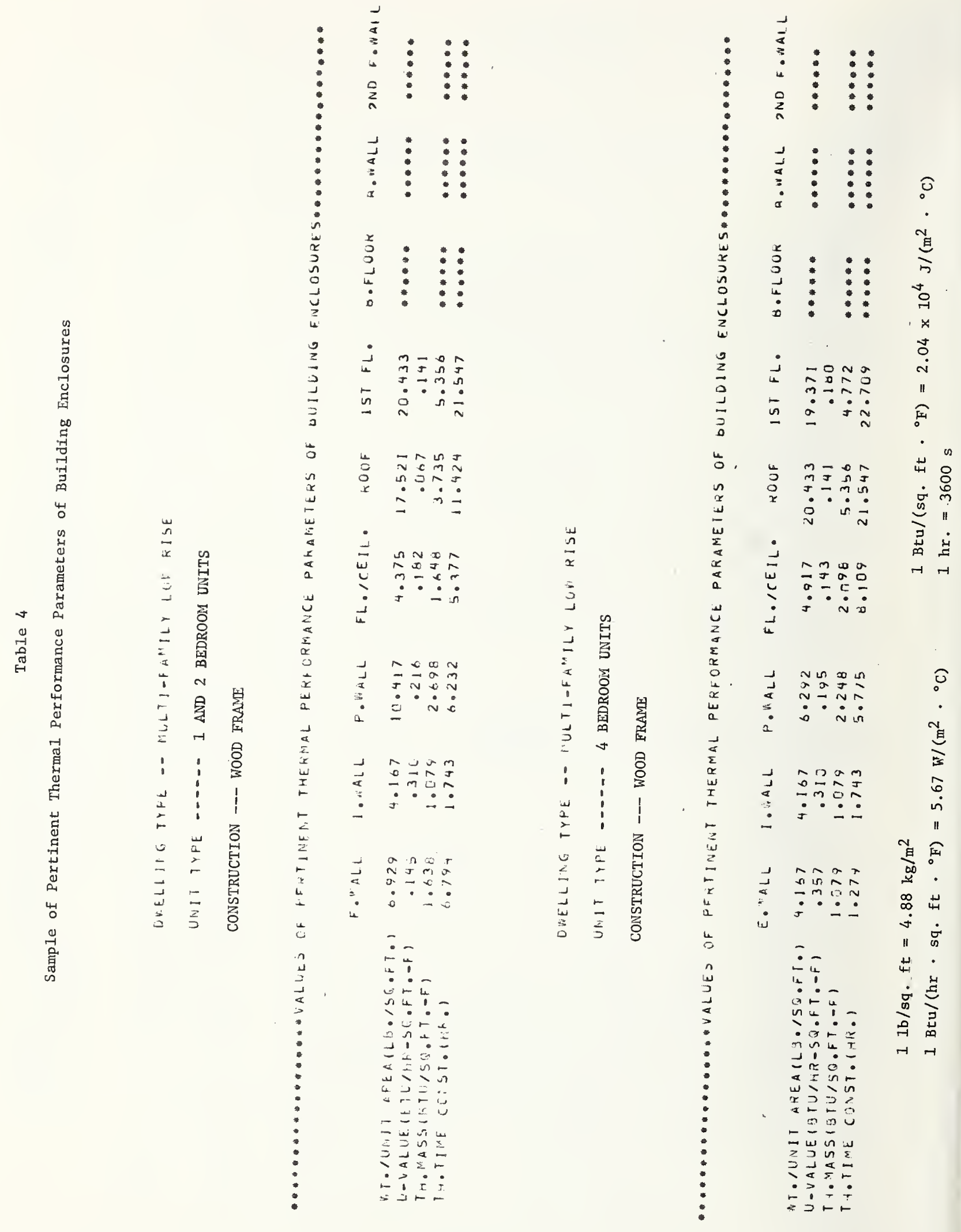




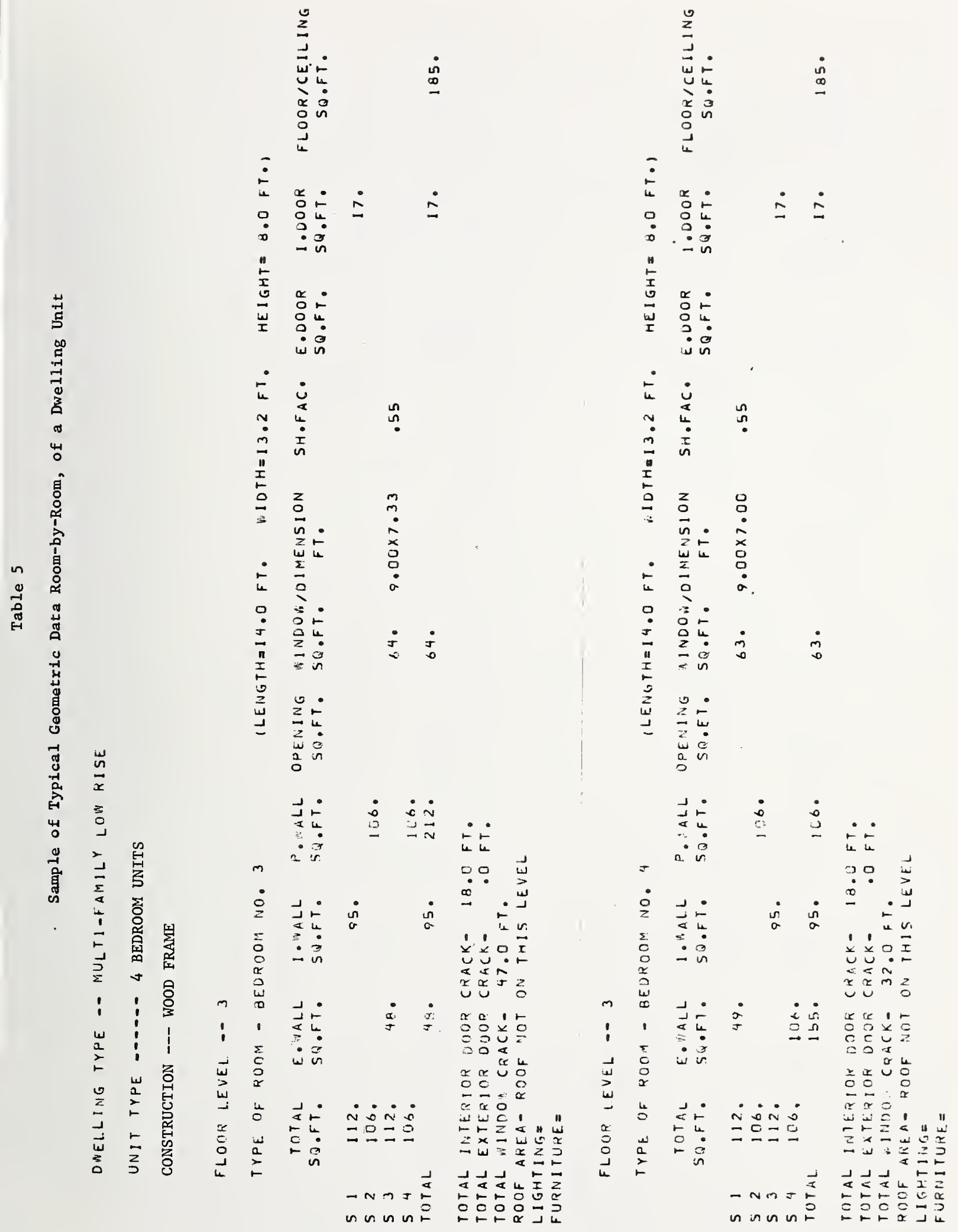




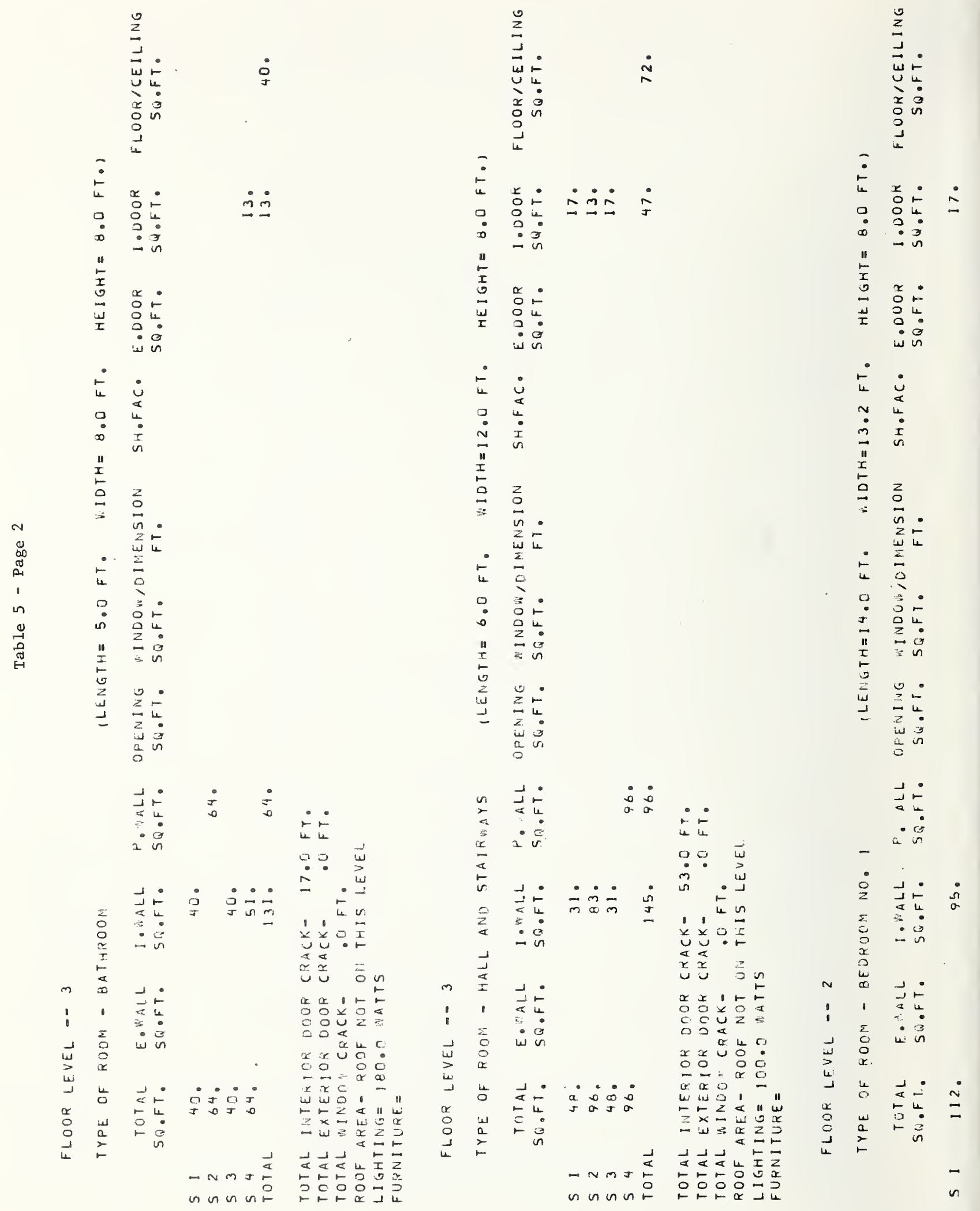



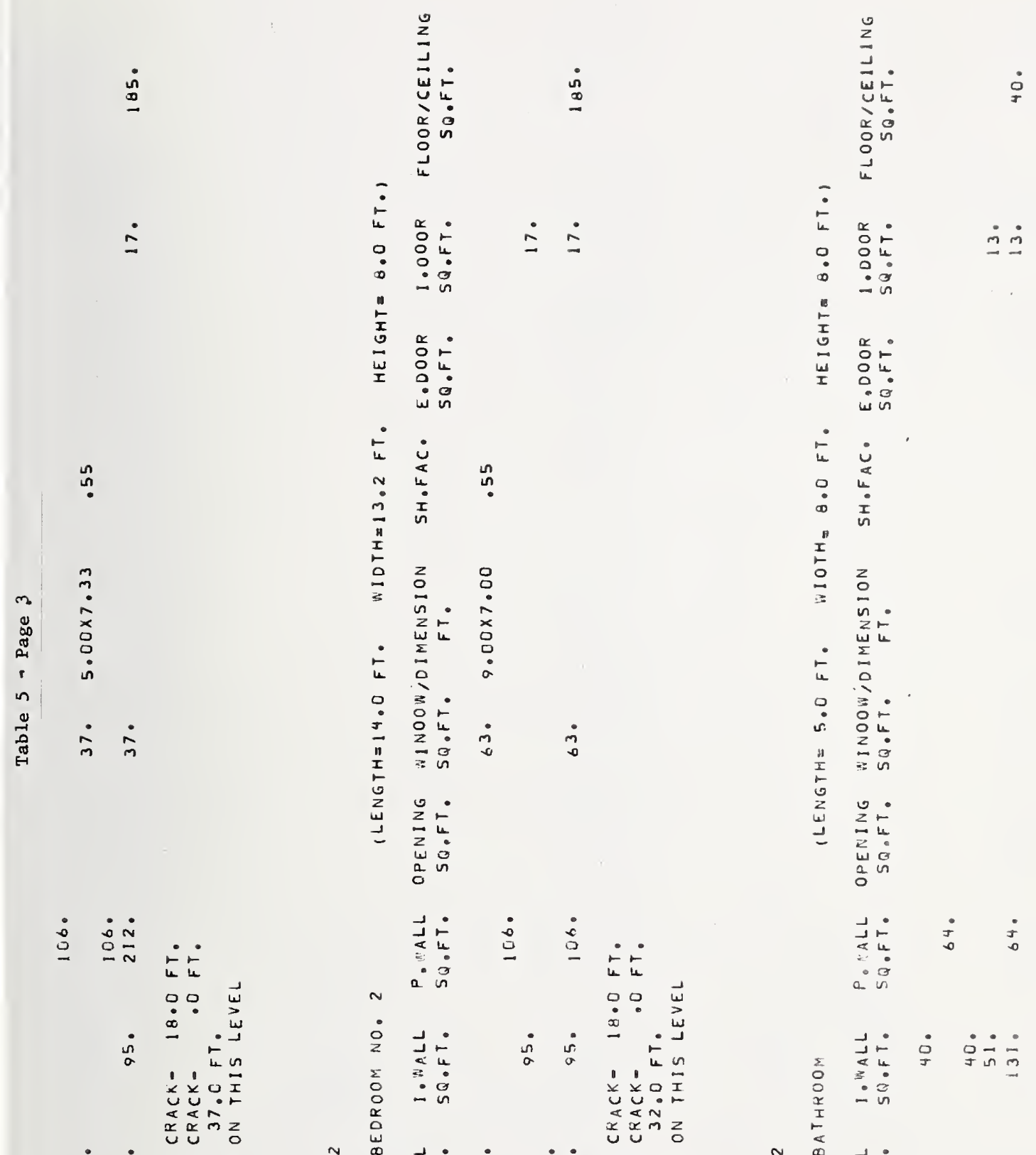

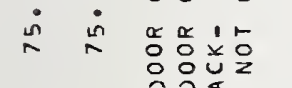

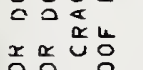
$\begin{array}{lll}x & 0 \\ 0 & 0 & 0 \\ 0 & 0\end{array}$

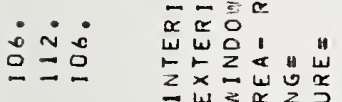

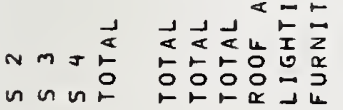

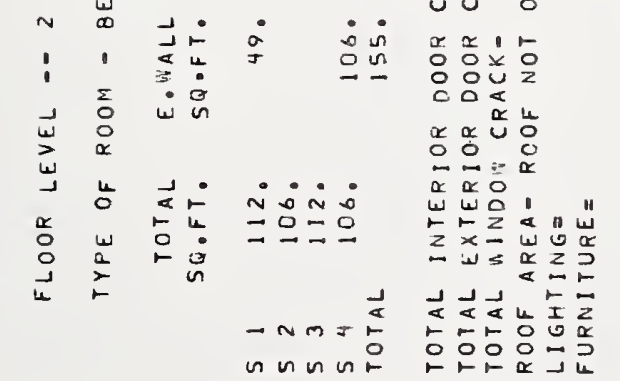




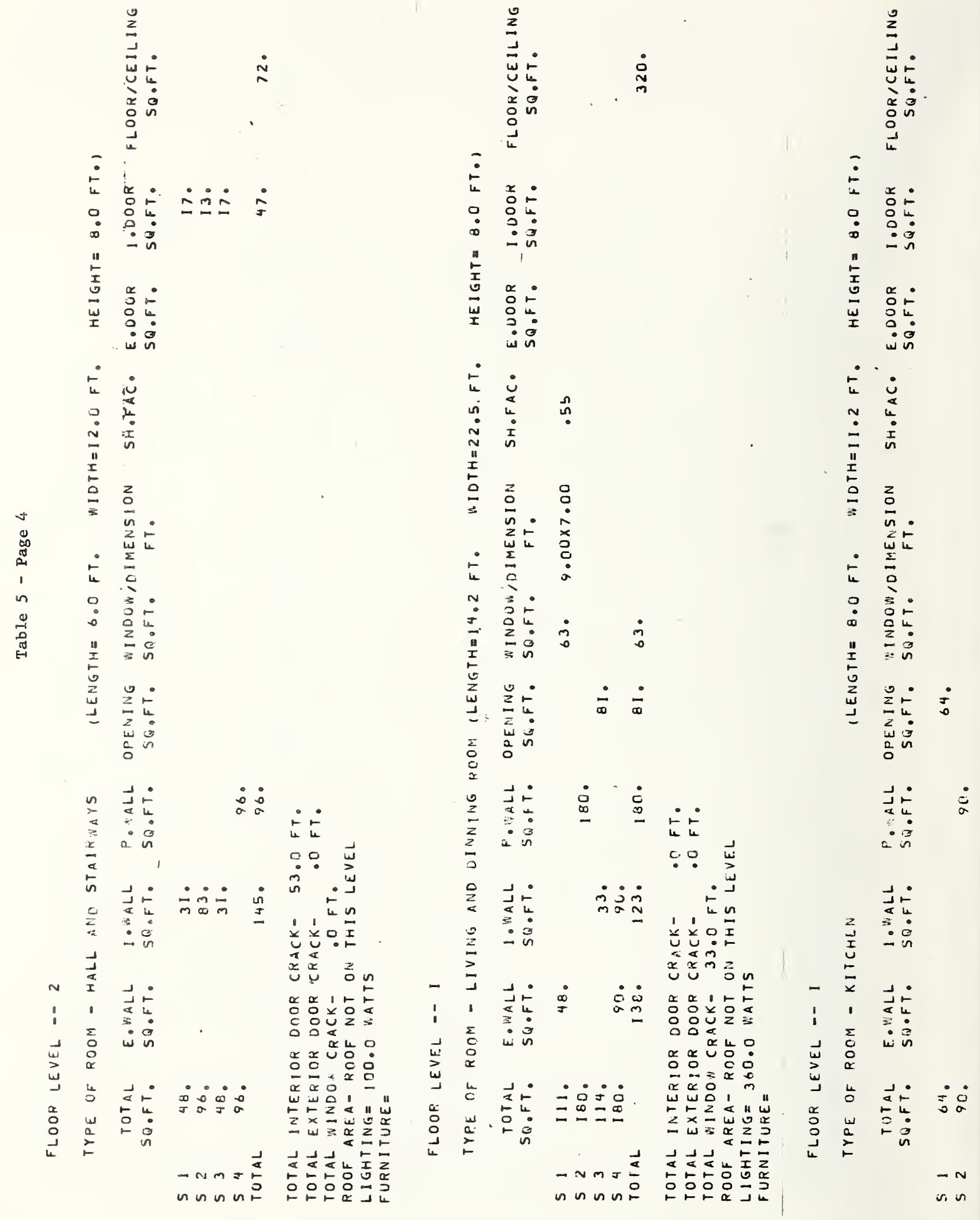



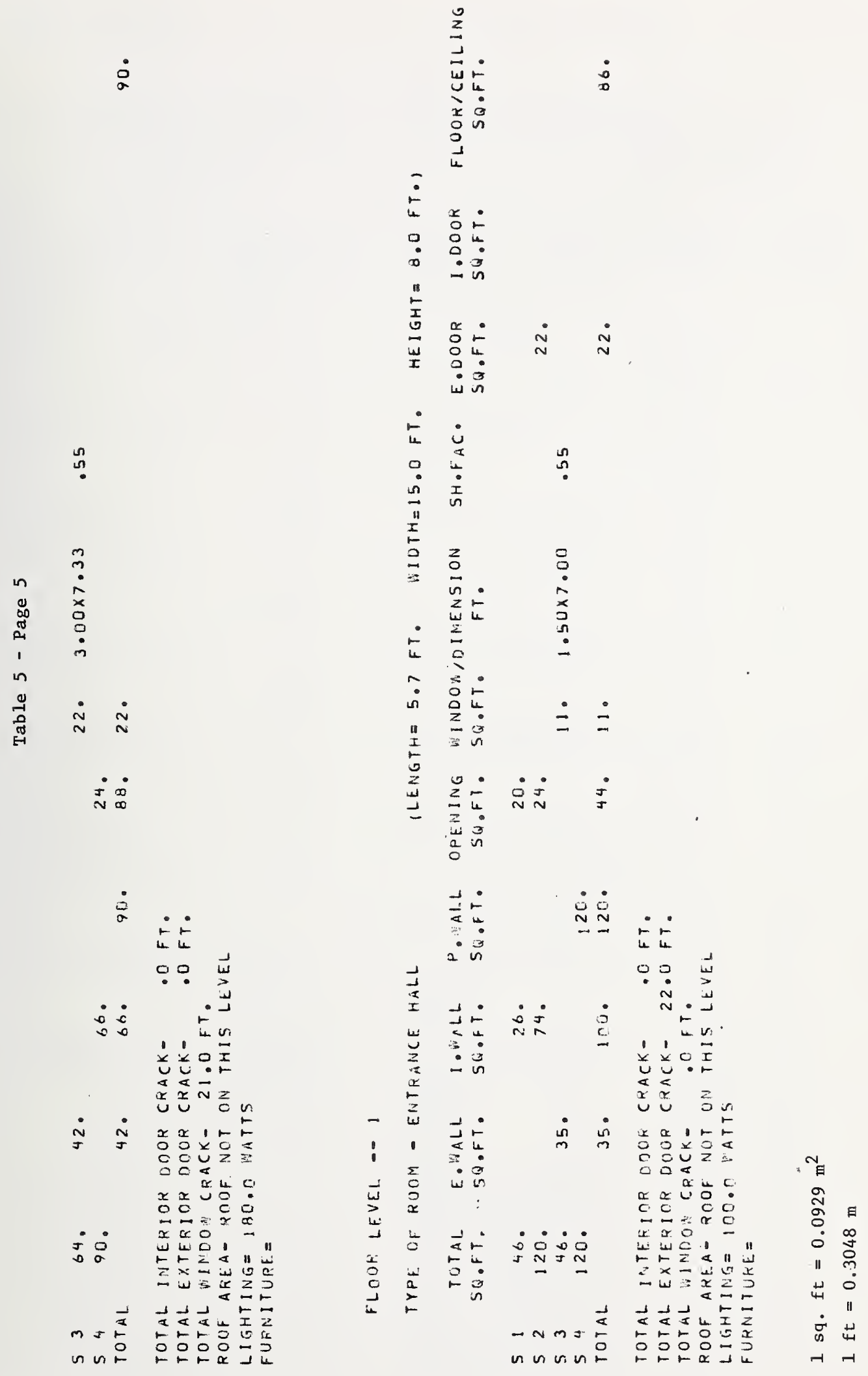


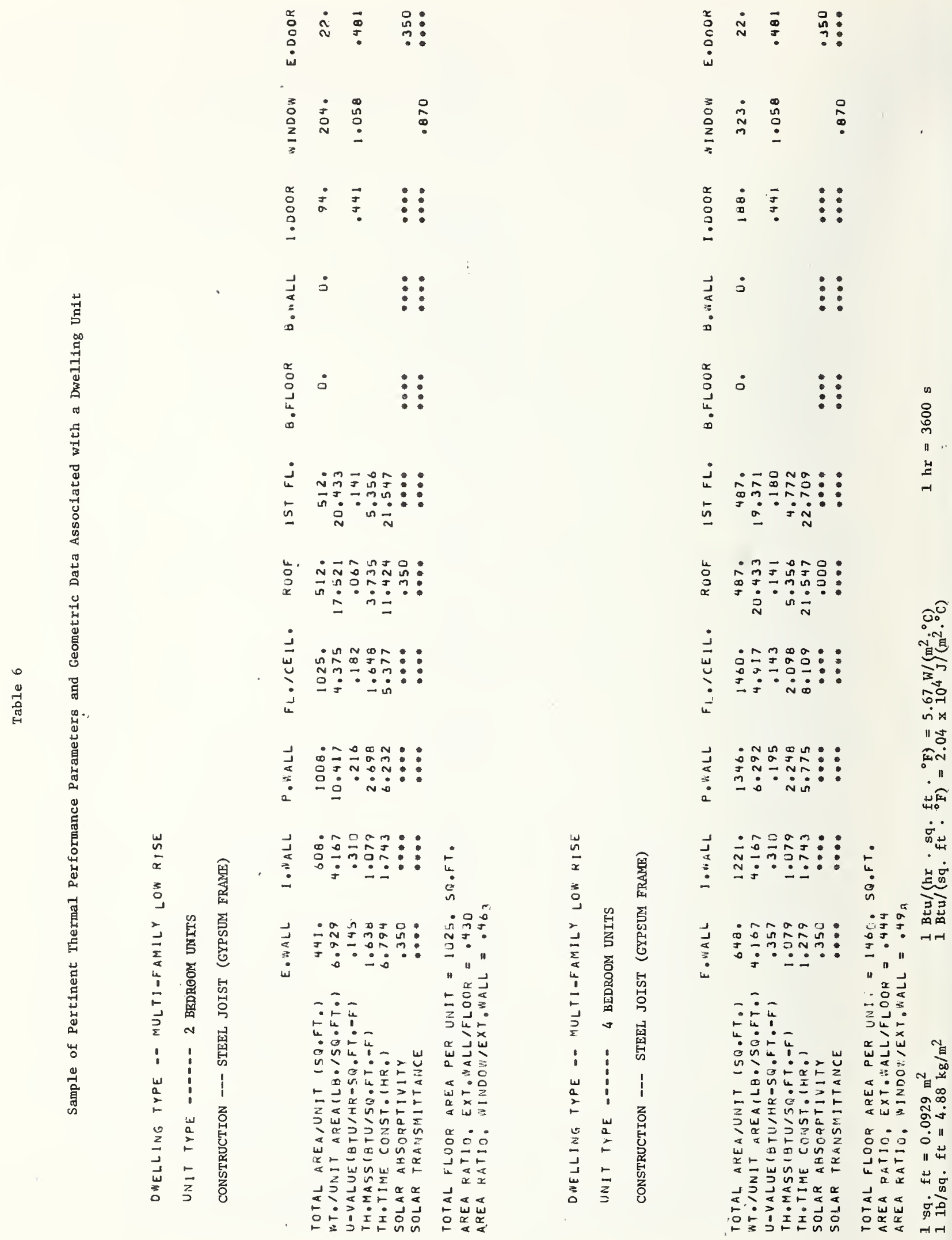


Table 7

Summary of Simulation Results for a Heavywelght Apartment in Jersey City, New Jersey

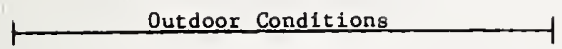

Indoor Cond1tions

$\begin{array}{cl}\text { Month } & \text { Total No. of Hours } \\ \text { and } & \text { in } 4 \text { Months } \\ \text { Year } & T_{\text {dry-bulb }} \geq 80^{\circ} \mathrm{F} \\ & \left(26.7^{\circ} \mathrm{C}\right)\end{array}$

1949

June

July

August

September

1950

June

July

August

September

1951

June

July

August

September

1952

June

July

August

September

1953

June

July

August

September

1954

June

July

August

September

1955

June

July

August

September

1956

June

Ju1y

August

September

1957

June

$\mathrm{July}$

August

September

1958

June

July

August

September

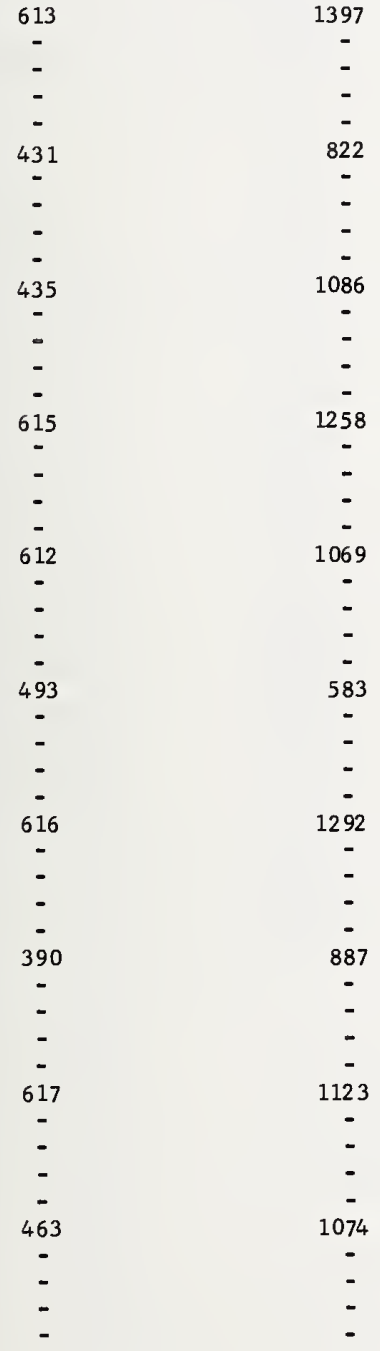

Percent of

Percent of Percent of ET $\geq 81$

Time New
ET $\geq 85$ I Ime KSU $\geq 5$ $\mathrm{T}_{\text {wet-bulb }} \geq 67^{\circ} \mathrm{F}$ $\left(19.4^{\circ} \mathrm{C}\right)$

$\begin{array}{cc}\text { Time PMV } & \text { Percent of } \\ 21 & \text { Time } \\ (0.25 \mathrm{clo}) / & \text { HSI } \geq 40\end{array}$

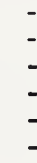

11.7

20.3

9.9

5.8

9.2

30.6

22.6

0.8

18.9

60.8

20.6

3.3

24.3

42.5

20.8

17.9

8.7

22.8

8.1

3.1

4

4.7
70.8

51.2

0.0

-

10.5

21.5

2.4

-

36.2

17.5

11.9

1.0

43.3

28.1

3.7

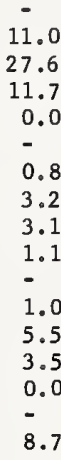

11.0

11.7

0.0

0.8

3.2

3.1

1.1

1. 0

5.5

3.5

0.0

8.7

27.0

1. 1

0.1

5.7

16.5

8.5

13.9

1.0

4.7

3.1

0.0

0.0

35.9

24.9

0.0

5.1

5.1
1.7

3.4

0.0

-

13.3
12.4

4.6
0.7

$-$

0.0

13.2

3.5

0.0
8.1

22.4

8.7

0.0

0.6

2.0

1.5

0.4

0.6

2. 0

0.5

0.0

6.1

6.1
21.1

0.4

0.0

4. 0

4.0
11.7

7.5

12.2

1.0

4.2

2.4

0.0

0.0

26. 1

17.3

0.0

3.9

0.8

1.9

0.0

9.4

10.5

3.2

0.4

0.0

7.0

1.2

0.0

\section{9 \\ 20.6 \\ 8.2 \\ 0.0 \\ 0.7 \\ 1.9 \\ 0.7 \\ 0.1 \\ 0.3 \\ 0.3
1.6 \\ 0.4 \\ 0.0 \\ 6.0 \\ 6.0
19.4 \\ 0.1 \\ 0.0}

3.6

10.8

7.1

11.1

1. 1

4.3

2.6

0.0

0.0

25.5

15.9

0.0

3.9

0.7

1.3

0.0

8.5

10.9

3.5

0.4

0.0

6.5

0.9

0.0
0.0

0.5

0.0

0.0

0.0

0.0

0.0

0.0

0.0

0.0
0.0

0.0

0.0

1. 1

0.3

0.0

0.0

0.0

0.0

0.0

0.0

0.0

0.0

0.0

0.0

0.0

0.0

0.0

0.0

0.0

0.0

0.0

0.0

0.0

0.0

0.0

0.0

0.0

0.0

0.0

0.0 
Correlation Coefficients for the Maximum KSU (Inside) and Daily Average $\mathrm{T}_{\mathrm{dry}}$-bulb (Outside) for a Heavyweight Apartment, Jersey City

Month-Year

June 1949

July 1949

August 1949

September 1949

$$
\text { June } 1953
$$

July 1953

August 1953

September 1953

June 1954

Ju1y 1954

August 1954

September 1954

June 1955

July 1955

August 1955

September 1955

June 1956

July 1956

August 1956

September 1956
Correlation Coefficient

0.96

0.94

0.95

0.92

0.96

0.94

0.95

0.97

0.95

0.96

0.88

0.97

0.96

0.93

0.97

0.95

0.95

0.91

0.94

0.96 
Frequency Distribution ' of Average Outside

Dry-bulb Temperature, Jersey City, 1949

JFRSEY CITY, 1949

TEMPERATURE FRFQUFNCY TABLE

\begin{tabular}{|c|c|c|c|c|c|c|c|}
\hline$E M P, F$ & FREQ & $T F M P, F$ & FRFQ & $T F M D, F$ & FRFO & TFMP, F & FPEQ \\
\hline 0 . & 355 & 25. & $35 ?$ & 50 & 278 & 75. & 6? \\
\hline 1. & 365 & 26. & 361 & 51. & ? & 76. & 55 \\
\hline 2. & 365 & 27. & 350 & 52. & 214 & 77. & 45 \\
\hline 3. & 365 & 23. & 356 & 53. & $? 14$ & 78. & 38 \\
\hline 4. & 365 & 29. & 350 & 54. & $? \cap 4$ & 79. & $3 ?$ \\
\hline 5. & 365 & 30. & 346 & 55. & 107 & 80 . & 25 \\
\hline 6. & 365 & 31. & 340 & 56. & 191 & 81. & 2.3 \\
\hline 7. & 365 & 32. & 337 & 57. & 185 & 8?. & IR \\
\hline 8. & 365 & 33. & 329 & 58. & gan & 83. & 16 \\
\hline 9. & 365 & 34. & 320 & 59. & 169 & 84. & 13 \\
\hline 10. & 765 & 35. & 314 & 60. & 163 & 85. & 9 \\
\hline 11: & 365 & 36. & 308 & 61. & 153 & R6. & 7 \\
\hline 12. & 365 & 37. & $3 \cap 1$ & 62. & 943 & 87. & 6 \\
\hline 13. & 365 & 38. & 298 & 63. & 93.2 & R8. & 3 \\
\hline 14. & 365 & 39. & 203 & 64. & 100 & Ra. & 1 \\
\hline 15. & 365 & 40. & 287 & 65. & $12 ?$ & 90 . & 0 \\
\hline 16. & 355 & 41. & 28.3 & 66. & 116 & 91. & 0 \\
\hline 17. & 365 & 4?. & 276 & 67. & 113 & 92. & \\
\hline 18. & 365 & 43. & 272 & 58. & $1 \cap 0$ & 93. & U \\
\hline 19. & 365 & 44. & 267 & 69. & $1 \cap 9$ & 94. & 0 \\
\hline ?0. & 365 & 45. & $? 64$ & 70. & 97 & 95. & 0 \\
\hline 21. & 365 & 46. & 255 & 71. & 90 & 96. & n \\
\hline 22. & 365 & 47. & 247 & 72. & 86 & $970^{\circ}$ & 0 \\
\hline ?3. & 365 & $4 \dot{8}$ & 238 & 73. & 79 & 98. & 0 \\
\hline 24. & 364 & 49. & 231 & 74. & $7 n$ & 00. & 0 \\
\hline & & & 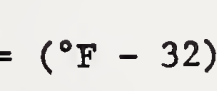 & - $\frac{5}{9}$ & & & \\
\hline
\end{tabular}




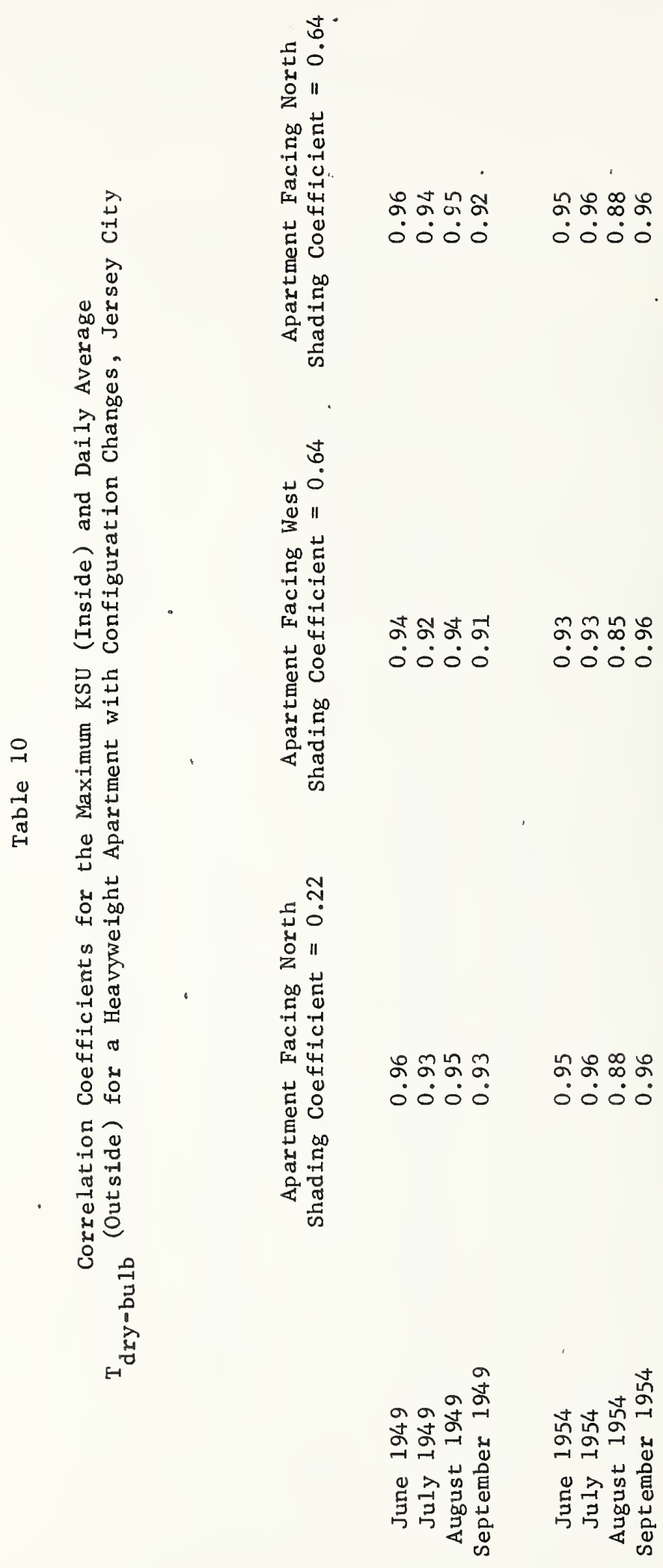




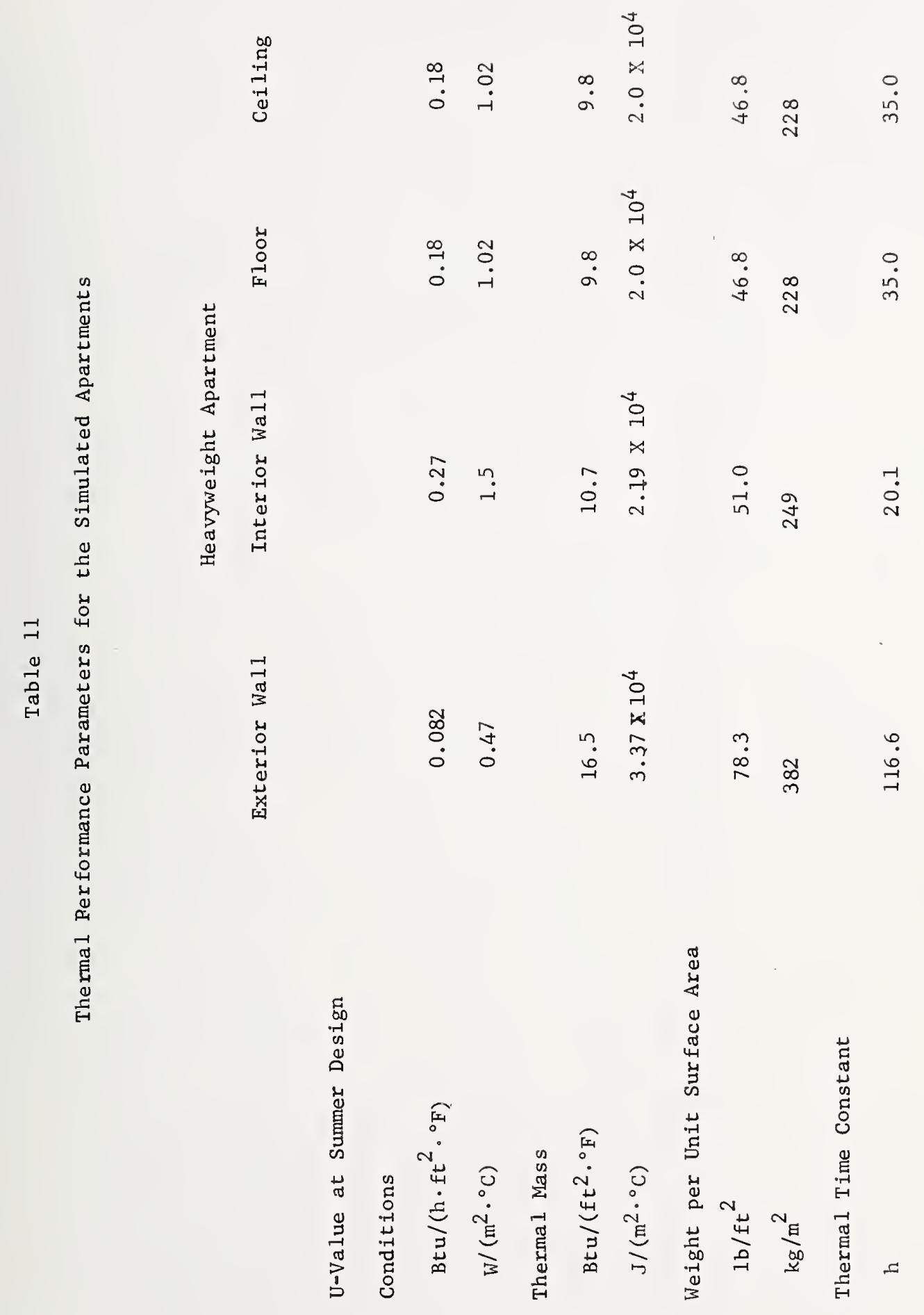



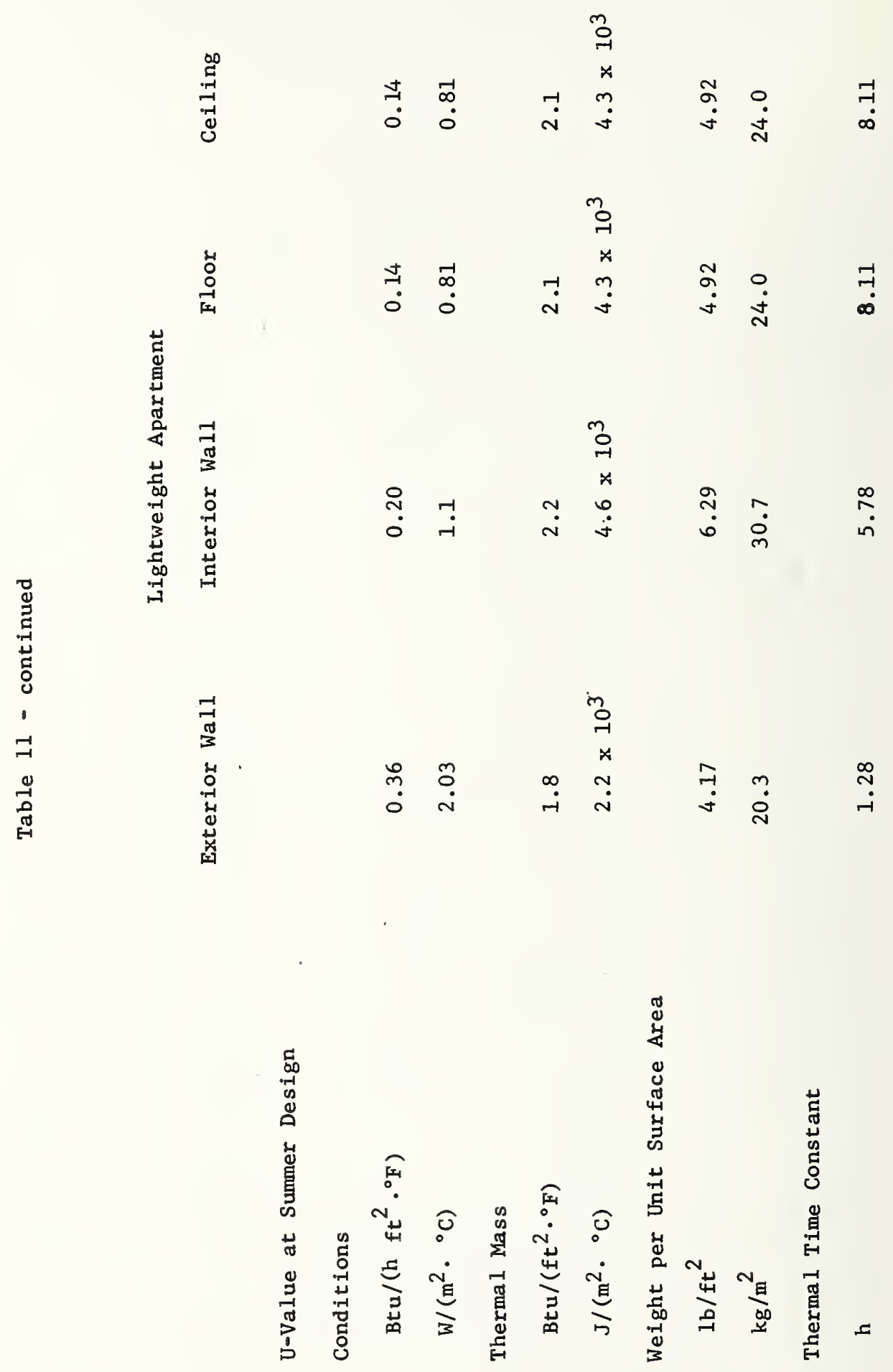
Correlation Coefficients for the Maximum KSU (Inside) and Daily Average $\mathrm{T}_{\mathrm{dry}}$-bulb (Outside)

for a Heavyweight Apartment, Macon, Georgia

Month-Year

June 1951

July 1951

August 1951

jeptember 1951

$$
\text { June } 1952
$$

July 1952

August 1952

September 1952

June 1953

July 1953

August 1953

September 1953

June 1954

July 1954

August 1954

September 1954

June 1955

July 1955

August 1955

September 1955

$$
\text { June } 1956
$$

July 1956

August 1956

September 1956

$$
\text { June } 1957
$$

July 1957

August 1957

September 1957

June 1958

July 1958

August 1958

September 1958
Correlation Coefficients

0.92

0.96

0.86

0.95

0.91

0.94

0.93

0.91

0.82

0.93

0.96

0.95

0.93

0.94

0.84

0.91

0.93

0.70

0.88

0.89

0.94

0.77

0.89

0.95

0.93

0.91

0.92

0.98

0.86

0.84

0.92

0.96 
이옹 닝

잉

ลูกั ตั

$\begin{array}{lll}2 & 0 \\ \infty & 0 \\ 0 & 0 & 0\end{array}$

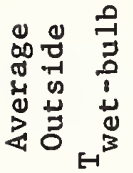

하유

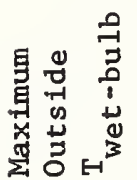

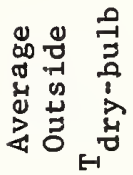

目㖧
ने

ஸे

ळ.

๖ ஃ

ํํㅇㅇํㅇ

กุ

$\infty$
$\infty$
0

नㅎํㅇ

$\infty \dddot{1}=1$
00
0

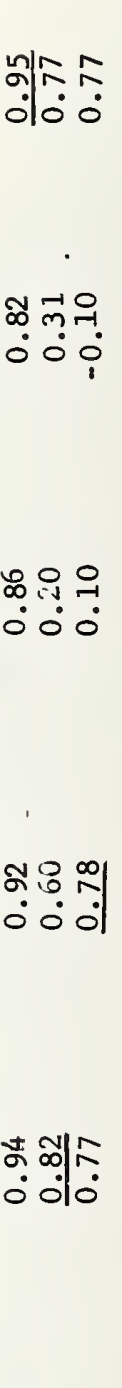

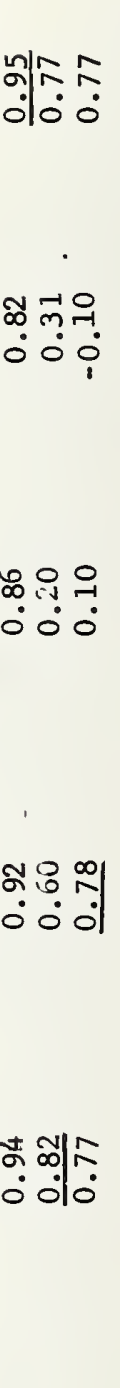

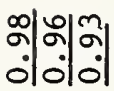

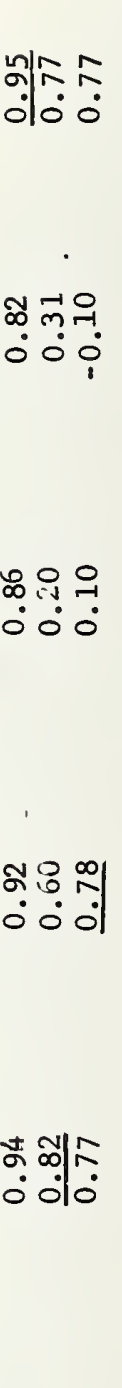

○ं

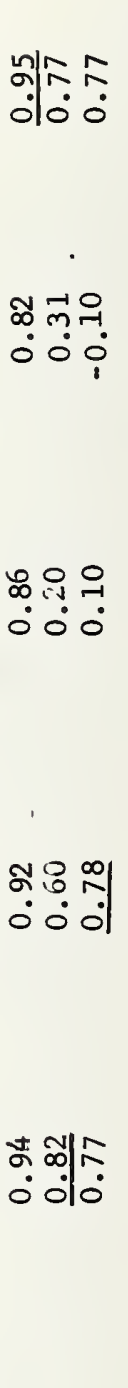

สิ ने ซू

$\circ \dot{0}$

ดั สั ส

$\infty$
$\infty$
0

०००

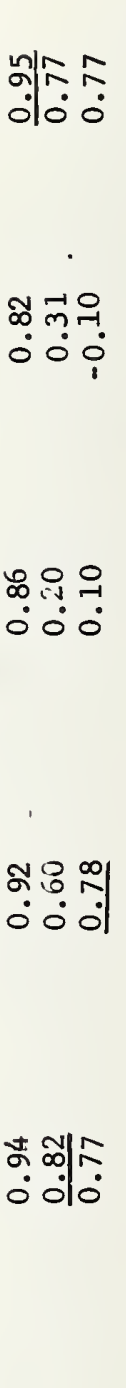

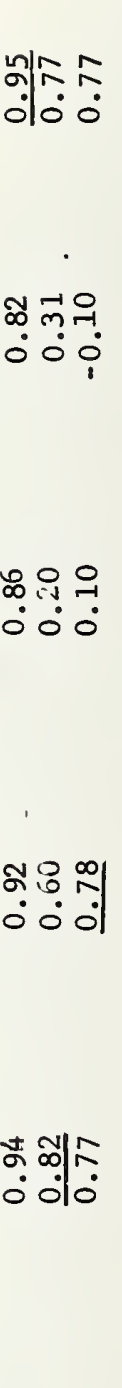

a 
ASHRAE 1\% Design Weather Conditions for Selected Cities

Location

Portland, Maine

Concord, N. H.

Hartford, Conn.

West Chester, $\mathrm{Pa}$ 。

New York, N. Y. (Kennedy)

Jersey City, N. J。

Washington, D. C 。

New York, N. Y。

(Central Park)
Average Outside

Dry Bulb Temperature, ${ }^{\circ} \mathrm{F}$
$\underline{\mathrm{T}_{\mathrm{db}},{ }^{\circ} \mathrm{F}} \quad \underline{\text { Range, }}{ }^{\circ} \mathrm{F}$

88.0

22.0

26.0

22.0

20.0

16.0

91.0

94.0

20.0

84.0

94.0

18.0

85.0

94.0

17.0

85.5

$$
{ }^{\circ} \dot{\mathrm{C}}=\left({ }^{\circ} \mathrm{F},-32\right) \cdot \frac{5}{9}
$$



Appendix A

Derivation of the Equations to Calculate the Mean Radiant Temperature Within NBSLD,

$1 a$ 
Applying Kirchoff's law at node $J_{P}$ :

$$
\begin{gathered}
p_{p}^{Q}=\left(J_{p}-J_{1}\right) A_{p} F_{p 1}+\left(J_{p}-J_{2}\right) A_{p} F_{p 2} \\
+\left(J_{p}-J_{3}\right) A_{p} F_{p 3}+\left(J_{p}-J_{4}\right) A_{p} F_{p 4}^{*}
\end{gathered}
$$

From the definition of the mean radiant temperature:

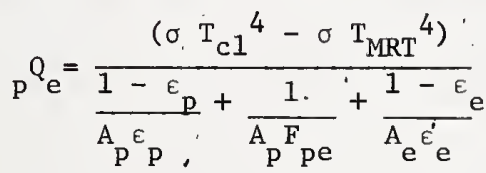

$$
\begin{aligned}
& P_{P} Q=A_{p} E_{p} \sigma\left(T_{c l}{ }^{4}-T_{M R T}{ }^{4}\right)
\end{aligned}
$$

Equating equations (1) and (3):

$$
\mathrm{J}_{\mathrm{p}}=\sigma \mathrm{T}_{\mathrm{cl}}{ }^{4} \varepsilon_{\mathrm{P}}\left(1-\varepsilon_{\mathrm{p}}\right) \sigma \mathrm{T}_{\mathrm{MRT}}{ }^{4}
$$

Equating equations (2) and (3) and utilizing the derived expression for $\mathrm{J}_{\mathrm{p}}$ (equation (4)):

$$
\mathrm{T}_{\mathrm{MRT}} 4=\frac{1}{\sigma}\left(\mathrm{J}_{1} \mathrm{~F}_{\mathrm{p} 1}+\mathrm{J}_{2} \mathrm{~F}_{\mathrm{p} 2}+\mathrm{J}_{3} \mathrm{~F}_{\mathrm{p} 3}+\mathrm{J}_{4} \mathrm{~F}_{\mathrm{p} 4}\right)
$$

In order to use equation (5) for calculating mean radiant temperature, the radiosities $\mathrm{J}_{1}, \mathrm{~J}_{2}, \mathrm{~J}_{3}, \mathrm{~J}_{4}$ must be determined. Most building materials have a high emittance, and for the calculation, it is often an acceptable approximation to disregard the reflections, i.e., to assume that all the surfaces in the room are black. Equation (5) is thus simplified to:

$$
\mathrm{T}_{\mathrm{MRT}}{ }^{4}=\mathrm{T}_{1}{ }^{4} \mathrm{~F}_{\mathrm{p} 1}+\mathrm{T}_{2}{ }^{4} \mathrm{~F}_{\mathrm{p} 2}+\mathrm{T}_{3}{ }^{4} \mathrm{~F}_{\mathrm{p} 3}+\mathrm{T}_{4}{ }^{4} \mathrm{~F}_{\mathrm{p}} 4
$$

As the sum of the angle factors is unity, the fourth power of the mean radiant temperature is seen to be equal to the mean value of the surrounding surface temperatures to the fourth power, weighted according to the size of the respective angle factors.

If there are only relatively small temperature differences between the surfaces of the enclosure, equation (6) can be further simplified by linearizing, ,

$$
\mathrm{T}_{\mathrm{MRT}}=\mathrm{T}_{1} \mathrm{~F}_{\mathrm{p} 1}+\mathrm{T}_{2} \mathrm{~F}_{\mathrm{p} 2}+\mathrm{T}_{3} \mathrm{~F}_{\mathrm{p} 3}+\mathrm{T}_{4} \mathrm{~F}_{\mathrm{p} 4}
$$

In other words, the mean radiant temperature is calculated as the mean value of the surrounding temperatures weighted according to the magnitude of the respective angle factors. Fanger [1] ${ }^{\mathrm{a}}$ has shown that the error in using equation (7) compared to equation (6) is less than $0.2{ }^{\circ} \mathrm{C}$ for most realistic building applications.

In calculating the mean radiant temperature using equation ( 7 ), it is necessary to know the angle factors between persons and typical surfaces. These are sometimes difficult to calculate and therefore an additional rough approximation has often been used. The mean radiant temperature is calculated as the mean temperature of al.1 the surfaces in the enclosure:

$$
T_{M R T}=\frac{T_{1} A_{1}+T_{2} A_{2}+T_{3} A_{3}+T_{4} A_{4}}{A_{1}+A_{2}+A_{3}+A_{4}}
$$

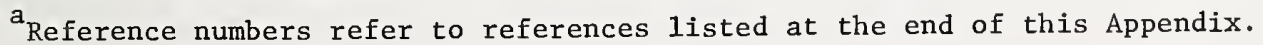


This is equivalent to assuming:

$$
\begin{aligned}
& F_{p 1}=\frac{A_{1}}{A_{1}+A_{2}+A_{3}+A_{4}} \\
& F_{p 2}=\frac{A_{2}}{A_{1}+A_{2}+A_{3}+A_{4}}
\end{aligned}
$$

The authors compared the results of calculating $\mathrm{T}_{M R T}$ using equations (7) and (8) for a person located in the center of the masonry building apartment described in section 6 . and the results were different by less than $0.1^{\circ} \mathrm{C}$.

\section{$\underline{\text { References }}$}

1. P. O. Fanger, Thermal Comfort, Danish Technical Press, Copenhagen, 1970.

2. E. M. Sparrow and R. D. Cess, Radiation Heat Transfer, Wadworth Publishing Company, Be1mont, Ca1ifornia, 1970. 


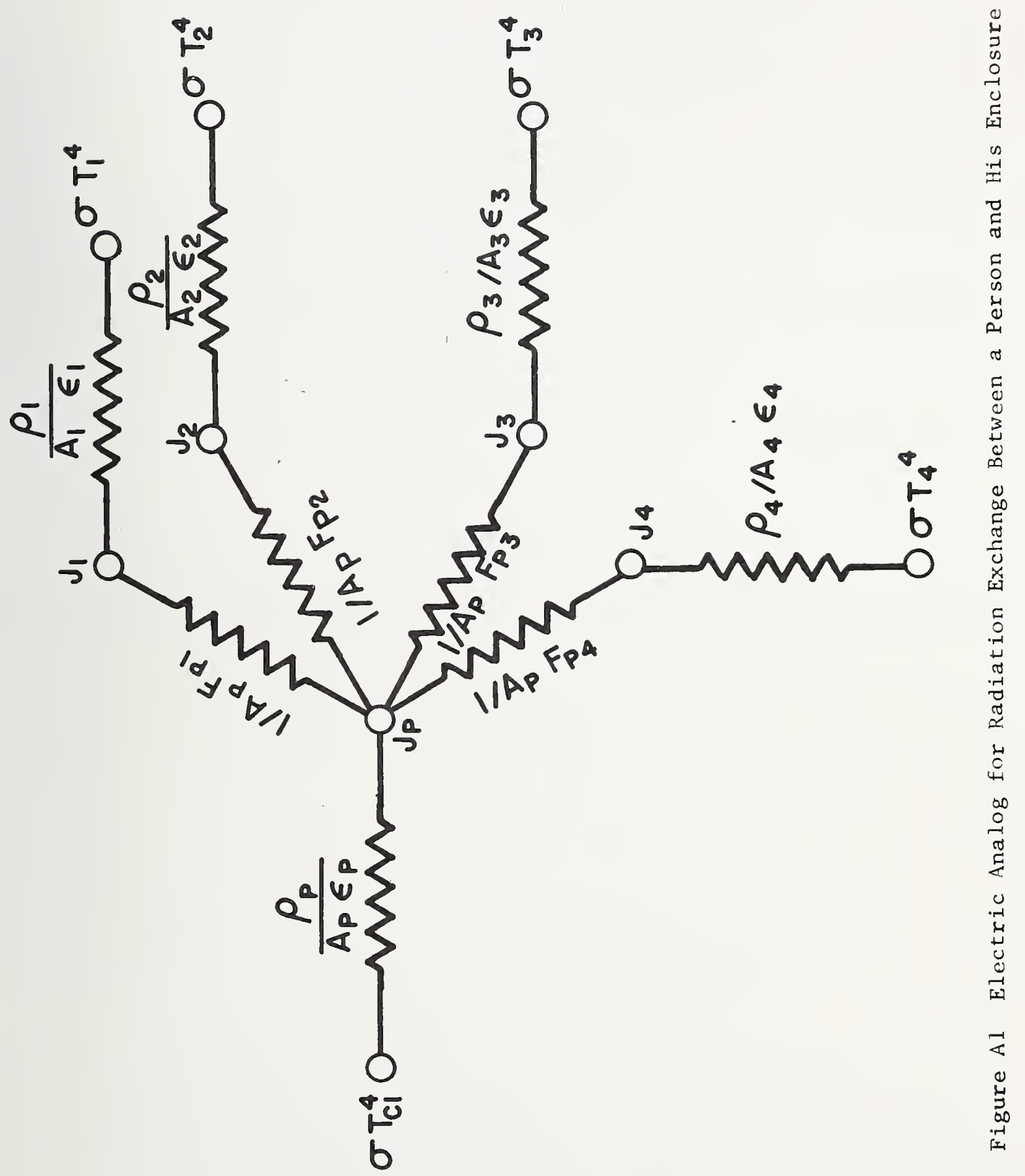



Appendix B

A Review of Comfort and Physiological Indices 
In this Appendix, the methods of computation for several of the analytically determined comfort indices are discussed. The expressions for heat transfer rate between the subject and environment by convection, radiation, etc., are given at the end of each section where appropriate. Unless otherwise specified, the following nomenclature applies to the various relations :

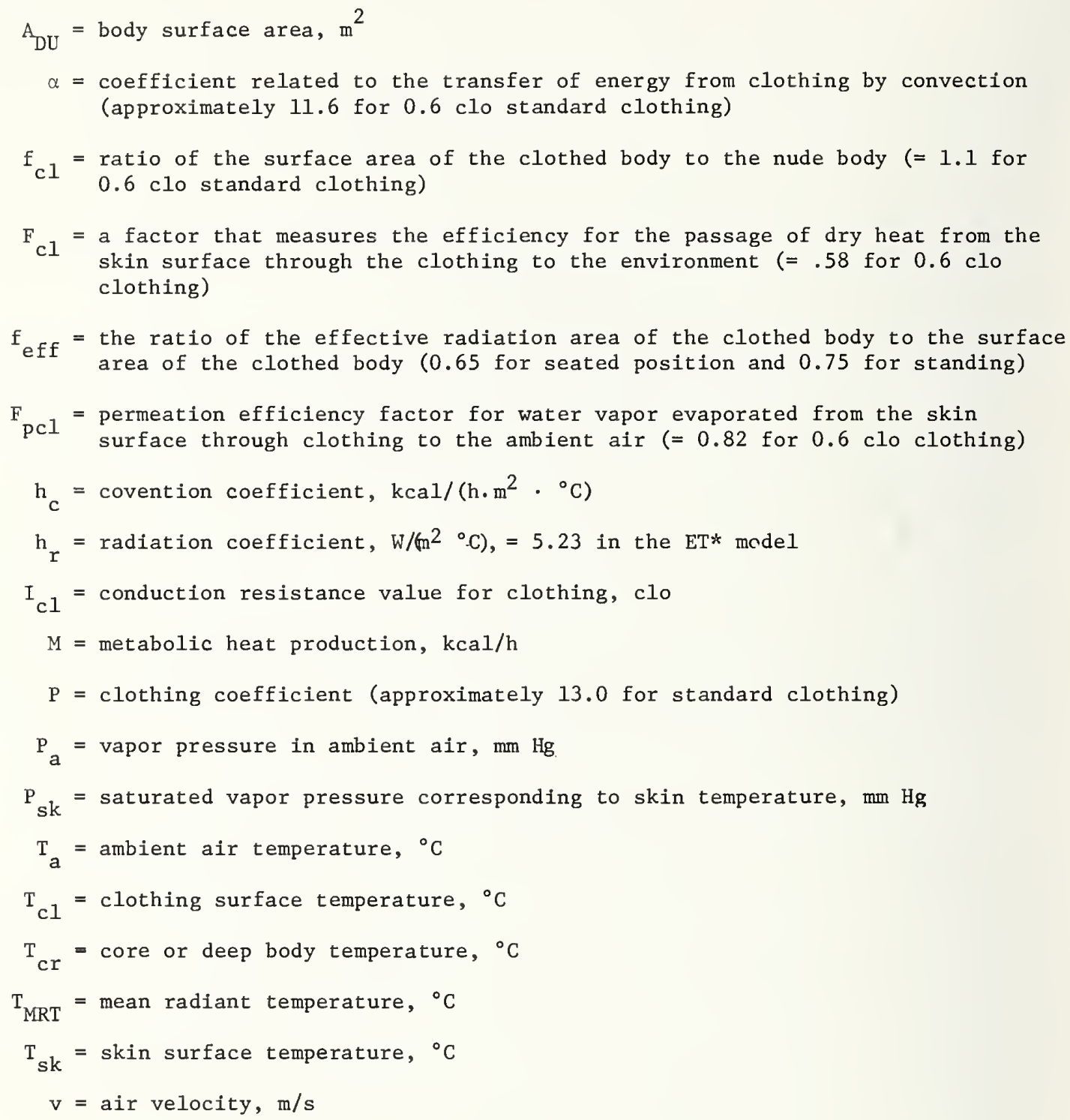

Old Effective Temperature (ET)

Undoubtedly the most familiar of all comfort indices is the American Society of Heating, Refrigerating and Air Conditioning Engineers' Effective Temperature. The scale was first established in the 1920's by Houghten and Yaglou [1] ${ }^{\mathrm{a}}$. Subjects wearing clothing having an unspecified insulation value ${ }^{b}$ were passed between test chambers in which the temperature, air

\footnotetext{
aeference numbers refer to references listed at the end of this Appendix.

$\mathrm{b}_{\text {At }}$ the time this particular index was developed, the analysis of human comfort had not progressed to the point that insulation values for clothing ensembles were being given.
} 
velocity, and humidity were maintained at specified levels and were asked to describe their feeling immediately upon entering the new environment. The results are shown in Figure B1 where lines of constant thermal sensation are shown plotted on a standard psychrometric chart. The experiments were conducted for a large range of air velocities; however, the data shown here is for an air velocity of less than $20 \mathrm{fpm}^{\mathrm{a}}(0.1 \mathrm{~m} / \mathrm{s})$. The lines of constant thermal sensation were arbitrarily given numerical values corresponding to the dry-bulb temperature at which the line intersected the saturation curve (100\% relative humidity). If the drybulb temperature were a sole indicator of thermal comfort according to this scale, the lines would run vertically. The data therefore indicates that as the relative humidity is increased, the temperature has to be decreased to maintain the same feeling. This is natural since cooling by sweat evaporation is restricted somewhat as the relative humidity increases.

This scale originally did not take into account the effect of radiation to or from room walls where the walls' temperature is maintained at values quite different from the room air. However, a correction was proposed later [2] in order to account for this effect. The ET scale continues to be accepted as valid in the very hot region where man's cooling rate depends almost entirely on his sweat evaporation but has been abandoned as inaccurate in the comfort region or the region of most interest to this study.

As a result of the apparent disagreement between field tests and the lines of constant thermal sensation or effective temperature at the moderate temperatures, ASHRAE undertook an additional study at their research laboratory in 1960 and the results are shown in Figure B2. In this study [3], subjects wore light indoor clothing and were seated at rest. Room surfaces were held at the same temperature as the room air in all tests, and the air motion in the space was $20 \mathrm{fpm}(0.1 \mathrm{~m} / \mathrm{s})$ or less. The thermal sensation votes used in analyzing the test data were those which were cast in the chamber at the end of the three hour occupancy period. These lines show the conditions under which subjects cast votes of $3,4,5$, or 6 , indicating sensations of slightly cool, comfortable, slightly warm, and warm respectively. It is evident from Figures B1 and B2 that the old effective temperature index predicts a considerably greater effect of relative humidity on the thermal sensation feeling than do the lines determined by Koch, Jennings, and Humphreys [3]. In defense of the old effective temperature, it may be explained that the two groups of data apply to different conditions. The effective temperature lines indicate a person's feeling imnediately after entering the conditioned space, while the lines of Figure B2 are for people who have been in the conditioned space for approximately three hours and are in equilibrium with their environment.

\section{Resultant Temperature}

In 1948, Missenard [4] proposed an index called the resultant temperature. Its development was motivated by the fact that the effective temperature was not based on experiments where thermal equilibrium was achieved between the human body and the environment. The experiments on which the resultant temperature was based were conducted with about six subjects in a psychrometric chamber with a duration of exposure greater than was used in the experiments for the effective temperature. The resultant temperature is identical in structure with the effective temperature and is shown in Figure B3 for clothed subjects exposed to an air velocity of $0.1 \mathrm{~m} / \mathrm{s}(20 \mathrm{fpm})$. The resultant temperature shows that thermal sensation is much less dependent on humidity than it was with effective temperature. However, the results still indicate more of a dependence of humidity in the moderate temperature range than do the comfort votes of Koch, et. al.

\section{Kansas State Index}

Perhaps the most definitive experimental study on thermal comfort is one conducted on over 1600 college students at Kansas State University over the past several years [5, 6]. The students were exposed (over a 3 hour period) to a uniformly heated or cooled environment (wall temperatures identical to the air temperature) with moderate air velocities and asked to vote on a scale from 1 to 7 which ranged from cold to hot:

\footnotetext{
a For purposes of this study, the data for all the indices described will be for very nominal air velocities (i.e., $20 \mathrm{fpm}$ or $0.1 \mathrm{~m} / \mathrm{s}$ ) since higher velocities very rarely occur in residences.
} 

1. cold
2. $\operatorname{cool}$
3. slightly cool
4. comfortable
5. slight ly warm
6. warm
7. hot

All subjects, males and females alike, were clothed in cotton twill shirts and trousers. The shirts were worn outside of the trousers. The subjects wore the underwear they had on when reporting for this test, which usually consisted of cotton undershorts or jockey shorts for the men and brassieres and underpants for the women. All other clothing, including Tshirts, girdles, slips, etc., were removed. The subjects wore cotton sweat socks without shoes. The net insulating value for the clothing ensemble, as computed by means of an electrically heated copper manikin [7] has been determined to be $0.6 \mathrm{clo}{ }^{\mathrm{a}}$ which has been generally accepted as the standard clothing for thermal comfort studies.

Even though the results are available for men and women separately and also for the votes taken at each half an hour for the entire 3 hours of exposure, the data shown in Figure $\mathrm{B} 4$ is an average for the votes of men and women taken together at the end of the 3 hours.

Until very recently, the results of comfort studies were represented as lines on a pyschrometric chart as done above. As Rohles of Kansas State University pointed out in 1969 [8], "from a purely operational point of view this [type of representation] is totally impractical since there is nothing in the way of a range or plus or minus limit about the 1ine. Moreover, the requirement for limits of this type becomes more apparent when we consider the data used in the construction of the line itself are based on value judgments of unknown reliability". As an alternative, Rohles [9, 10] proposed zones or envelopes of the thermal comfort.

The Modal Comfort Envelope (MCE) was derived purely by trial and error from the distribution of thermal sensations from the above-mentioned study with 1600 subjects. The set of 15 conditions which has been identified as the MCE are: $80{ }^{\circ} \mathrm{F}\left(26.7{ }^{\circ} \mathrm{C}\right)$ at $15,25,35$, and $45 \% \mathrm{RH} ; 78{ }^{\circ} \mathrm{F}\left(25.6{ }^{\circ} \mathrm{C}\right)$ at $15,25,35,45,55$ and $65 \% \mathrm{RH}$; and $76^{\circ} \mathrm{F}\left(24.4{ }^{\circ} \mathrm{C}\right)$ at $45,55,65$, 75 and $85 \%$ RH. The distribution of thermal sensations within this envelope after an exposure of 3 hours showed that none of the subjects voted hot or cold; approximately $3 \%$ were warm and cool and $94 \%$ reported a sensation of slightly cool, comfortable, or slightly warm. The mean sensation was 4.0 or "comfortable" with a standard deviation of 0.72 .

Besides defining the thermal environment in which sedentary man is comfortable, the MCE forms a prescribed set of temperature-humidity conditions that can be used for studying the thermal senstion as a function of such factors as age, clothing, activity, radiant temperature, air movement, color of the surroundings, and illumination levei. As such, it replaces the traditional approach to studies in this area which arbitrarily select temperatures which are equally spaced physically yet totally unequal from the standpoint of the thermal sensation.

$a_{1}$ clo represents a measured resistance to heat transfer of the clothing ensembled of 0.18 $\left(\mathrm{m}^{2} \cdot \mathrm{h} \cdot{ }^{\circ} \mathrm{C}\right) \mathrm{cal}\left(0.88\left(\mathrm{ft}^{2} \cdot \mathrm{h} \cdot{ }^{\circ} \mathrm{F}\right) / \mathrm{Btu}\right.$ or equivalent of an overall heat transfer coefficient $\left.=1.13 \mathrm{Btu} /\left(\mathrm{h} \cdot \mathrm{ft}^{2} \cdot{ }^{\circ} \mathrm{F}\right)\right)$. 
The Modal Comfort Envelope has been used in two studies to determine the indépendēnce of the environmental consistuents that affect the thermal sensation. In the first application, the thermal sensations of elderly subjects were compared to those of college students [11], and in the second study the MCE was used to determine the influence of clothing and temperature on sedent'ary comfort' [12].

The MCE was also used as a reference in defining the KSU-ASHRAE Comfort Envelope in the 1972 ASHRAE Handbook of Fundamenta1s [13]. This envelope is represented in Figure B5 as the quadrilateral having its points at $80^{\circ} \mathrm{F}\left(26.7{ }^{\circ} \mathrm{C}\right) .45 \% \mathrm{RH} ; 80^{\circ} \mathrm{F}\left(26.7{ }^{\circ} \mathrm{C}\right) 15 \% \mathrm{RH} ; 76{ }^{\circ} \mathrm{F}$ $\left(24.4^{\circ} \mathrm{C}\right) 85 \% \mathrm{RH}$; and $76^{\circ} \mathrm{F}\left(24.4^{\circ} \mathrm{C}\right) 45 \% \mathrm{RH}$.

For purposes of comparison, the shaded envelope on the chart defines the limits of the conditions prescribed in ASHRAE Standard 55-74 [14]. Whereas the KSU-ASHRAE Comfort Envelope applies to subjects wearing clothing whose insulation value is $0.6 \mathrm{clo}$, the ASHRAE Comfort Standard applies to subjects wearing 0.8 to $1.0 \mathrm{clo}$. In addition, the KSU-ASHRAE Comfort Envelope applies to sedentary activity whereas the ASHRAE Standard applied to office work which is slightly greater than sedentary. The differences in activity level and clothing account for the differences in the two envelopes. The area where the two envelopes overlap is recommended as the "design conditions for comfort" [15].

\section{Predicted Mean Vote and Predicted Percentage of Dissatisfied}

One of the most significant attempts to predict analytically the thermal interaction between man and his environment is presented by $P$. O. Fanger of the Technical University of Denmark in his recent book Thermal Comfort [16]. He begins by pointing out the most important variables which influence the condition of thermal comfort:

1. activity level (heat production in the body)

2. thermal resistance of the clothing (clo-value)

3. air temperature (dry-bulb)

4. 'mean radiant temperature

5. relative air velocity

6. water vapor pressure in ambient air

The basis of his analysis in the so-called general comfort equation which defines all combinations of the variables which will create thermal comfort. Its specific form is as follows :

$$
M-E_{\text {diff }}-E_{\text {sw }}-E_{\text {res }}-D=K=R+C
$$

where

$$
\begin{aligned}
M & =\text { the internal heat production in the human body } \\
E_{\text {diff }}= & \text { the energy loss by water vapor diffusion through the skin } \\
E_{S w}= & \text { the energy loss by evaporation of sweat from the surface of } \\
\text { the skin } & \\
E_{\text {res }}= & \text { the latent respiration heat loss } \\
D= & \text { the dry respiration loss }
\end{aligned}
$$


$\mathrm{K}=$ the heat transfer from the skin to the outer surface of the clothed body (conduction through the clothing) ${ }^{a}$

$\mathrm{R}=$ the heat loss by radiation from the outer surface of the clothed body

$\mathrm{C}=$ the heat loss by convection from the outer surface of the clothed body

The double equation expresses that the internal heat production $M$ minus the heat loss by evaporation from the skin $\left(E_{d i f f}+E_{S W}\right.$ ) and by respiration $\left(E_{r e s}+D\right)$ is equal to the heat conducted through the clothing $K$ and dissipated at the outer surface of the clothing by radiation and convection $(R+C)$. It is assumed that the evaporation corresponding to $\mathrm{E}_{\mathrm{SW}}$ and $\mathrm{E}_{\mathrm{diff}}$ takes place at (or underneath) the skin surface.

After formulating expressions for each component in the above equation (see the end of this section) and substituting them into equation (1), two algebraic equations result in the following 9 unknowns:

$$
\begin{aligned}
& \mathrm{M} \text { - (defined previously) } \\
& \mathrm{T}_{\mathrm{S}} \text { - skin surface temperature } \\
& \mathrm{P}_{\mathrm{w}} \text { - water vapor pressure in the ambient air } \\
& \mathrm{E}_{\mathrm{SW}} \text { - (defined previously) } \\
& \mathrm{T}_{\mathrm{a}} \text { - ambient air dry-bulb temperature } \\
& \mathrm{T}_{\mathrm{cl}} \text { - clothing surface temperature } \\
& \mathrm{I}_{\mathrm{cl}} \text { - insulation value of the clothing } \\
& \mathrm{T}_{\mathrm{MRT}} \text { - mean radiant temperature of. the environment } \\
& \mathrm{V} \text { - the relative air velocity }
\end{aligned}
$$

Six of the unknowns ( $M, P_{W}, T_{a}, I_{c l}, V$, and $T_{M R T}$ ) can be considered as controllable or specified for any particular subject--environment situation. Two of the remaining unknowns are eliminated by what may be considered Fanger's most questionable assumption. During studies at Kansas State University on college students, data was obtained for mean skin temperature and evaporative heat loss of the subjects while they reported being comfortable conducting various activities (different $M^{\prime} s$ ). $E_{S W}$ and $T_{S}$ were plotted individually as a function of the metabolic production and even though the data was rather widely scattered, linear equations

$$
\mathrm{T}_{\mathrm{S}}=\mathrm{f}(\mathrm{M})
$$

and

$$
\mathrm{F}_{\mathrm{sW}}=\mathrm{f}(\mathrm{M})
$$

were determined by regression analysis. The procedure then used was to specify 5 of the 6 controllable or specified quantities $\left(M, P_{w}, T_{a}, I_{c I}, v\right.$, and $\left.T_{M R T}\right)$, and use the 4 equations $(1,2$, and 3) to determine the remaining four unknowns, one of which is the sixth of the controllable parameters that would give thermal comfort. The results are presented in the form of comfort charts.

\footnotetext{
$a_{\text {The }}$ resistance value for the clothing is determined in such a way that it accounts for the heat transfer from the nude portion of the body as well.
} 
Having determined the conditions for optimum thermal comfort, Fanger recognized the need for being able to evaluate an existing room climate and quantify its deviation from the comfort condition. A similar scale to the one used in the Kansas State studies were chosen:

$\begin{array}{ll}-3 & \text { cold } \\ -2 & \text { cool } \\ -1 & \text { slightly cool } \\ 0 & \text { neutral } \\ +1 & \text { slight1y warm } \\ +2 & \text { warm } \\ +3 & \text { hot }\end{array}$

The numerical values however are lower by 4. A scale is thus obtained which is easier to remember, as it is symmetrical around the zero point, so that a positive value corresponds to the warm side and a negative value to the cold side of neutral. He then proposed that the thermal sensation values, to be called the Predicted Mean Vote (PMV), would be a function of the thermal load of the body, defined as the difference between the internal heat production and the heat loss to the actual environment for a man hypothetically kept at the comfort values of the mean skin temperature and the sweat secretion of the actual activity leve1.

$$
P M V=f\left(M-E_{\text {diff }}-E_{\text {sW }}-E_{\text {res }}-D-R-C\right)
$$

The nature of equation (4) enabled Fanger to use the same component expressions as in the general comfort equation. The particular form of the function was determined from analyzing the Kansas State studies once again as well as similar experiments conducted at the Technical University of Denmark.

Values of the predicted mean vote (PMV) are shown on the psychrometric chart. in Figure B6. The data was calculated assuming a resting metabolic rate $\left(M=50 \mathrm{kcal} / \mathrm{h} \cdot \mathrm{m}^{2}\right.$ ), an air velocity of $0.1 \mathrm{~m} / \mathrm{s}$, a mean radiant temperature equal to the ambient air temperature, and a clothing insulation value of $0.6 \mathrm{clo}$. In Figure B7 the results are compared with the experimentally determined KSU comfort vote. As can be seen the agreement is excellent for the comfort line ( $\mathrm{KSU}=0$, PMV $=4$ ) but not so good for environmental conditions outside of the comfort range.

An advantage of an analytical model such as this is the capability of observing the effect of one of the six controllable parameters without having to conduct extensive experiments. For example, it may be unrealistic to determine air conditioning criteria using subjects that wear the standard $0.6 \mathrm{clo}$ clothing ensemble. Certainly in hot weather people would be more inclined to wear lighter clothing such as shorts and an open neck shirt with short sleeves. Data for this type of clothing ensemble (clo $=0.25$ ) is shown in Figure B8 and compared with the standard Kansas State clothing ensemble in Figure B9. The comparison shows what one might intuitively expect. With lighter clothing, subjects would report comfort at 4 or $5^{\circ} \mathrm{F}$ ( 2.2 or $2.8^{\circ} \mathrm{C}$ ) warmer temperature. It would be expected that they would vote cool at a somewhat higher temperature also (approximately $6{ }^{\circ} \mathrm{F}$ or $3.3^{\circ} \mathrm{C}$ ). However, both subjects would vote hot at approximately the same temperature and relative humidity.

Instead of just giving the predicted mean vote as an expression for the thermal environment, Fanger felt it might be even more meaningful to state what percent of persons can be expected to be decidedly dissatisfied since this can readily be interpreted by both the engineer and the layman. This same concept has been proposed more recently by Nevins and McNall [17]. After choosing the limits of -2 and +2 for being dissatisfied on the cold and hot side respectively, the American and Danish experiments already mentioned were again analyzed to determine the percent of the subjects voting cool or below and warm or above at each environment condition. The same relationship was assumed to hold between PMV and the new factor, predicted percentage of dissatisfied (PPD). The exact relation is given below. 
The relevant mathematical relations used by Fanger in his work were:

Rate of Heat Loss by Convection (C):

$$
\begin{gathered}
\mathrm{C}=\mathrm{A}_{\mathrm{DU}} \mathrm{f}_{\mathrm{cl}} \mathrm{h}_{\mathrm{c}}\left(\mathrm{T}_{\mathrm{cl}}-\mathrm{T}_{\mathrm{a}}\right) \mathrm{kcal} / \mathrm{h} \\
\mathrm{h}_{\mathrm{c}}=2.05\left(\mathrm{~T}_{\mathrm{cl}}-\mathrm{T}_{\mathrm{a}}\right)^{0.25} \text { for } 2.05\left(\mathrm{~T}_{\mathrm{c} 1}-\mathrm{T}_{\mathrm{a}}\right)^{0.25}>10.4 \sqrt{\mathrm{v}} \\
=10.4 \sqrt{\mathrm{v}} \text { for } 2.05\left(\mathrm{~T}_{\mathrm{cl}}-\mathrm{T}_{\mathrm{a}}\right)^{0.25}<10.4 \sqrt{\mathrm{v}}
\end{gathered}
$$

Rate of Heat Loss by Radiation (R):

$$
R=4.8 \times 10^{-8} A_{D U} f_{c 1} f_{e f f}\left[\left(T_{c 1}+273\right)^{4}-\left(T_{M R T}+273\right)^{4}\right] \mathrm{kcal} / \mathrm{h}
$$

Rate of "Dry" Heat Loss in Respiratory Passages (D):

$$
\mathrm{D}=.0014 \mathrm{M}\left(34-\mathrm{T}_{\mathrm{a}}\right) \mathrm{kcal} / \mathrm{h}
$$

Rate of Energy Loss Due to Evaporative Cooling in Respiratory Passages (E ${ }_{\text {res }}$ ):

$$
\mathrm{E}_{\text {res }}=.0023 \mathrm{M}\left(44-\mathrm{P}_{\mathrm{a}}\right) \mathrm{kca} 1 / \mathrm{h}
$$

Rate of Energy Loss Due to Evaporative Cooling, Normal Skin Diffusion ( $\mathrm{E}_{\mathrm{d} \text { iff }}$ ):

$$
\mathrm{E}_{\operatorname{diff}}=.35 \mathrm{~A} \text { DU }\left(43-0.061 \frac{\mathrm{M}}{\mathrm{A}_{\mathrm{DU}}}-\mathrm{P}_{\mathrm{a}}\right) \mathrm{kca} 1 / \mathrm{h}
$$

Rate of Energy Loss Due to Evaporative Cooling, Regulatory Sweat Production (E ${ }_{\text {sw }}$ ):

$$
\mathrm{E}_{\mathrm{sw}}=.42 \mathrm{~A} \text { DU }\left(\frac{\mathrm{M}}{\mathrm{A}_{\mathrm{DU}}}-50\right) \mathrm{kca} 1 / \mathrm{h}
$$

Rate of Heat Conduction Through Clothing (K):

$$
\mathrm{K}=\mathrm{A}_{\mathrm{DU}} \frac{\mathrm{T}_{\mathrm{sk}}-\mathrm{T}_{\mathrm{cl}}}{.18 \mathrm{I}_{\mathrm{cl}}} \mathrm{kca} 1 / \mathrm{h}
$$

Relation Between PMV and Body Heat Load (L):

$$
\mathrm{PMV}=\left[.352 \mathrm{e}^{-.942\left(\mathrm{M} / \mathrm{A}_{\mathrm{DU}}\right)}+.032\right] \mathrm{L}
$$

Relation for PPD:

A second order equation was fit to the tabular data given by Fanger'for the Predicted Percentage of Dissatisfied (due to heat only) as a function of PMV:

$$
\begin{array}{r}
\mathrm{PPD}=1.63+10.98(\mathrm{PMV})+13.41(\mathrm{PMV})^{2} \\
\text { New Effective Temperature (ET*) }
\end{array}
$$

The other major analytical contribution to the field of thermal comfort to be mentioned in this paper is a transient heat transfer model presented by Gagge, Stolwijk, and Nishi [18]. The model differs most significantly from Fanger's in the fact that physiological responses have included the effect of vascular restrictions and dilation on the blood flow to the skin and regulatory sweating proportional to a deep body temperature deviation from some predetermined set point. The human body is pictured as composed of two distinct parts; a central core and skin she11. An energy balance is written for each part: 
the rate of energy increase of the = skin shell the net rate of energy

transfer from + the core to the skin the net rate of energy transfer from the environment to the skin

and

\begin{tabular}{|c|c|c|c|c|c|c|}
\hline $\begin{array}{l}\text { the rate } \\
\text { of energy } \\
\text { increase } \\
\text { of the } \\
\text { central } \\
\text { core }\end{array}$ & $=$ & $\begin{array}{l}\text { the rate } \\
\text { of energy } \\
\text { generation } \\
\text { (metabolic } \\
\text { production }\end{array}$ & + & $\begin{array}{l}\text { the net rate } \\
\text { of energy } \\
\text { transfer from } \\
\text { the skin to } \\
\text { the core }\end{array}$ & + & $\begin{array}{l}\text { the net rate of } \\
\text { energy transfer } \\
\text { from the environ- } \\
\text { ment to the core }\end{array}$ \\
\hline
\end{tabular}

or in equation form

$$
M_{s k} C_{s k} \frac{d T s k}{d \tau}=Q_{c o n}+Q_{b 1}-E_{d i f f}-E_{r s w}-R-C
$$

and

$$
M_{c r} C_{c r} \frac{d T}{d \tau}=M-Q_{c o n}-Q_{b 1}-E_{\text {res }}
$$

where

$M_{s k}=$ mass of the skin shell

$\mathrm{C}_{\text {sk }}=$ specific heat of the skin shell

$\mathrm{T}_{\text {sk }}=$ temperature of the skin shell

$M_{c r}=$ mass of the central core

$C_{c r}=$ specific heat of the central core

$\mathrm{T}_{\mathrm{cr}}=$ temperature of the central core

$\tau=$ time

$Q_{\text {con }}=$ heat transferred by conduction from the core to the skin (a function of $\mathrm{T}_{\mathrm{cr}}$ and $\mathrm{T}_{\mathrm{sk}}$ )

$Q_{b 1}=$ energy transferred by blood flow from the core to the skin (a function of $\mathrm{T}_{\mathrm{cr}}$ and $\mathrm{T}_{\mathrm{sk}}$ )

$E_{\text {diff }}=$ the energy loss by water vapor diffusion through the skin

$\mathrm{E}_{\text {rsw }}=$ the energy loss by evaporation as a result of regulatory sweat production (a function of $\mathrm{T}_{\mathrm{cr}}$ and $\mathrm{T}_{\mathrm{sk}}$ ) ${ }^{\mathrm{a}}$

$\mathrm{R}=$ the heat loss by radiation from the skin to the environment

$C=$ heat loss by convection from the skin to the environment

\footnotetext{
a This particular component is extremely important in the performance of the model yet the expression doesn't agree with all physiological observations reported in the literature. A discussion of this discrepancy is given in Appendix C.
} 


$$
\begin{aligned}
\mathrm{M} & =\text { metabolic heat production in the core } \\
\mathrm{E}_{\text {res }} & =\text { the latent respiration loss from the lungs }
\end{aligned}
$$

The form of the differential equation implies a lumped capacity analysis or in other words; the temperature of the skin and core are assumed"uniform throughout at every instant. The model is no doubt unrealistic in this respect, since the temperature can and does often vary widely within the body. Recently another dynamic model [19] has been developed in which 25 nodes (instead of 2 in the present mode1) are used to represent the thermal characteristics of the body, with four nodes each representing the head, trunk, arms, hands, legs and feet. The twenty-fifth node represents the central blood,

After formulating expressions for the various energy components and choosing appropriate numerical values for the various parameters (see below), the two differential equations are solved simultaneously (numerically' on a digital computer) to predict the time variation of the core and skin temperatures when the controllable parameters mentioned previously are specified. The model predicts a response that levels off at the end of approximately one hour. Once $\mathrm{T}$ and $\mathrm{T}$ have been determined, it is possible to work back through the analysis and calculate ${ }^{C}$ he regullatory sweat production (at the end of one hour), associated with the given environmental-human conditions. Mass transfer theory is then used to calculate the maximum possible evaporation cooling for given skin temperature and ambient temperature and vapor pressure. The ratio of calculated regulatory sweat evaporation to the maximum possible is given the notation of skin wettedness. It is then postulated as a result of experimental observation) that in warm environments, various conditions giving the same skin wettedness will also cause the same thermal sensation or feeling of warmth or coolness. This particular point is debatable and is the subject of discussion in Appendix $C$.

Lines of constant skin wettedness at the end of one hour's exposure are shown in Figure B10 for a resting subject $\left(58.2 \mathrm{~W} / \mathrm{m}^{2}\right)$ with the standard clothing $(0.6 \mathrm{clo})$ subjected to a small air velocity. This model has been proposed to ASHRAE and accepted as properly predicting the lines of constant thermal sensation. Consequently the lines in Figure B10 are labelled as lines of New Effective Temperature (ET*). Actually the model predicts zero regulatory sweating at $77^{\circ} \mathrm{F}\left(25^{\circ} \mathrm{C}\right)$ and $50 \% \mathrm{R} . \mathrm{H}$. or in other words, the $77 \mathrm{ET}^{*}$ lines correspond to a skin wettedness of 0 . Effective temperature lines below this temperature are simply drawn as parallel to the $77 \mathrm{ET} *$ line. The numerical values associated with the lines were determined by using the dry-bulb temperature at the intersection of the constant skin wettedness line and the $50 \%$ relative humidity curve. This in contrast to the original effective temperature where experimentally determine lines of constant thermal sensation were given numerical values corresponding to the dry-bulb temperature where the lines intersected the saturation or $100 \%$ relative humidity eurve. The labelling of the new effective temperature seems more reasonable since the values will more closely correspond to dry-bulb temperatures experienced in everyday living. However, the confusion that results from the two effective temperature scales can be seen by observing Figure B1l. The numerical values of the two scales are very widely separated. Since the old effective temperature was considered standard for almost 50 years, many guidelines and comfort limits will have to be reevaluated in terms of the new scale.

By observing the new scale, one sees that the dependence of thermal sensation on relative humidity at the higher temperatures is approximately the same as with the old effective temperature. This is quite acceptable since the old effective temperature scale was considered accurate at these temperatures. However, at temperatures near the comfort zone, the new model predicts a much less dependence on relative humfity which is in good agreement with the most recent studies. These two factors no doubt contributed significantly to the new scale's acceptance by ASHRAE.

The component expression used by Gagge, et. al. are as follows:

Rate of heat Loss by Convection (C):

$$
\begin{aligned}
& \mathrm{C}=\mathrm{h}_{\mathrm{c}}\left(\mathrm{T}_{\mathrm{sk}}-\mathrm{T}_{\mathrm{a}}\right) \mathrm{F}_{\mathrm{cl}} \mathrm{W} / \mathrm{m}^{2} \\
& \mathrm{~h}_{\mathrm{c}}=11.6 \mathrm{v}^{0.5} \mathrm{~W} /\left(\mathrm{m}^{2} \cdot{ }^{\circ} \mathrm{C}\right)
\end{aligned}
$$


Rate of Heat Loss by Radiation (R):

$$
R=h_{r}\left(T_{s k}-T_{a}\right) F_{c l} W / m^{2}
$$

Rate of Energy Loss Due to Evaporative Cooling in Respiratory Passage (E res ):

$$
\begin{gathered}
\mathrm{E}_{\text {res }}=.0023 \mathrm{M}\left(44-\mathrm{P}_{\mathrm{a}}\right) \mathrm{W} / \mathrm{m}^{2} \\
\mathrm{M}=\text { metabolic heat production, } \mathrm{W} / \mathrm{m}^{2}
\end{gathered}
$$

Rate of Energy Loss Due to Evaporative Cooling, Normal Skin Diffusion (E diff $)$ :

$$
\begin{aligned}
& E_{\text {diff }}=0.06 \cdot 2.2 h_{c}\left(P_{s k}-P_{a}\right) F_{p c l} W / m^{2} \\
& h_{c}=\begin{array}{c}
\text { convection coefficient given in the previous } \\
\text { section, } W /\left(\mathrm{m}^{2} \cdot{ }^{\circ} \mathrm{C}\right)
\end{array}
\end{aligned}
$$

Rate of Energy Loss Due to Evaporative Cooling, Regulatory Sweat Production (E ${ }_{\text {rsw }}$ :

$$
\begin{gathered}
\mathrm{E}_{\text {rsw }}=70\left(\mathrm{~T}_{\mathrm{cr}}-36.6\right)\left(\mathrm{T}_{\mathrm{sk}}-34.1\right) \mathrm{W} / \mathrm{m}^{2} \\
\text { for } \mathrm{T}_{\mathrm{cr}} \geq 36.6{ }^{\circ} \mathrm{C} \text { and } \mathrm{T}_{\mathrm{sk}} \geq 34.1{ }^{\circ} \mathrm{C} \\
\mathrm{E}_{\mathrm{rsw}}=0.0 \\
\text { for } \mathrm{T}_{\mathrm{cr}}<36.6{ }^{\circ} \mathrm{C} \text { or } \mathrm{T}_{\mathrm{sk}}<34.1{ }^{\circ} \mathrm{C}
\end{gathered}
$$

Maximum Evaporative Cooling Rate Possible $\left(\mathrm{E}_{\max }\right)$ :

$$
\begin{aligned}
& \mathrm{E}_{\text {max }}=2.2 \mathrm{~h}_{\mathrm{c}}\left(\mathrm{P}_{\mathrm{sk}}-\mathrm{P}_{\mathrm{a}}\right) \mathrm{F}_{\mathrm{pcl}} \mathrm{W} / \mathrm{m}^{2} \\
& \mathrm{~h}_{\mathrm{c}}=\begin{array}{l}
\text { convection coefficient given in the previous } \\
\text { section, } \mathrm{W} /\left(\mathrm{m}^{2} \cdot{ }^{\circ} \mathrm{C}\right)
\end{array}
\end{aligned}
$$

\section{Heat Stress Index}

The heat stress index was developed by Belding and Hatch at the University of Pittsburgh and first published in 1955 [20]. The postulation that forms the basis of their index is as follows: the metabolic production of the body minus the energy that can be given off by radiation and convection to the surroundings equals a quantity of energy that must be given off by sweat evaporation in order to maintain thermal equilibrium with the environment. Consequently the expression for the required evaporative cooling ( $E_{\text {req }}$ ) is

$$
\mathrm{E}_{\text {req }}=\mathrm{M}-\mathrm{R}-\mathrm{C}
$$

As mentioned previously, for a given skin temperature and ambient air temperature and vapor pressure, mass transfer theory can be used to calculate the maximum evaporative cooling possible. The heat stress index is defined as being equal to the ratio of the two quantities $\mathrm{E}_{\text {req }} / \mathrm{E}_{\max }$ multiplied by 10 . Belding and Hatch assumed a constant skin temperature of $35{ }^{\circ} \mathrm{C}$ and used the most up-to-date (at that time) expressions for radiation and convection heat loss from the body to calculate values of the index and present them in nomographs as functions of the metabolic production and environmental conditions. In addition, physiological and hygienic implications of 8 hour exposures to various heat stresses were given and are shown in Table B1. 
Calculations have been made using the original expressions for radiation and convection losses and maximum evaporative cooling from the body for a resting person subjected to a uniform environment with an air velocity of $20 \mathrm{fpm}(0.1 \mathrm{~m} / \mathrm{s})$. The results are shown in Figure B12 in the form of lines of constant heat stress index. Notice that using these expressions sweat evaporation to maintain body equilibrium is not required until the environment reaches approximately $82^{\circ} \mathrm{F}\left(27.8^{\circ} \mathrm{C}\right)$. This is in definite contrast to Gagge's effective temperature model which shows regulatory sweat production starting at approximately $5^{\circ} \mathrm{F}\left(2.2{ }^{\circ} \mathrm{C}\right)$ lower. The expressions were reevaluated and updated in 1966 by McKarns and Brief [21]. ASHRAE recommends in their 1972 Handbook of Fundamentals [13] the calculation of the index using the same expressions for $R, C$ and $E_{\max }$ that were used in the new effective temperature model. In addition, expressions for dry and latent heat losses from the lung passages have been subtracted from the right side of equation (7) and the results of new calculations are shown in Figure B13 and compared with the original lines of constant heat stress in Figure B14. The latest computations seem to be reasonable since the evaporative cooling as a result of sweat production is seen to be necessary at a temperature as low as $74{ }^{\circ} \mathrm{F}\left(23.3^{\circ} \mathrm{C}\right)$.

In retrospect, it can be seen that the quantity called skin wettedness in the new effective temperature model is very similar to a heat stress index. Instead of dividing the maximum possible evaporative cooling rate into a required evaporative cooling rate, the maximum value is divided into a sweat cooling rate that is predicted from known physiological responses.

As stated above, the expressions for $C, R, E_{\text {res }}$, $E_{\text {diff }}$, and $E_{\max }$ used in computing the heat stress index according to ASHRAE [13] are identical with those used in computing ET*. In addition, the expression for $D$ was:

$$
\begin{gathered}
\mathrm{D}=.0014 \mathrm{M}\left(34-\mathrm{T}_{\mathrm{a}}\right) \mathrm{W} / \mathrm{m}^{2} \\
\mathrm{M}=\text { metabolic heat production, } \mathrm{W} / \mathrm{m}^{2}
\end{gathered}
$$

The component equations used in calculating HSI (original) are as follows:

Rate of Heat Loss by Convection (C):

$$
\mathrm{C}=2 \mathrm{v}^{0.5}\left(95 .-\mathrm{T}_{\mathrm{a}}\right) \mathrm{Btu} / \mathrm{h}
$$

where

$$
\begin{aligned}
\mathrm{v} & =\text { air velocity, } \mathrm{fpm}_{\mathrm{pm}} \\
\mathrm{T}_{\mathrm{a}} & =\text { ambient air temperature, }{ }^{\circ} \mathrm{F}
\end{aligned}
$$

Rate of Heat Loss by Radiation (R):

$$
\begin{aligned}
& \mathrm{R}=22\left(95-\mathrm{T}_{\mathrm{MRT}}\right) \mathrm{Btu} / \mathrm{h} \\
& \mathrm{T}_{\mathrm{MRT}}=\text { mean radiant temperature, }{ }^{\circ} \mathrm{F}
\end{aligned}
$$

Maximum Evaporative Cooling Rate Possible ( $\left.\mathrm{E}_{\max }\right)$ :

$$
\begin{aligned}
\mathrm{E}_{\max } & =10 \mathrm{v} \cdot 4\left(\mathrm{P}_{\mathrm{sk}}-\mathrm{P}_{\mathrm{a}}\right) \mathrm{Btu} / \mathrm{h} \\
\mathrm{v} & =\text { air velocity, fpm }
\end{aligned}
$$

\section{Thermal Comfort When Equilibrium is Maintained by Sweating}

Before publishing a new effective temperature model, Gagge and his associates published still another model for indicating thermal comfort [22] that is very similar to the heat stress index. The cooling due to evaporation of sweat production necessary to maintain body thermal equilibrium is determined by subtracting the body heat loss by radiation, convection, latent loss from the lung passages and the loss due to evaporation of moisture diffusing 
through the skin from the metabolic heat production. The resulting required evaporative cooling is divided by the maximum possible and then multiplied by 100 to give a factor "percentage of wettedness".

The main difference between this model and the two previous ones mentioned is that the skin temperature is not held constant as in the case of heat stress index or predicted from known physiological responses as with the new effective temperature model, but rather assumed to be a polynomial function of the environment temperature (see below). The function was determined by fitting an equation (by regression analysis) to experimental data that was determined at the John B. Pierce Foundation. Computations were made using the model and the results are shown in Figure B15 for a resting person with the standard clothing (0.6 clo) subjected to a uniform emvironment with an air velocity of $20 \mathrm{fpm}(0.1 \mathrm{~m} / \mathrm{s})$.

The equations used in computing the values of $\mathrm{C}, \mathrm{R}, \mathrm{E}_{\text {res, }}$, and $\mathrm{E}_{\mathrm{max}}$ were identical to those used in computing ET*. In addition, the following two expressions were used:

Rate of Energy Loss Due to Evaporative Cooling, Normal Skin Diffusion ( $\left.\mathrm{E}_{\mathrm{diff}}\right)$ :

$$
\mathrm{E}_{\text {diff }}=.35\left(\mathrm{P}_{\mathrm{sk}}-\mathrm{P}_{\mathrm{a}}\right) \mathrm{F}_{\mathrm{pcl}} \mathrm{W} / \mathrm{m}^{2}
$$

Relation for Skin Temperature as a Function of Ambient Air Temperature:

$$
\mathrm{T}_{\text {sk }}=25.49+.249 \mathrm{~T}_{\mathrm{a}}{ }^{\circ} \mathrm{F}
$$

\section{Index of Thermal Stress}

Givoni [23, 24] has done extensive work over the past few years on measuring and evaluating heat stress. Having compared actual response with the predictions of many models and found much disagreement, he developed his own "index of thermal stress" (ITS) which according to additional extensive experiments conducted by Givoni correctly predicts the physiological strain imposed on resting and working people by metabolic and environmental factors. The index is structured exactly like the heat stress index with two important differences. An expression has been included for the radiant heat load due to solar radiation so that the index can predict responses for people working or resting outdoors. This is not directly applicable to this study but certainly makes a useful addition to the field of heat stress evaluation. The other difference is a factor called cooling efficiency of sweating (f) and is included in the equation as follows:

$$
\mathrm{E}_{\text {req }}=[M-R-C] \frac{1}{f}
$$

The concept is that where other indices assume al1 the sweat produced or required is evaporated and provides cooling for the body, this may not be true. For example, some of the evaporation could occur in the clothing and not result directly in cooling for the body. Calculations using Givoni's expressions have been made and are shown in Figure B16. The data used was for a resting person ( $=100 \mathrm{kcal}$ ), subjected to a uniform environment with an air velocity of $.1 \mathrm{~m} / \mathrm{s}$. The clothing ensemble chosen (affects the radiation and convection, expression) was very similar to the Kansas State standard clothing. It should be noted that the upper ijirit for comfort (according to Givoni) is associated with an evaporative 10 ss of $60 \mathrm{~g} / \mathrm{h}$ and that distinct thermal discomfort is experienced progressively as the sweat rate is elevated above $100 \mathrm{~g} / \mathrm{h}$.

Even though Givoni states that the model predicts a sweat rate that is in agreement with experimentally measured rates, the results shown in Figure B16 appear questionable. Sweating is seen necessary at approximate $1 y 64{ }^{\circ} \mathrm{F}\left(17.8{ }^{\circ} \mathrm{C}\right)$. The index does show small dependence on relative humidity at the lower temperatures and somewhat more dependence at the higher temperature which agrees with the new effective temperature mode1. However, it should be remembered that what is shown in the figure is sweat rate and not the ratio between the sweat rate and some maximum possible. 
The equations used to calculate the values of ITS are as follows:

Rate of Heat Loss by Convection (C):

$$
\mathrm{c}=\alpha \mathrm{v}^{0.3}\left(35-\mathrm{T}_{\mathrm{a}}\right) \mathrm{kcal} / \mathrm{h} \text {. }
$$

Rate of Heat Loss by Radiation (R):

$$
\text { accounted for in the convection term by replacing } \mathrm{T}_{\mathrm{a}} \text { by } \mathrm{T}_{\mathrm{MRT}}
$$

Maximum Evaporative Cooling Rate Possible $\left(\mathrm{E}_{\max }\right)$ :

$$
\mathrm{E}_{\max }=\mathrm{PV}^{\cdot 3}\left(42-\mathrm{P}_{\mathrm{a}}\right) \mathrm{kcal} / \mathrm{h}
$$

Relation for sweating Efficiency:

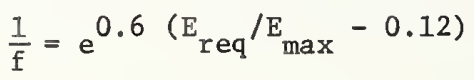

\section{Predicted Four Hour Sweat Rate}

The P4SR index was developed by McArdle and his colleagues during World War II at the Royal Naval Research Establishment [25]. Sweat rate was measured for fit, young men dressed in shorts only or overall and shorts when subjected to many different combinations of temperature, humidity, and air velocities for four hour periods. The results were presented in the form of nomographs and have been adapted to a psychrometric chart as shown in Figure B17. The particular conditions for this chart are a metabolic production of $54 \mathrm{kcal} /\left(\mathrm{m}^{2} \cdot \mathrm{h}\right)$, a uniform radiation environment (mean radiant temperature equal to air temperature), and an air velocity of $10 \mathrm{fpm}(0.05 \mathrm{~m} / \mathrm{s})$. As was the case with the original heat stress index, sweat production is shown to start only after the temperature has reached approximately $80^{\circ} \mathrm{F}\left(26.7^{\circ} \mathrm{C}\right)$. Based on the experiments, a limit of 3.0 was established as the upper tolerable limit for daily, exposure.

\section{Wet-Dry Index}

In 1957 Lind and Hellon [26] proposed the use of the Oxford Index or wet-dry index to assess the severity of hot climates. It is simply a combination of the wet-bulb and dry-bulb temperatures $\left({ }^{\circ} \mathrm{F}\right)$ according to

$$
W D=0.85 \mathrm{~T}_{\mathrm{wb}}+0.15 \mathrm{~T}_{\mathrm{db}}
$$

The extreme dependence on relative humidity is obvious and is shown in Figure B18. Due to its simplicity it has been used quite often in setting limits or correlating data in extremely hot and wet conditions where there is no radiant stress and very low air velocity.

\section{Temperature-Humidity Index}

Another index very similar to the Oxford Index is one called the temperature-humidity index defined by

$$
\mathrm{THI}=0.4\left(\mathrm{~T}_{\mathrm{db}}+\mathrm{T}_{\mathrm{wb}}\right)+4.8
$$

where all values are in ${ }^{\circ} \mathrm{C}$. This index like the last, attempts to combine the effect of temperature and humidity in environments where radiant stress and air velocity are not important. Figure B19 shows that the THI index is much less dependent on humidity than the 
W-D index was. As an example of its use, Bridger and Helfand [27] correlated death rates during the 1966 heat wave in St. Louis and found that when the 24 hour average of the THI was greater than $81^{\circ} \mathrm{F}\left(27^{\circ} \mathrm{C}\right)$, there was an usually large number of deaths due to heat stroke.

Table B2 has been included here as a summary to give the range of application of the various indices that have been discussed. 
1. F. C. Houghten and C. P. Yaglou, "Determination of the Comfort Zone", ASHVE Transactions, Vo1. 29, p. 361, 1923.

2. T. Bedford, "Environmental Warmth and Its Measurement", MRC War Memorandum No. 17, HMSO, London, 1946.

3. N. Koch, B. H. Jennings and C. M. Humphreys, "Sensation Responses to Temperature and Humidity Under Still Air Conditions in the Comfort Range", ASHRAE Transactions, Vol. 66, p. 264,1960 .

4. H. Missenard, "Equivalences thermiques des ambiences; equivalences de passage; equivalences de sejour", Chaleur et Industrie, July-August, 1948.

5. R. G. Nevins, F. H. Rohles, W. E. Springer, and A. M. Feyerherm, "A Temperature Humidity Chart for Thermal Comfort of Seated Persons", ASHRAE Transactions, Vo1. 72, Part 1, 1966.

6. R. G. Nevins and F. H. Rohles, "The Nature of Thermal Comfort for Sedentary Man", ASHRAE Transactions, Vo1. 77, Part 1, 1971.

7. O. Seppanen, P. E. McNal1, D. M. Munson, and C. H. Sprague, "Thermal Insulating Values for Typical Clothing Ensembles", ASHRAE Transactions, Vol. 78, Part 1, 1972.

8. F. H. Rohles, "Psychological Aspects of Therma1 Comfort", ASHRAE Journal, Vo1. 13, pp. 86-90, 1971.

9. F. H. Rohles, "The Modal Comfort Envelope - A New Approach Toward Defining the Therma1 Environment in Which Sedentary Man is Comfortable", ASHRAE Transactions, Vo1. 76, pp. 2.1-2.8, 1970 .

10. F. H. Rohles, "The Revised Modal Comfort Envelope", ASHRAE Transactions, 1973.

11. F. H. Rohles and M. A. Johnson, "Thermal Comfort in the Elderly", ASHRAE Transactions, Vo1. 78, pp. 131-137, 1972.

12. F. H. Rohles, J. E. Woods, and R. G. Nevins, "The Influence of Clothing and Temperature on Sedentary Comfort", ASHRAE Transactions, 1973.

13. ASHRAE Handbook of Fundamentals, ASHRAE, 345 East 47 th Street, New York, New York 10017, 1972 .

14. ASHRAE Standard 55-74, "Thermal Environmental Conditions for Human Occupancy", ASHRAE, 345 East 47th Street, New York, New York 10017, 1966.

15. F. H. Rohles and R. G. Nevins, "Thermal Comfort: New Directions and Standards", Aerospace Medicine, Vol. 44, Part 7, pp. 730-738, 1973.

16. P. O. Fanger, Thermal Comfort, Danish Technical Press, Copenhagen, 1970.

17. R. G. Nevins and P. E. McNall, Jr., "Proposed Classification of Human Response to the Environment", ASHRAE Journal, Pp. 44-47, June 1971.

18. A. P. Gagge, J. A. J. Stolwijk, and Y. Nishi, "An Effective Temperature Scale Based on a Simple Model of Human Physiological Regulatory Response", ASHRAE Transactions, Vol. 77, Part 1, 1971.

19. J. A. J. Stolwijk, "A Mathematical Model of Physiological Temperature Regulation in Man", NASA Report CR-1855, August 1971.

20. H. S. Belding and T. F. Hatch, "Index for Evaluating Heat Stress in Terms of Resulting Physiological Strain", Heating, Piping, Air Conditioning, Vol 27, p. 129, 1955. 
21. J. S. McKarns, and R. S. Brief, "Nomographs Give Refined Estimates of Heat Stress Index", Heating, Piping and Air Conditioning, Vo1. 38, p. 113, 1966.

22. A. P. Gagge, J. A. J. Stolwijk, and Y. Nishi, "The Prediction of Thermal Comfort When Equilibrium is Maintained by Sweating", ASHRAE Transactions, Vo1. 75, Part II, p. 108, 1969.

23. B. Givoni, Man, Climate, and Architecture, Elsevier Publishing Company, 1969.

24. B. Givoni, "Estimation of the Effect of Climate on Man: Development of a New Thermal Index", Research Report to UNESCO, Building Research Station, Technion, Haifa, Israel, 1963.

25. B. McArdle, W. Durham, H. E. Holling, W. S. S. Ladell, J. W. Scott, M. L. Thomson, and J. S. Weiner, "The Prediction of the Physiological Effects of Warm and Hot Environments", MCR R. N. P.,. Vo1. 47, P. 391, 1947.

26. A. R. Lind, and R. F. Hellon, "Assessment of Physiological Severity of Hot Climates", Journal of Applied Physiology, Vo1. II, p. 35, 1957.

27. C. A. Bridger and L. A. Helfand, "Mortality From Heat During July 1966 in Illinois", Int. Jour. Blomet., Vo1. 12, p. 51, 1968. 


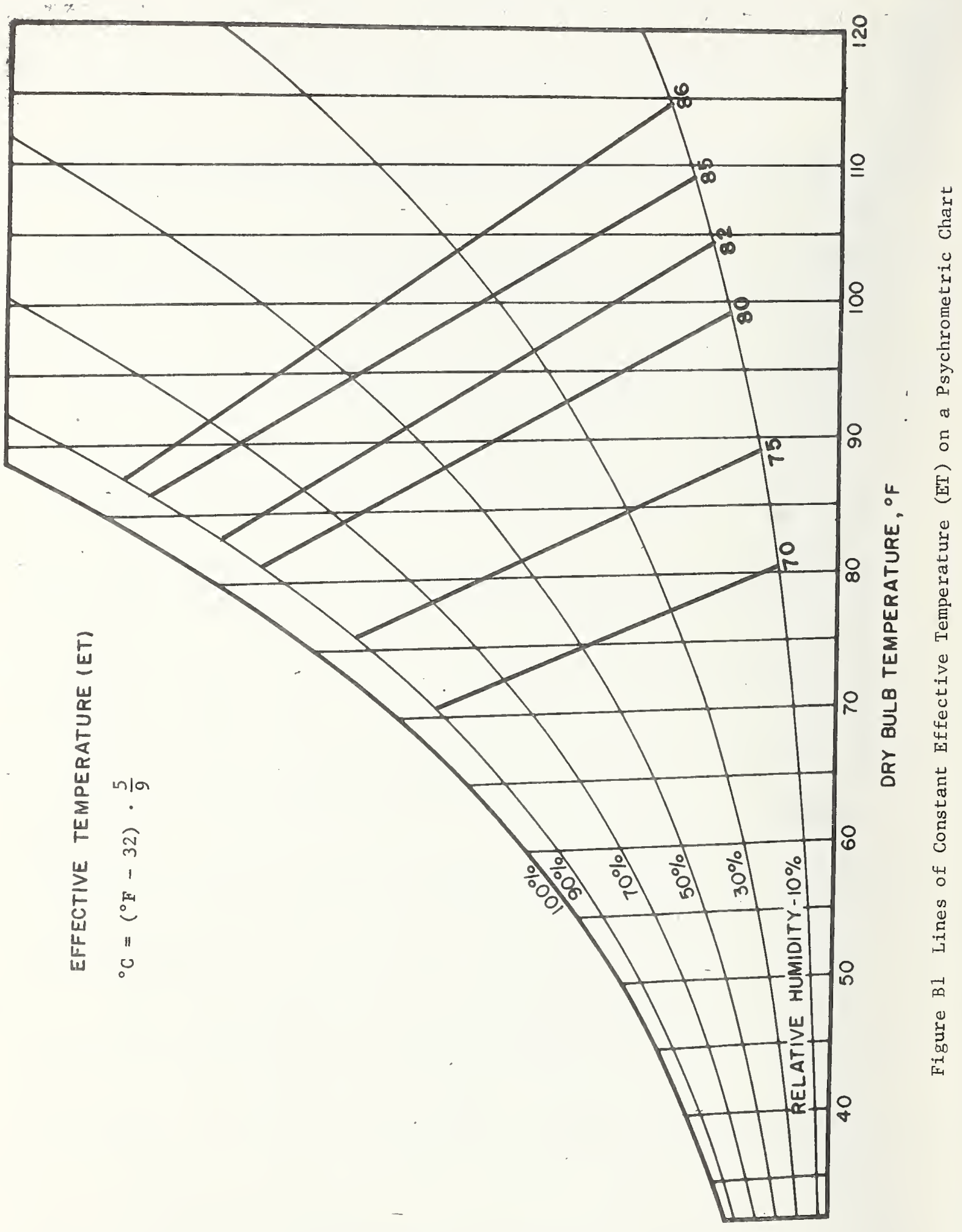




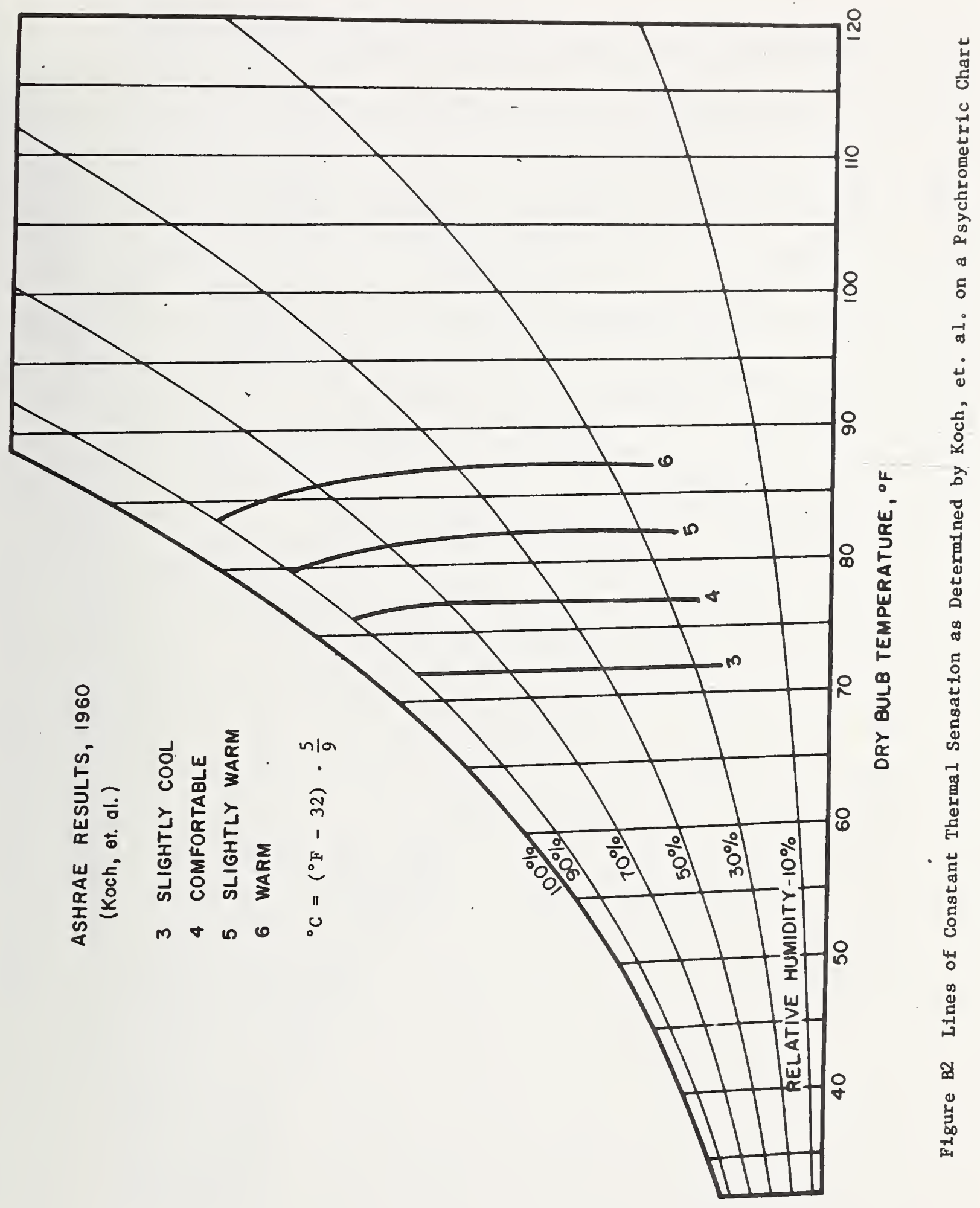




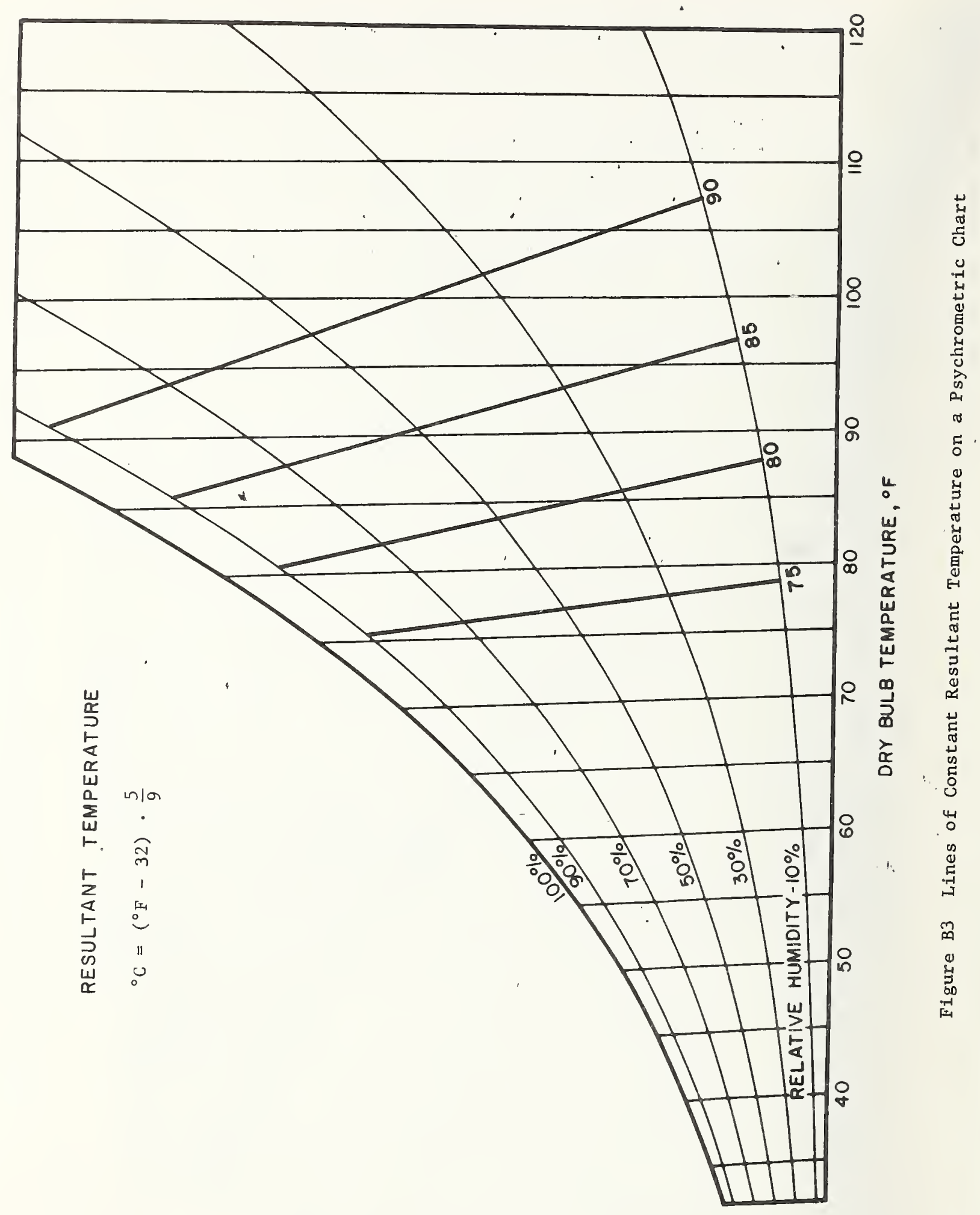




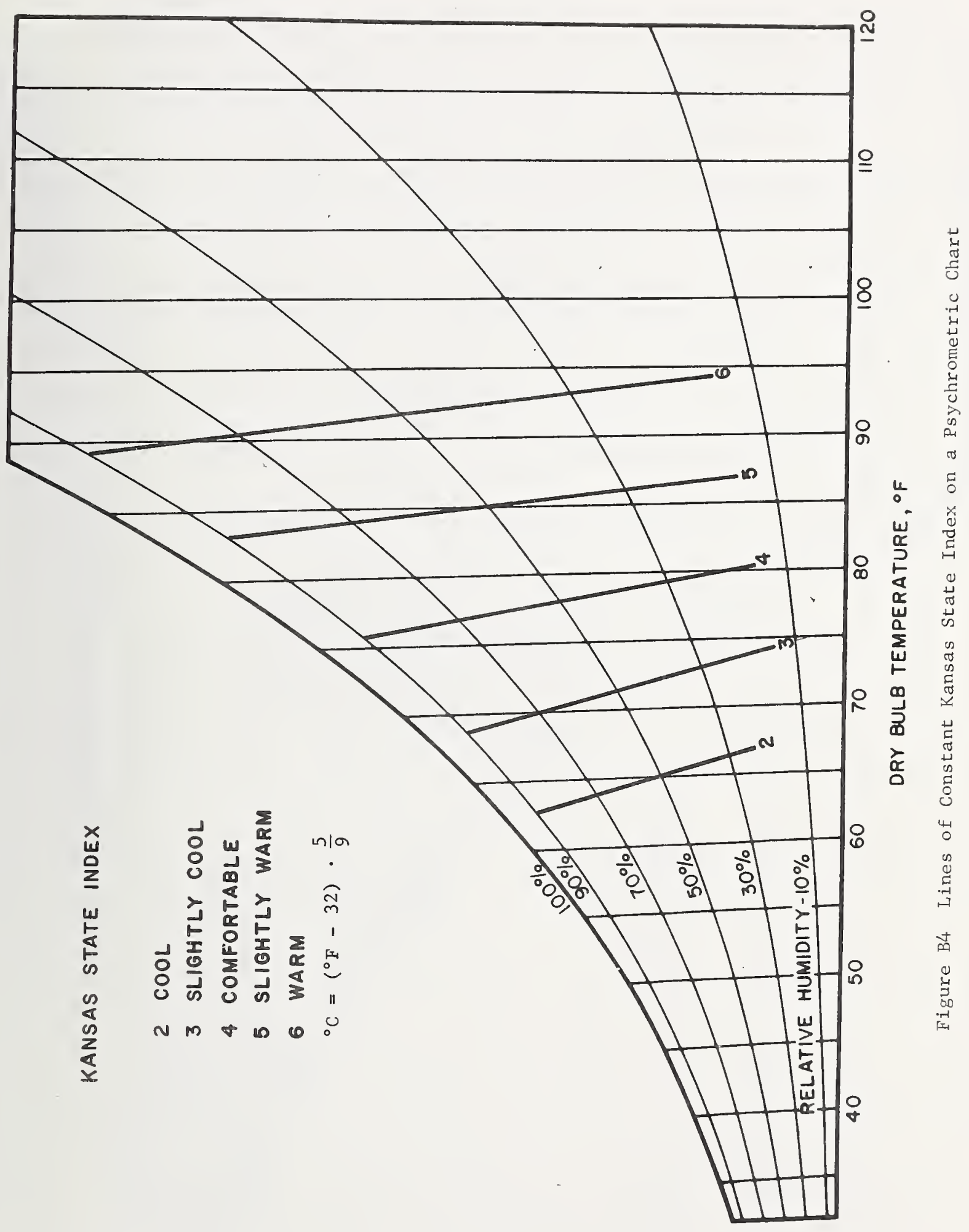




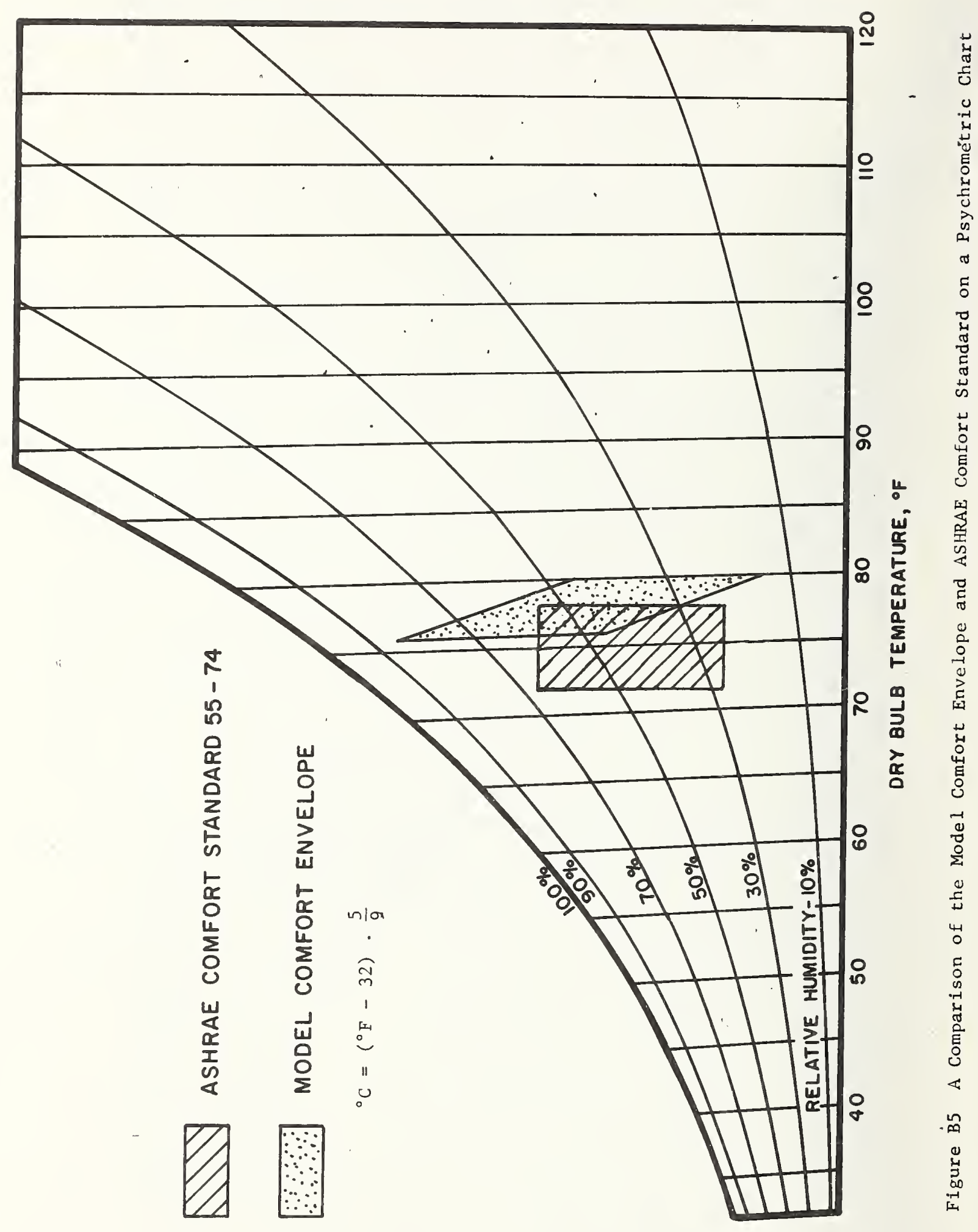




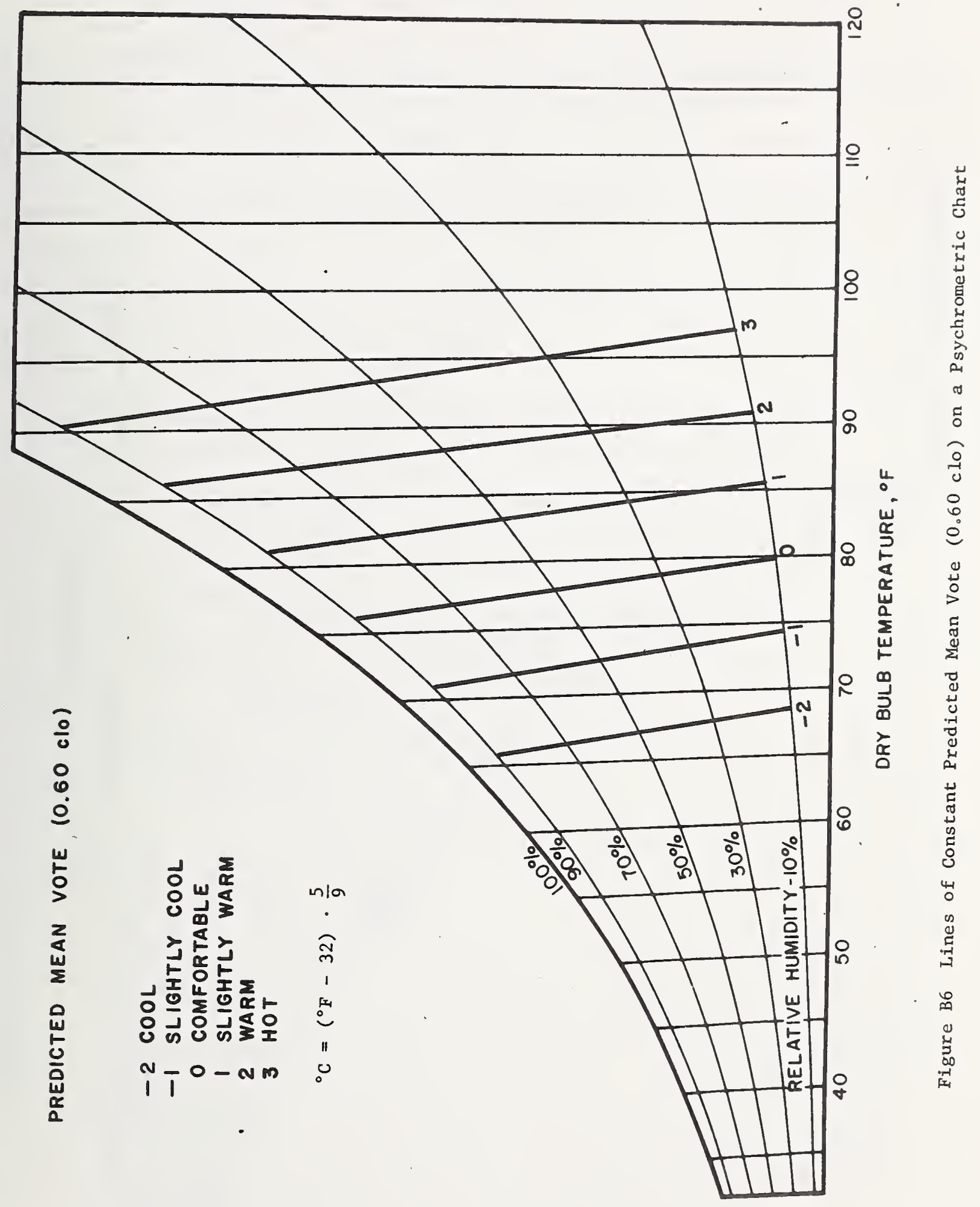




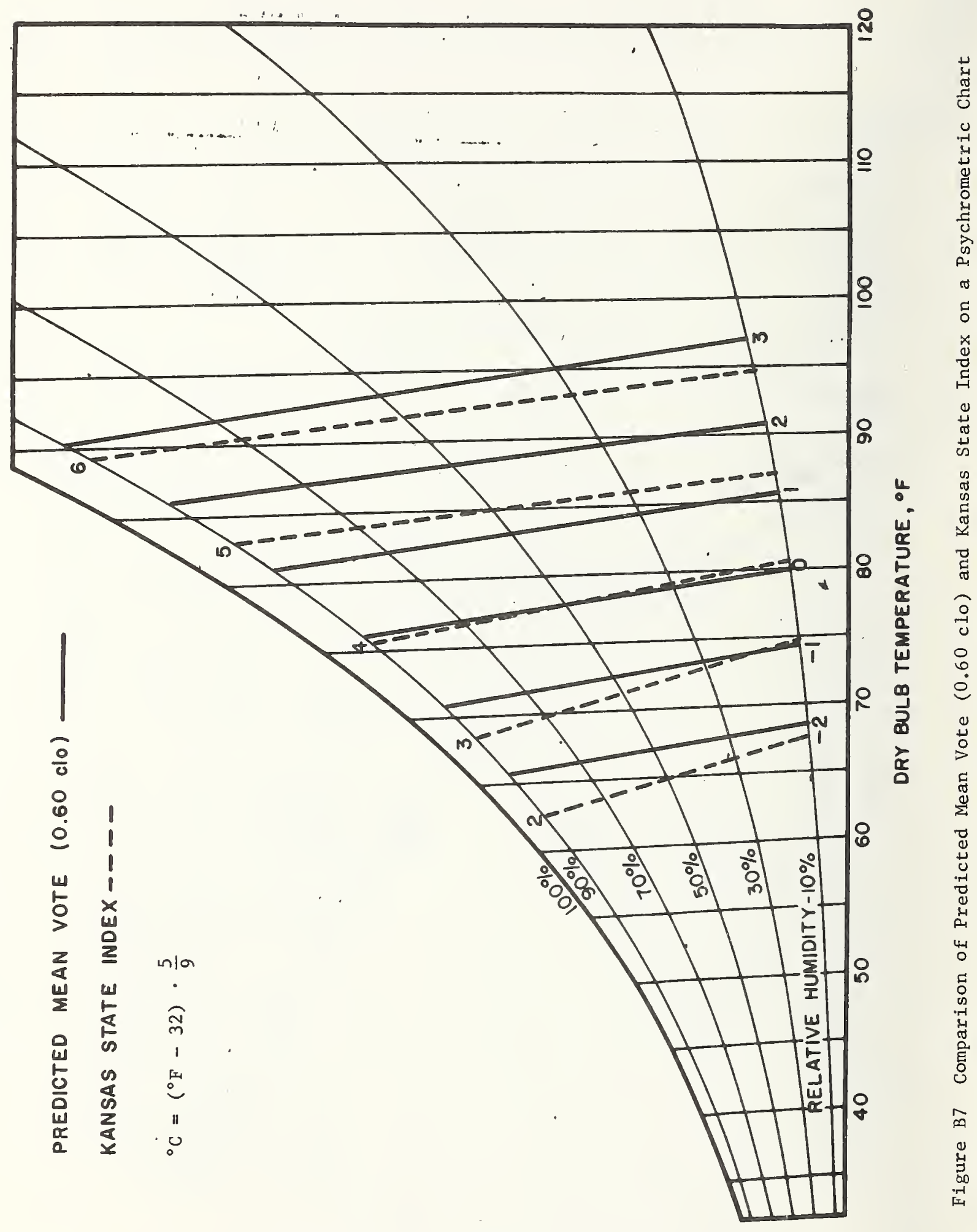




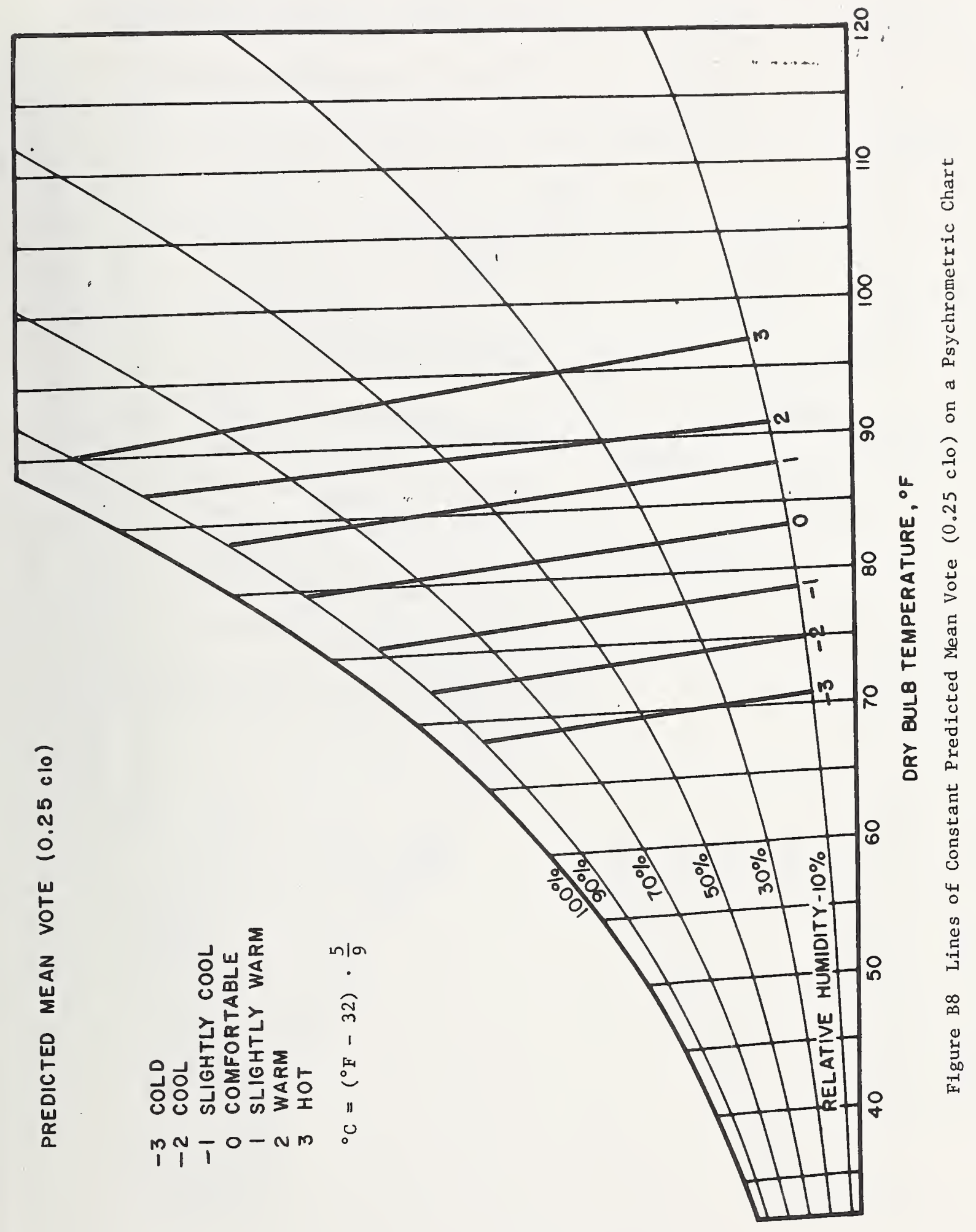




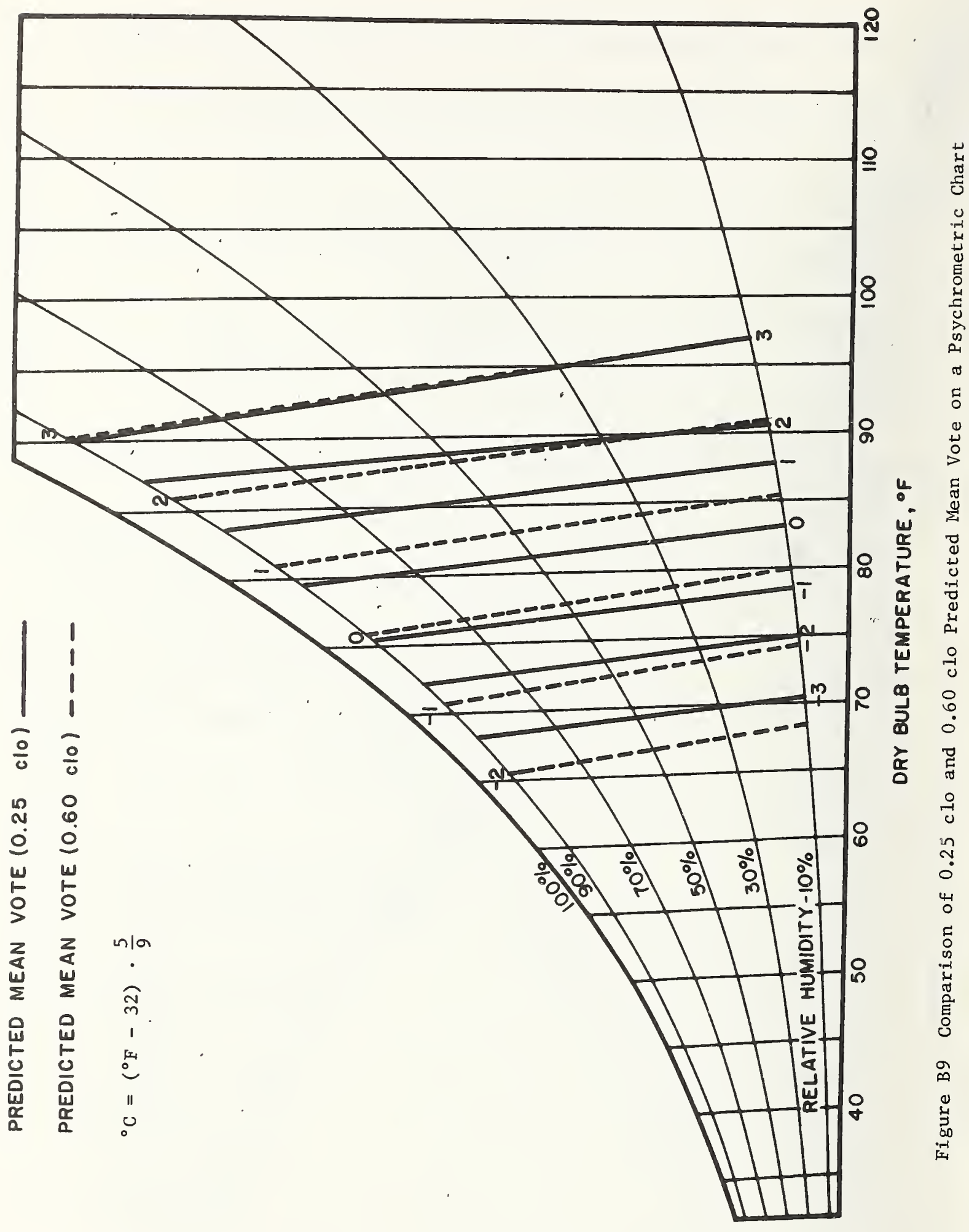




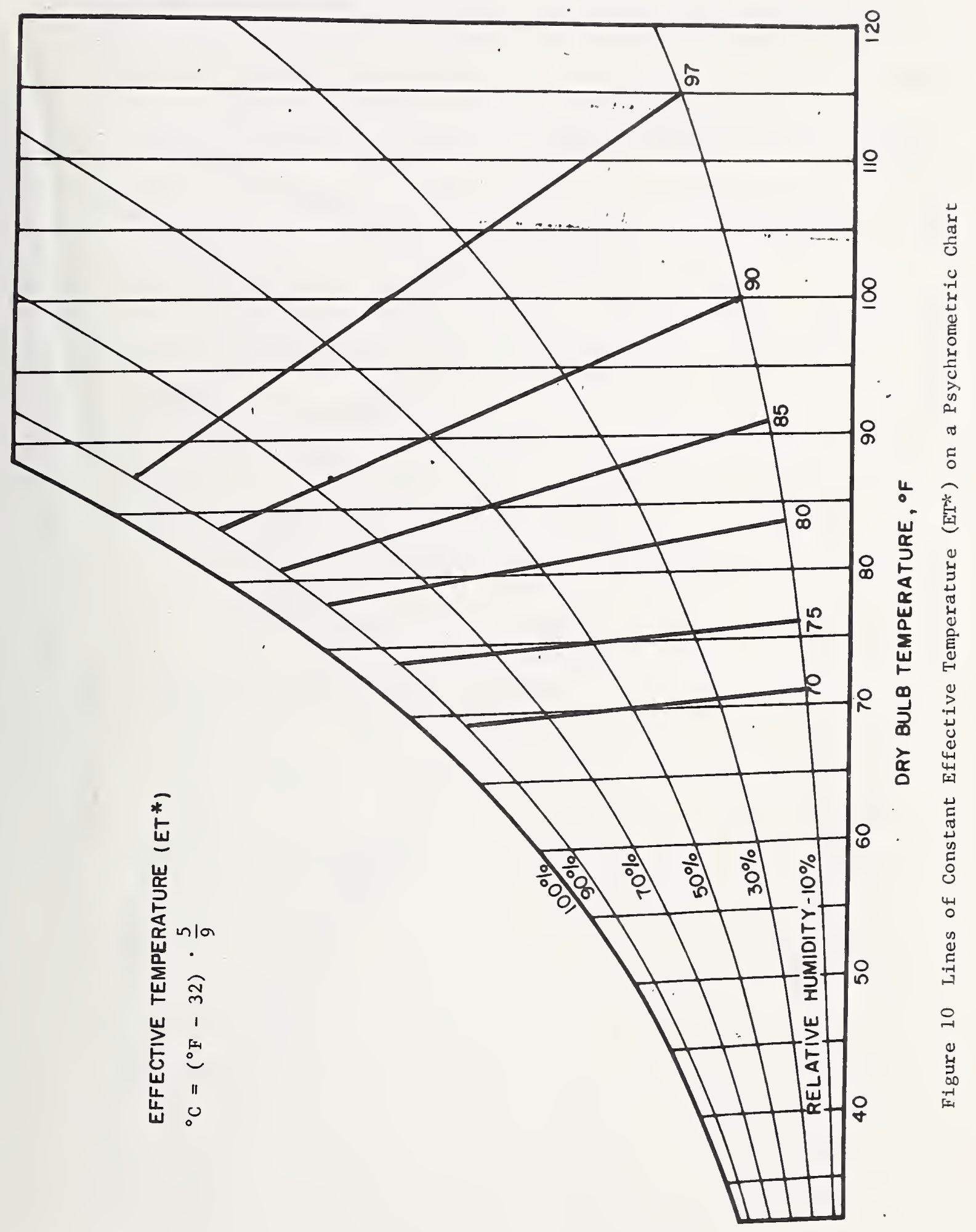




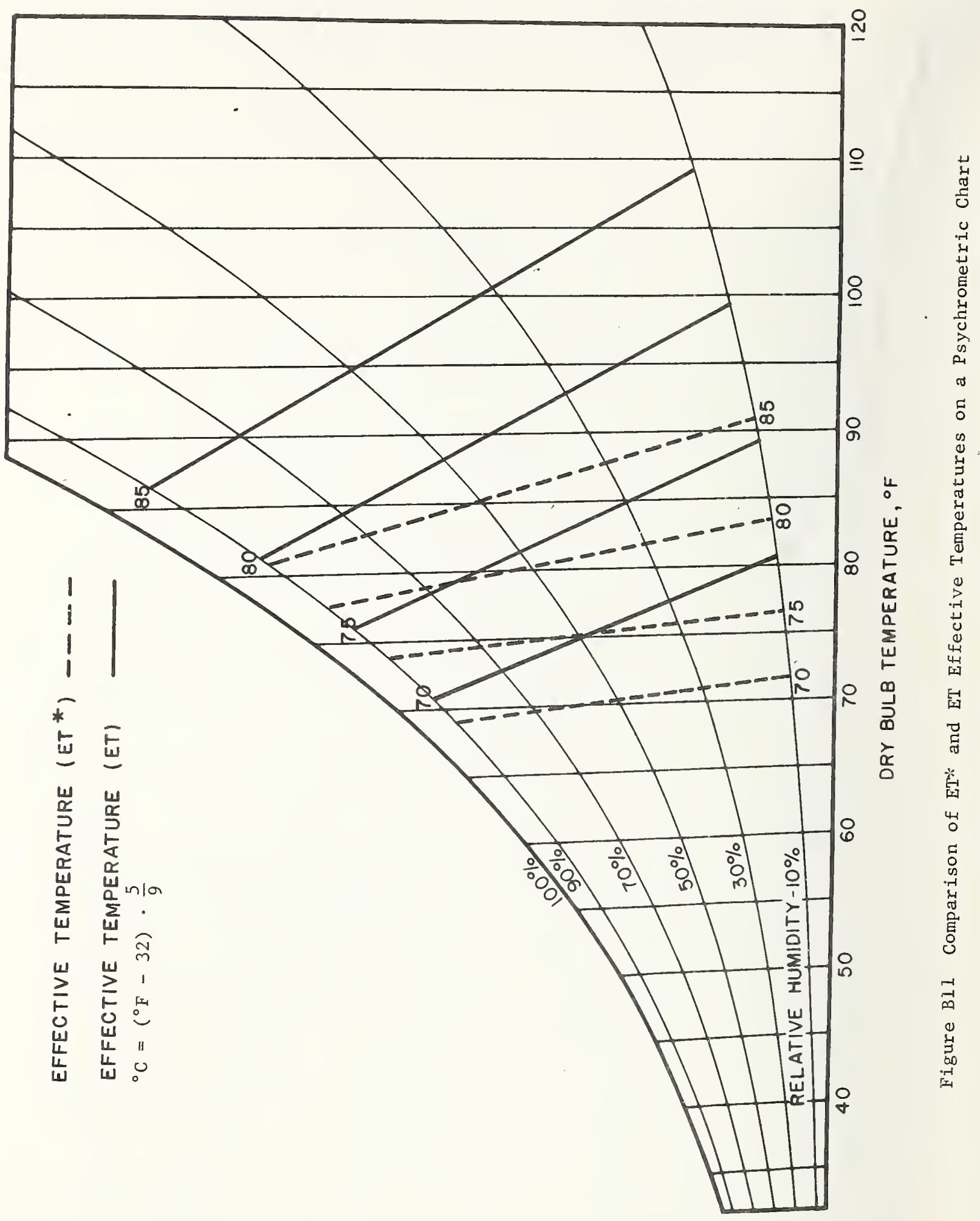




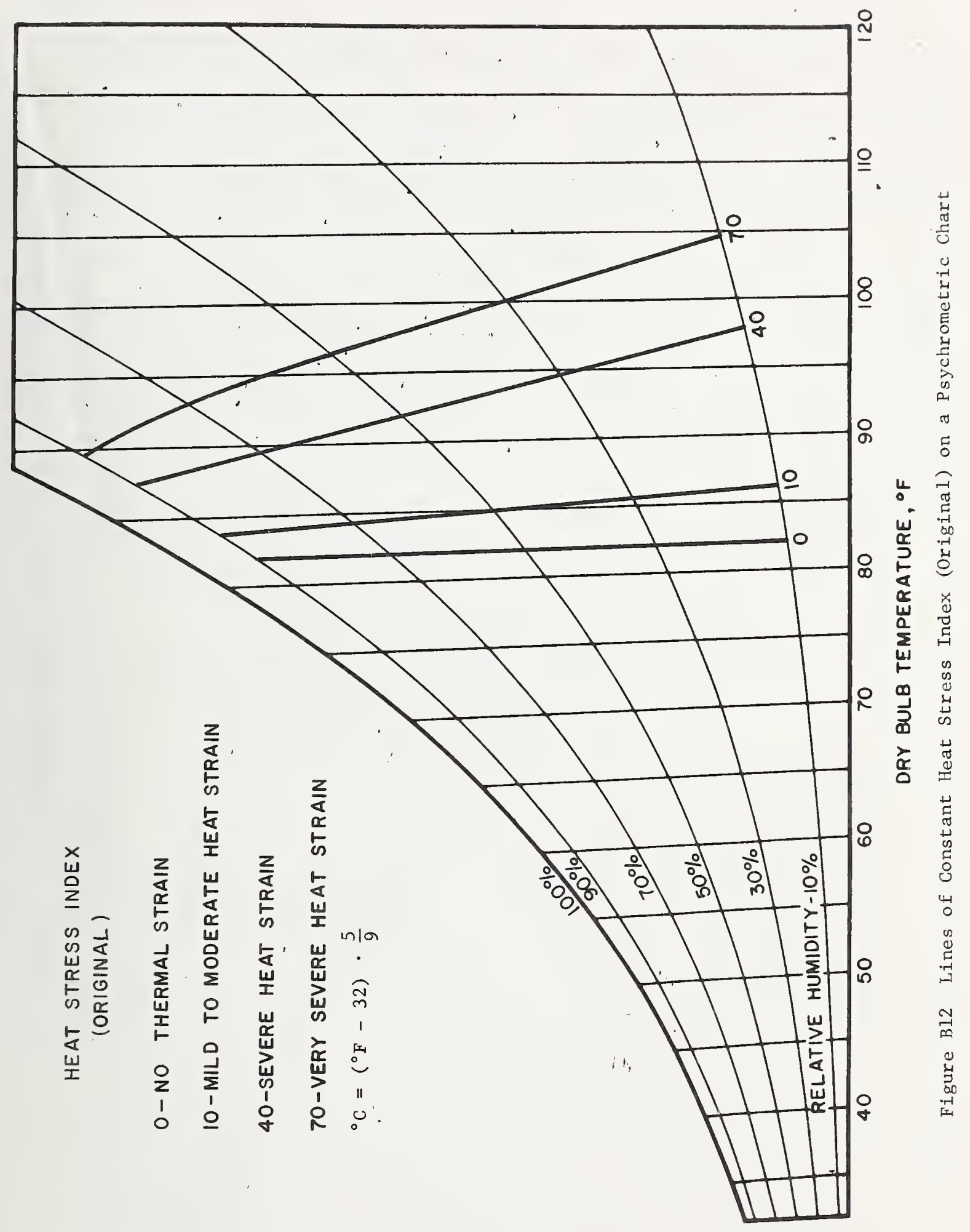




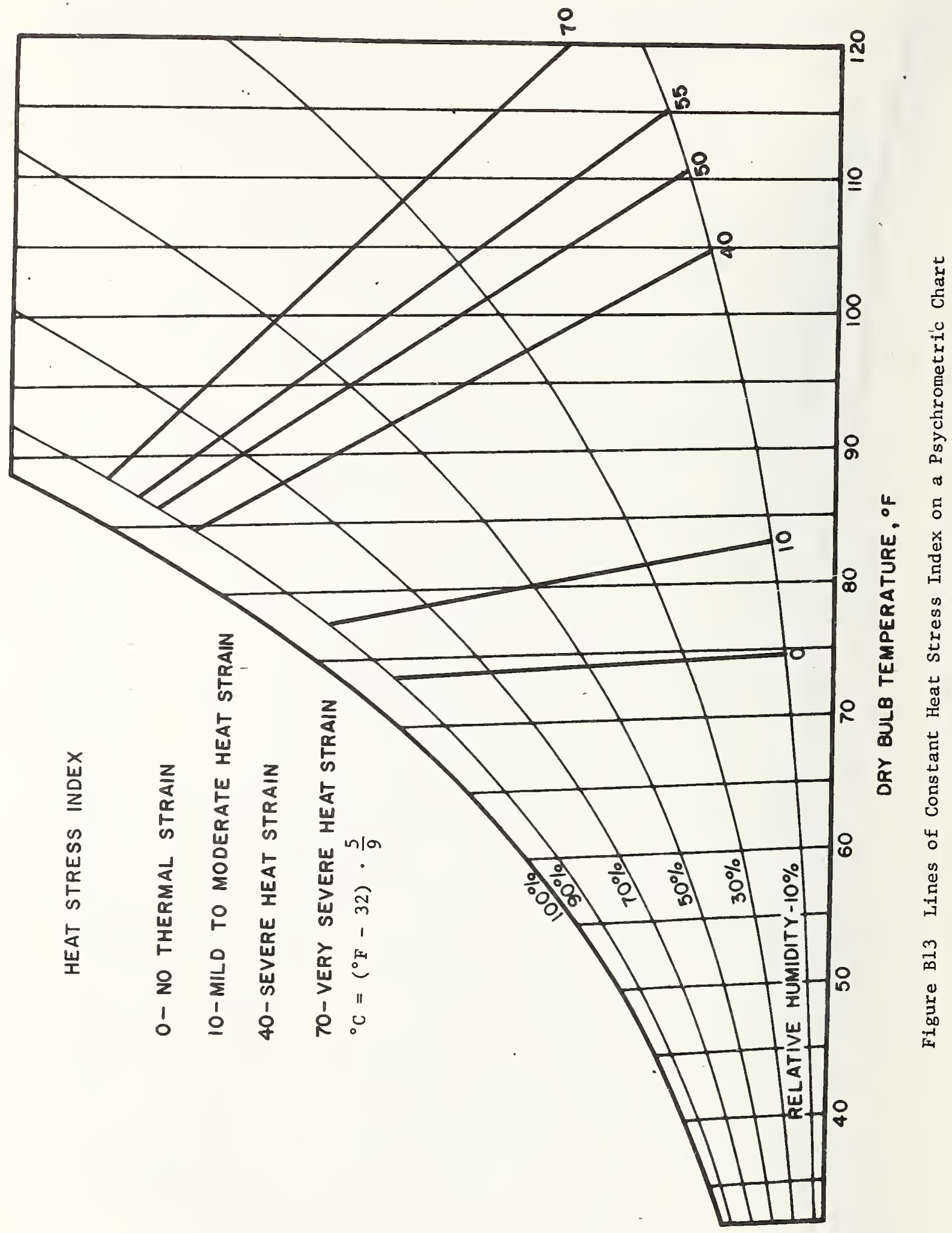




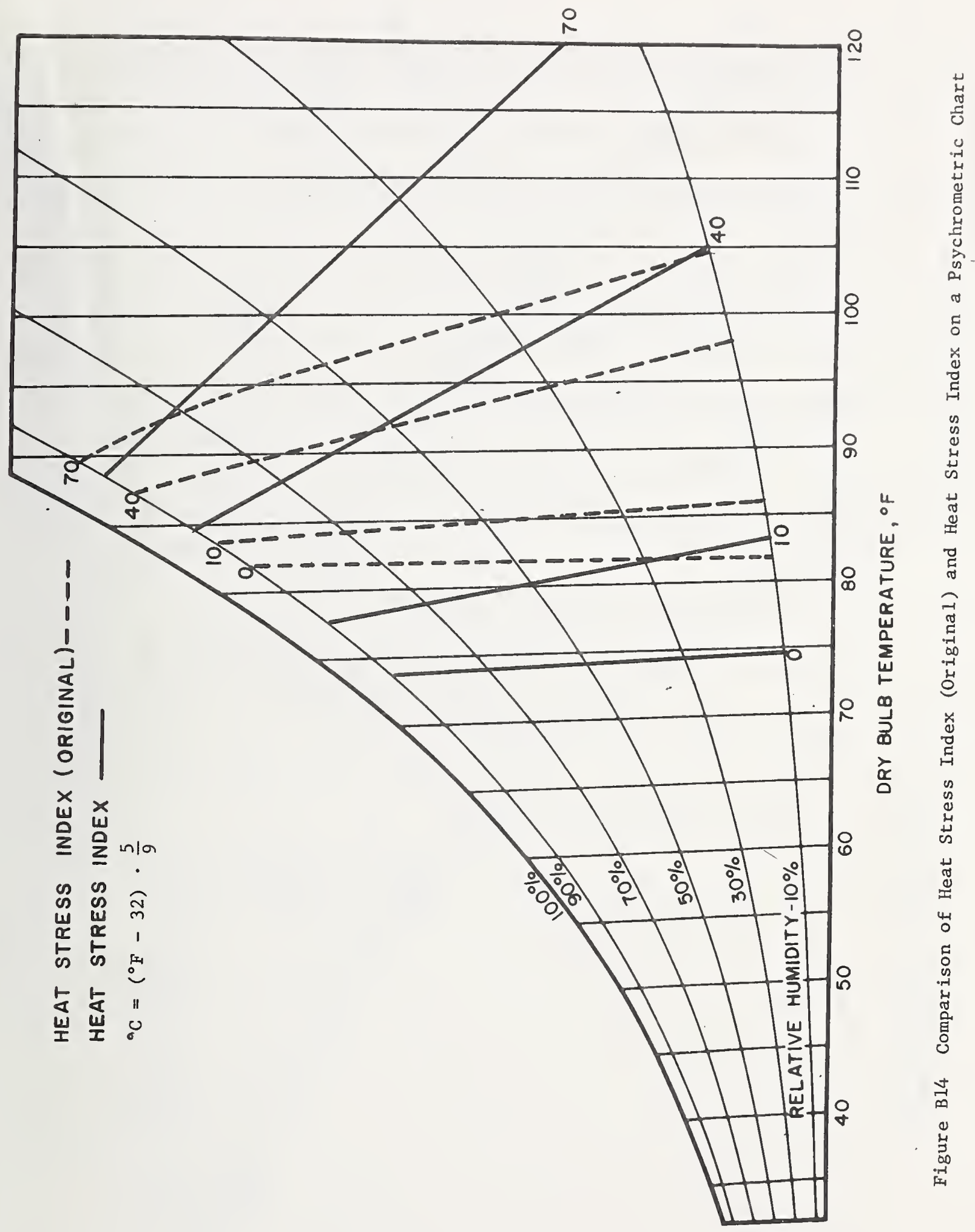




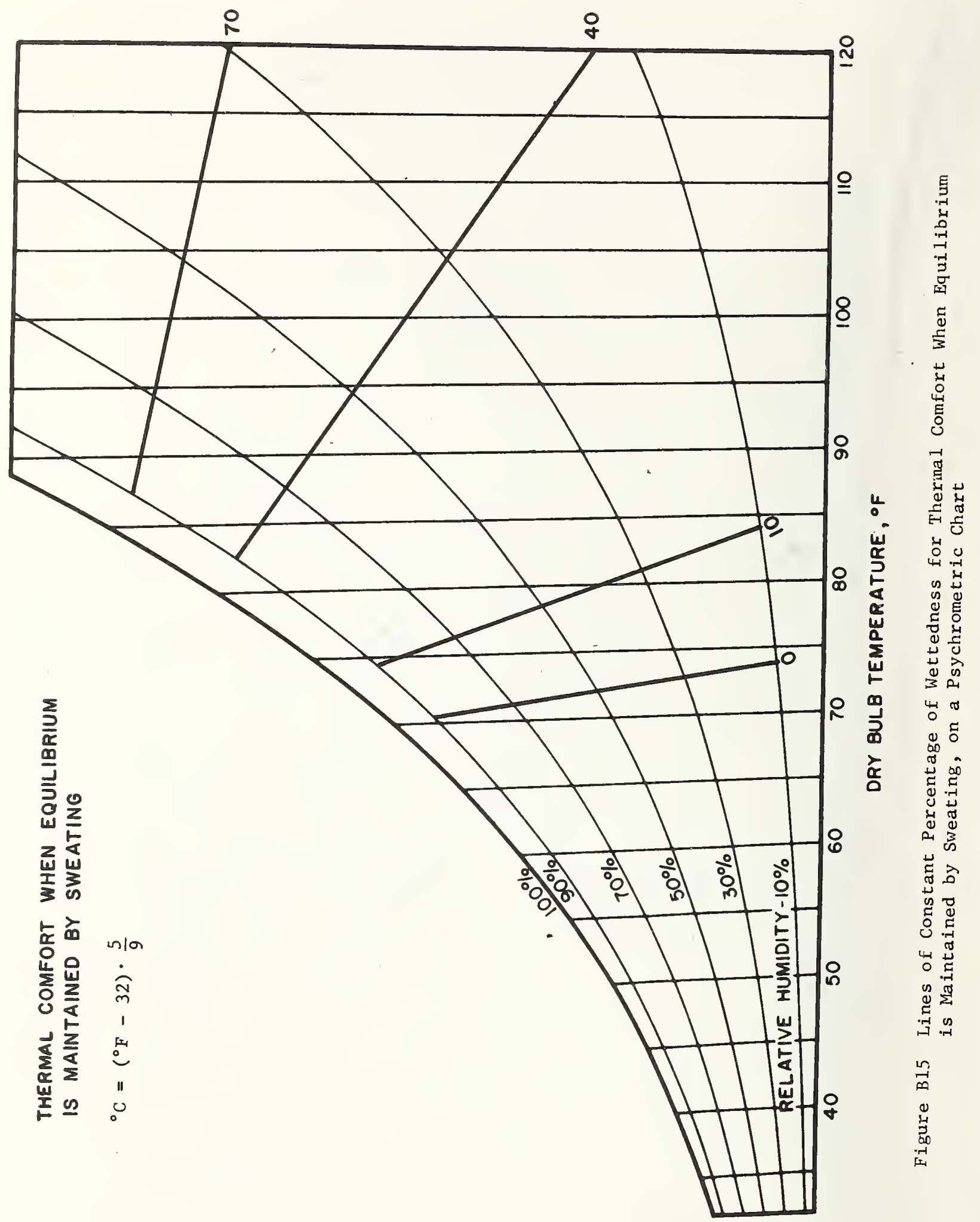




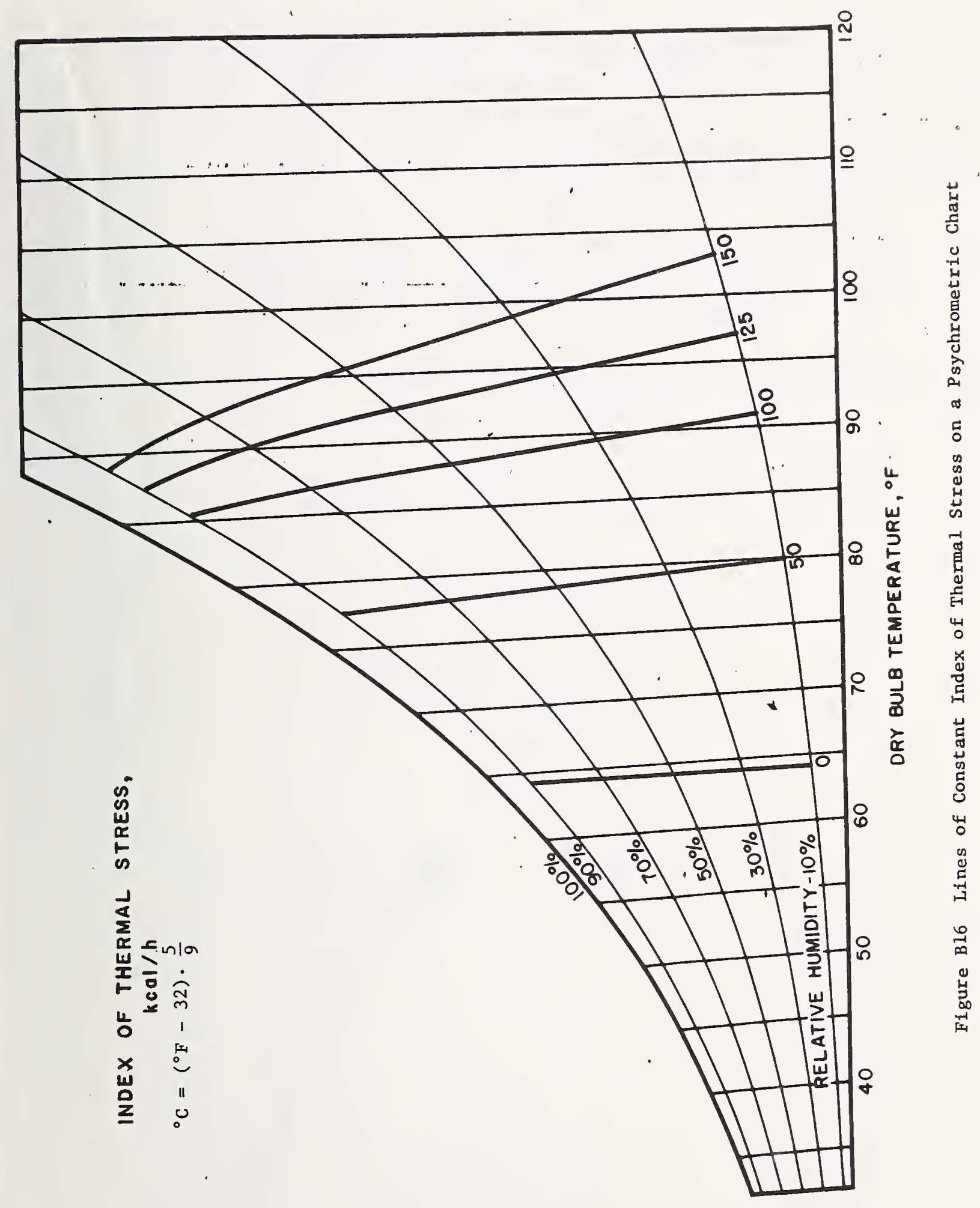




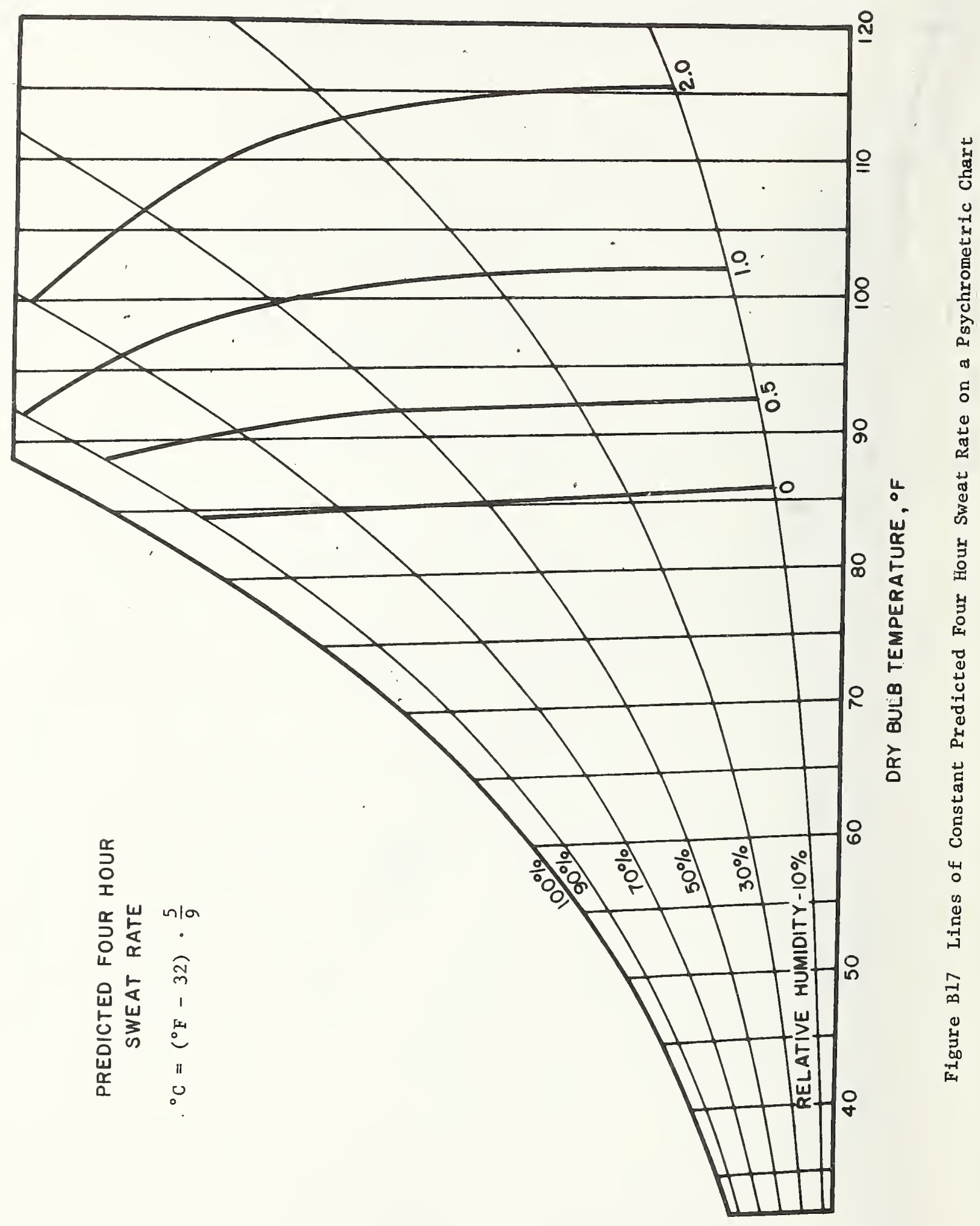




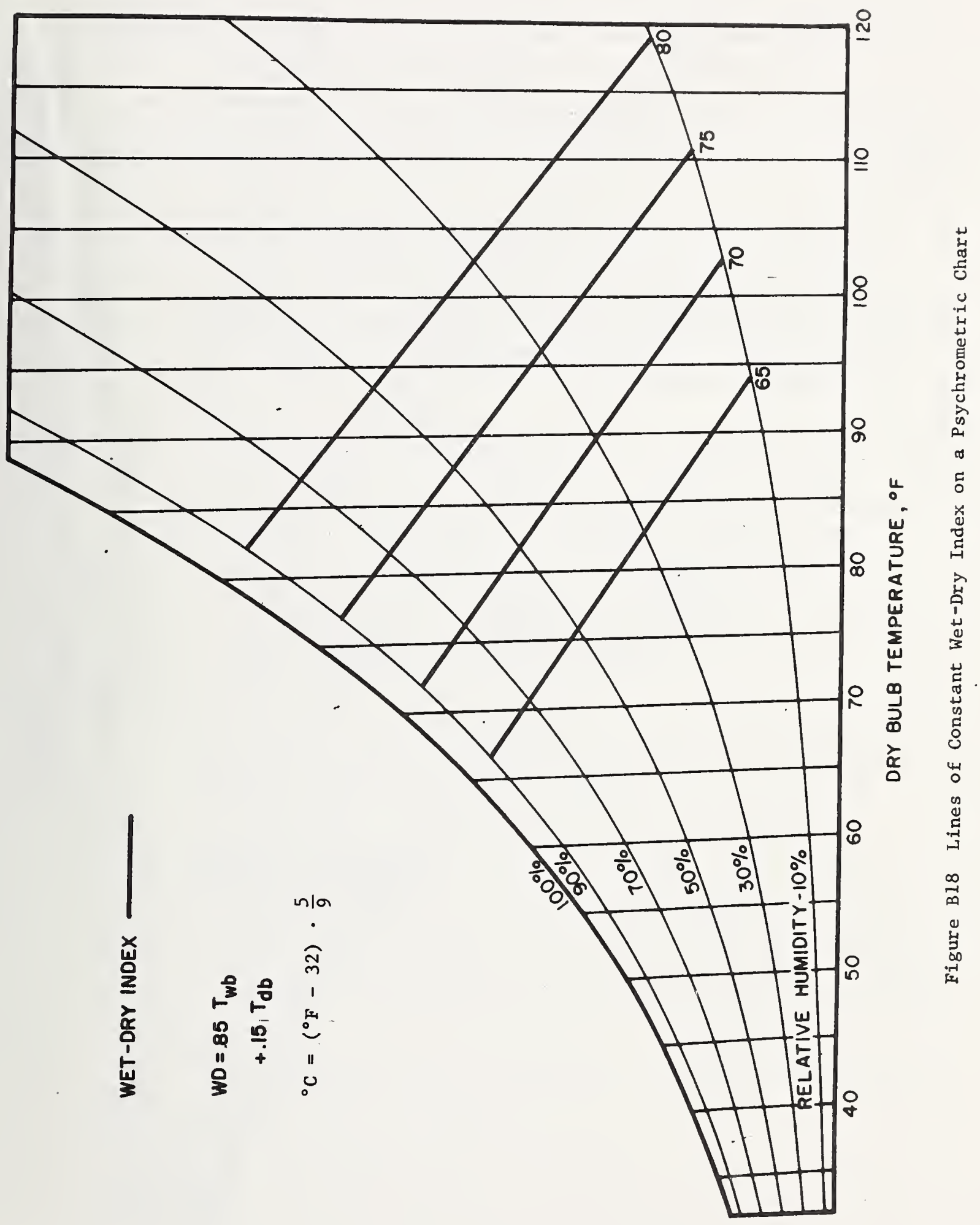




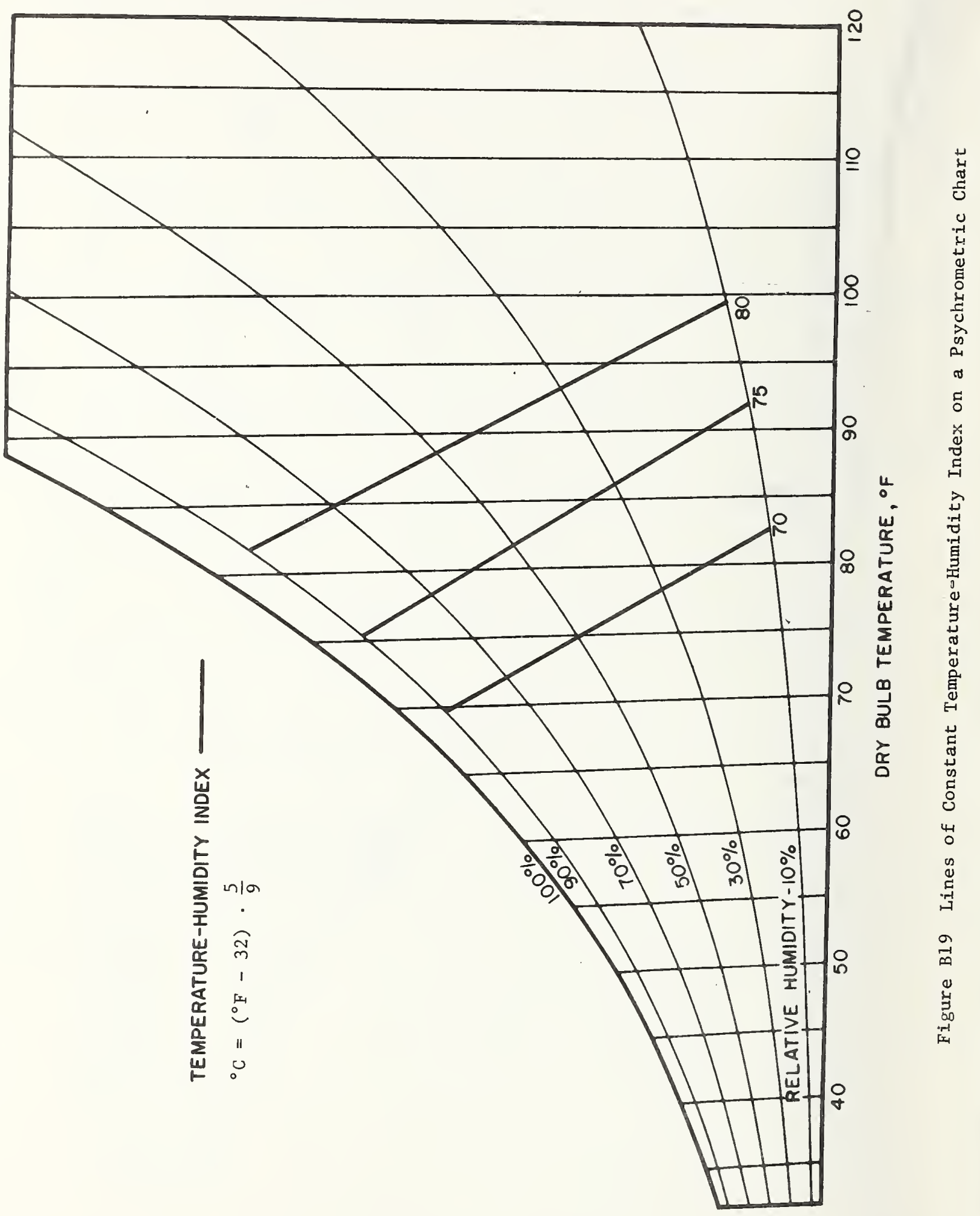


Index of Heat

Stress
Physiological and Hygienic Implications of 8-Hr Exposures to Various Heat Stresses
40

50

60

70

80

90

100
No thermal strain

Mild to moderate heat strain. Where a job involves higher intellectual functions, dexterity, or alertness, subtle to substantial decrements in performance may be expected. In performance of heavy physical work, little decrement expected unless ability of individuals to perform such work under no thermal stress is marginal.

Severe heat strain, involving a threat to health unless men are physically fit. Break-in period required for men not previously acclimatized. Some decrement in performance of physical work is to be expected. Medical selection of personnel desirable. because these conditions are unsuitable for those with cardiovascular or respiratory impairment or with chronic dermatitis. These working conditions are also unsuitable for activities requiring sustained mental effort.

Very severe heat strain. Only a small percentage of the population may be expected to qualify for this work. Personnel should be selected (a) by medical examination and (b) by trial on the job (after acclimatization). Special measures are needed to assure adequate water and salt intake. Amelioration of working conditions by any feasible means is highly desirable, and may be expected to decrease the health hazard while increasing efficiency on the job. Slight "indisposition" which in most jobs would be insufficient to affect performance may render workers unfit for this exposure.

The maximum strain tolerated daily by fit, acclimatized young men. 


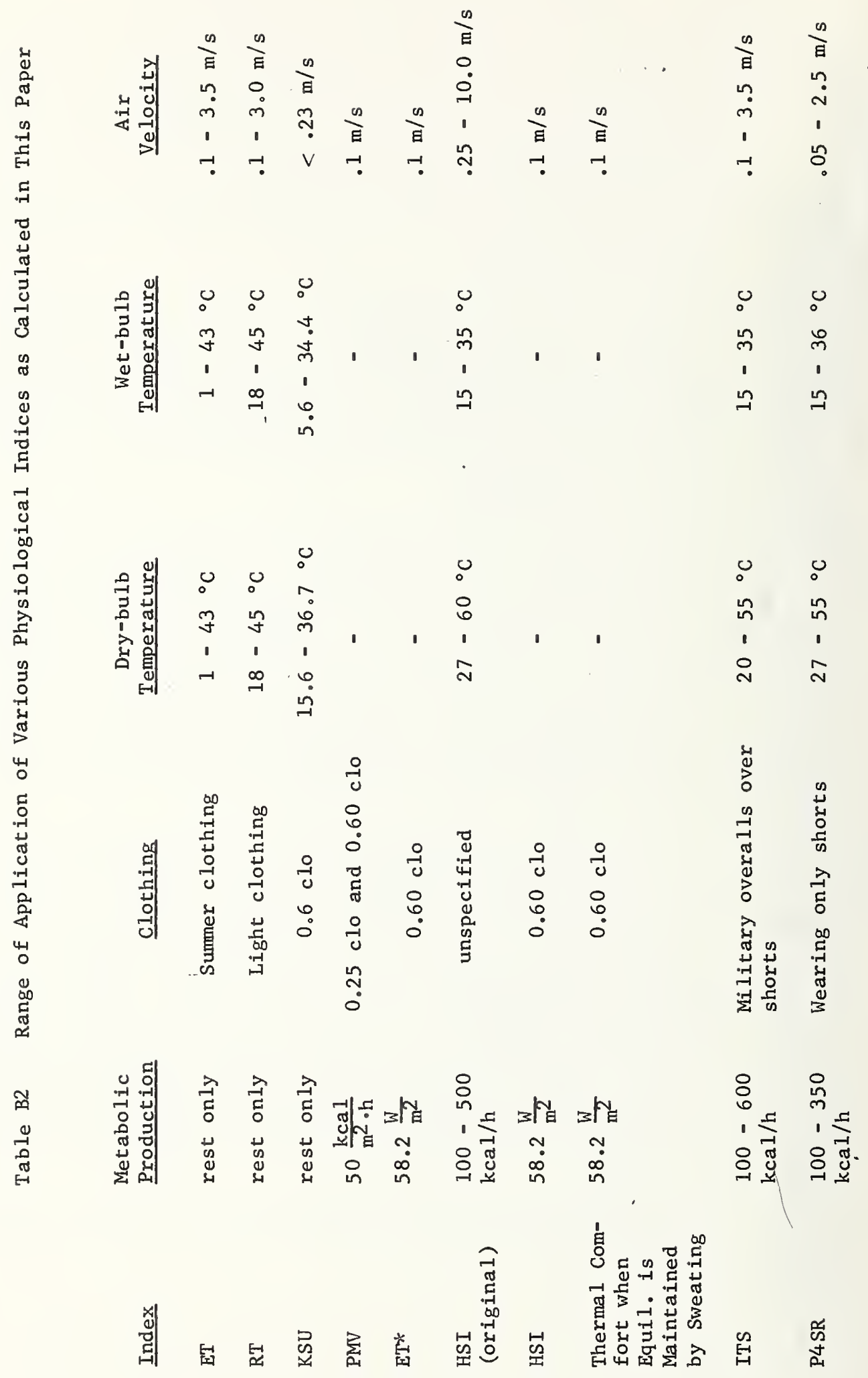


Appendix C

Discussion of Regulatory Sweating Model.

$1 c$ 
In Appendix B it was noted that the component expression for regulatory sweating in the new effective temperature model contributed significantly to the response of the model. As given in Appendix $B$, the component expression is

$$
\begin{gathered}
\mathrm{E}_{\mathrm{rsw}}=70\left(\mathrm{~T}_{\mathrm{cr}}-36.6\right)\left(\mathrm{T}_{\mathrm{sk}}-34.1\right) \mathrm{W} / \mathrm{m}^{2} \\
\text { for } \mathrm{T}_{\mathrm{cr}} \geq 36.6{ }^{\circ} \mathrm{C} \text { and } \\
\mathrm{T}_{\mathrm{sk}} \geq 34.1{ }^{\circ} \mathrm{C} \\
\mathrm{E}_{\mathrm{rsw}}=0 \text { if } \mathrm{T}_{\mathrm{cr}}<36.6{ }^{\circ} \mathrm{C} \text { or } \\
\mathrm{T}_{\mathrm{sk}}<34.1{ }^{\circ} \mathrm{C} .
\end{gathered}
$$

The interpretation of this expression is that sweat production is caused by signals from both the skin and the deep body. If the temperature in either one of the regions rises above the normal value, then the body secretes sweat for the purpose of evaporative cooling. This sweating model is in definite contrast to the results of experiments conducted by Dr. T. H. Benzinger of the Naval Medical Research Institute $[1,2]^{a}$. Dr. Benzinger concludes as a result of his studies, that the signal for sweat secretion is a sole function of the temperature in the anterior portion of the hypothalamus region of the brain. When this temperature rises above a sharply determined set point, warm sensitive neurons begin to fire and excite sweating such that the rate of sweat production is directly proportional to deviation beyond the set point.

The skin temperature does play a role in the evaporative cooling process; however, in contrast to the interpretation of Hardy and Stolwijk [3, 4] (which has been adapted for the new effective temperature model), Benzinger concludes that the effect is one of inhibition. Whenever the skin temperature drops below approximately $33{ }^{\circ} \mathrm{C}$ the rate of sweat production begins to decrease below its normal value (given a hypothalamus temperature above the set point) and the amount of decrease is proportional to the deviation of skin temperature below $33{ }^{\circ} \mathrm{C}$. A comparison between these two distinctly different interpretations is shown in Figure Cl. The rate of evaporative cooling is plotted against the deviation of skin temperature from $33^{\circ} \mathrm{C}$. As can be seen, Gagge's model simulates zero cooling by sweat evaporation as long as the skin temperature is below $34.1{ }^{\circ} \mathrm{C}$ and is directly proportional to $\left(\mathrm{T}_{\mathrm{sk}}-34.1\right)$ - $\left(\mathrm{T}_{\mathrm{cr}}-36.6\right)$ above this point. Benzinger's data indicates a constant rate of sweat production whenever the skin temperature is above $33^{\circ} \mathrm{C}$ (the value of the rate dependent on $\left.\left(\mathrm{T}_{\mathrm{Cr}}-36.6\right)\right)$ and a progressively decreasing rate as the skin temperature drops below $33^{\circ} \mathrm{C}$.

The importance of the evaporative cooling in the model can be seen in Figure C2 where new effective temperature lines are plotted that have been calculated using Benzinger's results for sweat production. Since his data generally gives larger values of evaporative cooling for specified core and skin temperatures, it would be expected that this modified scale would show more dependence on humidity than the standard new effective temperature lines and this can be seen in Figure C3. It is not recommended that the new data be used in the simulation of the body response since the experiments used to generate them were very special in nature. Men were enclosed in a gradient calorimeter [5] such that all sweat evaporated could be instantly carried away. This may not be true in ordinary environments, particularly where the humidity of the ambient air is high. However, it should be obvious that much more study and refinement is needed before an accurate simulation of human response to an environment can be accomplished.

The interpretation that lines of equivalent thermal comfort are identical with lines of constant sweat ratio could be adjusted in light of Dr. Benzinger's findings. The feeling of thermal comfort is no doubt linked to the necessity for sweat secretion when subjected to warm environments. However, as a result of his studies this is in turn linked directly to the hypothalamus temperature or deep body temperature since this is the sole source of the sweating signal. The reasoning is substantiated by an additional experiment conducted by him.

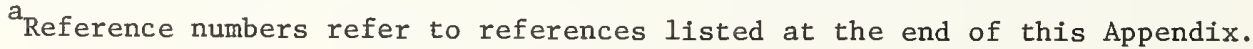


A subject was cooled in a tank of cold water until the hypothalamus temperature was well below the individual's set point. He was then put into a very hot bath where the skin temperature and hypothalamus temperature vere monitored with time. Even though the skin temperature went to a relatively high value almost immediately, the subject did not report discomfort until the hypothalamus temperature began to rise above his set point.

\section{References}

1. T. H. Benzinger, "Clinical Temperature, New Physiological Basis", Journal of the American Medical Association, Vol. 209, pp. 1200-1206, 1969.

2. T. H. Benzinger, "Peripheral Cold Reception and Central Warm Reception, Sensory Mechanisms of Behavioral and Autonomic Thermostasis", Physiological and Behavioral Temperature Regulation, Chapter 56, Charles C. Thomas, Springfield, Illinois, 1970.

3. J. D. Hardy and J. A. J. Stolwijk, "Partitional Calorimetry Studies of Man During Exposure to Thermal Transients", Journal of Applied Physiology, "Vo1. 21, pp. 1799-1806, 1966.

4. J. A. J. Stolwijk and J. D. Hardy, "Temperature Regulation in Man - A Theoretica1 Study", Pflugers Archiev., Vol. 291, pp. 129-162, 1966.

5. T. H. Benzinger and C. Kitzinger, "Gradient Layer Calorimetry and Human Calorimetry", Temperature - Its Measurement and Control in Science and Industry, Vol 3, Part 3, Reinhold Publishing Corp., N.Y., N.Y., 1963. 


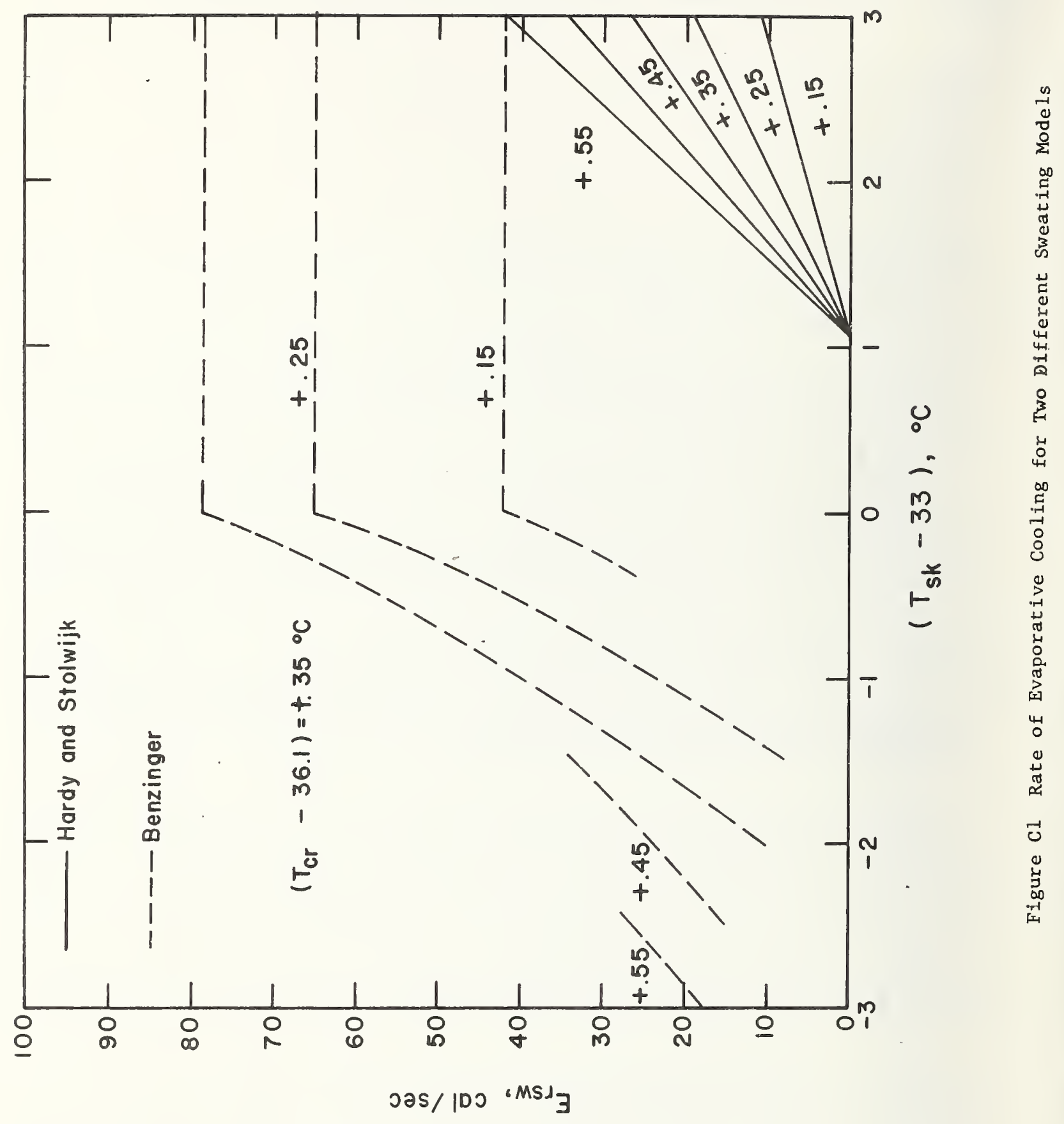




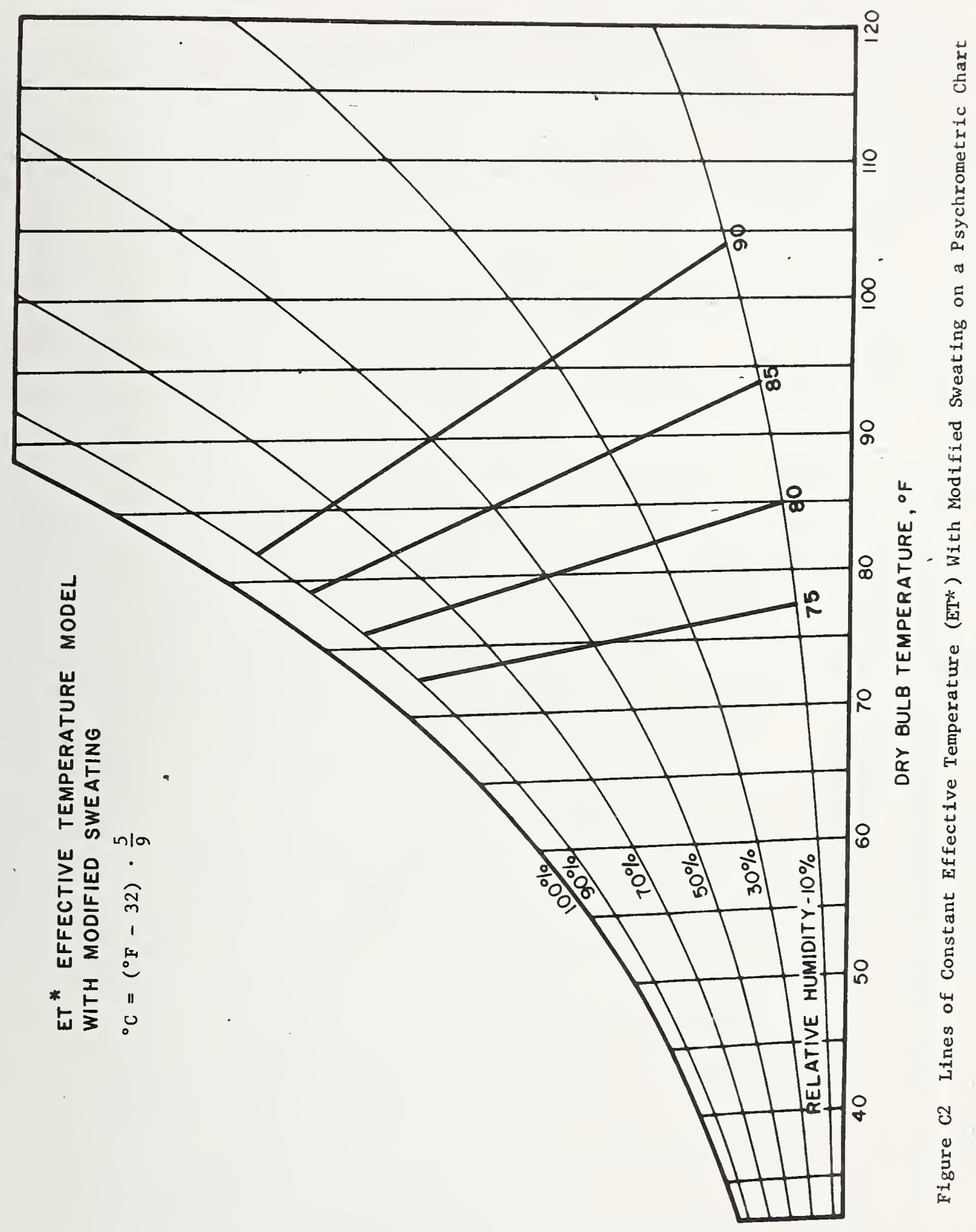




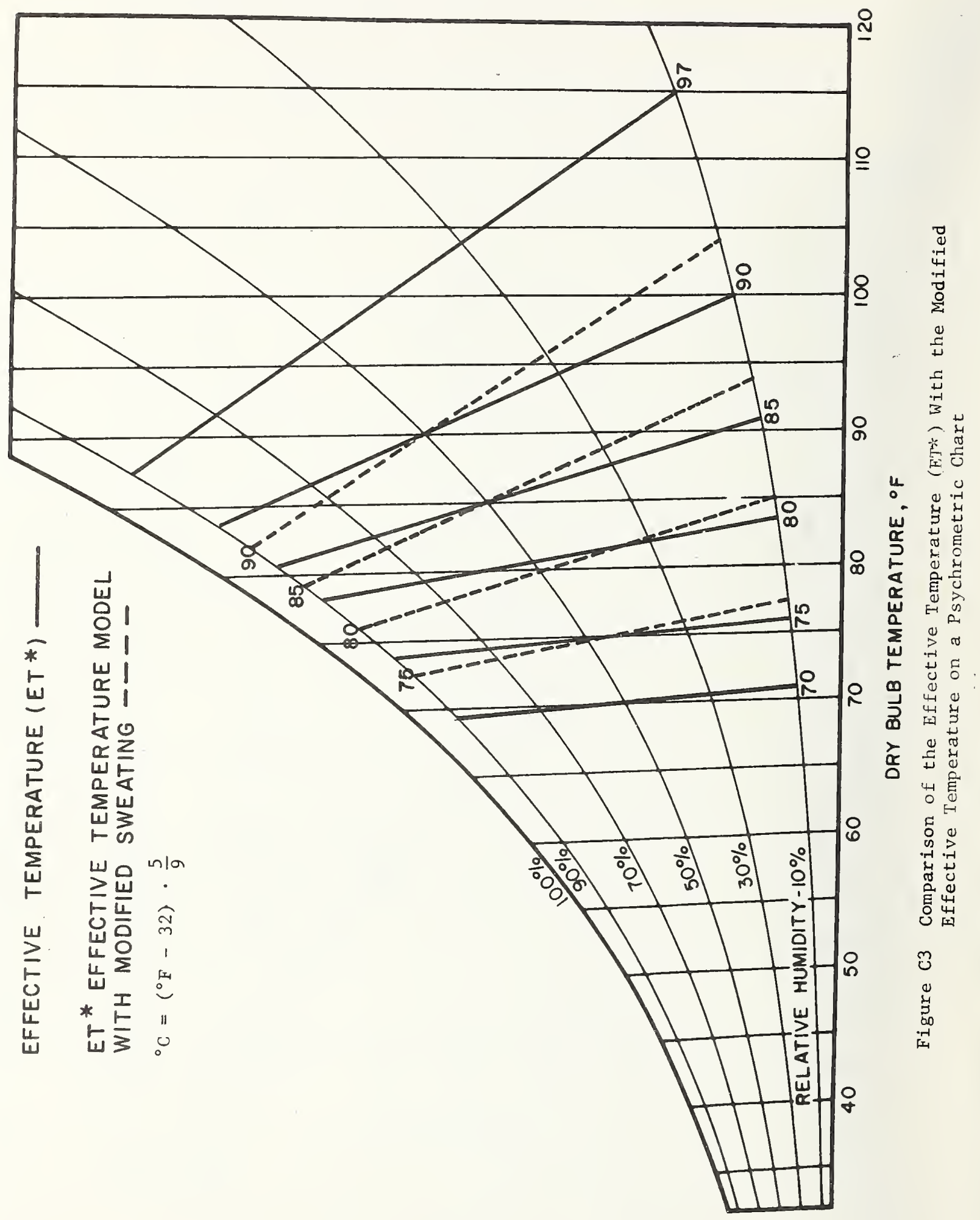


NBS-114A (REV. 7-73)

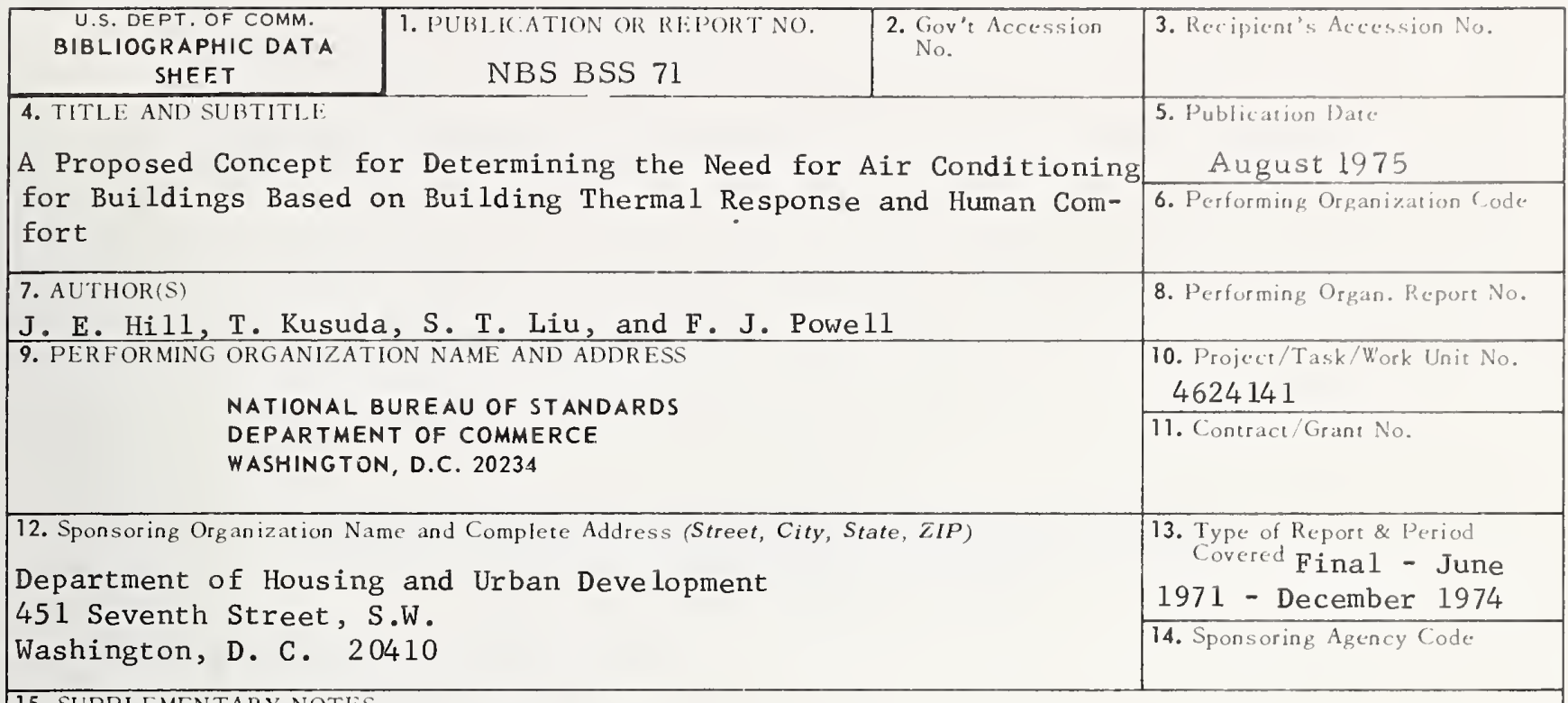

15. SUPPIEMENTARY NOTES

Library of Congress Catalog Card Number: 75-619194

16. ABSTRACT (A 200-word or less factual summary of most significant in formation. If document includes a significant bibliography or literature survey, mention it here.)

Determining the need for air conditioning can be based on a wide variety of factors. To date, the only criteria that have been written and can be referenced are those of several federal organizations and many are not really criteria in the true sense of the word. They are guidelines to be used in the determination of fund allocation; in other words, provisions are made to air condition federal facilities in specific geographical locations if pertinent weather characteristics of that locality meet certain requirements. This paper presents the concept that a true criteria can be established based both on weather characteristics of the locality as well as characteristics of the building or structure under consideration.

The paper gives the details of a study showing the feasibility of such a scheme. A simulation was made of two proposed residences in several geographical localities. For the simulation, actual hour-by-hour weather data was used in conjunction with a sophisticated computer program. The results revealed for the non air-conditioned spaces, the extent and duration of undesirable indoor conditions based upon general1y accepted comfort indices. The concept of a new "comfort" or "discomfort" index called Predicted Indoor Habitability Index (PIHI) is introduced. The authors indicate the way in which a criterion could be established that would be in the form of tables, indicating for a given specified building and geographical locality, whether mechanical cooling should or should not be installed.

17. KEY WORDS (six to twelve entries; alphabetical order; capitalize only the first letter of the first key word unless a proper name; separated by semicolons)

Air conditioning criteria; building thermal response; comfort indices; human comfort; predicted indoor habitability index

18. AVAILABILITY $\mathrm{X}$ Unlimited

For Official Distribution. Do Not Release to NTIS

X Order From Sup. of Doc., U.S. Government Printing Office Washington, D.C. 20402, SD Cat. No.C13,29/2:71

Order From National Technical Information Service (NTIS) Springfield, Virginia 22151

\begin{tabular}{|l|c|}
\hline $\begin{array}{l}\text { 19. SECURITY CLASS } \\
\text { (THIS REPURT) }\end{array}$ & 21. NO. OF PAGES \\
UNCL ASSIFIED & 155 \\
\hline $\begin{array}{l}\text { 20. SECURITY CLASS } \\
\text { (THIS PAGE) }\end{array}$ & $\begin{array}{c}\text { 22. Price } \\
\$ 2.25\end{array}$ \\
UNCLASSIFIED
\end{tabular}





\section{ANNOUNCEMENT OF NEW PUBLICATIONS IN BUILDING SCIENCE SERIES}

Superintendent of Documents, Government Printing Office, Washington, D.C., 20402

Dear Sir:

Please add my name to the announcement list of new publications to be issued in the series: National Bureau of Standards Building Science Series.

Name

Company

Address

City State Zip Code

(Notification key N-339) 



\section{NBS TECHNICAL PUBLICATIONS}

\section{PERIODICALS}

JOURNAL OF RESEARCH reports National Bureau of Standards research and development in physics, mathematics, and chemistry. It is published in two sections, available separately:

- Physics and Chemistry (Section A)

Papers of interest primarily to scientists working in these fields. This section covers a broad range of physical and chemical research, with major emphasis on standards of physical measurement, fundamental constants, and properties of matter. Issued six times a year. Annual subscription: Domestic, $\$ 17.00$; Foreign, $\$ 21.25$

- Mathematical Sciences (Section B)

Studies and compilations designed mainly for the mathematician and theoretical physicist. Topics in mathematical statistics, theory of experiment design, numerical analysis, theoretical physics and chemistry, logical design and programming of computers and computer systems. Short numerical tables. Issued quarterly. Annual subscription: Domestic, $\$ 9.00$; Foreign, $\$ 11.25$

DIMENSIONS/NBS (formerly Technical News Bulletin)-This monthly magazine is published to inform scientists, engineers, businessmen, industry, teachers, students, and consumers of the latest advances in science and technology, with primary emphasis on the work at NBS. The magazine highlights and reviews such issues as energy research, fire protection, building technology, metric conversion, pollution abatement, health and safety, and consumer product performance. In addition, it reports the results of Bureau programs in measurement standards and techniques, properties of matter and materials, engineering standards and services, instrumentation, and automatic data processing.

Annual subscription: Domestic, $\$ 9.45$; Foreign, $\$ 11.85$.

\section{NONPERIODICALS}

Monographs-Major contributions to the technical literature on various subjects related to the Bureau's scientific and technical activities.

Handbooks-Recommended codes of engineering and industrial practice (including safety codes) developed in cooperation with interested industries, professional organizations, and regulatory bodies.

Special Publications-Include proceedings of conferences sponsored by NBS, NBS annual reports, and other special publications appropriate to this grouping such as wall charts, pocket cards, and bibliographies.

Applied Mathematics Series-Mathematical tables, manuals, and studies of special interest to physicists, engineers, chemists, biologists, mathematicians, computer programmers, and others engaged in scientific and technical work.

National Standard Reference Data Series-Provides quantitative data on the physical and chemical properties of materials, compiled from the world's literature and critically evaluated. Developed under a world-wide program coordinated by NBS. Program under authority of National Standard Data Act (Public Law 90-396).

NOTE: At present the principal publication outlet for these data is the Journal of Physical and Chemical Reference Data (JPCRD) published quarterly for NBS by the American Chemical Society (ACS) and the American Institute of Physics (AIP). Subscrtptions, reprints, and supplements available from ACS, 1155 Sixteenth St. N. W., Wash. D. C. 20056.

Building Science Series-Disseminates technical information developed at the Bureau on building materials, components, systems, and whole structures. The series presents research results, test methods, and performance criteria related to the structural and environmental functions and the durability and safety characteristics of building elements and systems.

Technical Notes-Studies or reports which are complete in themselves but restrictive in their treatment of a subject. Analogous to monographs but not so compre. hensive in scope or definitive in treatment of the subject area. Often serve as a vehicle for final reports of work performed at NBS under the sponsorship of other government agencies.

Voluntary Product Standards-Developed under procedures published by the Department of Commerce in Part 10, Title 15, of the Code of Federal Regulations. The purpose of the standards is to establish nationally recognized requirements for products, and to provide all concerned interests with a basis for common understanding of the characteristics of the products. NBS administers this program as a supplement to the activities of the private sector standardizing organizations.

Federal Information Processing Standards Publications (FIPS PUBS)-Publications in this series collectively constitute the Federal Information Processing Standards Register. Register serves as the official source of information in the Federal Government regarding standards issued by NBS pursuant to the Federal Property and Administrative Services Act of 1949 as amended Public Law 89-306 (79 Stat. 1127), and as implemented by Executive Order 11717 ( 38 FR 12315, dated May 11, 1973) and Part 6 of Title 15 CFR (Code of Federal Regulations).

Consumer Information Series-Practical information, based on NBS research and experience, covering areas of interest to the consumer. Easily understandable language and illustrations provide useful background knowledge for shopping in today's technological marketplace.

NBS Interagency Reports (NBSIR)-A special series of interim or final reports on work performed by NBS for outside sponsors (both government and non-government). In general, initial distribution is handled by the sponsor; public distribution is by the National Technical Information Service (Springfield, Va. 22161) in paper copy or microfiche form.

Order NBS publications (except NBSIR's and Bibliographic Subscription Services) from: Superintendent of Documents, Government Printing Office, Washington, D.C. 20402 .

\section{BIBLIOGRAPHIC SUBSCRIPTION SERVICES}

The following current-awareness and literature-survey bibliographies are issued periodically by the Bureau:

Cryogenic Data Center Current Awareness Service

A literature survey issued biweekly. Annual subscription: Domestic, $\$ 20.00$; foreign, $\$ 25.00$.

Liquefied Natural Gas. A literature survey issued quarterly. Annual subscription: $\$ 20.00$.

Superconducting Devices and Materials. A literature survey issued quarterly. Annual subscription: $\$ 20.00$. Send subscription orders and remittances for the preceding bibliographic services to National Technical Information Service, Springfield, Va. 22161.

Electromagnetic Metrology Current Awareness Service Issued monthly. Annual subscription: $\$ 100.00$ (Special rates for multi-subscriptions). Send subscription order and remittance to Electromagnetics Division, National Bureau of Standards, Boulder, Colo. 80302. 
U.S. OEPARTMENT OF COMMERCE

National Bureau of Standards

Washington. D.C. 20234

OFFICIAL BUSINESS

Penaity for Private Use, $\$ 300$
POSTAGE AND FEES PAID

U.S. DEPARTMENT OF COMMERCE

$C O M-215$

SPECIAL FOURTH-CLASS RATE BOOK

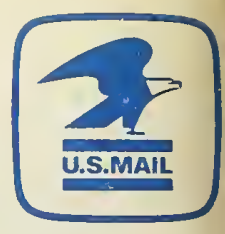

